\title{
Firm internal labour markets in the Netherlands : a contract-theoretical approach
}

Citation for published version (APA):

Wolfs, G. L. M. (1992). Firm internal labour markets in the Netherlands : a contract-theoretical approach. [Doctoral Thesis, Maastricht University]. Datawyse / Universitaire Pers Maastricht. https://doi.org/10.26481/dis.19920610gw

Document status and date:

Published: 01/01/1992

DOI:

10.26481/dis.19920610gw

Document Version:

Publisher's PDF, also known as Version of record

\section{Please check the document version of this publication:}

- A submitted manuscript is the version of the article upon submission and before peer-review. There can be important differences between the submitted version and the official published version of record.

People interested in the research are advised to contact the author for the final version of the publication, or visit the DOI to the publisher's website.

- The final author version and the galley proof are versions of the publication after peer review.

- The final published version features the final layout of the paper including the volume, issue and page numbers.

Link to publication

\footnotetext{
General rights rights.

- You may freely distribute the URL identifying the publication in the public portal. please follow below link for the End User Agreement:

www.umlib.nl/taverne-license

Take down policy

If you believe that this document breaches copyright please contact us at:

repository@maastrichtuniversity.nl

providing details and we will investigate your claim.
}

Copyright and moral rights for the publications made accessible in the public portal are retained by the authors and/or other copyright owners and it is a condition of accessing publications that users recognise and abide by the legal requirements associated with these

- Users may download and print one copy of any publication from the public portal for the purpose of private study or research.

- You may not further distribute the material or use it for any profit-making activity or commercial gain

If the publication is distributed under the terms of Article $25 \mathrm{fa}$ of the Dutch Copyright Act, indicated by the "Taverne" license above, 
FIRM INTERNAL LABOUR MARKETS IN THE NETHERLANDS A. Contract-Theoretical Approach 


\title{
FIRM INTERNAL LABOUR MARKETS IN THE NETHERLANDS
}

\author{
A Contract-Theoretical Approach
}

\author{
PROEFSCHIRIFT \\ ter verkrijging van de graad van doctor \\ aan de Rijksuniversiteit Limburg, \\ op gezag van de Rector Magnificus, \\ Prof. mr. M.J. Cohen, volgens het besluit van \\ het College van Dekanen ${ }_{x}$ in het openbaar \\ te verdedigen op woensdag 10 juni 1992 \\ om 16.00 uur
}

door 
Promotor:

Compromotor:

Beoordelingscommissie:
Prof. dr. I. Muysken

Dr. P. de Gijsel

Prof. dr. J.A.H. Maks (voorzitter)

Prof. dr. $\mathbb{K}$. Gerlach (Universitat Hannover)

Dr. A. de Grip

CIP-GEGEVENS KONINKLIJKE BIBIOTHEEK, DEN HAAG

Wolfs, Guido Lodewijk Marie

Firm Internal Labour Markets in the Netherlands : a contract-theoretical approach/Guido Lodewijk Marie Wolfs. - Madstricht : Universitaire Pers Maastricht. III., fig., tab.

Proefschrift Maastricht. - Met 1it. opg. - Met samemvatting in het Nederlands.

ISBN $90 \quad 5278 \quad 029 \quad 3$

NUGI 685

Trefw.: arbeidsmarkt ; Nederland.

(C) Guido Wolfs, Maastricht

(c) Grafische vormgeving: Aad van Monurik, Maastricht

Druk: Datawyse Maastricht / Krips Repro Meppel 
To Annick

and my parents 



\section{CONTENTS}

List of tables $\quad$ ix

List of figures $\quad x$

Preface $\quad$ xi

CHAPTER 1 INTRODUCTION

1.1 General introduction 1

1.2 Scope 3

1.3 Outline 5

CHAPTER 2 DEFINING THE INTERNAL LABOUIR MARKET

2.1 Introduction 7

2.2 Origin of the internal labour market concept 8

2.3 Labour market segmentation 11

24 Concepts of the internal labour market 15

2.5 Definition of the internal labour market 17

$\begin{array}{ll}2.6 \text { Conclusion } & 20\end{array}$

CHAPTER 3 LABOUR MARKET THEORIES AND INTERNAL LABOUR MARKETS

3.1 Introduction $\quad 21$

3.2 The radical approach 21

3.3 Transaction cost theory 23

3.4 Human capital theory 26

3.5 Implicit contract theory 28

3.6 Efficiency wage theory 31

3.7 Insider - outsider theory 36

3.8. Conclusion 38

CHAPTER 4 THE FIRM INTERNAL LABOUR MARKET AS A MULTI-PERIOD CONTRACT

4.1. Introduction 43

4.2 Williamson revisited 44

4.3 Classification of contracts 48

4.4 One-period contracts 53

4.5 Internal labour market contracts: the Malcomson model 56

4.6 Internal labour market contracts and wages 64

4.7 Consequences of internal labour market contracts $\quad 71$

4.8 Further characteristics of internal labour markets 73

4.9 Summary and conclusions 75 
viii

CHAPTER 5 PREVIOUS EMPIRICAL RESEARCH

5.1 Introduction $\quad 77$

5.2 Research on the Dutch economy 78

5.3 Concepts of the internal labour market 84

5.4 Characteristics of the internal labour market 89

5.5 Internal labour markets and wages 93

5.6 Internal labour markets and job tenure $\quad 100$

$\begin{array}{ll}5.7 \text { Conclusion } & 105\end{array}$

CHAPTER 6 THE SIZE OF THE INTERNAL LABOUR MARKET

$\begin{array}{ll}6.1 \text { Introduction } & 107\end{array}$

6.2 Operationalization of the internal labour market 108

6.3 Description of the data 110

6.4 Measuring eventual tenure 112

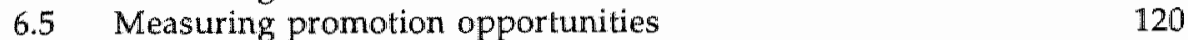

$\begin{array}{ll}\text { 6.6 Size of the internal labour market } & 122\end{array}$

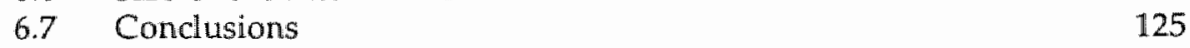

CHAPTER 7 THE INTERNAL LABOUR MARKET

IN THE NETHERLANDS

$\begin{array}{lll}7.1 & \text { Introduction } & 127\end{array}$

$\begin{array}{ll}7.2 & \text { Characterizing the internal labour market } \\ 7.3 & 128\end{array}$

$\begin{array}{lll}7.3 & \text { Internal labour markets and wages } & 135\end{array}$

7.4 Consequences of the internal labour market $\quad 145$

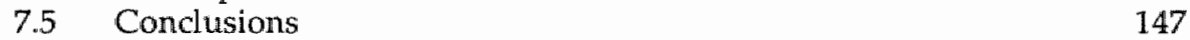

CHAPTER 8 SUMMARY AND CONCLUSIONS

$\begin{array}{lll}8.1 & \text { Summary and conclusions } & 149\end{array}$

8.2 Evaluation and further research 153

$\begin{array}{lr}\text { SAMENVATTING } & 159\end{array}$

$\begin{array}{ll}\text { REFERENCES } & 163\end{array}$ 


\section{List of tables}

Table 1.1 Research questions of this study 4

Table 2.1 Segmentation according to (a) Kerr (1954), (b) Doeringer and Priore (1971), and (c) Althauser and Kalleberg (1981) 12

Table 2.2 Definitions of internal labour markets 16

Table 3.1 Summary of features of internal labour markets 38

$\begin{array}{lll}\text { Table 4.1 Contract classification } & 48\end{array}$

Table 5.1 Summary of internal labour market concepts $\quad 87$

Table 5.2 Tenure distribution and average tenure $\quad 101$

Table 5.3 Actual and eventual tenure distribution 102

Table 6.1 Some characteristics of the sample $(N=1846) \quad 111$

$\begin{array}{lll}\text { Table } 6.2 & \text { Estimation results for hazard functions } & 117\end{array}$

Table 6.3 Correlations between hazards of three specifications $(\mathrm{N}=1846) \quad 119$

Table 6.4 Correlations between eventual tenures of three specifications $(\mathrm{N}=1846)$

Table 6.5 Questions concerning promotion opportunities (translated $\begin{array}{ll}\text { from OSA, 1985) } & 121\end{array}$

Table 6.6 Labour market segmentation based on actuall tenure $(N=1846) \quad 123$

Table 6.7 Labour market segmentation based on actual tenure for men (left, $N=1219$ ) and women (right, $N=627$ )

Table 6.8 Labour market segmentation based on eventual tenure for full-time (left, $\mathrm{N}=1817$ ) and part-time workers (right, $\mathrm{N}=429$ ) 124

Table 6.9 Labour market segmentation based on actual tenure $(\mathrm{N}=1846) \quad 125$

$\begin{array}{lll}\text { Table 7.1 } & \text { Research questions and related hypotheses } & 128\end{array}$

Table 7.2 Characteristics of jobs and workers 130

Table 7.3 Probit results on probability of employment on the internal labour market

Table 7.4 Internal labour market per industry $(\mathbb{N}=1846) \quad 133$

Table 7.5 Probit results on probability of employment on the internal labour market

Table 7.6 Average wages for several categories in guilders 138

Table 7.7 Wage equations for all workers 140

Table 7.8 Hourly wages before and after substitution 143

Table 7.9 Chow test for different equations 144

Table 7.10 Variables on mobility and payment 146

$\begin{array}{lll}\text { Table 8.1 Research questions of this study } & 150\end{array}$

$\begin{array}{lll}\text { Table } 8.2 & \text { Research questions and related hypotheses } & 152\end{array}$ 


\section{List of Figures}

Figure 4.1a Two period (Hutchens, 1989) 69

Figure 4.1b Stylized 69

$\begin{array}{lll}\text { Figure 4.2a Stylized (Lazear, 1979) } & 70\end{array}$

Figure 4.2b Two-period (Malcomson, 1984) 70

Figure 6.1 Distribution of promotion opportunities

$\begin{array}{lr}\text { (For all workers, men and women) } & 122\end{array}$ 


\section{Preface}

The research which has resulted in this thesis has been conducted during the past four years at the Faculty of Economics of the Rijksuniversiteit Limburg. The Internal Labour Market project is imbedded in a larger project, called "Arbeidsmarkt en Arbeidsorganisaties". In this project an interdisciplinary approach is pursued, following the ideas of Muysken and Schreuder (1985). The purpose of the project on Internal Labour Markets was to gain insight into the internal labour market both from an organizational and an economic point of view. This thesis represents the latter emphasis.

This work is a result of reading, thinking and talking. The latter is at least as important as the former two. In this respect I have to thank some colleagues. Most of all, I would like to thank my co-promotor Peter de Gijsel for being a fair discussant and a "sparring partner'. I am not sure the job would have been finished without him. Of course my promotor Joan Muysken deserves as much honour. Aside from them, many colleagues have provided useful comments during the past years. I like to thank Ron Dekker, Marcel Lever, Erik de Regt, Rolf Schwan and Rombout de Wit. A special word of thanks must be directed to Kristian Kerckhoffs, whose support was very welcome indeed. Jacqueline Reason was so kind to check the text on 'Dutch English'. Many hours of sleep were sacrificed by Aad van Mourik for the lay-out of this thesis. At this place also some assistent students who provided some help must be mentioned: Hugo Hollanders, Marcel Janssen, and Marco Doudeyns. A special word of thank is for R. Kunnen of the Organization for Strategic Labour Market Research (OSA), who allowed me to use their survey data. Finally, I like to follow an old, but valuable, tradition in books like this, and thank my wife, Annick, for being so patient.

Maastricht, april 1992 


\section{CHAPTER}

\subsection{General introduction}

The topic of this study is at the heart of present-day labour economics: the labour market within an organization. It concerns a discussion of employer-employee relations in a contractual context, and incorporates problems of monitoring and motivation, risk and uncertainty, and mobility and turnover. Accordingly, it relates to matters discussed in organization theories, the economics of personnel, and, of course, micro- and macroeconomics. The drawback of such topical research is that it has to be carried out in an area of indistinct phenom mena and variables, which are not always clearly defined and whose relationships must be disentangled. As a result, many questions are still unanswered in this research area.

Therefore, a demarcation is needed. The study offers no complete treatment of all aspects of internal labour markets and -unfortunately-various interesting topics had to be dropped along the way in order to cut down the investigations to a manageable size. Some of these topics are touched upon in the last chapter, since they prowide a research agenda for the future. In this study we shall try to bring clarity by clearly defining the central concept of the study: the internal labour market. Next, we discuss a limited set of questions concerning the internal labour market, both theoretically and empirically. In doing so, we hope to improve on previous studies which follow either a theoretical or an empirical approach.

The purpose of this introductory chapter is to explicitly formulate the questions to which our research is directed. The scope of this study is formulated in Secrion 1.2. A further outline, following the thread of our investigations, is presented in Section 1.3. In the remainder of Section $1 . /$ the core concept is pictured in a broader perspective to show the relevance of investigating the internal labour market.

From a macroeconomic perspective, the problem underlying research into internal labour markets is that of unemployment. Much scientific effort is devoted to understanding the causes of unemployment (Akerlof, 1984, p. 4, Akerlof and Yellen, 1986, p. 1). The challenge of this problem is expressed by Solow (1980, p. 2): "The labor market"s own special pathology, unemployment, is particularly visible, particularly unsettling, and particularly frustrating". Its existence has led to discussion on the source, character and policy sollutions to unemployment. Accordingly many categories of unemployment are distinguished, such as 
voluntary or inwoluntary, natural or structural, frictional, demand deficient, or temporary, unemployment (for a taxonomy, see Muysken, 1990).

An important element in research on the causes of unemployment is the recognition that (some parts of) the market for labour differ from an auction market as discussed in Walrasian economics. "This message is not new; many economists have already pointed to the importance of social behaviour, psychological aspects and institutions, such as trade unions, minimum wages, unemployment benefit and labour market segments. However, there are signs that neoclassical economists are picking up some of the findings of institutionalists, and trying to incorporate these into their framework. ${ }^{2}$ This gives rise to new approaches to the Jabour market which discuss market imperfections, market failures and rigidities of all kinds (Solow, 1980), the influence of information imperfections (Arrow, 1974), uncertainties (Axariadis, 1975; Baily, 1974; Gordon, 1974), all kinds of cost (Phelps, 1970; Lindbeck and Snower, 1988), customs and norms (Akerlof, 1984), labour market segmentation (Solow, 1980) and bounded human rationality (Williamson, 1975). Moreover, new schools of thought and overlapping theories have developed, such as New Institutionalists, the New Economics of Personnel ${ }^{3}$, Transaction Cost Economics, Information Economics, and Contract Economics. For all these theories it holds that it is generally felt that a considerable part of the labour market cannot be anallysed within the traditional competitive framework. Instead a different approach or set of assumptions is required, and reference is made to alternative frameworks, one of which is the internat labour makket (see for instance Mace, 1979, p. 50; George and Shorey, 1985, p. 425; Creedy and Whitfield, 1988, p. 248). In this light, a further discussion of this concept seems worthwhile.

Since labour immobility and wage rigidity are important elements in explaining unemployment (De Grip, 1985, p. 333), some of the new directions in labour market economics look for acceptable explanations for the immobility of labour (or long-term labour relations) and wage rigidity 4 . The discussion on these approaches not only involve the level of wages and

\footnotetext{
${ }^{1}$ Illustrative are remarks that the labour market differs from a flower auction (Hartog, 1984), should not be modelied as a cloth market (Solow, 1980, p. 3), and resembles the marriage market better than the bourse (Rosen. 1985, p. 1145). Creedy and Whitfield (1988) remark that "there are significant areas of the labour market where the process emphasized in the model of wage competition do not operate or operate only to a very limited extent:" (p. 248). They emphasize that "labour is a qualitatively different factor of production from capital" (p. 266). This different nature of the labour market is due to "serious considerations of quality (in terns of effort and morale)" (Akerlof and Yellen, 1986. p. 9) and further "Unlike labor, capilall need not be motivated" (Pratt and Zeckhauser, 1985, p. 10).

${ }^{2}$ Some authors would interpret this development as neoclassical expansion or imperialism (Hartog and Theeuwes, 1990), while others reverse the relationship by stating that institutional theories tend to use more neoclassical concepts (De Grip, 1985, p. 343). Willianson (1990) states that New Instiutional Economics is new not in the recognition of the importance of institutions, but in the operationalization of institutions ( $p .9$ ), and argues that the "new theories of the firm ... were initially regarded as rivals to the neoclassical theory. Increasingly, however, they are coming to be treated as complemerals (p. 2).

3. See, for instance, the Proceedings of the Goldwater Conference on The New Economics of Personnel. in the Journal of Labor Economics (1987).

4. To present two examples: "wage-stickiness is a first-order factor in a reasonable theory of unemployment" (Solow, 1980, p. 9), and in the same lime: "it is widely recognized that the assumption that wages are rigid is central to Keynes' explanation of the persistence of unemployment" (Stiglitz,
1986 , p. 153).
} 
employment, but also concentrates on the variables which determine individual wages, and the 'quit-or-stay' decisions of workers, which may result in long-term employment relations. Although discussion on individual wage differences is far from new (see, for instance, Adam Smith, 1776, book X), the emphasis on fim internal processes and decisions is - at least for economics. It is hoped that opening the black box, as the firm in the traditional approach is referred to, offers new insight into the way workers and employers beliave within a firm, how wages are paid, and how employment relations unfold inside the firm (Edwards, 1975, p. 5; Creedy and Whitfield, 1988, p. 249; Williamson, 1990, introduction). Discussing these firm internal processes might lead to a better understanding of unemployment in the future. Taking these general arguments into account, the internal labour market is analysed in economic terms $5^{5}$ in this study, with special reference to the relationship between internal labour markets, wages and labour (im)mobility. In the next section the problem under investigation is more precisely defined.

\subsection{Scope}

As pointed out above, the rigidity or stickiness of wages, and the relative immobility of labour are considered as possible explanations for unemployment. These two causes ask for an explanation themselves. Further research into the inflexibility of labour involves the question why employers and employees might engage in long-term labour relations, with the extreme example of life-time employment, which is anecdotal for Japanese firms (Giebel, 1982, p. 29; Hashimoto and Raisain, 1985, p. 721). A second, closely related, question is how these long-term employment relations influence the wage level and the wage structure. Answering these questions requires attention on firm internal processes with regard to wages and internal mobility. With the relatively new concept of internal labour markets, an instrument for the discussion of wage rigidity and labour immobility between firms is available. As the phrase 'internal labour market' indicates, the focus of the employer and the employee is on the firm internal amount of labour and the availability of jobs. Workers focus on firm internal opportunities for career advancement and future rewards, and employers must decide to whom they offer long-term employment and, eventually, career opportunities. In general, internal labour market positions are assumed to be attractive" jobs are described as "good jobs' with career opportunities, and accordingly the internal labour market is referred. to as the primary sector of the labour market. This broad description suffices for the moment. In the next chapter we turn to a proper definition of the internal labour market.

Of course, many questions concerning firm internal processes with respect to compensation and incentives are still unsettled (see for instance Baker et al., 1988, p. 594). In the present study attention is inevitably restricted to a limited set of questions, which are summarized in Table 1.1. Emphasis on immobility and wage rigidity reflects our interest stated above. The questions which are investigated are fundamental, and are discussed both in a theoretical and empirical way. Basically, the purpose of the present study is to define the internal labour market and subsequently apply this definition in order to answer the research questions of Table 1.1.

5 Traditionally this field has been studied by "psychologists, behawiorists, human resource consultants and personnel executives" who follow a non-economic approach, "focusing on notions such as fairmess, equity, morale, trust, social responsibility, and culture" (Baker et al., 1988, p. 594). 
Table 1.1 Research questions of this study

1) What ire ue characteristic teatures or workers and jobs on the intermal labour narket?

11. What ts we rationship between tirm niternat labour warkets and wages?

11. What ate he eonsecuences of internil labour markets for the flexibility of wages ind he rnobiny or labour?

The first question focuses on the 'content' of the internal labour market. Since it encompasses only a part of the labour market (De Grip, 1985, p. 343), viz. that part for which the auction market model seems inadequate, the question is how it differs from other parts of the labour market. Are jobs and workers on the internal labour market different from those outside it? And if $\mathrm{so}_{\text {, what }}$ are the reasons for these differences, since they can be the result of difference in the capacity, abilities and effort of workers, or of differences between firms and jobs, caused by the production technology, personnel practices, or general job characteristics. In the first part of this study these questions are discussed theoretically, by looking for reasons why worker and job features of the internal labour market might differ from those outside it. The hypotheses which follow from these discussions will be empirically tested in the second part of the study, by reviewing existing research as well as performing our own investigations.

The second question of our study concerns the relationship between the firm internal labour market and wages. Usually it is assumed that on internal labour markets higher wages are paid (Mace, 1979; Doeringer, 1986, p. 48) and that seniority systems, which lead to upward sloping age-earnings profiles, are prevalent (Althauser and Kalleberg, 1981, p. 126 ff; Barron and Loewenstein, 1985, p. 437). Inwestigating these assumptions we examine if employment on an internal labour market indeed leads to higher average wages, since it is a priori unclear why average wages on an internal labour market should be higher. Moreover, this current question into the average wage level on internal labour markets must be discussed in the light of the findings of the previous question: wages can differ because of differences between employees and jobs on the internal labour market and those outside. Thus it must be examined whether wage differences exist after correcting for such differences in features. This implies that supply as well as demand-side variables are introduced in the analysis, since worker features, such as education or experience, as well as firm or job characteristics, such as job level or firm size, detemine the wage level. "If wage differences disappear after correction for worker and job heterogeneity, we can conclude that wage differences initially observed only reflect differences in employee or job features, and the internal labour market is merely a selection mechanism. However, if wage differences remain, other explanations

6 Traditionally, labour market research tended to emphasize supply-side variables, in line with human capital theory (Becker, 1975). More recent research has shifted this attention to structural or demand-side variables. This is partly the result of some puzzles posed by this recent research, which indicates a separate influence of the demand-side variables on the wage level (Thaler, 1989). In this respect two obvious findings are that larger firms pay higher wages and that payment levels in some industries are consequently above those in other industries (see Chapter 5). 
must be found, since comparable labour market positions apparantly lead to different wages.

The discussion on internal labour markets and wages is related to many other topics, such as sallary structure, income distribution, and payment schedules. At this point we mention two discussions which are closely related to the analysis of internal labour markets and wages: that of the relationship between wages and productivity, and that of the age-earwings profile and seniority wages. It is usually assumed that wages outside the internal labour market equal (marginal) productivity, as in textbook treatments of competitive markets (Koutsoyannis, 1979; Varian, 1984). If wages on the internal labour market differ from these wages outside the internal labour market, the question of the relationship between wages and productivity on the internal labour market arises. With competitive firms, and thus wages equal to productivity, higher wages on internal labour markets imply higher productivity on internal labour markets. This higher productivity must accordingly be explained. On the other hand, if there are no differences in the average wages of workers employed on the internal labour market and those outside, the question arises whether wages on an internal labour market differ from those outside in other aspects. This remark leads to the second discussion, which addresses the age-earnings profile. Do wages on an internal labour market rise with age or seniority? Do they rise more with seniority on the internal labour market than on the external labour market? And if so, what is the reason for this mone steeply age-earnings profile? Perhaps upward sloping profiles might explain higher wages on internal labour markets. But if wages on internal labour markets do not differ from those outside, why should age-earnings profiles slope upwards? This kind of question, concerning the relationship between internal labour markets and wages, will be a matter for discussion below.

The third question of Table 1.1 relates to the consequences of the internal labour market for wage rigidity and labour mobility. This, of course, refers to our discussion in Section 1.1. on the general background of research into intemal labour markets. Although they might ultimately contribute to a better explanation of the problem of unemployment, a decisive answer on this topic is beyond the scope of this study. Therefore, if the consequences of internal labour markets are discussed in this study, attention is restricted to the mobility of labour and the rigidity of wages.

In this study the concept of the internal labour market is discussed at length. Of course, the answers to our research questions are largely dependent upon our definition of the internal labour market. In choosing a definition, worker and job characteristics are already sorted to some extent, and thus the answer is influenced. Therefore we hope to improve on previous work on internal labour markets by providing a theoretically sound definition of the internal labour market, which can be used in empirical investigations as well. It is the purpose of the next chapter to clearly define the internal labour market. The analysis of our research questions mentioned above is then consistently based on this definition of the intermal labour market. This study also hopes to improve on previous work by combining theoretical and empirical discussions using the same underlying definition. In sum, in this study the internal labour market is discussed in economic terms, by clearly defining it and subsequently answering the three research questions theoretically, as well as empirically. The study is set up as follows.

\subsection{Outline}

This thesis consists of a theoretical part, from Chapter 2 to Chapter 4 , followed by an empirical part, consisting of Chapter 5 to Chapter 7. Naturally, the theoretical part starts with a discussion on the core concept of this study, the internal labour market. The main purpose of 
Chapter 2 is to clearly define this concept, since agreement on its precise definition is lacking. Therefore, the origin of the concept is described, and its relation to other labour market segmentation concepts, such as primary and secondary labour markets, is discussed. A review of theoretical definitions of the internal labour market leads to the conclusion that there is no agreement on the essentials of the internal labour market and that it is usually described by a list of features. The chapter ends by arguing that for our purposes the internal labour market can be defined by long-tem employment and internal promotion opportunities. Hawing decided on the definition of the internal labour market attention is tumed in Chapter 3 to the research questions of Table 1.1: who participates in the internal labour market, how does this influence wage payments, and what are the consequences for labour mobility and wage rigidity. Recent labour market theories are reviewed in order to find suitable answers. The conclusion of the review is that present labour market theories do not offer definite answers to our questions on the internal labour market. However, from the review it can be concluded that for a proper discussion of internal labour markets two elements are of importance: monitoring problems concerning the productivity of workers, and the development of firmmspecific skills. Therefore, in Chapter 4 , a framework for the internal labour market, based on these elements, is presented. In this framework the internal labour market is interpreted as a kind of employment contract, featured by long-term employment relations and internall promotion opportunities. These intemal labour market contracts are referred to as multi-period combacts or deferred payment contracts. Subsequently, the three research questions are examined within this intemal labour market framework. This results in a series of hypotheses, which will be tested in the empirical part of this work.

Although a considerable proportion of the empirical part is made up of new empirical research, first, in Chapter 5 , previous empirical research is discussed. It is examined whether in previous research into intemal labour markets satisfactory answers to our questions and hypotheses can be found. Since it turns out that previous research is rather scarce and scattered, and since various definitions of the internal labour market are used, no direct answers to our research questions are found. Therefore we are compelled to perform our own empirical research, which is based on data on the Dutch labour market. In Chapter 6 the data are discussed and the internal labour market, as defined above, is operationalized. As mentioned in Chapter 2, the internal labour market is defined by long-term employment relations and firm internal promotion opportunities. Variables which can be applied immediately are tnavailable for either feature. Hence, proxies are constructed for both features. These indicate for each worker whether he will remain employed with the same firm for a long time, and whether his job prowides fim internal promotion opportunities. With these two variables the size of the internal labour market is measured for the Netherlands. Next, in Chapter 7 our research questions are empirically examined by testing the hypotheses derived in Chapter 4. Accordingly, in a first step difference in worker and job features between those employed on the internal labour market and those employed outside the internal labour market are examined. In a second step, the wage level and the wage profile on the internal labour market are compared to that outside the internal labour market. Finally, in an attempt to derive some conclusions on the consequences of internal labour markets, some variables which reflect the (im) nobility of employees are investigated. In Chapter 8 , general conclusions and a summary are presented. The shortcomings of this study are then listed, as well as the topics which ask for further reseurch. 


\section{CHAPTER}

2

\subsection{Introduction}

The main purpose of this chapter is to find a definition of the internal labour market which serves as a basis for subsequent theoretical and empirical analyses. In order to grasp the origin of the internal labour market, the discussion starts with a -very- short review of the development of the concept, mentioning some historical highlights. In this way we arrive at the discussion on labour market segmentation in the sixties, which was at the outset of the internal labour market concept. Since that period, the concept appears regularly in labour market studies. Below, a closer examination of several segmentation theories is provided. It is argued that it is not in the interest of this study to produce a detailed segmentation of the labour market. Instead, we opt for an approach in which the firm internal labour market is compared with the remainder of the labour market, referred to as the external labour market. This requires a clear definition of the internal labour market. A review of prior internal labour market descriptions results in a comprehensive list of overlapping features and closely related characteristics, instead of a proper definition. The lack of agreement on its essential features forces us to make our own choice. Hence, we argue in favour of an interpretation of the internal labour market featured by long-term employment relations and good internal promotion opportunities. So, instead of following previous, rather descriptive, approaches, we choose a clearly defined concept of the internal labour market.

There are several reasons for the rather extensive treatment of the internal labour market concept in this chapter. The first is obvious: since the intemal labour market is the central concept of our investigations it must be ensured that the concept is clear to the reader. The second is that the internal labour market, as we will see, has often been described, but seldom defined. These descriptive approaches give rise to many different descriptions of the internal labour market and to even more features and characteristics adhered to it. This is hardly satisfactory for a discussion of internal labour markets, since everyone seems to pick the features which suit their arguments, without justifying their choice. A third reason is that one of our goals is to examine the internal labour market empirically by means of cross section survey data. Therefore, a definition of the intemal labour market is needed which enables us to use 
such data. More precisely, this requires a definition which identifies on an individual level whether a worker is employed on an internal labour market. Since no such definition, acceptable to us, is directly available from previous discussion, we construct our own.

The outline of the chapter is as follows. In Section 2.2 we walk with seven-league boots through history, starting with the origins of the concept by referring to Mill and Caimes in the 19 th century, then give more recent references from the work of Dunlop and Kerr in the $1940 \mathrm{~s}$ and $1950 \mathrm{~s}$, and end up with the true birth of the internal labour market concept from the segmented labour market approach of the American institutionalists in the $1960 \mathrm{~s}$. This research culminated in the founding definition of the internal labour market by Doeringer and Piore in 1971. In Section 2.3 a closer look at labour market segmentation is provided. Some proposals to segment the labour market, as well as the critical remarks from orthodox economics, are reviewed. It will be shown that various subdivisions were previlously adwanced, which however do not always excel in clarity, nor in correspondance between different proposals. For our goals, as summarized by our research questions (Table 1.1), a dichotomization of the labour market into an internal and an external labour market is sufficient. Next, in order to find a clear definition prewious definitions and descriptions of the internal labour market are reviewed in Section 2.4. A profusion of features adhered to the internal labour market forces us to make our own choice, in Section 2.5. Since it is argued that the essence of the internal labour market is captured by its protected character, it is accordingly defined as long-term employment relations and internal promorion opportunities. The chapter is summarized in Section 2.6.

\section{2}

\section{Origin of the internal labour market concept}

To describe the roots of the internall labour market concept we start with some quotations from early economists. In the first chapter we pointed to the relationship between internal labour markets and the analysis of variables which influence the wage level. Explaining wage differences has always been a major topic in labour market economics. In this respect an important assumption was that of a homogeneous competitive labour market. Among the first to question the reality of this orthodox assumption were John Stuart Mill and J.E. Cairnes. Although Adam Smith offered several causes for wage differentials', Mill and Caimes pointed to the existence of non-compering growps as an important explanation for the persistence of wage differentials in the long run (see Cain, 1976, p. 1225; Kerr, 1954, p. 49). In this respect Mill opposed to the principle of compensation by Smith, which states that workers employed under poor working conditions are compensated by higher wages.

"The really exhatusting and the really repulsive labours, instead of being betier paid than others, are almost invariably paid the worst of all, because performed by those who have no choice. .. Partly from this cause, and pirtly from the natual and artificial monopolies..., the inequalities of wages are gencratly in an opposite direction to the equitable principle of compensation

In chapter X of book 1 the following causes for wage differentials, which are still relevant today, are found: ".first, the agrocibleness or disagreableness of the employments themselves; secondly, the easiness and cheapness, or the difficully and expense of leaming them; thirdly, the constancy or inconstancy of employment in them; fourthly, the small or great trust whinch must be reposed in those who exercise them, and firthly, the probability or improbability of success in them." (Adam Smith, 1776). 
erroneously represented by Adam Smith ats the general law of remuneration of Labour" (Mill. 1848$, p. 388 $)^{2}$.... "To conclude...there are kinds of labour of which the wages are fixed by custom, and not by competition." (Mill, 1848, p. 403).

The degree of competition on the labour market is also addressed by Cuines (1874). After mentioning the "existence of a large amount of capital in commercial countries in disposable form-or, to speak less equivocally, in the form of money or other purchasing power, capable of being turned to any purpose required" "which "is sufficient for the purpose, ... to render competition effective among the warious industries", Caimes argues that on the labour market "within certain limits and subject to certain qualifications" the same condition is satisfied. "A young generation is constantly coming forward, whose capabilities may be regarded as still in disposable form, fulfilling the same function in relation to the general labour force of the country which capital, whille yet existing as purchasing power, discharges in relation to its general capital". But then Cairnes goes on to qualify the point and provides arguments for the existence of a segmented labour market. There are

"..certain limitations on the action of competition in the labour markel. .. These limits are the limits set by the qualifications required lor each branch of trade and the amount of preparation necessary for their acquisition... What we find, in effect, is, not a whole population competing indiscriminately for all occupations, but a series of industrial layers, superposed on one another, within each of which the various candidates for employment possess a real and effective power of selection, while those occupying the several strata are, for all purposes of effoctive competition, practically isolated from each other. .. We are turs compelled to recognise the existence of non-competing industrial groups as a feature of our social cconomy." (Caimes, 1874, pp. 6873).

In the 1940s and 1950s, Dunlop and Kerr further developed the concept of non-competing groups by explicitly referring to parts or segments of the labour market. Kerr, for example, refers to the 'balkanization' of labour markets. Employment relations are divided into segments by worker and employer preferences, as well as by institutional rules, resulting from actions of united workers, employers or the gowernment (Kerr, 1954, p. 51). He argues that "structure enters the market when different treatment is accorded to the 'ins' and to the 'outs'." (Kerr, 1954, p. 54, note 16). Although in the extreme every labour position could be called a separate market (Kerr, 1954, p. 50), two basic systems of rules are to be distinguished, which accordingly give rise to two types of structured markets. These are the communal ownership of craft unions and the private property of industrial workers. Under the former, the union acts on behalf of its members and imposes rules conceming entrance, apprenticeship, working conditions, and wages. Ability is emphasized and mobility is largely horizontal, that is between firms, but within the occupation. Under the private property system, it is not the occupation, but the plant which is the boundary of the market; changes in accupation within the firm regularly appear. Mobility is vertical and attention is more on seniority than on ability. The basic result of these institutional rulles is that the labour market is divided into a structured part on the one hand, consisting of the craft (or guild) market and the industrial (or manorial) market, and the unstructured (or open) market on the other, which

\footnotetext{
2 These artificial monopolies refer to "apprentice laws, and the rules of corporations which restrict admission into many of the sikilled cmployments" (Mill, 1848, p. 391), while natural monopolies refer 10 monopolies caused by ancicnt custom or restriction of jobs to persons of social ranks.
} 
corresponds to the orthodox market and on which "onlly nexus is cash" (Kerr, 1954, p. 51).

In his article on the task of contemporary wage theory Dunlop ernphasizes the need to explain the wage structure alongside the traditional questions concerning the general wage rate. The relevant question is "What determines the structure of wage rates among firms, industries and occupations?" (Dunlop, 1957, p. 13). In providing some general remarks he stresses that

"A distinction is to be made between the wage structure within a plant, firm, or other grouping in which wages are set by the same authority and the complex of interfirm or group structures set by a number of different agencies. From the point of view of the individual decision makers, the first wage structure is internal while the second is extemal." (Dunlop, 1957, p. 15).

In the short run the firm internal wage structure is relatively fixed by technology, administrative organization of the production process, or custom, while in the long run it is influenced by extermal influences based on conditions and competition in the product market, reflecting the pattern and speed of industrialization. In later years Dunlop points to the need for more insight into changing job content, duration and measurement of job wacancies, and the mechanisms of internal labour markets, defined as

".the complex of rules which determines the movement of workers among job classifications
within administrative units, such as enterprises, companies, or hiring halls. These moventents
may be transfers, promotions, demotions, or layoffs to the exterior labor market; they may be
temporary or permanent, which may affect the operation of the rules." (Dunlop, 1966, p. 32 ,
note (1).

In the sixties American institutionalists examined the influence of training programmes as described in human capital theory (see Cain, 1976, p. 1218 ff). Studying the labour market position of black people in the American ghettos, it was found that they could scarcely improve their labour market position, even after having received considerable education and training. "The labour market, instead of being a competitive market, seemed to be divided into good and bad jobs, with the good jobs being reserved for a restricted part of the labour force, mostly white males. This idea gave rise to the concept of segmented labour markets. The labour market was assumed to be segmented into parts, usually a primary and a secondary part. The primary market consists of 'good' jobs, mainly featured by employment stability, while workers in the secondary part are employed in 'bad' jobs with high turnover and low wages. Unfortunately, clear definitions of primary and secondary markets are absent, and usually a list of features is adhered to them.

Ultimately this research resulted in the seminal study of Doeringer and Piore which prowided an explicit treatment of internal labour markets. In their study the internal labour market is investigated both empirically and theoretically. The subject of their research was the internal labour market for blue-collar workers, and their empirical investigations are mainly based on interviews with personnel managers on their personnel policies and on firm data on the internal labour market. Doeringer and Piore present a definition of the internal labour market, which has served as a starting point for many investigations thereafter. Their definition, which closes this section, considers the internal labour market as

${ }^{3}$ As an example of the wage structure Dunlop points to the wage rates of unionized truck drivers in the Boston area in 1951 , which range from $\$ 2.25$ to $\$ 1.20$ (Dunlop. 1957, p. 21) 
"an administrative unit such as a manufacturing plant on which the pricing and allocation is govemed by a set of rules and procedures. The intemal labor market. govemed by administrative rules, is to be distinguished from the external labor market of conventional economic theory where pricing, allocating, and training decisions are controlled directly by economic variables. These two markets are unterconnected, however, and movement between them occurs at certain job classifications which constitute ports of enry and exit to and from the intemal labor market. The remainder of the jobs within the intemal labor market are filled by the promotion or transfer of workers who have already gained entry. Consequendly, these jobs are shiclded from the direct inlluences of competitive fotces in the external labor market" (Doeninger and Piore, 1971, pp. 1 2).

\subsection{Labour market segmentation}

The discussions of Kerr, Dunlop, and Doeringer and Piore have led to research into the segnents of the labour market. Since research into internal labour markets also implies a segmentation of the labour market, some of these segmentation concepts are discussed below. In fact three divisions, those of Kerr (1954), Doeringer and Piore (1971) and Althaser and Kalleberg (1981), are presented in some detail. However, instead of providing an exhaustive List of all conceptual definitions used in the segmentation approaches, our main purpose is to show that, although the concepts display great resemblance, they lead to confusion because of a lack of agreement on the precise definitions of internal, external, primary and secondary labour markets. Hence, a more detailed subdivision does not always lead to greater clarity. It depends, of course, on the question of research whether a detailed subdivision is necessary and useful. For our research such a detailed subdivision is not essential and thus in the next Sections we continue with a division in two parts: the internal versus external labour market.

As mentioned in Section 2.2, Kerr divides the labour market into two main parts: the structured and the unstructured part. Of the structured market two types exist: guild and manorial systems. On these structured labour markets labour is allocated by institutional rules, while on the unstructured part wages are responsible for the allocation. Further, on a structured market the number of entry ports, contrary to the situation on the unstructured market, is limited. The structured part can be subdivided into un intermal and an extemal part. "The internal mar. ket may be the plant or the craft group", while the external part "consists of .. workers actively or passively awailable for new jobs ... and of the port or ports of entry which are open or potentially open to them" (Kerr, 1954, pp. 54-55, note 16). On the structureless market the "only nexus is cash", which corresponds to the orthodox descriptions of a competitive labour market. On this market workers compete for jobs and are rewarded according to their (marginal) productivity.

A second partitioning of the labour market is presented in Doeringer and Piore (1971, p. $167 \mathrm{ff}$ ), who distinguish between external (competitive) labour markets and the internal labour market. The internal labour market is defined as above. In fact, there are two kinds of internal labour markets: first, an enterprise market on which workers are strongly attached to the plant, "jobs are arranged in seniority districts or lines of progression" (Doeringer and Piore, 1971 , p. 3), and "layoffs and promotions to non entry jobs are generally determined by relatively fixed standards of seniority and ability" (Doeringer and Piore, 1971, p. 3). Second, there are craft markets, on which workers are grouped to occupation, and unions have great influence on the pricing and allocation. These two closely resemble Kerr's guild and manorial system. With respect to the distinction, emphasized by dual labour market theory, between the primary 
and secondary sector, Doeringer and Piore argue that the internal labour market has two parts: one part belonging to the primary, the other to the secondary internal labour market.

A third alternative segmentation of the labour market can be found in an elaborate discussion of the different concepts of internal, primary and secondary labour markets of Althauser and Kalleberg (1981). Since they are not satisfied by the definitions of Kerr, Doeringer and Piore, and others, they propose a new structuring of the labour market. Their main objections to previously provided segmentations and definitions are twofold. First, they argue that the definitions of the concepts are inadequate compared to the original, broad definitions. Second, they find that the levels of labour market stratification (such as firms, sectors, jobs or markets) are confounding (Althauser and Kalleberg, 1981, p. 120). They therefore propose a division of the labour market in three main parts, consisting of five subgroups. First, they distinguish two types of internal market: a firm internal labour market and the occupational internal labour market. The remainder of the jobs, which we refer to as the external labour market, consists of the firm and occupational labour market on the one hand, and the secondary labour market on the other. "The primary labour market consists of everything except the secondary part. The abovementioned labour market segmentations are summarized in Table 2.1.

\section{Table 2.1}

Segmentation according to (a) Kerr (1954), (b) Doeringer and Piore (1971), and (c) Althauser and Kalleberg (1981)

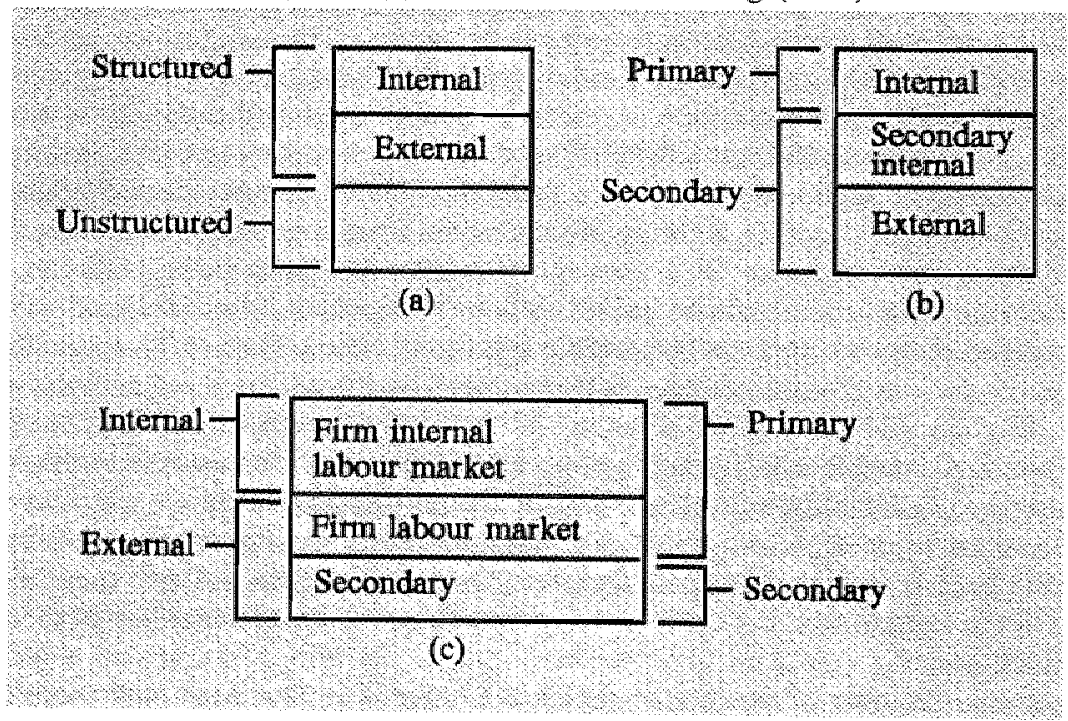

In order not to complicate things in this table, the difference between (craft or) occupational intermal labour markets on the one hand, and (industrial, manorial or) firm internal labour markets on the other, are ignored and only reference is made to firm internal labour markets. From this table it can easily be seen that there is much difference between the divisions of the labour market. Although the concepts, internal, external, primary, and secondary, show 
up in all divisions, there is no agreement upon the use of their definitions. ${ }^{4}$ Sometimes the primary market is part of the internal labour market (as in Doeringer and Piore), while in other definitions the relation is reversed (as in Althauser and Kalleberg). Furthermore, the content of the external labour market differs greatly, since it can be part of the structured market (as in Kerr) or it consists explicitly of the bad jobs (as in Doeringer and Piore). Accordingly the content of the secondary sector exceeds that of the external labour market (Doeringer and Piore) or not (Althauser and Kalleberg). Ryan rightly states that "the wide currency attained by concepts such as "segmentation", 'duality" and 'internal labour markets" has not, however, been accompanied by a generally accepted sense of their meaning and interrelationships" (1981, p. 3). This shows that one must be cautious using these concepts. However, it also shows that a clear definition of the concept of internal labour market is necessary, especially if it is to be investigated empirically. Such a definition of the internal labour market is provided in the next section, but first some remarks on the segmentation approach are in order.

The segmentationist approach, especially the extreme dualistic version, is criticized on several grounds (Wachter, 1974; Cain, 1975, 1976; Ryan, 1981; Taubman and Wachter, 1986). The common argument is that, although the segmented labour market approach undoubtedly points to problems which tend to be overlooked or ignored by orthodox or neoclassical economists, it offers no complete alternative framework (Cain, 1976, p. 1224, 1248; Ryan, 1981, p. 4; Wachter, 1986, p. 680). Examples of such problems reported by segmented labour market theories are the unequal position of some groups of workers on the labour market (especially minorities), the failure of education and training programmes to offer these workers good jobs, the causes of discrimination, the persistence of unemployment and "the institutional dimensions of internal labor markets" (Cain, 1975, p. 21). Indeed, some of these problems are clear "puzzles" in the orthodox framework, but others can be explained by adjusting the traditional framework. Taubman and Wachter state that "many of these hypotheses can be integrated into the neoclassical apparatus" (1986, p. 1184). On the other hand, the alternative theoretical framework offered by segmented labour market theories is insufficient to replace the orthodox framework, since these theories are theoretically and methodologically vague and descriptive (Ryan, 1981, Creedy and Whitfield, 1988, p. 250). Cain concludes "that until the SLM (segmented labour market, gw) theories are formulated more explicitly and precisely, the empirical rather than methodological challenges provide more useful topics for debate" (Cain, 1976, p. 1230). In the same sense Taubman and Wachter state that "The SLM model as a theory, howewer, is incomplete, with important links missing. "This is partly a result of its tendency to rely on historical and descriptive analysis" (1986, p. 1184). Accordingly the conclusion of most critics is not to reject the segmented labour market model, but to adjust neoclassical theory in order to answer the questions raised by segmented labour market theories. Wachter, in this respect, states that the internal labour market "is best wiewed

${ }^{4}$ The following quotations show some of the confusion: "we follow the convention of identifying the intemal labor market with primary sector firms" (Taubman and Wachter, 1986, p. 1186). "The secondary labor market, which roughly overlaps large sections of the extemall labor market..." (Cain, 1976, p. 1222). "The central hypothesis of the dual model is the existence of wo sectors of the economy; a high-wage primary and a low-wage secondary sector. The fomer is composed of industries or firms-or, more precisely, of their components-that have internal labor markets" (Wachter, 1974, p. 642). "Intemal markets thus form a part, indeed the largest part, of the primary market" (Edwards, 1975, p. 16). 
as an efficient institutional response by firms to the basic market imperfections arising from the costs of information and of specific and on-the-job training" (Wachter, 1974, p. 678).

We agree with critical remarks of segmented labour market theories on the explanatory power of the competitive model if it is applied to the labour market as a whole. However, as long as an alternative framework is lacking, one should try to incorporate the segmented labour market ideas into the orthodox framework, which seems flexible enough to adapt itself to new and unexplained findings, instead of rejecting this orthodox framework (Creedy and Whitfield, 1988, p. 253; Wachter and Wright, 1990, p. 242). Ryan argues that rejection of strict duality (as is done by orthodox economists) does not imply the acceptance of the walidity of the competitive model of the labour maket (Ryan, 1981, p. 8), and he states that "(T)he contrast between competitive and segmented markets suggests that these are two qualitative opposed categories. Yet segmentation is clearly a matter of degree - you can have more or less of it" (Ryan, 1981, p. 18).

Our argument to follow a more general approach is that a detailed subdivision of the labour market is pointless in itself, since in principle every employment position can be considered as a separate labour market (Kerr, 1954, p. 50). It depends on the aim of the investigation whether the labour market should be divided in two (as in dual labour market), three (as in Kerr, 1954; Doeringer and Piore, 1971), four (as in Mok and Bracke, 1976), five (as in Althauser and Kalleberg, 1981), or even more submarkets or segments. Only if one desires to give a precise description of the labour market and the differences between jobs and workers, are detailed subdivisions useful. However, it is not the purpose of our research to offer such a detailed classification of the labour market. As stated in Chapter 1, we are interested in the firm internal labour market model, as a possible alternative framework to the orthodox auction market model of the labour market. As it appears that a considerable part of the labour market cannot be treated by the auction market model, since these parts do not show the expected wage and employment flexibility, we are interested in analysing how the alternative model of the internal لybour market differs from the auction market model.

In this respect we compare that part of the labour market in which workers focus on firm internal opportunities, and thus change jobs less frequently, with that of the external market. So our attention is restricied to the firm internal labour market, and we show no interest in any occupational or craft markets. As argued above, the intemal labour market will be distinguished from the remainder, which we refer to as the external labour market. So the distinction between primary and secondary labour markets, and thus between primary and internall labour markets will not be the subject of discussion. Considering the review of previous literature on these matters, the use of the distinction primary versus secondary, with internal versus external, would only lead to confusion. Therefore we adhere to the stress laid by dualists on the distinction between different Jabour market positions $5^{5}$ on the Jabour market. There may be an essential difference between the mechanisms of pricing and allocation on the internal labour market and the external labour market, but although the traditional orthodox framework is better equipped to describe the external labour market, internal labour market aspects may very well be incorporated in this orthodox framework, if the focus is on the right aspects (such as imperfect information or firm-specific skills). As argued above, this focus makes a

5 The term positions can refer 10 jobs or workers. It is often argued that it is the job which deternines whether a worker is said to be on the internal labour market or not. But, as we argue later, creatiod. 
more detailed taxonomy of the labour market unnecessary. From the discussion, it is con cluded that the concept of the intemal labour market in segmentation theories is far from clear. A proper defintion of the firm internal labour market, as opposed to the external labour market, is required in order to answer our questions (see Table 1.1). In the next section exis. ting definitions of the internal labour market are reviewed to examine if such a clear-cut definition is available.

\subsection{Concepts of the firm internall labour market}

Kerr mentions that structure enters the market (which means that an internal market arises) when different treatment is accorded to the 'ins' and the 'outs' (Kerr, 1954, p. 54). This essential feature refers to the existence of preferred positions. Of course, we must also refer to the definition given by Doeringer and Piore (1971), as stated in Section 2.2, which stresses the existence of rules and procedures, instead of the price mechanism, for the allocation and pricing of labour. In the same spirit we find that internal labour markets "are specific, usually contrived mechanisms by which job vacancies are filled" (Edwards, 1975, p. 5). And accordingly Osterman $(1984$, p. 2 ) describes the internal labour market by

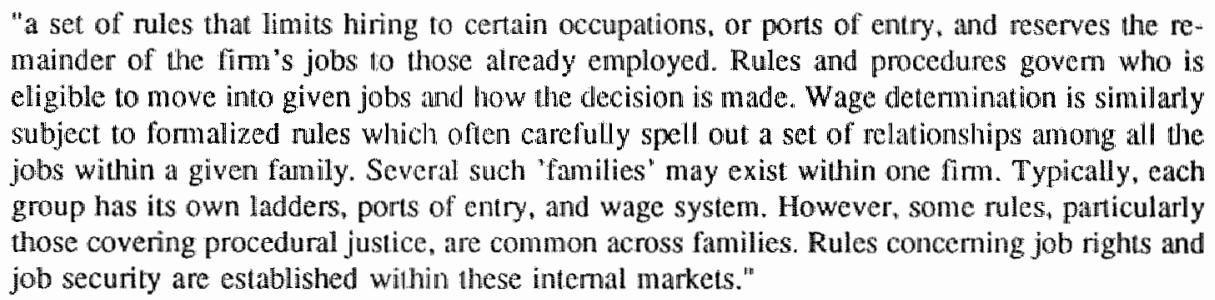

Another description is given by Wachter and Wright, who define the internal labour market as "a set of explicit or implicit, more or less long-term agreements between a firm and its workers. These agreements include implicit and explicit rules governing wages, hours of work, promotion opportunities, and grievance procedures" (Wachter and Wright, 1990, p. 240). Their definition stresses the ongoing employment relationship as an essential feature of a firm internal labour market, which is a result of sunk cost investments (Wachter and Wright, 1990 , p. 243). In a review article on internal labour markets Creedy and Whitfield describe the internal labour market by a list of features which are,

"inter alia, high employment stability, the restriction of entry to lower level positions, the filling of higher level positions by internal promotion, a heavy emphasis on seniority in promotion, the according of major importance to internal factors in wage determination and the attachment of wages to jobs rather than workers." (Creedy and Whitfield, 1988, p. 247).

At this point we can only agree with Althauser and Kalleberg that the original definitions are broad and general. They state that "such breadth...increases the difficulty of generating a cogent theory of the consequences of ILMs (internal labour markets, gw) for wages and employment patterns. The concept will prove far more useful if it is more carefully and less broadly defined than has been the case in the past" (Althauser and Kalleberg, 1981, p. 127). As an altemative they propose a new definition for the internal labour market: 
"The concept of an ILM should inclurde any cluster of jobs, regardless of occupational titles or employing organizations, that have three basic structural features: (a) a job ladder, with (b) entry only at the bottom and (c) movement up this ladder, which is associated with a progressive development of knowledge or skill." (Althauser and Kalleberg, 1981, p. 130).

Nevertheless, some objections can be made to this definition. First, the extent of the internal labour market is limited by this narrowing definition. Feature (b) especially is very restrictive since it excludes cases with entrance half way up the job ladder. Furthemore, requirement (c), which states that movement is to be accompanied by skill development, is restrictive in that it excludes the use of internal promotions for incentive considerations or for a reduction in tumover. Second, attention is directed to the job-side of the market, while we opt for an integrated approach including both worker and job aspects (see footnote 5). Third, this concept seems difficult to operationalize, for instance with respect to the operationalization of the job ladder concept.

Table 2.2

Definitions of internal labour markets

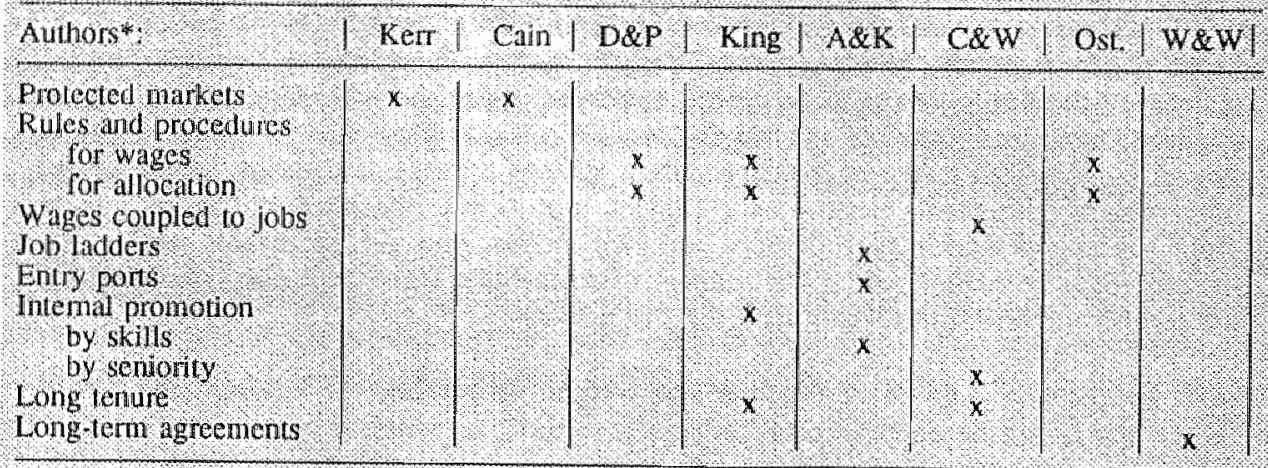

* The definitions are found in Ker (1954), Cán (1976), King (1990), Aluauser and Kalleberg (1981), Creedy and Whitheld (1988), Osteman (1984), and Wachter and Wright (1990).

Table 2.2 , which is representative rither than exhaustive, summarizes definitions found in previous articles by listing their main variables. The conclusion from studying theoretical literaw ture on internal labour markets is, first, that there is much agreement on the broad description of the internall labour market, but, second, that the descriptions used are vague and general.

There is no clear-cut definition or framework which adequately reflects the internal labour market (Wachter and Wright, 1990, p. 242; Osterman, 1984, p. 20; Creedy and Whitfield, 1988, p. 262). This partly explains the lack of empirical research into internal labour markets. Creedy and whitfield (1988) mention several reasons for this. First, there is no framework of the internal labour market with a restricted number of features (p. 262). Existing research mostly concentrates on one feature such as low tumover or seniority pay (p. 254). Second, there is no technique available for investigating a complex of features (p. 249), so other, more heuristic techniques, such as case studies or interviews, are applied (p. 262). Third, there are no proper data to investigate the internal labour market. It is argued that longitudinal firm 
data are needed (p. 249), which are lacking.

The absence of a clear definition of the internal labour market seerns to be a najor problem. In vain one has tried to explain all features from a single factor Wachter and Wright, 1990 p. 242). This leaves us with two options. One is to explain all features of the intermal labour market from several factors and develop an integrated model (as in Wachter and Wright, 1990). This however impedes empirical research for the reasons mentioned above. The other is to "pin down" the intemall labour market to its essentials and develop a framework based on these essential features. Some however argue that this is impossible (Creedy and Whitfield, 1988, p. 262). Mace is quite explicit in this respect and states that

"ILMs are the result of forces, .., that do not give rise to a unique set of precisely quantifiable consequences in firms. Thus, no single statistic, such as tumover rate, is sufficient to establish the existence of an ILM. What is necessary to establish the existence of ILMs is a collection of characteristics that occur together, none of which alone can be precisely predicted" (Mace, 1979 , p. 51).

This is not our opinion. The purpose of scientific research is to compress the complexity of a problem and to describe its main causal relationships. Accordingly, the definition of the internal labour market has to be restricted to the most essential features, which are sufficient for the investigation of the research questions. The choice of relevant characteristics of the internal labour market is of course problem-related. In this respect our research questions require a definition of the internal labour market on an individual level, which still captures the essence of the internal labour market, since we have to compare those employed on the internal labour market to those not employed on the internal labour market. The purpose of Section 2.5 is to find such a definition.

\subsection{Definition of the internal labour market}

As stated above, we focus on the difference between the firm internal labour market and the external labour market. On the external labour market all labour positions or jobs are open to everyone, while on the internal labour market jobs are reserved for insiders. Entrance is restricted to entrance jobs or ports of entry. At this point it must be enphasized that a single firm can have a part belonging to the firm internal labour market and a part which belongs to the external labour market at the same time. "Only in a few cases will all jobs in a single firm or plant comprise a single internal labour market" (Althauser and Kalleberg, 1981, p. 125). So our internal labour market definition does not (always) encompass the whole firm (Edwards, 1975, p. 21, note 6), as in other approaches (see Blossfeld and Mayer, 1988; Szydlik, 1990), and requires variables which characterize the internal labour market on an individual level (see footnote 5 ).

From the discussion in Section 2.4 it follows that the essence of the internal labour market is in its shielded or protected character (Kerr, 1954; Doeringer and Piore, 1971; Bruderl, 1990, p. 7). Internal labour markets are referred to as "protected labor markets" (Cain, 1976, p. 1241). Workers already employed on the internal labour market have privileges over those who have not entered the intermal labour market (yet), and can be referred to as outsiders.

${ }^{6}$ So-called insider-outsider theories are discussed in Chapter 3 (Section 3.7). 
The employer prefers vacant jobs to be occupied by those workers already employed inside the firm, instead of hiring new workers from outside. The rules and procedures, explicitly described in manpower development programmes, and personnell planning systems, or implicitly resulting from previous decisions of the employer, or from customs, norms or habits, are such that workers on the internal labour market will not be dismissed, but change jobs inside the internal labour market. Vacancies are occupied by workers either by horizontal mobility, filling the vacancy by a worker at the same hierarchical level in the firm, or by vertical mobility, by workers lower down the job ladder. So labour market positions on the internal labour market can only be occupied by those who have already gained entry into the internallabour market. Thus, on an internal labour market the attention is directed to mobility within the firm, which can be vertical, over hierarchical levels, or horizontal. However, since it is difficult to determine on an individual level whether there are protected jobs, or whether there are sufficient rules and procedures to decide whether a worker is employed on an internal labour market, other variables are needed which characterize the internal labour market on an individual level.

We state that, for an internal labour market to exist, both worker and firm must have an interest in developing and maintaining an employment relation, since both are (up to some juridical restrictions) free to break the labour relation. This means that workers must not frequently leave the firm, since then the occupation of the vacancies would require entrance of outsiders which contradicts the essential character of the internal labour market. On the other hand, employers who frequently fire employees wil never establish an internal labour market, characterized by protection or shielded positions. Therefore, we define long-term employment relations to be an essential characteristic of an internal labour market. Workers on the internal labour market more likely occupy vacancies by internal mobility on the internal labour market than that they are laid off or dismissed, or that vacancies are filled by outsiders. Since long tenure is related to turnover on firm level, one could take turnover as a basic feature of an internal labour market. However, a firm can have both an internal and an external part, with high turnover on average but low turnover for those on the internal labour market part. Concentrating on (average) turnover then might lead to wrong conclusions concerning the existence of an internal labour market. Therefore we choose for individual tenure as a distinctive feature of an internal labour market.

Although the restriction of our definition to just one variable is attractive for clarity, and empirical research, it is not appropriate to define the internal labour market simply by longterm relations (as some do, for instance Akerlof and Main, 1981; Main, 1981; Collier and Knight, 1985), since it ignores essential internal labour market features. For instance, a worker employed on an assemblly line night expect to remain employed at the same firm for a long time, without the slightest opportunity for improvements in his employment position. Nevertheless, it is hard to regard such a worker as employed on an internal labour market, since future prospects, such as career advancement, internal career opportunities or skill improvements, are generaly considered to be essential features of internal labour markets. Therefore, next to long-term employment we define the existence of internal promotion opportunities as a necessary complementary feature of an internal labour market. Workers employed on a firm internal labour market expect to remain employed at the same firm for a long time, but also expect to expenience firm internall promotion opportunities.

These internal promotion opportunities can either be ("physical") internal promotion to other jobs with higher wages, but they can also refer to ("non-physical") internal promotion on a hierarchy of salaries (Bruderl, 1990, p. 2). In the latter case the worker does not change his job, but advances on a salary schedule. It is assumed that the rules and procedures include 
those that couple wages to jobs, and construct a salary structure that parallels the job structure, as is common in most organizations. "The reason for this "broad' interpretation of the intemall labour market is that it is hardly possible to distinguish between these "physical' and 'non-physical' internal promotion. It is for instance, difficult to assess whether a worker has received a physical promotion, if he moves to a higher level job, which consists of the same set of tasks, but has a higher salary level. ${ }^{8}$ What is essential to such a promotion is the salary increase, due to the promotion, and we also regard such changes as internal promotions, irrespective of the fysical mobility. Such a description of internall promotions leaves us with a definition of the internal labour market based on only two features: long-term employment and internal promotion oppartumities.

With respect to the variables mentioned in Table 2.2 the following renarks apply. First of all, the rules and procedures for wages and allocation result in long-term employment relations with internal promotion opportunities and protected markets. Furthermore, it is assumed that wages are coupled to jobs and that job ladders or job hierarchies exist (Lawler III, 1987. p. 260). So these features are implicilly included as well. An important feature of the internal labour market is the port of entry. The definition of the internal labour market, as long-term employment with intermal promotion opportunities, already includes the notion of a port of entry. For a prerequisite to have promotion opportunities is to have a 'low level' job which is the port of entry - this will be elaborated in Chapter 4. If an entry port offers long-term employment with internal promotions it is part of the internal labour market. Finally, the other features are explicitly included in our definition of the internal labour market.

Furthermore, the choice of our definition is justified by the fact that it does not deviate significantly from the original definition of Doeringer and Piore, as summarized by King (1990):

"First, there must be a substantial degree of permanency to the attachment between employer and worker, which is reflected in the length of the typical job. Second, there must be substantial opportunities for advancement within the firm through intemal training and promotion ... Third, the allocation of tasks and rewards ..must be subject to a well-defined framework of rules.." (King, 1990, p. 73-74).

In our definition the first and the second feature are explicitly met. The third feature is only implicitly met, since it is assumed that in a firm with promotion opportunities for its employees and with development of long-term employment relations, tasks and rewards are condensed in a framework of rules.

How does our definition improve on other definitions? First, as already stressed, it has the advantage of capturing the essence of the internal labour market in only two variables, which is more useful for our research (Althauser and Kalleberg, 1981, p. 127). Second, this definition can be used in empirical research, since both variables can be measured, as will be shown in the empirical part of our study. Third, this definition can both be used on firm or job level, as well as on worker level. This is an important improvement since various data sets can now be used to investigate the intemal labour market. In labour market research

${ }^{7}$ In this respect it is maintained that men are molded to jobs instead of jobs molded to men (Doeringer and Piore, 1971, p. 131).

${ }^{8}$ One can inagine that new hierarchical levels are created by employers to motivate employees who cannot receive further wage increases in their current job, and for whom no thigher level jobs were available. In fact such promotions can be considered as quasi-promotions. These can be a result of "divide and conquer" strategies of employers (see Section 3.2 on the Radicals). 
attention moves from supply-side features (under human capital theory) to the inclusion of demand-side influences (under segmentation theories). Accordingly it is argued that structural or demand-side data are needed to study the internal labour market. We disagree with this opinion, since the supply-side is as important for the internal labour market: the internal labour market is not fully determined by the demand-side (the firm or the employer), nor by the supply-side (the worker). Ideally, both must be analysed. Consider, for example, an employer who tries to install an internal labour market, but is unable to convince his employees of the promotion opportunities. Since his employees do not perceive the existence of the internal labour market, its influence will be low, and turnower will not decrease. Thus, the effective installment of an internal labour market is determined by supply factors as well as demand factors. This legitimates empirical research based on household surveys, next to those based on firm data. Fourth, as will be shown in Chapter 4 , with this definition the internal labour market can be examined in a contractual framework, in which our questions of research can be analyzed, and which evokes other questions with respect to internal labour markets too (see Chapter 8). Together these arguments justify our definition of the internal labour market.

\subsection{Conclusions}

In order to answer the questions of Table 1.1, the internal labour market is to be distinguished from the other part of the labour market. The difference between occupational and firm internal markets is left aside, as attention is directed to firm internal labour markets versus external labour markets. Furthermore, the confusing concepts of primary and secondary markets are not under investigation. Reviewing previous internal labour market descriptions it is argued that for our purposes the internal labour market can be defined by long-term employment relations and internal promotion opportunities. Workers are assumed to remain employed at the same firm for a long time, at the same time experiencing promotion opportunities, either by internal mobility to higher level jobs (with higher wages), or by future wage increases without job changes.

Having defined the internal labour market in this way, it is asked in the following chapters how the two essential features of the internal labour market, long-term employment and internal promotion opportunities, can be explained. Furthermore, we return to the questions of Table 1.1, and examine which workers and jobs appear on the firm internal labour market, how workers are paid, and investigate (some of) the consequences of firm internall labour markets. In an attempt to answer these questions it is only natural to turn to contemporary labour market theories first. 


\section{CHAPTER}

\section{LABOUR MARKET THEORIES AND FIRM INTERNAL LABOUR MARKETS}

\subsection{Introduction}

In the previous chapter the firm internal labour market is defined in terms of both long-term employment relations and internal promotion opportunities. In this chapter we look for explanations for these two features. Also an attempt is made to answer some of the questions discussed in Chapter 1 (see Table 1.1). Since recent years have witnessed an increased attention to firm internal processes and related topics that are essential to the internal labour market, a review of present-day theories seems natural. ${ }^{1}$ Therefore, in this chapter six theories are examined on their explanatory power. In the following sections the essence of each theory and its relevance for the internal labour market is examined.

The chapter is organized as follows: Section 3.2 starts with a discussion of the Radical Approach. Transaction Cost Economics is summarized in Section 3.3. Both theories more or less oppose to, or revolt against, the traditional labour market framework and try to offer an alternative framework. Next, some theories are discussed which are more in line with traditional reasoning, emphasizing maximization under constraints. Section 3.4 is devoted to Human Capital Theory and Section 3.5 discusses Implicit Contract Theory. The most recent labour market theories are discussed in Section 3.6, Efficiency Wage Theory, and Section 3.7, Insider Outsider Theory. An evaluation of the relevance of these theories for the internal labour market is presented in Section 3.8.

\subsection{The radical approach}

The radical approach is close to the segmented labour market approach (see Section 2.3). The analysis emphasizes groups instead of individuals, discusses control and power aspects, and points at historical developments in our Western economies. As in the segmented labour mar-

\footnotetext{
"For some rewiew articles on intemal labour markets, see De Grip (1985), Creedy and Whitfield (1988), Wolfs (1988), Wachter and Wright (1990).
} 
ket approaches, the labour market is segmented into a primary and a secondary sector. The existence and development of these segmented markets is not caused by exogenous sources, but by political and economic forces of the capitalist system (Reich, Gordon, Edwards, 1973). It is asserted that, historically, the capitalist system developed from competitive capitalism to monopoly capitalism, by expansion and mergers, giving rise to large, multi-plant firms and increased concentration (Edwards, 1975). As a result, the size and homogeneity of the workforce within such firms increased, and with it their organizing power. In order to (re)gain control over this large, increasingly homogeneous, labour force this development required a change in the control mechanism, used by the employer, from simple hierarchy with personal supervision, to bureaucratic control. Under the latter, control is increasingly institutionalised in hierarchical power, work criteria, rules and procedures, and internalisation of firm goals (as in the Weberian theory of bureaucracy, see Akerlof, 1984, p. 80). In these large firms employers "systematically and consciously" experimented with organizational structures (Edwards, 1975, p. 8), such as Taylorism, Scientific Management, and the development of personel departments (Reich, Gordon and Edwards, 1973, p. 361). Employers used a "divide et impera" strategy of dividing the homogeneous labour force in separate groups, treating each group differently, which explains the occurence of different jobs, hierarchical levels, and function classifications. With this divide and conquer strategy and with the development of the pyramidal work order, the capitalist became indispensable "as integrator of these separate operations into a product" (Marglin, 1974, p. 277).

In the radical approach much walue is attached to the underlying production process. The need to develop complex hierarchical structures, instead of control by simple hierarchy, is more prevalent in large capital-intensive firms. Such large firms required stable markets and therefore develop intemal labour markets, consisting of reliable workers with stable working habits. "Along with dualism in the industrial structure, there developed a corresponding dualism of working environments, wages, and mobility patterns" (Reich, Gordon and Edwards, 1973, p. 363). Employers offered career opportunities to these reliable workers, which gave rise to reduced turnover and wages increasing with seniority. The smaller, labour intensive, firms in the secondary market were more under influence of changing market conditions, and thus wages and working conditions were more unstable. In the view of the radicals "labour market segmentation arose and is perpetuated because it is functional - that is, it facilitates the operation of capitalist institutions." (Reich, Gordon and Edwards, 1973, p. 364).

Evaluating this radical approach of internal labour markets the emphasis on the historical aspect of the labour market and the relationship between the internal labour market and the underlying production process is striking. Assuming a close correspondence between internal labout markets and primary jobs, internal labour market jobs are featured by stable working habits, skill requirements on the job, relatively high wages and the existence of job ladders (Reich, Gordon and Edwards, 1973, p. 359). Accordingly, internal labour markets are to be found in large, capital intensive firms and stable industries (De Grip, 1985), and workers on these internal labour markets are loyal and have stable working habits. Employers select workers on these stability traits, thereby relying on signals, such as education or previous behaviour (Edwards, 1975, p. 14). Moreover, this theory explains the introduction of hierarchical structures from a need for improved control over employees, which is achieved by offering opportunities for career advancement. The explanation of the installment of hierarchical structures and the use of internal promotions from an attempt to (re)gain control, instead of economic explanations (as in Stiglitz, 1975), is discussed later in more detail, in discussions on monitoring problems (Calvo and Wellisz, 1979; Bowles, 1985). 
With respect to the relationship between internal labour markets and wages, primary or internal labour market jobs are described as better paid jobs with career ladders and "rewards for tenure and seniority within the firm" (Edwards, 1975, p. 15). So wages on the internall labour market are considered to be above those on the secondary market. However, it is not clear whether this reflects productivity differences between workers on the internal labour market and those outside. On the one hand, workers on the intemal labour market differ from those outside, and on an internal labour market more productive (or more reliable) workers might be employed. On the other hand, the radicals point at the appearance of discrimination. Some groups, such as women, black people or minority groups, scarcely gain entrance to the internal labour market, even if they have received considerable training and can be assumed to be equally productive. "This implies that wages on the intemal labour market are higher, but not for productivity reasons. The difficulty is that the radicals argue that "employers in the primary market expect, reward, and therefore elicit stability in work behavior, while those in the secondary market do not expect, may even discourage, and therefore fail to elicit stability" (Edwards, 1975, p. 16). It remains unclear whether internal labour markets select more stable (and more productive) workers and accordingly pay higher wages, or whether the payment of higher wages elicits stable behaviour from initially equal productive workers. A final remark concerning the age-earnings profile is that seniority is rewarded on the internal labour market by career advancement, reducing turnover in that segment (Edwards, 1975, p. 19).

To conclude, although the emphasis on class struggle as an explanatory concept seems. somewhat overstated, some aspects of the relationship between employer and employee are rightly accentuated. In this respect the concern for mutual conflicting interests of employer and employee, and the need for control is notable. These issues reappear in agency models (see Section 3.5). Furthermore, the interpretation of career ladders and the division of workers into groups as incentive devices seems worthwhile.

\subsection{Transaction cost theory}

Based on early contract theoretical considerations the analysis of transaction cost economics focuses on the influence of transaction costs in make-or-buy decisions (Van Ham et al., 1988, p. 1109) and the choice between alternative contracting or organizing modes. In this regard a fundamental choice is that between markets or hierarchies. In this view hierarchies (or internal organization) is regarded as an alternative way of organizing to markets ${ }^{2}$, which are mainly the subject of traditional labour market analyses (Williamson, 1975, 1985). The objection of transaction cost economics to traditional theory is the neoclassical postulate of a fric w tionless world. This postulate is incorrect and following Coase (1937) transaction cosis are explicitly introduced as the basic unit of analysis. Explicitly introducing transaction costs into the analysis leads to alternative explanations for some phenomena. For instance, hierarchies do not arise because of technological indivisibilities, or nonseparabilities (Alchian and Demsetz, 1972), but because of transaction cost. Since the explanation of internal Iabour markets in a way parallels the explanation of using hierarchies instead of markets, the transaction cost approach is examined somewhat further below.

The transaction cost approach is based on the so-called organizational failures framework

${ }^{2}$ See Schreuder (1990) for a further discussion on the dichotomy between markets and hierarchies. 
which is a set of assumptions on environmental factors and human behaviour (Williamson ${ }^{3}$, 1975; schreuder, 1985). The human factors are bounded rationality and opportunism, and the envirommental factors consist of uncertainty or complexity and small numbers exchange. Contracts between parties must be agreed upon, taking these circumstances into account. The main argument of the transaction cost approach is that the market mode can be inefficient (compared to the hierarchical or organizational mode) if there is recurrent contracting. This inefficiency arises because of the simultaneous appearance (or pairing) of bounded rationality and complexity/uncertainty on the one hand, and opportunism and small numbers on the other. As indicated below, both pairs give rise to problems which can be reduced by using the hierarchical contracting mode (or internal organization), instead of contracting through markets.

The first pair is bounded rationality and uncertainty or complexity. Bounded rationality refers to the fact, mentioned by Simon, that human behaviour is "intendedly rational "but only limitedly so" (Williamson, 1975). This bounded rationality is a result of neurophysiological, as well as language, limits. However, "bounds on rationality are interesting, of course, only to the extent that the limits of rationality are reached - which is to say, under conditions of uncertainty and/or complexity." (Williamson, 1975). If these circumstances appear together under recurrent contracting, the use of internal organization can be efficient, since it economizes in three ways (Williamson, 1975, p. 25). First, by emphasizing actual outcomes ("let the future unfold") instead of considering (and specifying) all possible outcomes in advance (which is costly). Second, internal organization will lead to the development of a less. costly, informal idiosyncratic language to nefer to complex events. Third, internal organization promotes convergent expectations on both sides which reduces the uncertainty of the employers and employees.

The second pair is opportunism and small numbers exchange. Opportunism refers to the assumed behaviour of individuals, described as self-interest seeking with guile. This does not create problems in situations of large numbers exchange, since opportunistic behaviour will be driven out by competition. Instead, it is the pairing of opportunism with small numbers exchange which causes problems. Small numbers exchange appears in situations of bilateral monopoly. In these circumstances employer and employee are dependent on each other, for instance because parties posses specific products or skills, which accordingly leads to difficult bargaining and contracting situations. If there is recurrent contracting, internal organization can economize on the problems in several ways under these conditions (Williamson, 1975, p. 29). First, more co-operative, and less opportunistic behaviour of participants inside the firm is attained, since parties are more likely to pursue the same goals. Second, there are auditing advantages of an internal auditor, compared to an extemal one. Third, disputes are less likely to occur and are settled more efficiently.

A final derivative concept in the organizational failures framework is information impactedness. This arises if information is not public, mainly due to uncertainty or complexity and opportunism (Williamson, 1975, pp. 32-33; Williamson et al. 1975, pp. 259-260). ${ }^{4}$ These

${ }^{3}$ In a later article Williamson points at the close correspondence "albeit with terminological differences" (Williamson, 1990, pp. 15-16) between the premises of the organisationall failures framework and other theories based on (implicit or incomplete) contracts.

"In fact "three types of information impactedness conditions may be distinguished" (Williamson et al., 1975, note 33) with small differences. "I emphasize, however, that the problems posed by information asymmetry differ in degree but not in kind from those posed when information sets are 
situations can lead to costly small numbers exchange on which internal organization can econonize. What matters here is that the discussion of information impactedness emphasizes the importance of information in contracting relations, as is recognized by other theories (such as efficiency wage theory).

This organizational failures framework can be explicitly applied to the employment relation (Williamson, Wachter and Harris, 1975) to analyse under which circumstances internal labour markets appear. Considering the internal labour market as a contracting mode, transaction cost economics shows that in situations of idiosyncratic skills the intemal labour market can be more efficient than other contracting modes, which suffer from important disadvantages, according to the organizational failures framework. Since we adopt the idea of regarding the internal labour market as a contracting mode the approach of Williamson (et al., 1975) is further examined in Chapter 4 . For the moment the main advantages of internal labour market contracts over other contracts are summarized and some objections are presented.

Basically, under these contracts labour is hired without exactly specifying all the tasks to be performed. Instead, a worker is assigned to a job, which in turn is coupled to a wage. The advantage of such contracts in situations of recurrent contracting in the above-mentioned organizational failures framework are as follows. First, these contracts have lower bargaining costs, since there is less individual haggling over wages. Second, "the internal wage structure is rationalized in terms of objective task characteristics" (Williamson, 1975) which reduces costly individual bargaining. Third, on an internal labour market "consummative rather than perfunctory cooperation is encouraged" (Williamson, 1975). Perfunctory behaviour means "job performance of a minimally acceptable sort", while consummative cooperation is "an affirmative job attitude". The consummative attitude is partlly attained by offering workers internal promotion possibilities. The fourth advantage of the internal labour market contracting mode is that "investments in idiosyncratic types, which constitute a potential source of monopoly, are undertaken without risk of exploitation" (Williamson, 1975).

In sum, transaction cost economics describes the internal labour market in contracting terms. The main argument is that, because of the human nature and environmental factors described above, situations occur in which organizations are a cost-reducing means of production compared with market-mediated production. Internal labour market contracts are an efficient alternative labour contract in situations of imperfect information or firm-specific skill development. Under these situations small-number bargaining occurs in which worker and employer are dependent on each another. Two objections towards this contract approach of internal labour markets are made. First, only casual remarks are made concerning the wages, although we consider these as an essential aspect of laboum contracts. Thus conclusions concerning the relationship between wages and internal labour markets are hard to derive. It is assumed that wages are coupled to jobs, and incentives are provided by promoting workers internally who are of value to the firm and show co-operative behaviour. "Consequently, although the attachment of wages to jobs rather than to individuals may result in an imperfect correspondence between wages and marginal productivity at ports of entry, productivity differentials will be recognized over time and a more perfect correspondence can be expected for higher level assignments in the internal labor market job hierarchy" (Williamson et al. 1975, pp. 274-275). It may be expected that wages on an internal labour market rise with seniority, due to internal promotion. It is however unclear whether wages are higher than

identical but incomplete or, while different, neither party can be said to enjoy a strategic information advantage" (Williamson, 1975, p. 33). 
outside the internal labour market. A second drawback of this theory is that, allthough it offers an overall framework, it is hardly tested, nor is it easily testable (see Soeters and Schwan, 1990, or Van Ham et al., 1988, for empirical applications of the transaction cost framework). Several concepts, such as transaction costs, and job or task idiosyncracy, remain operationally empty, however. Nevertheless, the importance of information and skill specificity and the contract approach will prove worthwhile and will be used in later discussions (see Chapter 4). As discussed in Section 3.2, the radical approach clearly opposes to the traditional framework by emphasizing historical, control and power considerations. The transaction cost approach, which iss on the border between traditional economics and opposing theories, uses traditional concepts, such as persuing efficiency, but also introduces elements which are no inherent part of traditional economics, such as bounded rationality. At this point we turn to theories which are thore clearly a continuation of traditional reasoning.

\subsection{Human capilal theory}

In traditional microeconomic theory wages equal marginal product in equilibrium for every worker of every category, and wage differences are attributed to preferences and to productivity differences between workers, or to compensating differentials. At this elementary level neoclassical theory does not provide an acceptable explanation for labour market aspects. such as the existence of long-term contracts, involuntary unemployment, career patterns and the existence of hierarchical work relations. Although it is easy to criticize neoclassical theory for this shortcoming, it concentrated on questions concerning labour market outcomes in competitive markets. Maclulup (1967, p. 9) refers to the "fallacy of misplaced concreteness" if neoclassical theory is asked to provide a detalled description of the behaviour of the firm. In this respect neoclassical theory rightly used Occam"s Razor. However, in order to describe firm internal processes, which are essential to internal labour markets, traditional theory must be adjusted. The theories examined in the next sections try do so. In this respect human capital theory investigates investment in human capital (Becker, 1975; Blaug, 1976; Siebert, 1985). During an initial period investment in human capital takes place in order to increase future revenue. The investment can consist of schooling, on-the-job training, or investment in information or health. As with investments in physical capital the amount of investment depends on the rate of return and on the time preference of the worker.

In human capital theory two cases are distinguished: general training and specific training (Oi, 1962, p. 540). General training concerns the development of skills which can be applied in other firms or jobs (Becker, 1975, p. 19ff). Specific skills, on the other hand, only increase productivity in the current firm (Becker, 1975, p. $25 \mathrm{ff}$ ). Under long-term employment relations in a competitive market with zero profits, the strict equality between wages and productivity in every period is replaced by the criterium that total expenditure equals total revenue over the time span of the employment relation. General training must be paid by employees, since it increases their productivity in all firms. If the firm would pay (part of) the training, employees would have an incentive to leave the firm after the training period and enter firms which do not pay the training of employees, and thus pay higher wages. But with the existence of general training long-term employment is not explained, since there is no reason for the firm, nor the employee, to pursue the employment relation. It can however be argued that wages increase in time with increased productivity.

For our research into internal labour markets the case of specific training is more interesting. Under specific training skills are acquired which can be applied only in the current 
organization. The basic difference with general training is that the productivity level, which can be attained after the investment period in that firm. cannot be attained in other firms. Thus, the opportunity wage is not directly affected by specific training. In this case there is a reason for the firm and worker to shan the cost of training. Furthermore, both have a preference for long-term employment relations. If the firm would pay all the training costs, and receives all the revenue from the extra productivity, there would be no reason for the employees not to leave the firm after the training period. Thereby the firm would lose its investment. So the firm would like the employee to pay (at least part of) the training. On the other hand, should the worker pay all the training costs, and receive all the gains, there would be no reason for the firm not to terminate the employment relation before the worker had "regained" his investment. ${ }^{5}$ In this case the employee would like the firm to contribute to his training. Hence it is to be expected that firm-specific training cost, as well as the gains of extra productivity which occur in later years, will be shared between worker and employer, and that both have an advantage in long-term employment relations (Oi, 1962, p. 545). Basically, this is caused by the "sunk" character of the investment in specific skills. In this respect labour is referred to as a quasi-fixed factor (Oi,1962). Once an investment is made in firmspecific human capitall there is an incentive to maintain the employment relation, even if wages temporarily exceed marginal productivity. The reason is that large investment must be made once more for a new worker. So workers with a greater degree of fixity (Oi, $1962, \mathrm{p}$. 543) enjoy more stable employment rellations. This degree of fixity depends on the amount of hiring cost and specific training born by the employer, as well as on the number of periods during which the fixed costs can be amortizised (as well as the rate of discount).

Also in the job competition model of Thurow (1975) the influence of investment in training is a central element. In this approach it is assumed that productivity depends on the job, and wages are coupled to jobs. Contrary to the (traditional) wage competition model, workers compete for jobs, not for wages. In the job-competition model employers rank all potential workers to the (expected) cost of training. Those employees which (are expected to) have low training costs are hired first. These workers receive on-the-job training from workers already employed in the firm. Seniority rules and the behaviour of employers not to accept underbidding by outsiders induce workers to provide such training to new entrants. "The net result is the formation of a series of internal labor markets with limited ports of entry." (Thurow, 1975, 85-86). The difference between the wage-competition model and the job-competition model is essential. "In the wage-competition model, wages fluctuate in the short run to clear markets, and these wage changes then induce shifts in the long-run supply and demand curves. In the job-competition model, supply and demand curves shift in the short run to clear markets. Markets clear by altering hiring requirements and the amount of on-thejob training they provide. Changes in relative wages occur only after a substantial period of disequilibrium in relative wages, if at all." (Thurow, 1975, p. 77). With respect to internal labour markets it can be derived from the job-competition model that wages are coupled to jobs which leads to rigidity of wages. Instead, hiring standards are adjusted to clear markets. Further, on-the-job training is important. Of course employers prefer to employ workers which are reliable and can be expected to show stable employment behaviour. Hence, workers with signals of these features, such as schooling level, are hired first and experience long-term employment relations. As a consequence, statistical discrimination can arise in the job-competition model. Since underbidding or wage competition is absent, individual applicants, who

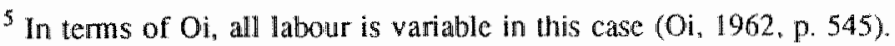


are judged against the average characteristics (or training costs) of the group they are identified with, cannot offer to work temporarily at a lower wage to demonstrate their individual characteristics (or productivity). An example is that of women looking for a lifetime job. To estimate the time they can be expected to stay at the firm, the employer will judge these women against the average tenure of all women, and he may decide not to hire women on lifetime jobs because the average tenure of women is low (Thurow, 1975, p. 178).

The question with respect to the internal labour market in human capital theory is which workers have a greater degree of fixity, and thus are likely to experience long-term employment relations. Oi argues that the occupations' "wage can serve as a proper proxy, and that highly skilled workers in high wage jobs, as well as non production workers, hawe a higher degree of fixity and accordingly more stable employment relations." Further, "firms may also adopt discriminatory hiring policies, hiring only those workers who possess characteristics associated with long employment tenure" (Oi, 1962, p. 544). Although this extended human capital approach offers an explanation for the feature of long-term employment relations of internal labour markets, it does not explicitly explain internal promotion or job hierarchies. If we assume, however, that entrance in higher level jobs requires firm-specific skills, the existence of internal promotion can be explained by this need for firm-specific skills. Summarizing, the following remarks apply. First, the theory addresses the importance of firm-specific human capital and related tumover costs of hiring new employees. High wages and long-term employment are accordingly explained by the development of firm-specific skills, while the influence of information, contrary to more recent developments, is not examined (Blaug, 1976). Second, human capital theory is mainly concerned with formal training, while internal labour market economists (Doeringer and Piore, 1971) emphasize the slow and ongoing process in which workers adapt their equipment and even get familiar with the "smell and sound" of the machinery (Blaug, 1976, p. 849; Blaug, 1987, p. 20). Third, in human capital theory wages are coupled to workers, who increase their productivity by investing in human capital; wage differentials are directly related to worker productivity differentials. Recent findings, however, focus on the separate influence of demand-side variables, such as firm size and industry, on the wages. Finally, as mentioned above, although human capital theory offers an explanation for long-term employment relations, it does not examine explicitly the second feature of internal promotion opportunities on internal labour markets. ${ }^{6}$

\subsection{Implicit contract theory}

Implicit contract theory extends microeconomic theory by focusing on the role of risk (for a review see Azariadis, 1979; Rosen, 1985; Taylor, 1987a, 1987b; Hart and Holmström, 1987; Manning, 1990). Since implicit contract theories (as well as other approaches, such as organization theories and efficiency wage theory) use the principal-agent framework, some general remarks concerning this framework are made first (for review articles on agency theory, see Fama, 1980; Fama et al., 1983a, 1983b; Grossman and Hart, 1981; Douma, 1983; Levinthal, 1988). In this framework the world is modelled by principal-agent relations in which the utility (for instance profits) of a principal (for instance the employer) depends on some action (effort or productivity) of the agent (the employee). Since the worker is assumed to dislike

\footnotetext{
Two recent exceptions to this general remark are Sicherman (1990) and Sicherman and Galor
990).
} 
effort, the employer must pay the worker to motivate him to perform at some effort level. Agency theory examines optimal contracts, given the problems of risk. These problems surround the contract as a result of differences in the state of the world which can occur, or as a result of the (imprecise) measurement of the action performed by the agent and his ability.

Two well-known kinds of problems are of decisive importance in such situations of imperfect information: moral hazard and adverse selection. ${ }^{7}$ Moral hazard arises if the employer is unable to perfectly observe the effort of the agent. A worker may lie about his true effort, if this leads to a higher utility than truth-telling. On the other hand, the employer may be the only one who knows the true state of the world, and accordingly might cheat (by announcing a false state of the world), if this would increase his profit. The problems are addressed as enforceability-problems since they refer to the problem of enforcing the contractual arrangements, if one of the parties does not possess the required information. The other case, adverse selection, arises if the worker has information about his ability, which is unknown to the employer, before the contract is signed. The problem results because an employer needs correct information about the ability of the worker, in order to hire the right worker and reward him properly. In general, agency theory is concerned with institutions (for instance contracts) which solve these incentive problems.

These general remarks bring us to implicit contract theory. The basic ideas were developed independently by Azariadis (1975), Baily (1974), and Gordon (1974). All three were searching for a microeconomic explanation of wage rigidity (or rather wage stickiness) in order to understand (involuntary) unemployment, as well as the observed greater variability of output and employment over wages during business cycles (Manning, 1990, p. 63). The basic idea of these models is that workers and employers agree on a "mutually advantageous unwritten long-term contract" (Taylor, 1987a, p. 126). In this respect "an implicit contract must be interpreted in the "as if" sense of an explicit one, as a mutual understanding between worker and employer that the invisible handshake implies,.." (Rosen, 1985, p. 1149). In implicit contract theory it is assumed that there is uncertainty about the state of the world which will occur. In the most simple model there is symmetric information: both the worker and the firm can observe the state of the world ex post. Furthermore, workers are assumed to be risk-averse and homogeneous, while employers are risk neutral, and an unemployment benefit exists (or some other activity which yields utility while unemployed). These simple models show that both parties prefer contracts with fixed, or state-invariant, wages. Under these contracts the employer may decide over the employment level, depending on the actual state of world which occurs. In sum, more workers will be laid off in a depression, the more "output demand shifts are volatile and/or demand is inelastic, unemployment compensation is high, workers are only 'slightly' risk-averse, there is a competitive demand for labour" (Taylor, 1987a, p. 139). In these models, risk-averse workers agree to give up uncertain wage in exchange for a lower, but certain, wage, thereby handing over part of the risk to the employer. So, in fact, employers offer workers an insurance against income fluctuations since workers receive a wage according to the productivity plas an insurance indemnity (if a bad state of the world

${ }^{7}$ Problems of moral hazard and adverse selection are also referred to as hidden action and hidden information (Arrow, 1985), wrong effort and wrong people (O'Keeffe ef al., 1984, p. 29) and imperfect information ex post and imperfect information ex ante. 
occurs) or minus an insurance premium (in a good state of the world). A finall result of these basic models is that "unemployment will never occur under an implicit contract unless it would also occur under the corresponding Walrasian spot auction" (Taylor, 1987a). So in these models the stickiness of wages does not lead to greater unemployment (Manning, 1990, p. 71 ).

These simple initial models were followed by models in which the assumptions, such as risk neutral employers, worker homogeneity, or symmetric information, are relaxed (Taylor, $1987 \mathrm{a}, 1987 \mathrm{~b}$ ). Some results of these models will be summarized. If workers are heterogenous in productivity, instead of homogeneous, it appears that in bad states of the world lower skilled workers are laid off before higher skilled workers. If this were not the case these higher skilled workers would demand much higher state-invariant wages (the underemployment premium, Azariadis, 1975) to compensate for a possible increased dismissal probability. The long-term employment feature of the intemal labour market indicates that, if these implicit contracts are considered as internal labour market contracts, higher skilled workers will be employed under internal labour market contracts. Relaxing the assumption of risk neutral employers leads to the result of sticky, but not always state-invariant, wages, provided the firm is less risk averse than the worker (Manning, 1990, p. 71). Unemployment, however, does not exceed Walrasian unemployment (Taylor, 1987, p. 160). Finally, relaxing the assumption of symmetric information leads to an extensive list of models, for example, those with asymmetric (or private) information (Azariadis and Stiglitz, 1983). One group of models assumes that only the employer can observe the true state of the world, and thus could cheat by announcing a different state (if this is profitable to him). Another group assumes the opposite: the employee possesses some private information which the employer cannot observe. A problem of cheating opportunities on both sides appears. It is in these models with asymmetric information in addition to risk averse employers that unemployment may occur, which exceeds unemployment in the Walrasian models (Rosen, 1985, p. 1169; Taylor, 1987, p. 170; Manning, 1990, p. 80). In these models, which have state-variant wages because of risk averse employers, it may be profitable for the firm to lie about the true state of the world. Problems of cheating and enforceability of contracts or agreements occur from asymmetric information in the principal agent framework. Such problems have resulted in discussions on so-called bonding issues, firm-reputation and worker-reliablity effects. Since these problems appear in efficiency wage models as well, a discussion is postponed to the next section.

Overall, with respect to implicit contract theory and internal labour markets the following remarks apply. A fundamental difference arises between implicit contract theory and the theory of internal labour markets, as the former concentrates on contracts with wage stickiness and employment variation, while the katter focuses on contracts with employment guarantee combined with wage variation inside the firm. So implicit contract theory tends to emphasize other aspects than internal labour market theory, and concentrates directly on explaining un-

The employer is assumed to be able to carry this risk because of better opportunities for risk spreading. This is usually justified by the assumption that employers (or firms) possess more endowments than workers, and that the human capital a worker possesses cannot be spread over many jobs. Firms, on the other hand, are better able to spread their non-human capital. Another explanation for the lower risk aversion of employers is that they are inherently less risk averse (Taylor, 1987a, p.
$126 \mathrm{ff}$. Manning. 1990 , p. 65). 
employment. ${ }^{9}$ Furthermore, the explanation for long-term employment based on risk aversion in implicit contract theory is not completely convincing (Wachter and Wright, 1990, p. 247). Firms in these models are both insurer and employer. Now if worker productivity differs over firms and time, insurance companies might take over the insurance activities of firms. It is. argued that such companies can hire risk averse workers, offer these workers a prefixed wage and then employ them at firms in which they are most productive. Accordingly, they are employed at different fims over time (Haltiwanger, 1983) and thus do not necessarily develop long-term employment relations at a single firm. "Hence, in the absence of any other factors promoting worker-firm inmobility, such risk shifting arrangements between an individual firm and its workers are not sustainable" (Haltiwanger, 1983, p. 572). Nevertheless, implicit contract theory rightly focuses on the development of efficient contracts between worker and employer and points to problems of risk.

\section{6}

\section{Efficiency wage theory}

Whilst implicit contract theory adjusts microeconomic theory by focusing on contracts and risk sharing, efficiency wage theory examines contracts under information imperfections (Akerlof, 1984, p. 67). Since this theory relates to some characteristic features of internal labour markets an extensive discussion is presented. We start with a summary of its essentials, mentioning several explanations for efficiency wage relations, and next examine the relevance of efficiency wage theory for internal labour markets.

Under the common heading "efficiency wage theory" a number of recent models are found, based on the efficiency wage hypothesis: wages do not serve the sole purpose of rewarding labour for its productivity: they also influence productivity itself. Hence, productivity depends upon the wages (Katz, 1986, p. 225; Akerlof and Yellen, 1986, p. 2; Stiglitz, 1986, p. 182; Weiss, 1991). Basically, efficiency wage theory tries to explain why wages do not always clear labour markets, thus offering a microeconomic foundation of sticky wages (Solow, 1979; Katz, 1986, p. 236). In efficiency wage models it is argued that wages will be chosen at the level where efficiency labour costs (labour costs per efficiency unit) are minimized. Deviation from that wage level will lead to an increase in labour costs which exceeds the gain from the wage change. Thus, although there may be unemployment at that wage lewel the employer will refrain from decreasing the wage or from hiring entrants who are underbidding current wages. This implies that wages can remain above a market-clearing level. It was Solow who first formallized a "piece of home-made sociology" concerning the reaction of workers to wage cutting by the employer (Solow, 1979, p. 80). This resulted in the famous Solow condition. "If labour is modelled in the production function in a labour-augmenting way,

${ }^{9}$ That implicit contract theory is surrounded by problens becomes clear in the evaluating statement of Stiglitz (1986, p. 192): "..., the implicit contract theory has had a long, but sad, history. The simpler models put forward ... provided an explanation of the lack of variability of real wages, but not an explanation of unemployment. The more complicated asymmetric information models were found unconvincing: they more easily gawe rise to overemployment than underemployment, and the foms of contracts to be expected, ..., are not observed."

${ }^{10}$ If the insurance company is considered to be the employer for these workers, ane could argue that these employees develop long term employment relations with the insurance company.

11 Ideas similar to this efficiency wage relation are found in Mill $(1848$, p. 404), Marshall (1920, p. 456 ff). Leibenstein (1957), and Becker (1975, p. $40 \mathrm{ff}$ ). 
maximizing profits with respect to wages and employment leads to this Solow condition, which states that the wage elasticity of effort equals unity. ${ }^{12}$

The "home-made sociology" reasons for the efficiency wage relation initially presented by Solow are bad morale, sabotage, loss of reputation and adwerse selection. Later research has increased the number of efficiency wage arguments and nowadays these are categorized according to the mechanism by which the wage influences productivity (Yellen, 1984; Akerlof and Yellen, 1986; Katz, 1986; Stiglitz, 1986, 1987). However, a common element in all models is that they are based on the assumption of imperfect information with respect to worker productivity. This is also why piece rates are usually excluded in these models (see also Section 4.4). The assumption that productivity cannot be perfectly measured or observed, and therefore highly productive employees can hardly be distinguished from low productive ones, leads to the payment of efficiency wages. Leaving the nutrition model of Leibenstein (1957), which is more appropriate for developing economies, aside for the moment, the following efficiency wage models are recognized.

In the adverse selection model higher wages increase the average quality of the pool of applicants. It is assumed that the employer has difficulties observing the ability of the workers (Katz,1986; Stiglitz, 1986, note 36) and that there is a (positive) relationship between the ability of the worker and his reservation wage. By offering lower wages, the best workers will leave this pool first, becase of the second assumption, which can lead to a non-optimal outcome. Therefore it can be efficient to hold wages at their high, non market-clearing level (Malcomson, 1981). Underbidding is hampered since a worker who offers to work for a lower wage will be considered a lemon (Akerlof, 1970), and will not be hired.

In the shirking model high wages reduce shirking, assuming that being caught shirking leads to (an increased chance of being fired. In this argument unemployment serves as a worker discipline device (Shapiro and Stiglitz, 1984), since those who are fired are assumed not to find a new job immediately. The higher the unemployment level, the lower the shirking level of the employees. So it can be optimal to keep wages at a non market-clearing level. Models of this kind are those of Bulow and Summers (1986), Calvo and Wellisz (1979), Foster and Wan (1984) and Shapiro and Stiglitz (1984).

The third model is the turnover model. While in the adverse selection models the argument concentrates on the inflow of new workers, in these models it concerns the outflow of those already employed. In this model firms pay turnover costs, such as hiring, firing and training. By offering higher wages workers can be induced to stay in the firm, which leads to lower turnover costs (Salop, 1979; Stiglitz, 1986).

In the sociological explanations group norms and group behaviour, instead of individuals, are emphasized. The models of Akerlof $(1982,1984)$ are associated with these theories, especially the partial gift exchange model, in which employees work harder than required in exchange for a higher wage than market clearing. In this model employer and employee exchange effort and wages. These models imply that the fairness of the firm internal wage structure is important for worker morale, which explains the emphasis laid by firms on their internal salary system and function evaluation systems. Akerlof gives some paradigms which support his partial gift exchange mode! (Akerlof, 1984). For instance the dual labour market hypothesis, in which on the primary sector efficiency wages are paid. Or the Weberian

${ }^{12}$ Lower equilibrium elasticities can be cost minimizing if "additional costs to the firm other than those of hiring more labor to replace the lost effort" (or productivity) are of impontance (Akeriof and Yellen, 1986, p. 14). 
bureaucratic model in which loyalty plays an important role. Further he mentions work groups, within which workers develop their own rules and norms, a wiolation of which leads to a decrease in productivity, and equity theory, arguing that overpaid workers produce more.

Finally, union threat models are mentioned as a type of efficiency wage models (Katz, 1986). In these models firms pay higher wages to keep the union out of the firm. If collective action cannot be prohibited or "yellow dog" contracts, which forbid union activity, are not enforceable, an employer might pay higher wages to keep the workers from organizing collective action. Insider outsider theories, as discussed in the next section, closely resemble this argument (Lindbeck and Snower, 1988).

At this point the relevance of these theories for the internal labour market, featured by long-term employment and internal promotion opportunities, is in order. The most explicit explanation for long-term employment is provided by the turnover model, which argues that higher wages reduce turnover. Most other models are not explicitly directed at explaining long-term employment relations or internal promotion. However, an impression of the relevance of efficiency wage theories for internal labour markets is found by the suggested relationship in Akerlof and Yellen (1986) between primary sectors and efficiency wage theory (see also Akerlof, 1984, p. 67, p. 85):

"Dual labor markets can be explained by the assumption that the wage-productivity nexus is important in some sectors of the economy but not in others. For sectors where the efficiency wage hypothesis is relevant - the primary sector - we find job rationing and voluntary payment by firms of wages in excess of market-clearing; in the secondary sector, where the wage-productivity relationship is weak or nonexistent, we should observe fully neoclassical behavior. The market for secondary sector jobs clears, and anyone can obtain a job in this sector, although it might be at lower pay." (Akerlof and Yellen, 1986, p. 3).

This, however, explains high wage primary sectors versus low wage secondary sectors, but not our internal labour market, defined as long-term employment with internal mobility, which can lead to future wage increases. Moreover, although it is tempting to assume that internal labour markets correspond to the primary sector and thus internal labour markets are featured by (high) efficiency wages (since the primary sector has efficiency relations), the relationship is more complicated. Before it can be concluded that internal labour markets payy higher wages in the long run it must be explained why there is no underbidding by outsiders and why there is no bonding. It has already been ascertained that underbidding does not occur, primarily because of monitoring or information problems. Workers who offer to work for lower wages can be expected to cheat, or shirk. But, as critics have argued, a solution to these problems would be the use of bonding arrangements.

The argument is that in (some of) these efficiency wage models the labour market would clear if bonding were allowed, that is if workers could be forced to post a bond (or pay a fee) for entering the firm, or if they were fined when showing low productivity. By this "bonding' new entrants can effectively underbid current workers, and market-clearing wages would result. "Thus, the puzzle of efficiency wages is not why wage levels differ across firms or industries but rather why the implicit rents are not dissipated in the form of bonds and upfront entry fees." (Baker et al. 1988, p. 613). Workers having paid such a bond would have an interest in showing non-shirking behaviour, in order to reduce the risk of losing their bond. Basically, this bond replaces the discipline device of unemployment and as a consequence some essential results of efficiency wage theory, especially the explanation of unemployment, disappear if bonding is allowed. Nevertheless, in reality such bonding schemes seem scarce. 
There may be several explanations for this. First, bonding might be hindered by imperfect capital markets, or other institutional constraints (Akerlof and Yellen, 1986, p. 7; Katz, 1986, p. 244). Second, there is the possibility of employer cheating. If bonding is used, or efficiency wages are paid, employers have an incentive to cheat. By falsely reporting low productivity, they can pay low wages, dismiss workers, or retain the bond. However, this objection is not serious if one assumes that firms have long horizons and considerable long-term reputation loss will keep them from cheating. Moreover, the use of clearly described (and verifiable) payment schedules, for instance seniority promotion rules, together with fixed hierarchies or the use of tournaments ${ }^{1 / 4}$ can keep employers from cheating (Katz, 1986, p. 245).

These arguments capture the essence of our discussion on internal labour markets. It is argued that the use of these alternative labour contracts, such as seniority payments or toumament payments, carn solve the bonding problem and induce non-shirking behaviour. Such payment schedules resemble the essential bonding feature of forestalled pay: part of the payment is delayed until the future, and serves the same role as the bond (Wachter and Wright, 1990, p. 249). Hence, such solutions can be referred to as 'long-term bonding'. Furthermore, the features of these seniority pay or tournament payments correspond surprisingly well to the features of internal labour markets. ${ }^{15}$ Under seniority pay wages increase with seniority, and thus higher wages are paid in the future. This induces workers to remain employed and solves the bonding problem (Lazear, 1979, 1981). In this way workers are employed for a long time and receive higher wages in the future, which corresponds to our definition of internal labour markets. Under tournament payments workers compete for a higher wage in the future, which is paid to a part of the workers (Lazear and Rosen, 1981; Green and Stokey, 1983; O'Keeffe, Viscusi and Zeckhauser, 1984; Nalebuff and Stiglitz, 1984). As an example a tournament can be modelled as workers competing for promotion into a high wage job. Provided such a tournament covers more than a single period, this rorestalled payment provides incentives for non-shirking behaviour, and also solves the bonding problem by long-term employment and future wage increases. Thus, such schedules include essential features of the intemal labour market, such as long-term employment and internal promotion opportunities by higher future wages. However, an interesting question is whether these internal labour market schedules lead to higher wages on internal labour markets compared to those outside the internal labour market. Since this concens one of the research questions of Table 1.1, this topic will be further discussed in Chapter 4 .

From this elaborate discussion of efficiency wage theory "some conclusions can be drawn. First, efficiency wage theory shows that the assumption of asymmetric information leads to considerable problems. If piece rates, increased monitoring, or (short-term) bonding are no efficient incentive devices, proper incertives might be provided by long-lerm bonding solutions. Second, efficiency wage theory is directed at explaining persistent high wages and unemployment. The theories are not developed to explain our internal labour market features.

13 This problem is present in shirking models, but not in turnover models (Katz, 1986), since in these models employers have no incentive to dismiss workers.

14 These toumaments are further discussed below, and in Chapter 4.

15 "The same problems, such as the inability of firms to monitor worker performance costlessly and costly iumover, that give rise to efficiency wage payments above the market clearing level create incentives for the use of altemative incentive devices and the development of intemal labor markets and long-term contractual relationships in the labor market" (Kati, 1986, p. 237). In Chapter 4 we present an efficiency wage model in an intertemporal context. 
of long-term employment and internal promotions, although arguments can be derived, for instance from the tumover models or from the discussion on the bonding issue (see, for in stance, Malcomson, 1984). In the next chapter this discussion is set forth. Furthermore, it remains unclear how high wage primary sectors are related to internal labour markets (Akerlof, 1984; Akerlof and Yellen, 1986; Katz, 1986). The same conceptual confusion, as reported in Chapter 2, arises. This seems to justify our attention to internall labour market contracts versus non-internal labour market contracts, and not on the confusing concept of the primary sector. Third, in efficiency wage theories all explanations are based on differences in the efficiency wage relation and efficiency labour costs. Nevertheless, precise predictions are difficult. In general, wages are higher if monitoring costs are higher (shirking model), training costs are higher (tumover models), work norms, teamwork, and ability to pay is more impor-

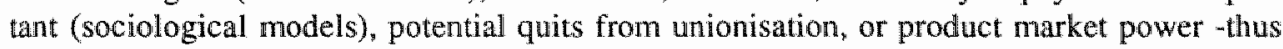
higher rents-, or capital/labour ratios are higher (threat model), or observability is lower (adverse selection). Also high wages appear if damage from low effort is high (Katz, 1986, p. 241 on Milkovich and Newman, 1984), or trust and responsibility is high (Katz, 1986, p. 241 on Eaton and White, 1982).

Nevertheless, some conclusions are unclear. For example, if it is assumed that higher skilled workers and higher level jobs are more difficult to monitor, unemployment must be higher among those with high skills. This contradicts our intuition based on casual observation. If we assume that higher skilled workers are less inclined to shirk (or are better motivated per se), the observed negative correlation between skill level and unemployment occurs (Akerlof and Yellen, 1986, p. 16). Another example concerns the unclear relationship between firm size and wages. Large firms have generally more monitoring problems (Katz, 1986, p. 244), so according to efficiency wage theory their wages will be higher. But if furms differ in the probabillity of cheating, one can argue that firms with higher probability for cheating (such as small firms which can be expected to withdraw from the market sooner) must pay higher wages to compensate the worker. This argument, however, leads to the contra intuitive result that small firms (or the secondary sector) will have to pay higher efficiency wages, while the primary sector can rely on deferred payment systems (Katz, 1986, p. 245). On the other hand, one can argue that firms with increased incentives because of forestalled payments can share rents with their employees, and thus have wages as high, or even higher, than small firms.

Overall, efficiency wage models offer fruitful clues for an exploration of internallabour markets. Nonetheless, a complete discussion of the consequences of efficiency wages would require a more complete (general equilibrium) approach. Our interest is limited to the relevance of efficiency wage theories for internal labour markets. Although these models are not developed to explain internal labour markets, the efficiency wage relation and the results concerning the bonding issue can be useful in modelling intemal labour markets (Lazear and Moore, 1984; Malcomson, 1984). This will be examined in Chapter 4, which focuses on an intertemporal efficiency wage model, based on Malcomson (1984). The emphasis on the relationship between wages and productivity is a welcome addition to economic theory, by the stress laid on the importance of demand-side variables and the introduction of aspects which were already known to payment system specialists, psychologists, industrial sociologists, and institutional economists. A major problem of efficiency wage theory is that it embraces a broad spectrum of theories, which gives room to contradictory predictions. Empirical research is required to find which model best describes the relationship between wages and productivity. In Section 3.8 and Chapter 4 the interest of the efficiency wage relation for the internall labour market questions is examined in more detail. 


\subsection{Insider - outsider theory}

The most recent group of models to be distinguished are united in Insider Outsider Theory (Lindbeck and Snower, 1988; Solow, 1985). The purpose of these models, as of Efficiency wage theories, is to explain involuntary unemployment and non market-clearing wages. Emphasizing the difference between insiders, those already employed inside a firm, and outsiders, those trying to gain access to that firm, it is explained why outsiders cannot sucessfully underbid insiders, and why insiders can have high, non market-clearing wages. ${ }^{16}$ This corresponds to efficiency wage theory, but stress is laid on labour tumover costs (Lindbeck and Snower, 1988, p. 3), instead of effort and productivity.

There are three kinds of turnover costs which explain the above-mentioned phenomena: 1) cost of hiring, training and firing workers, 2) cost of co*operation between employees and harassment of new workers, and 3) cost of effort responses to changes in job security or labour turnover (Lindbeck and Snower, 1988, p. 68). Because of these costs it is unprofitable for a firm to replace insiders by outsiders, and for this reason insiders are able to ask high, non market-clearing wages. To explain why there is no effective underbidding, an alternative distinction of labour tumover costs, between production-related and rent-related turnover costs, is made. Outsiders might be able to underbid insiders by offering to work for the current insider wage less the productivity difference between insiders and outsiders, and less the production-related costs. However, due to rent-related turnover costs this underbidding is ineffective (Lindbeck and Snower, 1988, p. 63). ${ }^{17}$ Due to these rent-related turnover costs insiders have more clout, since they have the power to influence the productivity of outsiders (for instance by refusing to co-operate with outsiders), or to influence their disutility of working (by harassment activities). Since these rent-related tumover casts are difficult to monitor or observe, and since effort-related payment systems are excluded (Lindbeck and Snower, 1988, p. 79), substitution of insiders for outsiders is not profitable for the firm.

It can be inferred from this reasoning that the analysis, as in efficiency wage theory, is based on the assumption of imperfect information concerning the productivity of employees. If workers could be paid according to their productivity, or the rent-related turnover costs could be measured perfectly, underbidding could be successful (provided that the reservation wage is low enough). So, although the difference between insider outsider theory and efficiency wage models is explicitly stressed, ${ }^{18}$ we argue that the essence of both models is the same. So if Lindbeck and Snower state that "When comparing the realism of the two theories, the vital issue that remains is whether firms' imperfect information or workers' market power is more important in providing microeconomic foundations for the existence and persistence of involuntary unemployment in market economies" (Lindbeck and Snower, 1988, p. 73), this can be relaxed somewhat. First, it can be questioned how far wages can be set, either indivi-

\footnotetext{
${ }^{16}$ An oulsider becomes an insider after an initiation period as an entrant, so in fact three groups are distinguished.

17 The exact nature of these rent-related costs is not discussed here, but Lindbeck and Snower state that "Il is job security legislation, union activity, and the structure of social relations between insiders and other workers that is responsible for the outsiders' restricted opportunities" $(1988$, p. 7$)$.

${ }_{18}$ Lindbeck and Snower state that "the theory is not a variation on a theme established by the efficiency wage theory" (1988, p. 9), while Krueger and Summers state: "We prefer to regard rent sharing as a species of efficiency wage theory rather than as an alternative explanation for wage
differentials." (1988, p. 280 ).
} 
dually or unillaterally by workers or unions. It can be questioned whether unions really ignore the position of outsiders if they set wages. Second, as argued, the essence of the argument concerning the impossibility of underbidding depends on the rent generating activities of insiders, and not on the production-related turnover costs. Only the rent-generating costs determine the real insiders' power. The relevance of these costs for a conscious action of individual insiders to keep outsiders out of the firm can be disputed. Third, as far as long-term contracts are unfeasible, because of imperfect information, the basis of both theories turns out to be the same: the imperfectness of information, or the problems of monitoring employees.

In fact, both models are complementary (Lindbeck and Snower, 1988, p. 9). While efficiency wage models stress effort and productivity aspects, and insider outsider theory concentrates on turnover costs, both concentrate on the relationship between wages and labour costs. It is argued that in some firms wages that are above the market-clearing level can persist in spite of (involuntary) unemployment, because reduction in wages or hiring outsiders leads to increased (turnover) costs, or reduced productivity (by effort, morale or average quality effects).

Some leads to the internal labour market can be found from the remarks of insider outsider theory on the primary and the secondary sector. ${ }^{19}$ If the difference between the primary sector and the secondary sector is assumed to depend on turnover costs (Lindbeck and Snower, 1988, p. 247), four features of the primary sector can be explained by insider outsider theory. First, those unemployed and those employed in the secondary sector (Lindbeck and Snower, 1988 , p. 247) prefer to be employed in the primary sector; second, in the primary sector retention probabilities are higher; third, employment is less variable; and fourth, more extensive job ladders and internal promotion appears in the primary sector. It is argued that firms, jobs and workers with higher turnover costs have higher wages and lower turnover. Thus, it can be derived that internall labour markets with lorig-term employment and internal promotion (and accordingly higher wages) appear if turnover costs are high. Higher tenure leads to more 'insider-ness', turnover costs, and power to negotiate higher wages, which explains wage scales and seniority systems on primary markets (Lindbeck and Snower, 1988, p. 248).

Considering the wage aspect in some detail, matters are more complicated. An insider has a higher wage, or higher expected wage, compared to the outsider or the entrant. It is assumed that the "present value of a firm's wage costs over a worker's remaining lifetime is positively related to the insider wage" (Lindbeck and Snower, 1988, p. 4). So increases in the insiders" wage are not accompanied by decreases in the entrants" wage. In fact, it is assumed that entrance wages are fixed ${ }^{20}$, and thus that bonding is excluded. The fundamental questions on the wage profile and the bonding solution of internal labour markets (see Section 3.6) are not examined in insider outsider theory. However, since the basic argument is the same under both insider outsider theory and efficiency wage theory, we refer to the previous section for a discussion of the wages under imperfect information.

Overall, we conclude that the difference between insiders and outsiders (see the tern

19 "It is well to keep in mind, however, that the sharp distinction between the primary and secondary sectors is made primarily for simplicity. In practice, the difference is one of degrec, and the insideroutsider theory may capture this difference through graduations in labor tumover costs, while the efficiency wage theory may do so through graduations in monitoring and in the responsiveness of productivity to wages" (Lindbeck and Snower, 1988, p. 249).

20 "In practice, we do not find that entrants' wages fall whenewer the insiders" wages rise" (Lindbeck and Snower, 1988, p. 9). 
"insiderness", Lindbeck and Snower, 1988, p. 248), as well as between insider outsider theory and efficiency wage theory, is one of degree rather than of kind, since both are based on imperfect information.

\subsection{Conclusions}

In this final section the relevance of the theories of Section 3.2 to 3.7 for internal labour markets is evaluated. First, the explanation for long-term employment and internal promotion is examined, and second, their relevance for some of the questions of Table 1.1 is discussed. Table 3.1 provides a summary of the theories previously discussed. They offer slightly different explanations, or emphasize different features, with respect to the existence of long-term employment and promotion opportunities, or the origin of internal labour markets. The radicals focus on control aspects and the underlying production process, transaction cost economics emplasizes transaction costs and idiosyncratic circumstances, human capital theory builds on firm-specific humar capital as an explanatory concept, implicit contract theory stresses risk, efficiency wage theory points to problems due to imperfect information on worker productivity and the explanatory element of insider outsider theory is turnover costs.

Table 3.1 Summary of features of internal labour markets

\begin{tabular}{|c|c|c|c|c|}
\hline & Origin & \multicolumn{2}{|c|}{$\begin{array}{l}\text { Internal labour market } \\
\text { Workers }\end{array}$} & Wages \\
\hline $\begin{array}{l}\text { Radical } \\
\text { approach }\end{array}$ & Control & $\begin{array}{l}\text { Stable working } \\
\text { behaviour } \\
\text { men, higher } \\
\text { educated }\end{array}$ & $\begin{array}{l}\text { Stable firms; } \\
\text { large, capital } \\
\text { intensive }\end{array}$ & $\begin{array}{l}\text { Higher wages; } \\
\text { senionty wages }\end{array}$ \\
\hline $\begin{array}{l}\text { Transaction } \\
\text { cost approach }\end{array}$ & $\begin{array}{l}\text { Thansaction? } \\
\text { costs }\end{array}$ & $\begin{array}{l}\text { Idiosyncratic } \\
\text { skills }\end{array}$ & $\begin{array}{l}\text { Idiosyncratic } \\
\text { tasks }\end{array}$ & $\begin{array}{l}\text { Wages coupled } \\
\text { to jobs }\end{array}$ \\
\hline $\begin{array}{l}\text { Human capital } \\
\text { theory }\end{array}$ & $\begin{array}{l}\text { Firm-specitic } \\
\text { skills }\end{array}$ & $\begin{array}{l}\text { High degree of } \\
\text { fixity }\end{array}$ & $\begin{array}{l}\text { High wage, } \\
\text { high skilled } \\
\text { jobs }\end{array}$ & $\begin{array}{l}\text { Higher wages: } \\
\text { share of } \\
\text { productivity }\end{array}$ \\
\hline $\begin{array}{l}\text { Implicit } \\
\text { contract theory }\end{array}$ & Risk (aversion) & High skilled & & $\begin{array}{l}\text { Stable, but } \\
\text { lower wages }\end{array}$ \\
\hline $\begin{array}{l}\text { Efficiency } \\
\text { wage theory }\end{array}$ & Incentives & $\begin{array}{l}\text { Monitoring } \\
\text { problems }\end{array}$ & $\begin{array}{l}\text { Moniloring } \\
\text { problems }\end{array}$ & Higher wages \\
\hline $\begin{array}{l}\text { Insider } \\
\text { Outsider theory }\end{array}$ & Turnover costs & $\begin{array}{l}\text { Rent-creating } \\
\text { power }\end{array}$ & $\begin{array}{l}\text { Unionized } \\
\text { firms }\end{array}$ & Higher wages \\
\hline
\end{tabular}

* Higher wages in this column refers to higher average wages for workers on intemal labour markets (Radicals). with firm-specific human capital (Human capital theory), with efficiency wages (Efficiency wage theory) or for insiders (Insider Outsider theory). 
Nevertheless, we summarize these different explanations for internal labour markets by distinguishing two groups of explanations. 21 The first group concentrates on efficiency arguments, while the second emphasizes sociological aspects, group processes or power considerations (Doeringer, 1986). The first group emphasizes the efficiency of internall labour markets, by pointing at cost minimizing contracts under imperfect information (efficiency wage theory), risk (implicit contract theory), or transaction and tumover costs (transaction cost theory and insider outsider theory). Williamson (1975), as well as Doeringer and Piore (1971), explicitly consider the internal labour markets as an efficient alternative to neoclassical markets. In these approaches the internal labour market is to the advantage of both employers and employees. The second group of models emphasizes social arguments and equity and power considerations. For instance, in some efficiency wage models, as well as under segmented labour market theories, social aspects lead to internal labour markets. Workers employed in the same firm develop norms and habits, which give rise to the rules and procedures mentioned by Doeringer and Piore. Akerlof points to similar relationships in his partial gift exchange model (Akerlof, 1982). Radical approaches, which point to power, control and strategic concern of employers to "remain in charge", are closely related to these arguments. ${ }^{22}$ In line with our statements on neoclassical theory (see Section 2.3), we decide to concentrate on the first group of explanations which focus on economic and individual aspects, instead of social or group aspects. This, however, implies that considerations of equity and fairness on internall labour markets are not an explicit topic of discussion (see Chapter 8).

The circumstances under which long-term employment relations and internal promotion opportunities arise are discussed below. Two explanations for long-term employment are distinguished in the theories presented above: the development of firm-specific human capital (and turnover costs) and information problems. ${ }^{23,24}$ Firm-specific skills in the first explanation are closely related to turnover costs since these arise partly from the specificity of skills (see Section 3.4). This explanation of long-term relations can be found in human capital theory, transaction cost theory, insider outsider theory and some efficiency wage models. The second explanation concentrates on imperfect information. Problems of monitoring employee productivity and the resulting costs of writing contingent contracts make long-term employment efficient. Efficiency wage theories are based on this explanation, but elements can also be found in transaction cost economics (information impactedness), implicit contract theory (uncertainty

21. A similar distinction is found in Creedy and Whitfield: "... ILMS can be interpreted as insititutions which reflect the interdependence of wages and productivity. This interdependence is seen to reflect either the incentive, signalling or tumover problems which are stressed by neoclassical theorists or sociological conventions and principles of appropriate behaviour" (1986, p. 8).

${ }^{22}$ It must be emphasized that the two groups of models are in a way complementary, since it is argued that deviation from existing noms and habits in the more sociological approaches can lead to inefficient outcome. The radicals point to efficiency considerations of the use of hierarchics for the mmployer, although their efficiency concept differs from the Pareto efficiency concept of the first group.

${ }_{23}$ This includes problems of moral hazard as well as adverse selcction. In this study we mainly focus on moral hazard problems.

24 Others have made a similar distinction in explanations of the intemal labour market: De Grip (1985, p. 343) distinguishes X-efficiency and reduction of turnower and selection cost: Elliot (1991. 358 ff) mentions specific skills and information; Abraham and Farber $(1987$, p. 278) refer to the "firmspecific human capital explanation and effort-incentive wage deferral explanations"; and Lazear and Moore (1984, p. 150) investigate human capital and incentive effects. 
on the state of the world), human capital theory (inwestment in information) and also in insider outsider theories (as we have argued in Section 3.7). The difference between both explanations is their reliance on the importance of information imperfections as an essential explanation of long-term employment. Explanations which emphasize the development of firmspecific human capital stress the (turnover) costs of offering short-term employment, more than the problems of monitoring worker productivity. However, both explanations are closely interrelated, since it is likely that workers who possess specific skills are more difficult to monitor exactly by the employer.

For the second feature of internal labour markets, internal promotion opportunities, it must be explained if and why workers experience future wage increases. This top ic is clearly underexposed in previous theories or treated in a general way. Usually, it is argued that workers on internal labour markets earn higher wages, which may be a result of internal promotions. Therefore, this matter is implicitly discussed when we investigate the relationship between the internal labour market and wages below. In Chapter 4 we address this matter more explicitly. From our definition of the internal labour market it follows that internal promotions are regarded as future wage increases. In fact payment schedules or contracts with delayed payment are a result of internal promotion opportunities. Thus, it is examined in Chapter 4 under which circumstances such contracts appear.

In the remainder of this section we turn to a discussion of the questions of Table 1.1. Hypotheses on these questions are formulated in Chapter 4 , which presents the discussion of the internal labour market as a contract. Nevertheless, a summary of the considerations of this chapters" review already offers some clues for the formulation of our hypotheses.

For the question concerning the characteristics of internal labour markets various answers are provided. The radicals argue that some groups have better acces to stable jobs, such as white men, and workers with reliable employment behaviour. The transaction cost approach points to skill specificity and human capital theory argues that workers with a higher degree of fixity have more employment guarantees, while implicit contract theory points to more skilled workers. Efficiency wage theories emphasizes efficiency wage relations as a result of information problems and turnover cost, while these tumover costs are also mentioned by insider outsider models. With respect to the jobs or firms which have internal labour markets similar arguments can be used. Firms featured by employment situations with monitoring problems, high tumover costs and firm specific human capital, have more reason to install an internal labour market by offering long-term employment. From these considerations with respect to the furst question it can be hypothesized that on the internal labour market workers with stable employment behaviour and large amounts of specific skills are employed. Furthemore, these internal labour markets occur in jobs or firms with monitoring problems. Hence, internal labour markets might employ higher educated, better skilled workers, and consist of high level jobs. In formulating lypotheses in Chapter 4 these variables will be discussed in more detail.

The question on the relationship between internal labour markets and wages falls apart in subquestions on the average wage level, the relationship between wages, productivity and senionity (see Chapter 1). With respect to the first (sub)question, most theories argue that average wages on internal labour markets are higher than those outside. The only exception is implicit contract theory in which wages may be lower, since employees pay for a wage certainty (or rigidity) by buying insurance. 25 However, as argued in Section 3.5, these

25. However, from Section 3.5 we know that not all models result in state-invariant wages. 
theories offer no convincing argument for long-term employment relations, which, we argued, is an essential feature of the internal labour market (Haltiwanger, 1983). All other theories seem to offer arguments for average wages on the internal labour market to be higher than wages outside the intemal labour market. However, since it is argued above that internal labour markets employ higher educated, better skilled workers, and consist of high level jobs, this result of high average wages on internal labour markets is not surprising. Additionally, in adverse selection models of efficiency wage theory a positive relationship between offering higher wages and attracting better workers is provided. The interesting question in this respect is whether wages on internal labour markets are higher for identical or homogeneous workers. Unfortunately, it is unclear from the theories above whether wage differences remain, after correcting for heterogeneity between workers employed on the internal labour market and outside. Therefore the discussion in Chapter 4 is directed to this question. If wage differences disappear after correction for worker differences, identical workers are equally paid on the internall labour market and outside, and the internal labour market turns out to be merey a mechanism which selects highly productive workers. On the other hand, if wage differences should remain, matters become more complicated; apparently, workers receive higher wages for other reasons if they are employed on an internal labour market.

This leads to a discussion on the relationship between wages, seniority and productivity. If identical workers are paid equal wages on the internal labour market and outside, they will be paid according to their productivity. However, if wages for workers on the internal labour market are above those outside the internal labour market, two possibilities exist. Either worker productivity on the internal labour market is higher, or workers are paid more than their productivity on the internal labour market and firms share rents with their employees. Finally, some remarks on the relationship between age and earnings are made. Two reasons for upward sloping age earnings profiles on internal labour markets can be distinguished. First, they can be the result of the development of firm-specific human capital. Second, steeper slopes offer incentives for increased effort or efficiency. Outside the internal labour market such a positive slope is less necessary since workers posses less firm-specific human capital or monitoring problems are smaller. Since the theories discussed in this chapter provide no decisive answers to these relationships, we turn to them in the next chapter. In the contract theoretical framework presented in Chapter 4 hypotheses concening the relationship between internal labour markets and wages are derived.

The third question on the consequences of internal labour markets is relatively underexposed in our review. Concerning the mobility of labour the following can be noted. In general, long-term employment relations, which is a feature of the internal labour market, indicate low inter-firm mobility. On internal labour markets workers remain employed for a long time, because of skill development, monitoring problems or job matching. Some approaches, such as the radicals, further point to increased intra-firm mobility as a result of career patterns and internal promotions. These considerations indicate higher intra-firm mobility and lower inter-firm mobility on the internal labour market compared to the external labour market. Turning to the rigidity of wages several theories argue that on internal labour markets wages are coupled to jobs (Thurow, Williamson). This indicates that wages are not adjusted frequently to changing economic conditions and rigidity in this sense occurs. However, due to the static nature of most approaches discussed above, these results ask for a cautious interpretation.

Overall, we conclude that the theories reviewed above provide no complete picture of the relationship between wages, long-term employment relations and intemal promotion opportunities. Nevertheless, from the discussion two types of explanation for longterm 
employment relations are derived: the development of firm-specific human capital and information problems. Workers and jobs on internal labour markets are featured by these. Further, while it is generally assumed that wages on the internal labour market are higher, it remains unclear whether this is to be expected after correction for worker and job differences. In the next chapter we elaborate on this discussion, using both explanations for long-term employment relations with promotion opportunities. 


\section{CHAPTER}

4

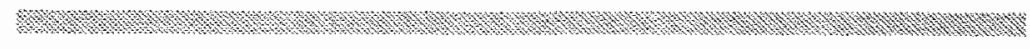

\section{THE FIRM INTERNAL LABOUR MARKET AS A MULTI-PERIOD CONTRACT}

\subsection{Introduction}

The research questions at the core of this study are (see Table 1.1): which jobs and workers characterize the firm internal labour market, how is the relationship between firm internal labour markets and wages, and what are the consequences of the internal labour market for the flexibility of wages and the mobility of labour. In this respect the internal labour market is defined in Chapter 2 by long-term enployment relations and firm internal promotion opportunities. In a first attempt to answer the questions current labour market theories have been reviewed in Chapter 3. Although a coherent framework for explaining long-term employment and internal promotion is lacking, two useful concepts for such a framework of the internal labour market were found: firm-specific skills and monitoring problems.

The problem to be discussed in the present chapter is how the firm internal labour market can be modelled in order to answer the research questions, especially the wage difference between the firm internal labour market and the external labour market. This requires modelling of the internal labour market, the external labour market, and the relationship between the two. Below this is examined within an equilibrium framework. In this framework the intemal labour market is interpreted as a contract, featured by long-term employment and internal promotion opportunities. A complete analysis requires a modelling of the extermal labour market in contract terms as well. Therefore which kind of contract is apparent on the externall labour market, and which wage level results, is discussed. Furthermore, the relationship between internal and external labour market contracts is examined, and some remarks on the market structure of the external labour market are made. In sum, the investigation concerns the structure of the internal and the external labour market and their interdependence. In this respect it must be emphasized that no complete model is offered in this chapter. Instead, we start with a model of the internall labour market presented by Malcomson (1984), and we investigate the structure of the internal and external labour market in this model. Next, the consequences for the wage difference and wage profile on the internal and external labour market are examined with this model. Since the model is not explicitly constructed for our set of questions it falls short on some points. Some directions in which the model should be adjusted to answer the 
employment relations are derived: the development of firm-specific human capital and information problems. Workers and jobs on internal labour markets are featured by these. Further, while it is generally assumed that wages on the internal labour market are higher, it remains unclear whether this is to be expected after correction for worker and job differences. In the next chapter we elaborate on this discussion, using both explanations for long-term employment relations with promotion opportunities. 


\section{CHAPTER}

4

\subsection{Introduction}

The research questions at the core of this study are (see Table 1.1): which jobs and workers characterize the firm internal labour market, how is the relationship between firm internal labour markets and wages, and what are the consequences of the internal labour market for the flexibility of wages and the mobility of labour. In this respect the internal labour market is defuned in Chapter 2 by long-term employment relations and firm internal promotion opportumities. In a first attempt to answer the questions current labour market theories have been reviewed in Chapter 3. Although a coherent framework for explaining long-term employment and internal promotion is lacking, two useful concepts for such a framework of the internal labour market were found: firm-specific skills and monitoring problems.

The problem to be discussed in the present chapter is how the firm internal labour market can be modelled in order to answer the research questions, especially the wage difference between the firm internall labour market and the extemal labour market. This requires modelling of the internal labour market, the external labour market, and the relationship between the two. Below this is examined within an equilibrium framework. In this framework the internal labour market is interpreted as a contract, featured by long-term employment and internal promotion opportunities. A complete analysis requires a modelling of the external labour market in contract terms as well. Therefore which kind of contract is apparent on the external labour market, and which wage level results, is discussed. Furthermore, the relationship between internal and external labour market contracts is examined, and some remarks on the market structure of the external labour market are macle. In sum, the investigation concerns the structure of the internal and the external labour market and their interdependence. In this respect it must be emphasized that no complete model is offered in this chapter. Instead, we start with a model of the internal labour market presented by Malcomson (1984), and we investigate the structure of the internal and external labour market in this model. Next, the consequences for the wage difference and wage profile on the internal and external labour market are examined with this model. Since the model is not expllicitly constructed for our set of questions it falls short on some points. Some directions in which the model should be adjusted to answer the 
employment relations are derived: the development of firm-specific human capital and information problems. Workers and jobs on internal labour markets are featured by these. Further, while if is generally assumed that wages on the internal labour market are higher, it remains unclear whether this is to be expected after correction for worker and job differences. In the next chapter we elaborate on this discussion, using both explanations for long-term employment relations with promotion opportunities. 


\section{CHAPTER}

\section{THE FIRM INTERNAL LABOUR MARKET AS A MULTI-PERIOD CONTRACT}

\subsection{Introduction}

The research questions at the core of this study are (see Table 1.1): which jobs and workers characterize the firm internal labour market, how is the relationship between firm internal labour markets and wages, and what are the consequences of the internal labour market for the flexibility of wages and the mobility of labour. In this respect the internal labour market is defined in Chapter 2 by long-term employment relations and firm internal promotion opportunities. In a first attempt to answer the questions current labour market theories have been reviewed in Chapter 3. Although a coherent framework for explaining long-term employment and internal promotion is lacking, two useful concepts for such a framework of the internal labour market were found: firm-specific skills and monitoring problems.

The problem to be discussed in the present chapter is how the firm internal labour market can be modelled in order to answer the research questions, especially the wage difference between the firm internal labour market and the external labour market. This requires modelling of the internal labour market, the external labour market, and the relationship between the two. Below this is examined within an equilibrium framework. In this framework the internal labour market is interpreted as a contract, featured by long-term employment and internal promotion opportunities. A complete analysis requires a modelling of the external labour market in contract terms as well. Therefore which kind of contract is apparent on the external labour market, and which wage level results, is discussed. Furthermore, the relationship between internal and external labour market contracts is examined, and some remarks on the market structure of the external labour market are made. In sum, the investigation concerns the structure of the internal and the external labour market and their interdependence. In this respect it must be emphasized that no complete model is offered in this chapter. Instead, we start with a model of the internal labour market presented by Malcomson (1984), and we investigate the structure of the internal and external labour market in this model. Next, the consequences for the wage difference and wage profile on the internal and extemal labour market are examined with this model. Since the model is not explicitly constructed for our set of questions it falls short on some points. Some directions in which the model should be adjusted to answer the 
research questions decisively are mentioned. Overall, the main purpose of this anallysis of the internal labour market in contract terms is to derive some hypotheses conceming the research questions, which can be empirically tested in later chapters. The investigation is concluded by formulating hypotheses, which are derived from the discussion of the Malcomson model.

The set up of Chapter 4 is as follows. In Section 4.2 the contract approach of Williamson, Wachter and Harris (1975) is revisited. Some critical remarks are made and a slightly different categorization of contracts is presented in Section 4.3 . In this section the relationship between the internal labour market and other contracting modes is examined. A crucial distinction is made between one-period and multi-period contracts. In Section 4.4 we concentrate on the relative efficiency of one-period contracts, investigating under what conditions salaries are preferred to piece rates. It appears that, in general, salary contracts suffer from the incentive problem: workers are not motivated to perform above a minimum required effort level. One way to solve this problem is to use multi-period contracts, such as the internal labour market contract. Next, in Section 4.5 we turn to the conditions under which these multi-period contracts improwe on one-period contracts. For this discussion the twoperiod framework of the internal labour market of Malcomson (1984) is presented, and two sources of internal labour market contracts are examined: monitoring problems and firmspecific human capital. With this framework attention returns to the research questions and some hypotheses conceming the relationship between internall labour markets and wages are derived in Section 4.6. In Section 4.7, the consequences of internal labour markets for labour mobility and wage rigidlity are discussed. Finally, some hypotheses on the differences of the characteristics of jobs and workers on the internal labour market are formulated in Section 4.8. In Section 4.9 a summary of the theoretical part is provided, together with an outlook on the empirical part.

\subsection{Williamson revisited}

In this chapter the labour market is modelled in contract terms. Our definition of the internal labour market, with long-term employment and internal promotions, is suitable for a contract theoretical approach. Furthermore, such a contract approach offers a useful analysing framework in which the internal labour market can be ordered and compared to other contracts. An analysis of the internal labour market as a contract ${ }^{\prime}$ is already provided by Williamson, Wachter and Harris (1975). This approach, which is already touched upon in Section 3.3, is critically evaluated in more detail below. In the next section we try to improve on these critical remarks by presenting a classification of contracts which differs from Williamson et al.

Using the organizational failures framework (see Section 3.3) they discuss the "employment relation in circumstances where workers acquire, during the course of their employment, significant job-specific skills and related task-specific knowledge" (Williamson et al., 1975, p. 251). These situations are referred to as idiosyncracy. Their analysis concentrates on transactions and contracting under these circumstances of idiosyncracy, emphasizing cost-economi-

1. Initiatly in this approach the firm was regarded as a "nexus of contracts" (Fama et al. 1983a, p. 321). More recently the broader tem "nexus of treaties" is used. For a discussion on the difference between these tems, see Williamson (1990). 
zing aspects ${ }^{2}$, instead of, for instance, technology considerations. Williamson et al , emphasize economic considerations for the appearance of the internal labour market, contrary to prior research on internal labour markets which made "efficiency considerations ... a minor theme." (Williamson et al., 1975, p. 253, note 11).

Essentially, the situation of small numbers exchange, which results from task idiosyncracies. (cf. the "sound and smell" argument of Doeringer and Piore, 1971), gives rise to transaction costs. Situations of task idiosyncracy appear if jobs with complex production tasks are involved and if tasks are "embedded in a complex set of technological and organizational circumstances" (Williamson ef al., 1975, p. 260). Such circumstances hamper the use of explicitly written contracts since adaptation to changing environmental conditions is required. Moreover, tasks in these circumstances require training which heavily relies on on-the-job training, and accordingly "specialized skills and knowledge accrue to individuals and small groups" (Williamson et al, 1975, p. 261). In general, circumstances of idiosyncracy lead to first-mover advantages and bilateral monopoly situations (Creedy and Whitfield, 1988, p. 255), or small numbers exchange.

A discussion of five alternative contracting modes leads to the conclusion that under the above-mentioned circumstances the internal labour market contract is more efficient in costeconomizing terms. More precisely, the five contracting modes discussed by Williamson et al., are the sales contract, recurrent (or sequential) spot contracting, contingent claims contracting, the authority relation and the internal labour market mode. Basicully, it is shown that the first four contracting modes suffer from serious shortcomings under the organizational failures framework and thus the internal labour market contract is efficient, as is summarized below.

The first contracting mode is the sales contract, under which one contracts "now for the specific performance of $\mathrm{x}$ in the future" (Williamson et al., 1975, p. 261). This contract is not discussed in detail by Williamson et al, because these rigid contracts are unable to respond to changing circumstances in the assumed environment, featured by complexity and uncertainty. The contingent claims contract contracts "now for the delivery of $x_{i}$ contingent on event $e_{i}$ obtaining in the future" (Williamson et al., 1975, p. 261). In situations of idiosyncracy these contracts fail because of bounded rationality. Ex ante it is hardly possible to write out every possible event $e_{\mathrm{i}}$ to occur, because of bounded rationality and complexity of the world. Also, ex posi problems of opportunism (what event did occur?) and information imm pactedness (did deliwery $x$ take place?) impede these contracts. Under the sequential spot contracts, one must "wait until the future materializes and contract for the appropriate (specific) $x$ at the time" (Williamson et al., 1975, p. 261). A long-term employment relation may result from a sequence of renegotiated spot contracts, but this is not a long-term contract. The party which is dissatisfied with the agreement is free to leave. However, these contracts are efficient only if transition costs (of turnover) are low, while jobs featured by idiosyncracy fall short of this assumption. Because of opportunism and first mover advantages these contracts are useless under idiosyncracy. So in this case it is not bounded rationality but opportunism which impedes the contract. In fact at the renewal date a situation of snall numbers and opportunism exists as a result of idiosyncracy. The fourth contract, the auhority relation, contracts "now

${ }^{2}$ These costs "include both production and transaction cost elements" (Williamson et al. 1975, p. 252). Furthermore, they quote Arnow by stating that "iransaction costs are here regarded in the broad sense of the term, namely, as the "costs of munning the economic system".. "(Willianson et al. (1975. note 7). 
for the right to select a specific $x$ from within an admissable set $X$, the determination of the particular to be deferred until the future" (Williamson et al., 1975, p. 262). Although this contract needs no elaborate specification $e x$ ante, it is hindered by the same problems as sequential spot contracts. Problems arise if wages are to be adjusted in due time, if unforeseen events occur, and if there are differences in observations concerning the event and the specific $x$. The conclusion is that "none of the above contracting schemes has acceptable properties for tasks of the idiosyncratic variety" (Williamson et al. 1975, p. 269). The internal labour market contract is the alternative offered by Williamson et al. The essential feature of the internal labour market contract is that it is a collective contract with wages coupled to jobs. This reduces the constant haggling over wages, which is rather costly. In addition, the internal labour market contract includes rules or procedures which determine who occupies which job. More efficient job matches are accomplished over time. As already summarized in Section 3.3, the advantages of such collective internal labour market contracts are lower bargaining costs, rationalized internal wage structure, consummative cooperation (because of group disciplinary effects and intemal promotion opportunities) and investments of idiosyncratic type.

At this point some critical remarks are in order. As Williamson admits, the description of the features of the internal labour market is not exhaustive (Williamson et al., 1975, p. 275). However, as already argued in Section 2.4, it is not of utmost importance to list all features of the internal labour market, but to discover the essential fearures which distinguish an internal labour market contract from other contracts. In this respect we argue that the internal labour market is featured by long-term employment relations and internal promotion opportunities. Although this is not contradictory to Williamson et al, it mitigates the assumed importance of the collective nature of the intemal labour market. Below this point is discussed further.

Secondly, we agree with Williamson (et al.) that the net gains of internal labour markets should be discussed, instead of emphasizing positive efficiency aspects of internal labour markets only (as they tend to do). The introduction of internal labour market contracts, featured by a set of rules and procedures on promotion and payment of employees, in an organization undoubtedly incurs extra costs. These costs must be taken into account as well, and in this respect the efficiency concept used by Williamson is not clear (Creedy and Whitfield, 1988, p. 256).

Thirdly, the list of contracting modes discussed by Williamson is not exhaustive and seems arbitrary up to a point. While, for instance, a sequential spot contract is discussed, a sequential sales contract is ignored as an alternative contract. A semionity contract, which is quite common on the labour market, is not explicitly discussed. Therefore, we try to offer a more complete taxonomy of contracts according to two prespecified citeria below.

A fourth remark concerns the essential feature of the collective nature of the internal labour market. It is unclear whether this collective feature means that workers (or unions) and employer collectively bargain ${ }^{3}$ over the employment terms, or that the employer designs an internal labour market by installing a job and salary structure with promotion rules and grievance procedures for all jobs collectively. The argument provided by Williamson et al., is that in situations in which an individual is "small in relation to the system-and thus his behavior,

${ }^{3}$ Creedy and Whitfield (1988) interprete Willianson in that he "views the intemal labour market in terms of a cooperative solution (arising from one sort of social contract) in order to avoid the problems of the individual pursuit of self interest in organizations" (p. 255). 
by itself, has no decisive influence on the system - and is unable to appropriate the collective gains that would obtain were he voluntarily to forego individual self-interest seeking" collective action would be a remedy. This collective action, instead of being restricted to state action, can be exercized by "both private collective action (of which the firm, with its hierarchical controls, is an example)" "but furthermore "norms of socialization are also devices for realizing cooperative solutions" (Williamson et al., 1975, p. 270). Then it is stated that the "internal labour market, .., is usefully interpreted in this same spirit" (Williamson et al., 1975, p. 270). It is not clear which of the two arguments is used. On the one hand "Internal labor market agreements are commonly reached through collective bargaining" (Williamson et al., 1975 , p. 271), are written in general terms and supplied with an arbitration apparatus and grievance procedures (in case disputes occur), but on the other hand "Unionization commonly" facilitates the orderly achievement of these results, though it is not strictly necessary, especially in small organizations" (Williamson et al., 1975, p. 277), which suggests that collective bargaining is not essential. Therefore, it is our point that the internal labour market can be analysed on an individual level, in the same way other contracts are analysed. If a worker is hired on an internal labour market his expectation of future individual rewards depends on his perspective on promotion opportunities. The internal labour market is, just like other labour contracts, an agreement between an employer and an employee on the workers' employment and (expected) wage (growth) terms. The internal labour market can (and should) be analysed in this way too.

A further point is that the difference between the internal labour market contract and the authority relation remains vague, since both rely on the freedom of the employer to specify later on what performance to ask from the worker. The advantage of an authority relation is the postponement of the decision on the exact terms of the exchange, but the disadvantages of this contract correspond to those of the sequential spot contract, as mentioned above. Of course the question is whether the internal labour market can improve on this. The difference between the authority relation and the internal labour market contract seems to be the collective character of the latter. Under an internal labour market contract the wage structure is coupled to the job structure, which avoids individual haggling over wages. However, this leaves the essential obserwability problem, caused by information impactedness, unsolved under the internal labour market. It must still be decided which workers will receive these higher jobs (and thus higher wages). Williamson, however, points to the efficiency of an arbitration apparatus in this respect, designed to solve these kind of disputes, and to the more consummative behaviour of workers. Nevertheless, in our opinion, under an internal labour market contract, the problem of the haggling over wages is only partly solved, since now it has become haggling over jobs or promotion.

Two finall remarks remain to be made. First, Williamson et al., do not discuss the relationship between internal and external labour market contracts. In fact, the contracts outside the firm are not discussed at all. Second, they emphasize the effort side of labour contracts, while the payment of workers remains unclear. Almost all contracts assume fixed wages, without discussion why it might be efficient (or necessary) to rely entirely on fixed wages. It is our point that both employment and wage terms are essential for a labour contract, and that effort terms are often only treated implicitly by a description of a "normal" or "standard" set of tasks to be performed. Of course, in every labour contract some relationship, either explicit or implicit, is made (or assumed) between wages and productivity (Pot, 1988), but the essential terms of a contract are considered to be the wage and employment terms, instead of the effort terms or its collective nature (Blaug, 1987, p. 23). 
In order to deal with these objections to Williamson et al., an extended categorization of employment contracts is proposed in the next section, which, however, resembles the approach of Williamson et al. in that it also emphasizes the economic character of an internal labour market and regards the internal labour market as a contract.

\subsection{Classification of contracts}

As mentioned above, in our opinion the essence of a labour contract is in the agreement on employment period and the wage terms of the contract, while effort (or productivity) terms usually are no (explicit) part of a contract. Generally, these effort terms are only defined implicitly, because of the difficulties in writing contracts which specify the effort terms (Becker, 1975, p. 35; Blaug, 1987, p. 23), and they are merely a result of the incentive structure of the contract. So, slightly different from Williamson et al.* in our classification the wage and employment terms are emphasized as criteria to distinguish between contracts. Accordingly contracts are classified along these two criteria (see Table 4.1), and the position of the internal labour market in this classification is discussed.

Table 4.1 Classification of contract

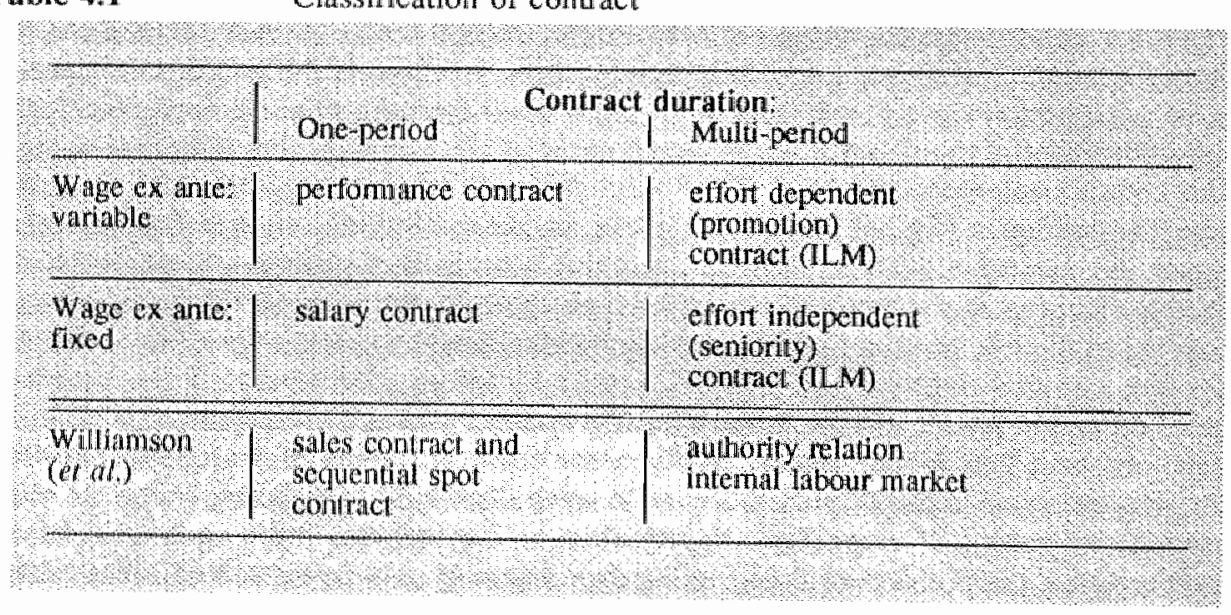

A contract is interpreted in a broad sense (Rees, 1985a) as an implicit or explicit agreement between employer and employee on both the number of periods a worker is to be employed and the (expected) wage he is to receive. During the time of the contract the wage rate can change because of an evaluation of the performance of the worker at a review moment, or because of the attainment of a seniority level. It is assumed that such a review moment coincides with the moment of payment. Hence, at such a moment a change in the wage rate is expected to take place. A period is defined as the time within which such a change of the wage rate does not take place. Now, contracts for one and more than one period are distinguished. Under a one-period or single-period contract employment is guaranteed for one period (within which the wage rate does not change). Under a multi-period contract the worker is hired for more than one period, and wage rates are allowed to change at the review 
moment between (not within) these periods. Thus, basically the classification of contracts rests on two dimensions: whether employment is ex ante fixed or variable for one or more periods, and whether wages are ex ante fixed or variable for the contracting period. Two comments may clarify these notions of one- and multi-period contracts. First, the moment of payment within a period is not essential in our approach. A single period may include more than one moment of pay. Contracts with weekly, monthly or yearly payments are all one-period contracts as long as the rate of payment does not change as a consequence of promotion or seniority. Second, since individual contracts are examined, changes in the wage rate under a multiperiod contract are related to the individual worker. For example, a change in the wage rate which is relevant for us can be a result from a workers" seniority or his performance, but it does not refer to a wage increase as a result of collective bargaining agreements. This does not exclude the case that workers are evaluated as a group, since group payments also influences the incentives and the salary of the individual worker. ${ }^{4}$ Following Table 4.1 this results in the following contracts.

First, one-period or spot contracts with employment guaranteed ex ante for one period are distinguished. Under these contracts wages can be fixed or variable ex ante. Under the former, income is not dependent on the performance of the employee, and these contracts are referred to as salary contracts (Lupton and Bowey, 1983). On the other hand, we have spot market contracts with variable wages, in which the income does depend on the ontput or effort of the employee (as under piece rate contracts). Such contracts are called performance contracts (Katz, 1986, p. 240; Baker et al., 1988; Foster and Wan, 1984, p. 57). Of course, at the expiration date of the one-period contract the employer is free to re-contract. A series of such contracts leads to the appearance of sequential spot contracts, which can either be a series of salary contracts or performance contracts. Since the extension of the contract is not guaranteed ex ante the difference between spot contracts and sequential spot contracts is not essential for our discussion.

Next, multi-period contracts are distinguished. As mentioned, the wage rate can change between these periods and employment is guaranteed during these periods. ${ }^{5}$ Of these multiperiod contracts with employment guaranteed (or fixed) ex ante, again two types can be distinguished. ${ }^{6}$ If the change in the wage rate between the periods is known ex ante, and thus

${ }^{4}$ Note that there is a conceptual difference between a long term contract and a multi-period contract. It is assumed that a multi-period contract covers a long time span. Thus a multi-period contract by definition is a long term contract. A one-period contract, however, can cither be a long tern contract, if the time span of the contract is long, or a short term contract, if the time span is short.

${ }^{5}$ The employment at the firm, need of course not always be guaranleed. Contracis which cover more periods can be signed, in which it depends on the state of the world whether the worker is employed at the firm or is laid off. A worker who is previously laid off, because of an economic downtum, can be recalled to work at the same fimn if the state of the world improves in later periods. Since these kind of contracts resemble those described in the implicit contract literature (sce Section $3.5)_{1}$ they can be referred to as implicit contracts. Under these contracts the wage to be paid every period is known in advance and depends on the state of the world which prevails. This can be interpreted as a contract with wages fixed ex ante. Implicit contracts in this sense are excluded here because they lack the employment guarantee which is essential for an intemal labour market contract.

${ }^{6}$ In a way this corresponds to Lawler (1987): "Perhaps the key strategic decision made in the design of any reward structure is whether or not it will be based on performance. . The major alternative to basing pay on perfomance is to tie it to seniority" (p. 260). 
this is independent of the effort of the worker, these contracts are called effort independent contracts. An example of such a contract is a seniority contract under which the worker knows in advance that his wage increases with seniority. If the change of the wage rate is not known in adwance and depends on the effort or the performance of the employee, an effort dependent contract appears. An example of such a contract is one under which the promotion of a worker to a higher level job (with a higher level wage) depends on the effort in the previous period.

In the previous section it was argued that Williarnson et al, categorized different contracts without specifying the wage terms. Their contracting modes can be ranked along the employment criterium (Table 4.1, last row), which results in a correspondence between their contracting modes and our classification of contracts. Spot contracts and sequential spot contracts appear in Wiliamson et al, without distinguishing ex ante fixed and variable wages, so the incentive problem is ignored (see Section 4.4 ). ${ }^{8}$ The authority contract corresponds to multiperiod contracts with fixed employment $e x$ ante. It is not surprising that these multi-period contracts with fixed employment can also be considered as internal labour market contracts, since one objection to Williamson et al. in Section 4.2 was the vague difference between authority contract and the internal labour market.

According to our definition the internal labour market contract differs from other contracts by its long-term employment character and the firm intemal promotion opportunities (which lead to wage increases). From the review in Chapter 3 it was found that most theories only concentrate on the long-term employment character of internal labour markets, and hardly consider the essential feature of internal promotion opportunities. By analysing the internal labour market as a contract we improve on this. An internal promotion (opportunity) is considered as an (expected) wage increase in later periods. Contracts with employment guaranteed ex ante and internal promotion (opportunities) are alternatively referred to as delayed payment contracts. The multi-period contracts of Table 4.1 , with employment fixed in advance, include both the features of long-term employment relations and internal promotion opportunities of internal labour marktes.

Thus, it is tempting to conclude that the internal labour market contract is identical to the multi-period contracts with fixed employment, but this interpretation is not justified. It must be noted that every internal labour market contract is such a multi-period contract, but the reverse is not true; not every multi-period contract with fixed employment is an internal labour market contract. A contract without internal promotion opportunities, which lead to expecied wage increases, is not an internal labour market contract. Thus, although the internal labour market is a multi-period contract under which workers are hired for a long time, it is a special kind of multi-period contract, since it is featured by internal promotion opportunities as well. In accordance with our definition of the internal labour market, an important assumption is that throughout it is assumed that on an internal labour market internal mobility never leads to wage decreases. Worker are roulated horizontally (re-allocation due to rearganiza-

${ }^{7}$ Usually a minimum effort or perfonnance level is established.

8 The contingent claims contract, in which the tasks to be delivered by the worker depend on the state of the world to appear, corresponds to the multi-period contract with wariable employment (see footnote 4 ). 
tions, or job roulation), or vertically (by intemal promotion) but never experience demotion.9 So an internal jabour market is a special kind of multi-period contract with expected wage increases as a second feature. ${ }^{10}$ This means that under an intemal labour market contract an employee is offered opportunities for further wage increases. Accordingly two types of internal labour market contracts are distinguished: seniority contracts (which are a sort of effortindependent contract) and promotion contracts (which are a sort of effort-dependent contract). If the (expected) wage increases are guaranteed ex ante, and increase with firm tenure (or seniority), we have a seniority contract. If they are dependent on previous effort, for instance by a promotion criterium, the contract is referred to as a promotion contract. It must be noted that, although every worker on an internal labour market contract expects wages to increase over time, it may be that there have not been wage increases ex post, if a worker is not actually promoted.

Thus, not every multi-period contract is regarded as an intemal labour market contract since a multi-period contract does not always offer internal promotion opportunities with wage increases. In our analysis we concentrate on the relative efficiency of multi-period internal labour market contracts and one-period contracts. This implies that for our analysis contracts which offer multi-period employment with possibilities for future wage decreases (Bester, 1989; Worrall, 1989) are ruled out as internal labour market contracts. A second set of multiperiod contracts which are not regarded as internal labour market contracts are so-called "upor-out" contracts. Models as discussed in Kahn and Huberman (1988) and the employer-specific information model of Barron and Loewenstein (1985) are of this type. Under these contracts a worker experiences a promotion ("up") in later periods if he reaches a prespecified performance level. Should he fail to reach that level he is fired ("out"). In fact such a contract can be regarded either as a one-period, or a multi-period contract. It can be interpreted as at one-period contract since employment is guaranteed for a single period; only the best have multi-period employment. One can also argue that these contracts are multi-period contracts since every worker is allowed to stay, but the wage offered to those who failed to reach the requared performance level is below their reservation wage, so they leave. The difference depends on whether the worker is fired or leaves "voluntarily". Nevertheless, we disregard these contracts as internal labour market contracts. Although they offer promotion opportunities to newly hired workers, which is commonly regarded as an essential internal labour market feature, they are not considered to be internal labour market contracts, acconding to our definition, since wage decreases are not excluded. Furthermore, furnover is actively pursued in these contracts for renewal of workers: "Up-or-out systems work better in situations where the required human capital is general rather than organization-specific, and where

${ }^{9}$ Although this restriction is arbitrary in a sense, we feel it appropriately reflects our concept of the internal labour market. Demotions are rare in practice (Brïderl, 1990, p. 60). Nevertheless, recent years have witnessed discussions on the acceptability of demotions for older workers who are unable to properly respond to the continuously changing environment, or for workers who change jobs within the firm because of a restructuring of the firm. Whether these demotions involve wage decreases is unclear. However, this ongoing debate may lead to the conclusion that demotions become an accepted phenomenon of internal labour market contracts, and might enlarge the definition of the internal labour market. The fact that demotions seldom occur in practice, points at an "asymmetry between rewards and punishments" in organizations (Baker et al., 1988, p. 607).

10 As mentioned in Section 2.5 these wage increases can be a result of "physical" job changes by internal mobility into higher level jobs with higher wages ${ }_{\text {or }}$ of "non-physical" movements along the hierarchy of salaries, without intemal mobility. 
lurnover is important to provide the new energy, ideas, enthusiasm and change that young people generate" (Baker el al, 1988, p. 605). In sum, internal labour market contracts featured by long-tem employment relations and intemal promotion opportunities can altematively be referred to as delayed payment contracts because of their feature of forestalled payment. It is admitted, however, that in a complete discussion of the effuciency of internal labour markeit contracts all contracts should be taken into account, and the relative efficiency of internal labour market contracts and other more-period contracts (such as "up-or-out" contracts) should be analysed as well.

For later discussion it is helpful to describe the contracts of Table 4.1 more formally. Attention is restricted to one-period contracts and internal labour market contracts. With wi for the wage in period $\mathrm{i}$ and $\mathrm{P}$ for the promotion opportunity between periods, we distinguish the following contracts. Under one-period contracts employment is fixed for one period, and it is the wage or wage rate which makes up the contract. Thus, we distinguish a performance contract with wage rate $r$, and the salary contract with the wage fixed in advance, (w). Under two-period contracts there are wages for both periods. Workers receive wage $w_{1}$ in the first period. They can be promoted to either a low wage, $w_{2}^{\mathrm{L}}$, in period 2 , or a high wage, $w_{2}^{\mathrm{H}}$. The probability of being promoted to the high wage is $\mathrm{P}$, with $0 \leq \mathrm{P} \leq 1$. In general wo period contracts are $\left\{w_{\mathbb{N}}, w_{2}, w_{2}^{H}, P\right\}$. With $P=0$ or $\mathbb{P}=1$ the contract reduces to the seniority contract $\left|w_{1}, w_{2}\right|$. II Under the promotion contract $P>0$, so $\left\langle w_{1}, w_{2}^{L}, w_{2}^{H}, P\right|$ occurs. It is the relative efficiency of these contracts which is discussed below.

Our approach differs slighly from other approaches. Instead of characterizing contracts along one dimension, for instance the individual versus the collective nature (Williamson et al., 1975), the fixed versus variable wage feature (Stiglitz, 1975), or the pay according to input versus pay for output (Lazear, 1986), contracts are classified according to the wage and employment dimension. Our approach improves on that of Williamson et al., (1975) on some points. First, referring to the remarks in Section 4.2 , the approach is based on a clearly defined internal labour market contract, and contracts are accordingly consistently categorized allong the more apparent contract dimensions of wage and employment terms, instead of effort terms. Nevertheless, the contracting modes of Williamson et al., can easily be related to ours. Second, we think our contract classification better stresses the essence of internal Jabour market contracts. Although it is tempting to emphasize the long-term employment feature of such internal labour market contracts, it is the (expected) increase in future rewards by changes in the rate of payment which is the essence of the internal labour market labour contract. Thus, the essential feature of an internal labour market contract is not its long-term employment, but its multi-period feature, which results in (expected) wage increases. Having settled the outline of the internal labour market as an employment contract with delayed payments, it is asked why and when these contracts appear. In fact we ask for a framework to analyse the questions of Table 1.1. Before we actually turn to these questions in Section 4.6 to 4.8 , a short dicussion of the relative efficiency of one-period contracts is provided in Section 4.4, while in Section 4.5 attention is turned to the multi-period contracts, including the internal labour market contract.

\footnotetext{
11 Remark that the seniority contract with $P=1$ gives $w_{2}=w_{2}^{H}$ and with $P=0$ gives $w_{2}=w_{2}^{L}$,
L assurning $w_{2}>w_{1}$.
} 
Although our main interest is in the relative efficiency of multi-period contracts over oneperiod contracts, in this section the relative efficiency of the one-period contracts of Table 4.1 is discussed. Thus intertemporal aspects are ignored. Nevertheless, a discussion of the relative efficiency of salaries and performance contracts provides some insight into the variables which influence the relative efficiency of contracts, into the problems which occur in designing optimal contracts and in the way in which multi-period contracts might solve these problems.

To compare contracts on their efficiency, in general two benchmarks are used. The first is to compare the results of a contract to the results which accur in situations of perfect information, which are known as first best. The second benchmark to evaluate the efficiency of contracts is not to compare these to some situation of perfect information which might never be achieved, but to compare contracts to each other using the Pareto criterium. ${ }^{12}$ A contract between an employer and an employee which, compared with another contract, leads to a higher profit for the employer, leaving the utility of the employee unchanged, or a contract which gives a higher utility, leawing profits unchanged, is Pareto more efficient (De Gijsel and Wolfs, 1989b). Thus, for one contract to be more efficient than another, a surplus of extra profits or extra utility must be generated. "One or both of the parties must be earning strictly more than in his best alternative, and neither can be earning less" (Carmichael, 1989, p. 68). How this surplus is distributed over the parties is not a matter of discussion here, but depends on the distributional rules or the bargaining power of the parties involved.

In this section some results on the relative efficiency of two altemative one-period contracts, performance (or piece rate) contracts and salary (or time rate) contracts (Stiglitz, 1975) are presented. There are several circumstances under which salary contracts ( $w$ ) dominate piece rate contracts with wage rate $\mathrm{r}$ (Stiglitz, 1975; Lazear, 1986). Note first, that the choice of a performance contract assumes that pay is a motivator for performance. However, psychologists and behaviorists have criticized this assumption by arguing that pay for performance can reduce intrinsic motivation and can result in adverse effects of employee morale and productivity because of horizontal equity considerations (Baker et al., 1988, p. 596). Nevertheless, assuming that pay-for-performance does induce effort, some conclusions can be presented.

In general, the cost of measuring the precise amount of effort of a worker is higher than the costs of finding out whether or not a worker is shirking. Thus a salary is offered the higher the cost of precisely monitoring the output of the worker, or the lower the cost of detecting shirking behaviour (Lazear, 1986). Usually it is assumed that the optimal level of effort, which is chosen under a piece rate, exceeds the level of effort under a salary contract, which results in only a minimum level of effort. The closer this minimum level of effort, under the salary contract, is to the optimal level of effort under the piece rate contract, the more efficient a salary is; it does not pay to measure output exactly by using a piece rate (Lazear, 1986). Furthermore, if the incentive effect of offering a piece-rate contract is low, and thus the change in effort is small, salaries are more efficient. So salaries are used under an inelastic effort supply (Stiglitz, 1975; Lazear, 1986). This refers to the assumption of pay-for-per-

12 In this respect Wachter and Wright (1990, p. 248, note 13) note that the difference between first best and second best is not essential since "informational constraints are, in principle, no different from the constraints imposed by the production function or any other aspect of the environment"." 
formance as a motivator for effort. Next, if the translation of input into observed output is not perfect, income risk is introduced. The higher the risk, and the higher the risk aversion of the employee, the more salaries are preferred (Stigliz, 1975). Moreover, if workers are heterogeneous, but this heterogeneity is not directly observable, salary contracts provide the same income to different workers, while piece-rate contracts reward different workers differently. More productive workers will prefer piece-rate contracts. Thus, the larger the heterogeneity of workers with respect to their productivity, the more efficient it is to use the piece-rate contract as a sorting device (Stiglitz, 1975, Lazear, 1986). Finally, piece-rate contracts tend to reward speed instead of quality. If output-quality considerations play an important role, compared with quantity considerations, salaries are preferred to piece rates (Stiglitz, 1975, p. 558).

From these considerations we conclude that in general workers on jobs with more problems of monitoring productivity or effort are employed on salary contracts. Monitoring problems may lead to increased income risk under piece-rate contracts or to extremely high cost of measuring performance. These problems may be due to the structure of the production and organisation process. They result from the development of firm-specific skills, since over time workers possess increasingly better information on their skills and the relationship between input and output. If this information is private, monitoring is increasingly difficult and situations of bilateral monopoly and idiosyncracy occur (see Section 4.2). Thus, both imperfect information and firm-specific skills might explain the use of salary contracts over spot contracts. However, it is clear that salaries suffer from an important drawback. Unless workers are intrinsically motivated, salary contracts offer no incentives for effort levels above the minimum required effort level. Of course, although piece rate contracts may provide enough incentives in this respect, they may be too costly or impracticable. ${ }^{13}$ In order to avoid the high cost of measuring individual effort under piece rate contracts, toumament contracts can be used. ${ }^{14}$ These toumament contracts can be modelled as one-period models (Lazear and Rosen, 1981; Green and Stokey, 1983) or multi-period models (Malcomson, 1984). However, under one-period tournaments a ranking is required every period, which is still rather costly. Therefore these one-period toumaments are not discussed in detail. Since multi-period tourna-

13 In this respect many recent models simply assume away the possibility of perfornance contracts because of extremely high monitoring costs. We present some examples: Lazear and Moore (1984, note 1) state: "picce rates are ruled out here by assuming that it is too costly to monitor the amount of shirking." Malcomson (1984, p. 163) argues that since output "cannot be verified by employees, such a payment schedule would be unenforceable". Leonard (1987, p. 138) argues: "Plece rates are also assumed to be impracticable, given the difficulty of observing effort or output". Finally, Katz (1986. p. 240) states:" "Piece rates and other direct pay-for-perfomance compensation schedules are often expensive to operate or impracticable since it may be difficult to observe an individual employec's contribution."

4 Tournament models are also teferred to as contests or rank-order systems. The essence of these models of performance contracts is that workers are paid according to an ordinal ranking of observed performance compared to their "peers" or fellow-workers, instead of an individual cardinal measurement as under piece rates. An advantage of this ordinal ranking is that it is less expensive than cardinal measurement of individual performance. In toumaments the prize is prefixed in advance, although it is unknown who will receive the prize, while under piece rates the reward or income is unkmown in advance and dlepends on the performance of the employee. Toumaments with internal promotion as a prize thus resemble intemal labour market contracts. 
ments resemble internal labour market contracts, these will be discussed in the next section. 15

Since under salaries only minimum effort results, at this point the question is how incentives for an optimal effort level can be provided if performance contracts are inefficient. This of course refers to the moral hazard problem (Section 3.5). Three alternatives to solve these incentive problems can be mentioned. First, an employer can hire supervisors, install hieratchies or introduce other monitoring devices; second, he can use the "carrot and stick" solution of paying higher (efficiency) wages; and third, he can offer intemall labour market contracts (cf. long-term bonding of Section 3.6). Under the first solution the incentive problem of salaries is solved by improved monitoring and the creation of some sort of piece-rate payment. For instance a supervisory solution can be used, which implies that a supervisor, or some monitoring technology, is applied to monitor the employees and observe at what effort level they perform. This resembles arguments brought to the fore by the radicals, as discussed in the previous chapter, with respect to the internal labour market. By introducing hierarchical levels with supervisors within a firm control over the workforce can be improved, which can increase efficiency. This solution is discussed in Stiglitz (1975), and Calvo and Wellisz (1979). These hierarchical structures capture elements of intemal labour markets, and accordingly one can argue that internal labour markets arise to improve control and measure worker productivity. Nevertheless, as we emphasize, it is the multi-period character with internal promotion opportunities of the internal labour market, not its hierarchical structure, which is crucial.

The altemative solution, discussed in Section 3.6, is to pay efficiency wages. By offering these higher wages workers are induced to bring forward an efficient amount of effort (Akerlof and Yellen, 1986). Some models explicitly discuss a trade-off between the (costly) forementioned supervisory solution of directly monitoring workers and the solution of payment of efficiency wages (or incentive wages or self supervision) in order to increase productivity in an indirect way (for a discussion see Bowles, 1985, or Drago and Perlman, 1989). With respect to the internal labour market it is noted that the efficiency wage solution can be modelled in a one-period or a multi-period framework. In fact, in Section 3.6 it is already mentioned that the efficiency wage solution can be related to internal labour markets if they are considered as long-term employment or multi-period efficiency wage contracts. Thus efficiency wage solutions to the moral hazard problem and internal labour market contracts are complementary, rather than excluding solutions. Since we defined internal labour markets as multi-period contracts, in the next section we turn to such multi-period models.

To conclude, in this section the relative efficiency of one period contracts, salaries and piece rates, is examined. Circumstances under which salaries are efficient are identified. However, salary contracts are confronted with an incentive or moral hazard problem: workers only perform at a minimum effort level. Two alternatives to solve this moral hazard problem are mentioned: the installment of supervisory hierarchies and the payment of efficiency wages. Both however are usually analysed in a one-period framework. As stated before, our interest is in the rellative efficiency of internal labour market contracts. In our discussion on the bonding issue (Section 3.6) long-term contracts with internal promotion opportunities (or internal labour market contracts) can also solve the incentive problem. Since we are interested in conditions under which internal labour market contracts are efficient, we do not elaborate

${ }^{15}$ In fact Malcomson (1984), on which our framework of Section 4.5 is based, is a sort of moreperiod toumament. 
on the relative efficiency of supervisory wersus efficiency wage solution in a one-period frimework, but focus on the relative efficiency of one-period versus multi-period contracts.

\section{5 \\ Internal labour market contracts: the Malcomson modell}

Our conclusions can be summarized as follows. First, internal labour markets are featured by long-term employment relations with internal promotion opportunities (sec Section 2.5 ), which leads to contracts with delayed payment. Second, long-term employment originates from two different sources: the development of firm-specific capital and monitoring problems on productivity (see Section 3.8). Third, in the above-mentioned classification of contracts two types of internal labour market contract are distinguished: seniority contracts with guaranteed wage increases and promotion contracts with uncertain wage increases (see Section 4.3).

Below we argue that by distinguishing two sources of internal labour markets, firm-specific human capital and monitoring problems, the two above-mentioned origins for long-term employments can be related to the two different contracting modes with the delayed payment feature. Our argument is that seniority contracts are efficient if firm-specific human capital is important, while promotion contracts are efficient if problems of monitoring individual productivity appear. In this way a link is provided between the origin of the internal labour market and the resulting contracting mode. The argument in this section is based on a model of Malcomson (1984) and amounts to the question under which circumstances employers use internal labour market contracts, instead of (a series of) one-period salary contracts at the prevailing market wage. The assumption of homogeneous workers in this analysis necessarily restricts our attention to the moral hazard, or incentive, problem (see Section 4.4), largely ignoring problems of adverse selection in this study. Furthermore piece rate contracts (see note 13 ) are a priori ruled out.

As mentioned, two sources of the internal labour market are distinguished: firm-specific human capital and monitoring problems. Since these sources are highly complementary, many previously published models include elements of both (for instance Cantor, 1990; Barron and Loewenstein, 1985). Nevertheless, we argue that a distinction between these two is interesting, since differences result from different sources of internal labour market contracts. Overall, the development of the economics of contracting has resulted in a rather technical field of research with few empirical implications (Baker et al., 1988, p. 594). Since the goal of this study is to derive some testable hypotheses concerning internal labour market contracts, it does not provide an elaborate and detailed discussion of all variants of promotion and seniority contracts. Instead, the different nature of both contracts is indicated, and the implications for our research questions are mentioned. Furthermore, some testable hypotheses are derived.

The starting point of the analysis is the Malcomson model, in which attention is restricted to monitoring problems as a source of internal labour market contracts. The discussion of firm-specific human capital is postponed since our examination in this respect departs from the original interpretation of the Malcomson model. In the two-period structure of the model attention focuses on differences in contracts for homogeneous workers whose utility depends on effort (e) and on wages (w) in both periods, i.e.,

$$
U\left(\mathrm{e}_{1}, w_{1}, \mathrm{e}_{2}, \mathrm{w}_{2}\right) \text {, with } \mathrm{U}_{1}, \mathrm{U}_{3}, \mathrm{U}_{11}<0, \mathrm{U}_{2}, \mathrm{U}_{4}>0
$$

The contract offered to workers is either a one-period salary contract $\left\{w_{i}\right\}$, with $i=1,2$, or a wo-period contract $\left(w_{1}, w_{2}, w_{2}^{H}, P\right)$. With promotion opportunity $0 \leq \mathrm{P} \leq 1$ the expected 
utility, $U^{e}$, of a worker under a two-period contract is

$$
\mathbb{U}^{\mathrm{e}}=(1-\mathrm{P}) \cdot \mathrm{U}\left(\mathrm{e}_{1}, w_{1}, \mathrm{e}, w_{2}\right)+\mathrm{P} \cdot U\left(\mathrm{e}_{1}, w_{1}, \mathrm{e}, w_{2}^{\mathrm{H}}\right) .
$$

The contract offered by the firm is observed by workers, who are assumed to maximize their expected utility level by choosing the optimal effort level. Furthermore, workers are assumed to retire after two periods, so effort in period 2 never exceeds the minimum level, $\mathrm{e}$. The firm can observe this minimum level without difficulty, and workers whose performance falls below a are fired. Under one-period contracts effort also never exceeds $\mathrm{e}$. This might indicate that, by assumption, salary contracts are offered (remember that piece rate contracts are ruled out). So the essential choice for a worker is his effort in period 1 under a two-period contract, $e_{1}$, which is always at least equal to $\mathrm{e}$.

In the model the employer maximizes his discounted profit, $\pi$, which depends on the output level $q$, output price $p$ and the wages paid to first and second period employees. For simplicity it is assumed that productivity depends proportionally on effort, $q=e$, and that prices are stable and equal to 1 . Of course the problem of the firm is to choose which contract to offer, taking into account (i) that workers choose their own effort level by maximizing their expected utility, (ii) that promotion opportunities are restricted by $0 \leq \mathrm{P} \leq 1$, and (iii) that workers can always leave the firm and earn the outside wage $W_{i}$ at the minimum effort level, e. So, to attract workers the expected utility must at least equal the level $U$, which is defined as

$$
\mathrm{U}=\mathrm{U}\left(\mathrm{e}, \mathrm{W}_{1}, \mathrm{e}, \mathrm{W}_{2}\right)
$$

Under one-period contracts workers are hired for a single period, receiving wage $w_{\mathrm{i}}$ in that period. As long as $w_{i}$ at least equals $W_{i}$ the firm can attract enough workers. Under twoperiod contracts both wage terms and the promotion opportunity must be specified by the firm. In the first period workers are all employed at the same job level, receiving wage $w_{1}$. A prespecified proportion $P$ of these workers employed at that job level in period 1 is promoted to the higher job level in period 2 , receiving $w_{2}^{H}$. The remainder of the employees receive wage $w_{2}$. Since it is assumed that workers can observe who is promoted, the firm has every incentive to promote only the best employees. It is allso assumed that there are moni toring problems, so it is not actual productivity e that is observed but a biased productivity $x$. Employees whose observed output exceeds the level of $x^{*}$, so $x>x^{*}$, are promoted. The error term $(x-e)$ is distributed according to $f(x-e)$ and the cumulative distribution function is $\mathrm{F}(\mathrm{x}-\mathrm{e})$. Thus, the promotion opportanity is $\mathrm{P}=1-\mathrm{F}\left(\mathrm{x}^{*} \mathrm{e}\right)$. Since $\mathrm{x}$ depends positively on e (Malcomson, 1984, p. 164), incentives for workers to perform at an effort level e $>$ a are provided if there are promotion opportunities. In the model it is further assumed that employment leads to the development of general human capital, hence productivity increases by a factor $s, s>1$. The productivity of workers increases from $\mathrm{e}$ in their first period of employment to s.e in the second period.

From the maximizing behaviour of employees it can be shown that the effort function has the following properties (Malcomson, 1984, p. 168): $\mathrm{e}_{1}=\mathrm{g}\left(\mathrm{w}_{\mathbb{1}}, w_{2}^{\mathrm{L}}, \mathrm{w}_{2}^{\mathrm{H}}, \mathrm{P}\right.$ ) with $\mathrm{g}_{\mathbb{1}}>0$ if $\mathrm{U}_{12}$ $>0 ; g_{2}<0 ; g_{3}>0 ; g_{4}>0$ if $\mathbb{f}^{\prime}\left(x^{*}-\mathrm{e}\right)<0$. These results are intuitively plausible: effort increases with first period wages if the marginal (dis)utility of effort increases with first period wages. This means that first period wages compensate in a way for aversion to effort. Further it is found that effort decreases if $w_{2}^{L}$ increases and if $w_{2}^{H}$ decreases. The last inequality implies that increased promotion opportunities lead to higher effort if the error 
distribution function $f(x-e)$ decreases. ${ }^{16}$

As mentioned, the employer maximizes his discounted profits taking this effort function into account, as well as the minimum utility requirement and the restriction that $0 \leq \mathrm{P} \leq 1$. Under one-period contracts the worker receives a fixed wage in every period and in turn provides the minimum effort level. Since there is no reason for firms to offer wages above the reservation level, profit maximizing behaviour of firms leads to one-period contracts with $w_{i}=W_{i}$. This results in unility level $U$, as in $(4.3)$, for workers employed under one-period contracts. Discounted maximum firm profit under one-period contracts is

$$
\pi=\mathrm{e}-\mathrm{W}_{1}+\mathrm{s} \cdot \mathrm{e}-\mathrm{W}_{2}
$$

If the firm offers two-period contracts, the worker receives a promotion with probability $\mathrm{P}$. In return the worker offers $e_{1}$ in period 1. Discounted profits under two-period promotion contract are

$$
\pi=e_{1}-w_{1}+s \cdot e_{1}-P w_{2}^{H}-(1-P) w_{2}^{L} \quad \text { if } w_{2}^{L} \geq w_{2} .
$$

Of course to rule out up-or-out contracts $w_{2}^{L} \geq W_{2}$ is required: second period wages under two period contracts are never below the wages to be earned outside the firm since this would induce workers to leave the firm. Comparing equation (4.4) and (4.5) shows that profits under the two-period contract are never worse than under one-period contracts, since the firm can always decide to offer a two-period contract with no promotion opportunities, with $w_{1}=W_{1}$, $w_{2}^{L}=W_{2}$, and $P=0$ (see Malcomson, $\left.1984, p .169\right){ }^{17}$ The worker is indifferent between such a two-period contract and two subsequent one-period contracts, since both lead to utility level $U$. Hence, a worker has no incentive to perform at an effort level which exceeds the minimum effort level e outside the firm. Workers are induced to exert effort levels above the minimum level, $e_{1}>e_{\text {, only }}$ if $P>0$ (and, of course $w_{2}^{H}>w_{2}^{L}$ ). Note that for this result on the surplus the development of general skills is not essential; the results remain unchanged if $s=1$.

Now the relative efficiency of the contracts which result from this maximizing bebaviour of employer and employee are investigated. In fact, as performance contracts are ruled out, as well as some effort-dependent and effort-independent contracts, such as "up-or-out" conuacts, concentration is on one-period salary contracts, promotion contracts and (later on) seniority contracts. ${ }^{28}$ Discussing the relative efficiency of two-period contracts over oneperiod contracts, the Pareto criterium is used, in the sense that contracts are considered to be more efficient if a surplus (see Section 4,4) arises from choosing two-period contracts instead of one-period contracts. This is modelled by requiring that employers are better off by higher profits, while workers are free to choose their effort level and are offered a contract with at

16 For a unimodal symmetric function fo.) this means that higher $P$ leads to higher effort if $x^{*}>\mathrm{e}$.

17 As mentioned in note 9 this amounts to the same outcome as a contract in which everyone is promoled wilh $\mathrm{P}=1, \mathrm{w}_{1}=\mathrm{W}_{1}$, and $\mathrm{w}_{2}^{\mathrm{H}}=\mathrm{W}_{2}$.

${ }^{18}$ In the original Malconson model the relative efficiency of seniority contracts and salary contracts is not discussed, but attention is restricied to the relative efficiency of two-period promotion contracts and one-period fixed wage contracts. 
least U. ${ }^{19}$

Warkers prefer two-period contracts to one-period contracts if their expected utility is higher, and firms prefer two-period contracts if discounted profits are higher. The first requires that $(4.2)>(4.3)$. If we assume, for simplicity, additive separability of the utility functions between periods, this leads to

$$
U\left(e_{1}, w_{1}\right)+U\left(e, w_{2}^{L}\right)+P \cdot\left[U\left(e, w_{2}^{H}\right)-U\left(e, w \frac{L}{2}\right)\right]>U\left(e, W_{1}\right)+U\left(e, W_{2}\right)
$$

If the utility function $U(w, e)$ is simply modelled as $U=w-V(e)$, with $V^{\prime}(e)>0$ and $V^{\prime \prime}(e)>0$, and a sort of bonus $B$ is defined as $B=w_{2}^{H}-w_{2}^{L}$, inequality (4.6) becomes (4.6 )

$$
w_{1}-w_{1}+w_{2}^{L}+P \cdot B-w_{2}>V\left(e_{1}\right)-V(e)
$$

According to $\left(4.6^{\prime}\right)$ the worker prefers a two-period contract over the one-period contracts if he is compensated in expected wage terms for the loss in utility terms, which are a result of his extra effort in period 1.

On the other hand the firm prefers such a contract if maximum profits under a two-period contract are higher than under a one-period contract, so $(4.5)>(4.4)$, with the symbols as defined above,

$$
e_{1}-e>\left(w_{1}+w_{2}^{L}+\text { P.B }-w_{1}-w_{2}\right)
$$

As mentioned, for two period contracts to be efficient over one-period salary contracts a surplus is required (Carmichael, 1989). From (4.6 ) and (4.7) it can be derived that a surplus exists if

$$
\left(e_{1}-e\right)-\left(V\left(e_{1}\right)-V(e)\right)>0
$$

Hence, the surplus is determined by the incentive effect of the two-period contract on effort in the first period, $e_{1}$. That is, when: ${ }^{20}$

$$
\mathrm{e}_{1}>\mathrm{e}^{\mathrm{m}}>\mathrm{e} \quad \text { with }\left(\mathrm{e}^{\mathrm{m}}-\mathrm{e}\right)=\mathrm{V}\left(\mathrm{e}^{\mathrm{m}}\right)-\mathrm{V}(\mathrm{e})
$$

a surplus will exist. By offering promotion opportunities $P>0$, the worker is motivated to an effort above the minimum level (if $g_{4}>0$ ). A surplus is created if the incentive effects are high enough to induce an effort level above $\mathrm{e}$ and to compensate the worker for his increased effort.

This analysis, which follows the Malcomson model, is entirely based on the source of incentives. The conclusion is that two-period contracts are more efficient than one period contracts if there are incentive effects from offering promotion opportunities. However, from our discussion in Chapter 3 a second source of internal labour market contracts is distinguished: development of firm-specific skills. In the Malcomson model the importance of firm-specific

${ }^{19}$ Altematively, this can be modelled by requiring that workers are better off (by higher utility levels), while firms experience identical (discounted) profits under both contracts. A further analysis of these altemative ways of modelling requires an examination of distributional problems.

${ }^{20}$ Due to the properties of the function $V, e^{\mathrm{m}}$ is uniquely defined. 
human capital is ignored, since productivity increases, modelled by $s$ are, completely general. $^{21}$ By making some additional assumptions it can be shown that two-period contracts are more fficient than one period contracts if firm-specific capital is important, even in the absence of an incentive effect. The assumptions to be made are

a) that human capital s is to be interpreted as firm-specific human capital, instead of general human capital, and

b) this firm-specific human capital is developed under two-period internal labour market contracts, while it is absent under one-period contracts outside the internal labour market. Thus employees on the internal labour market experience an increase in productivity from e to s.e, with $s>1$, while those employed under one-period contracts have $s=1$. This seems a rather sitrange sort of firm-specific capital since no worker effort or firm investments are required. ${ }^{22}$ Nevertheless, one can imagine that these firm-specific skills are a result of effortless productivity increases, due to on-the-job training or learning-by-doing, or that these productivity increases are a result of better job matches which occur in due time (Williamson, 1975; Jowanovic, 1979, 1984; Barron and Loewenstein, 1985). We repeat that the conclusion of the Malcomson modell is that the relative efficiency of two-period models over one-period models depends on the incentive effect. This implies that internal labour market contracts (or better: promotion contracts) are more efficient if incentive effects play a role.

Now our point is that, even in the absence of incentive effects, two-period contracts are more efficient than one-period contracts, provided firm-specific capital is important. If the incentive effect is absent, and thus $\mathrm{e}=\mathrm{e}$, the employer chooses $\mathrm{P}=0$. This implies that the worker always receives wage $w_{2}$ in the second period, so a seniority contract occurs. The implication of assumption a) and b) is that, in the absence of incentive effects, discounted profits under two-period seniority contracts (4.9) and one-period contracts (4.10) are

$$
\begin{aligned}
& \pi=\mathrm{e} \cdot \mathrm{w}_{1}+\mathrm{s} \cdot \mathrm{e}-\mathrm{w}_{2} \\
& \pi=\mathrm{e} \cdot \mathrm{W}_{1}+\mathrm{e}-\mathrm{W}_{2} .
\end{aligned}
$$

The worker is indifferent between these two contracts if he receives wages $w_{1}$ and $w_{2}$ equal to the outside wages $W_{1}$ and $W_{2}$. When the entrepreneur pays wages $w_{1}+w_{2}$ equal to $W_{1}$ $+W_{2}$, two-period contracts $(4.9)$ are more efficient if $s>1$ since a surplus of higher profits is created. This extra profit is found by subtracting (4.10) from (4.9) which gives a surplus e(s-1). Thus the efficiency of this type of two-period contract with firm-specific skills depends on the increases in firm-specific skills, and incentive effects are not essential since the same effort appears under two-period contracts without promotion opportunities (4.9) and oneperiod contracts (4.10). Whether it can be expected that the worker receives a part of the surplus, i.e. $w_{1}+w_{2}>W_{1}+W_{2}$, is discussed in Section 4.6 .

Overall, the conclusion of this analysis is that it seems instructive to distinguish the two (complementary) sources for internal labour market contracts: firm-specific skills and monito-

21 Malcomson remarks that new employees enter the firm at their marginal product s.c if they worked lor another firm in the previous period (Malcomson, 1984, p. 170). This implies that increases in skills are completely general.

${ }_{22}$ The increase in productivity. $s$, can however be interpreted as the net result of firm investment. Then, $s>1$ implies that the increase in productivity exceeds the amount of firm investment. 
ring problems. ${ }^{23}$ Accordingly two types of contracts can be identified: promotion contracts and seniority contracts. The latter create a surplus over one-period contracts if there are increases in firm-specific skills, $s$, which are assumed to be absent in one-period contracts. As mentioned, the former create a surplus over one-period contracts if the incentive effects are high enough to induce an effort level above e and to compensate the worker for his increased effort. For promotion contracts to be more efficient workers must actively increase productivity by increased effort, while for seniority contracts it is only required that workers remain employed at the same firm and develop firm-specific skills. It may be that the goal of seniority contracts is to tie the worker to the firm, and avoid turnover costs. On the other hand, promotion contracts (Carmichael, 1989; Lazear, 1979) are based on monitoring problems. Due to imperfect information on the effort or productivity, workers have no incentive to perform above the minimum effort level, and the moral hazard problem arises. If monitoring devices or piece-rate contracts are ruled out, long-term contracts with opportunities for future wage increases can induce workers to efficient effort levels above the minimum level. Thus the fuindamental moral hazard problem is solved by inducing the workers to productivity-increasing activities. In this way the multi-period internal labour market contract solves the bonding issue (discussed in Section 3.6 and Section 3.8). Different from seniority contracts the essence of promotion contracts is not to tie the worker to the firm, but to motivate his effort by future promises. Another difference between seniority and promotion contracts is that promotion contracts focus on increases in productivity in early years of employment in a firm, while seniority contracts consider productivity difference between insiders and outsiders in later years. 24

In the literature both influences are often modelled together. This is not surprising considering the fact that the occurence of firm-specific skills and incentives are highiy complementary. Increases in productivity in later years may usually require effort or investment of employees in earlier periods (which refers to e in our framework). Examples of such models are those in which investment in firm-specific human capital require effort (Barron and Loewenstein, 1985, p. 144; Cantor, 1990) or models of partial gift exchange (Akerlof, 1982). Above we have summarized some arguments why it may be useful to consider both effects separately.

Our analysis leads to the conclusion that two-period contracts are more efficient than oneperiod contracts if firm-specific skills play a role, or if incentiwe effects are apparent. However, nothing is said about the relative efficiency of promotion contracts over seniority contracts. In fact, the only conclusion concerning seniority contracts is that even in the absence of promotion opportunities, so $\mathrm{P}=0$, two-period seniority contracts can still be efficient over one-period contracts if firm-specific capital increases occur. A further shortcoming of the model used above is that costs of investment in human capital are ignored. For models which

23 The same two sources for intemal labour markets are identified by Hutchens who states that: "Theories like those of Lazear or Carmichael posited a subset of jobs withere older workers receive a wage greater than value of marginal product. This subset is in part a product of technology; some jobs utilize technologies that pose monitoring difficulties or involve specific training, and those technologies give rise to delayed payment contracts." (1989, p. 59).

24 In the Malcomson model workers are paid once, at the start of a period. "The results of the analysis change if workers are paid at the end of the employment period, or if more than one moment of payment within a period is allowed. These cases are not discussed in this thesis. For some remarks on these points we refer to De Gijsel and Wolfs (1989a, 1989b). 
explicitly take investment costs into account we refer to Hashimoto (1981) or Cantor (1990).

In the analysis above the conclusion on the relative efficiency of multi-period contracts over one-period contracts is derived by comparing two-period contracts to two subsequent oneperiod contracts. A slightly different approach in analysing the efficiency of multi-period contracts is to show that it is optimal to have a two-period contract instead of a one-period contract of equal length. This approach is followed by Cantor $(1988,1990)$. In these models conditions are discussed under which multi-period contracts are more efficient than a one-period contract. To obtain an impression of these conditions, the models are briefly summarized. Cantor (1988) is based on incentives and investigates whether it is efficient to have a prefixed review (or recontracting) moment between the start and the end of the contract. At such a review moment the wage terms are reconsidered. This model improves on the Malcomson framework above in that it explicitly examines the costs of monitoring (or recontracting), apart from the cost of effort. The model is based on some severe assumptions, such as infinitely-living risk-neutral employees, and discrete effort levels. In a zero profit world, it is asked whether a recontracting (or in our terms monitoring) moment is introduced ex ante. Two equilibrium contracts can appear: a long-term contract without recontracting, or a longterm, multi-period contract with equal periods in which recontracting occurs every period. The latter contract is always incentive compatible, and appears when "recontracting costs, ..., are small and when the return to effort, ..., is large" (Cantor, 1988, p. 347). These intuitively appealing results however are highly dependent on the assumptions, especially that of infinitelyliving employees, which make effort always incentive-compatible. ${ }^{25}$ It seems to us that the assumption of minimum effort during the last period of a contract, as in the Malcomson framework above, is more realistic. This corresponds to findings in empirical research that there is only a loose relationship between pay and performance (Section 5.5). Older workers, although showing no better performance, appear to receive higher wages (Baker et al., 1988; Medoff and Abraham, 1980, 1981).

Turning to Cantor (1990) the efficiency of a two-period contract over a long-term oneperiod contract is examined in a model with firm-specific human capital investment. Contrary to our discussion of firm-specific capital, in this model investment in firm-specific skills requires worker effort. Given a time horizon $[0, \mathrm{H}]$, and given that the firm receives all quasi rents from investment during the training period $[0, \mathbb{T}]$, while rents in the post investment period $[\mathrm{T}, \mathrm{H}]$ are divided between employer and employee, it is investigated whether a predetermined review moment $\mathrm{T}$ is (socially) efficient. It appears that without such a predetermined moment effort of employees is too low. The conditions which specify the length of the investment period, or the review moment of a multi-period contract, show that this moment $T$ appears later if $\mathrm{i}$ ) investment is higher, ii) time horizon is larger, iii) the share of the worker in the second period is higher, iv) the effort is lower, and v) the discount rate is lower (Cantor, 1990, p. 7). The results of these complex models are not surprising, and do not contradict our findings above. In order to induce the right incentives multi-period models are used instead of long-term one-period models. Although the model and the approach followed

25. This means that under the optimal contract workers never shirk. The Malcomson model has a fixed horizon (iwo periods), which implies that workers always shirk (or perform at $\mathrm{e}$ ) in the last period. The model of Cantor (1988) has an infinite horizon, so the problem of shirking behaviour in the last period is absent. Models with fixed time horizon are referred to as life cycle incentive models (Carmichael, 1989. p. 70). 
in these studies is different, they justify our conclusion that unlti-period contracts are more eflicient than one-period contracts as a result of monitoring problems and firm-specific skills.

This section concludes with some final remarks on the relevance of the analysis. In fact some shortcomings, which are a result of the simplicity of our framework, are mentioned. First of all, this concerns our attention to moral hazard or incentive problems above, without considering the problem of adverse selection. Instead of examining which type of workers are employed under internall labour market contracts, or which workers are attracted by the features of long-term employment and promotion opportunities, we concentrated on the contract offered to homogeneous workers. This choice is partly the result of the attention in most models for the incentive or moral hazard problem. However, another reason for this choice is our interest in the average wage level for identical workers on the internal labour market and those outside (see Section 4.6). In that section it is investigated whether the wage difference is merely a result of differences in workers on the internal labour market and outside, or whether workers employed on the internal labour market receive higher wages than identical workers outside the internal labour market. However, if workers are heterogeneous, serious adverse selection problems can occur. If differences between workers are known, these problems can be overcome by constructing handicapping systems, which correct for observable differences between workers in order to offer equal opportunities to earn higher wages to all workers (O'Keeffe et al., 1984). But serious adverse selection problems may exist if differences are unknown to the employer and remain unknown over time. In these situations proper handicapping systems cannot be developed and workers cannot be allocated in homogeneous groups. This however might be less realistic in practice where employers learn ability differences of their employees over time. Accordingly, we consider the question of wage differences between homogeneous workers more interesting and therefore focus on the moral. hazard problem. ${ }^{26}$

Second, the relationship between risk aversion and incentives is not considered explicitly above. As a result of the finding of Section 3.4 that risk aversion was insufficient to explain long-term employment relations within a firm (Haltiwanger, 1983), which is essential for our internal labour market, attention has been centred on the implications of asymmetric information, and especially those of moral hazard. Malcomson (1984) has shown that under some conditions the conclusions concerning the relative efficiency of two-period models hold for risk lovers, risk-neutral and risk-averse employees. The relationship between incentives and risk aversion is not discussed in detail. However, in general, a trade-off is identified between risk aversion and incentives. While risk-averse workers prefer fixed wages, these provide less incentives for effort above a minimum level. Viscusi (1986) investigates this relationship in a two-period framework, and reaches the same conclusion: in a two-period context a trade-off between the preferences of risk averse workers for equal wages across and within periods, and

${ }^{26}$ This is not to say that worker heterogeneity poses no serious problems for the choice of the contract. In this respect Baker et al., (1988) argue that "toumament pronotion systems cannot simultaneously provide optimal incenlives and matching. For matching to matter, employees must differ. For toumaments to provide optimal incentives, employes must be alike, since differences in ability lead to reduced incentives if participants know that those of high ability will win" (p. 602). Furthermore, they signal that handicapping systems are rare in practice, and they cast doubt on the matching capacities of firms by using toumaments. As an example the Peter Principle is mentioned, which states that workers who are more productive on one level need not be more productive on a higher lewel as well. 
the incentives provided by such contracts also appears. He states that "..the intrinsic trade-off between risk and incentives that is present in single period models extends to multiple periods as there is a desire to sacrifice some of the risk spreading capability of period two compensation to bolster the work incentives in an earlier period." (Viscusi, 1986, p. 1078).

Finally, in the model above, the relative efficiency of internal labour market contracts is examined by comparing these to a sequence of fixed wage or salary contracts. For the research question into the wage difference between the internal and external labour market such a comparison is debatable. In that respect it must be questioned whether the external labour market is properly modelled by fixed-wage contracts, which imply only minimum effort levels. This topic is discussed in later sections. There we examine whether the framework of the internal labour market can answer the questions on the relation to wages (Section 4.6), the consequences for mobility and wage rigidity (Section 4.7) and the features of jobs and workers on the internal labour market (Section 4.8).

\subsection{Internal labour market contracts and wages}

It is derived in the previous section that under some conditions internal labour market contracts produce a surplus of extra profits over one-period contracts. Now we turn to the question whether wages on the internal labour market exceed the wage level on the external labour market. In the preceding analysis the internal labour market is modelled as a (twoperiod) contract. For a comparison of wages on the internal and external labour market the latter has to be modelled as a contract as well. However, a shortcoming of the Malcomson model in this respect is that an explicit modelling of the external labour market is lacking. Some adjustments have to be made, or some additional arguments must be provided, to analyse the wage difference between the internal and the external labour market. This implies that the market structure of the external labour market and the long run equilibrium results must also be taken into account. Apart from the wage level on both the internal and external markets, the wage profile which arises under multi-period and one-period contracts, is discussed.

To avoid misunderstanding, two remarks are in order. First, our analysis focuses on gross ex ante wages. This means there is no correction for effort terms, and the level of $w$, instead of w corrected for e, is discussed. A major reason for this choice is that in later chapters we want to empirically investigate whether wages on internal labour markets are higher. Since information on effort levels is not avalaible in our survey, gross wages are investigated. Second, the expected wage level at the moment the contract is signed, instead of the ex post wage level, is examined. In Chapter 7 the empirical research into average wage levels is based on the assumption that ex ante wages must correspond to average (ex post) wage levels. This assumption seems reasonable if information on wage payments and promotion opportunities is passed from those previously employed in the firm to new employees. So we assume that higher (discounted) wages show in higher actual average wages.

Our analysis of internal labour market contracts in Section 3.8 shows that it is unclear whether workers employed on the internal labour market receive higher wages compared to identical workers on the external labour market. The term 'identical' in this case refers to worker features at the moment the contract is signed, since workers on the internal labour market may develop firm-specitic human capital or higher effort in due time, which make them differ from those outside. It is examined whether there are reasons for workers, employed on the internal labour market, to receive higher wages on average than those 
employed on the external labour market, after correction for differences in their worker and job characteristics. Since our model of Section 4.5 assumes homogeneous workers it is suited to analyse this question.

However, in the model above the emphasis was on the proper modelling of the internal labour market. At this point some general remarks are made on the problems of modelling the external labour market. These remarks concern, first, the type of contracts which exist on the external labour market, second, the market structure of the externall labour market, and third, the outcomes which prevail in the long run.

With respect to the first point, it must be mentioned that our definition of the internal and the external labour market implies that the external labour market may include all kind of contracts. Three of these contracts which may prevail on the external labour market are short term contracts, long-term contracts without promotion opportunities and workers which are self employed. The question is whether there are reasons to expect higher wages for workers employed under internal labour market contracts compared to those under these external labour market contracts. In the framework of the previous section the external labour market is not examined in detail. Some problems which are connected to this modelling of the external labour market are discussed below. If it is assumed that the external labour market consists of self employed workers, it is unclear whether wages for self employed are below or above those of employees under internal labour market contracts. ${ }^{27}$ The reason for us to ignore the existence of self employed on the external labour market is that our empirical research is restricted to employees.

If, on the other hand, it is assumed that on external labour markets long-term contracts without internal promotions or short term contracts exist, it can be argued that wages for workers under internal labour market contracts are higher, because of the development of firm-specific human capital (which is lower, or even absent, on the external labour market because of less incentives to invest in firm-specific skills), or because of incentives provided by these internal labour market contracts to attain higher effort levels. Our starting assumption is that the external labour market can be modelled by the one-period contracts of the Malcomson model, with wage $\mathrm{W}_{\mathrm{i}}$ and effort level Following this interpretation of the Malcomson model, in which the source of the surplus is the increased worker effort, the expected utility of workers employed under internal labour market contracts must at least equal expected. utility under extemal labour market contracts, so (4.2)> (4.3). Since the effort level under the promotion contract is never below that on the external market. $\mathrm{e}>\mathrm{e}$ workers must be compensated for this higher effort level by higher wages. Thus, if the internal labour market is a result of incentive effects, expected discounted wages on the internal labbour market for homogeneous workers exceed those outside the internal labour market. The same outcome is attained if employees on the external labour market are employed under long-term contracts (two-period in this case) which offer no promotion opportunities. Under these contracts workers are not motivated to perform at an effort level which exceeds the minimum level.

On the other hand, if we follow our interpretation of the previous section with assumptions (a) and (b) on the development of firm-specific capital, the case of firm-specific human skills as the source of the relative efficiency of internal labour market contracts over one-period contracts, can be examined. Under both contracts workers perform only at $\mathrm{e}$ in both periods. If the firm maximizes profits, constrained by $U \geq U$, wages on the internal labour market

${ }^{27}$ One argument for higher wages for self emplayed is that they experience more income risk and accordingly receive higher wages as a risk premium which compensates for this higher risk. 
equal those on the external labour market. In this case workers are indifferent between oneperiod contracts and a wo-period contract with $w_{1}=W_{1}$ and $w_{2}=W_{2}$. The firm however has extra profits as a result of $s>1$. However, if the worker leaves the firm at the end of period 1 , the surplus of the firm is foregone. The threat of employees to leave the firm unless the firm shares (part of) the surplus with the workers, provides an ad hoc argument to expect higher wages under the internal labour market contracts. Insider outsider theories present analogous arguments of worker threat which leads to higher wages (see Section 3.7). From this we conclude that if internal labour market contracts arise from the development of firm-specific human capital, it is expected that average wages exceed outside wages. As is mentioned above this conclusion is based on the assumptions that workers on the external market develop no firm-specific capital, both workers on the internal and external labour market have the same amount of general human capital, and the dewelopment of firm-specific capital occurs regardless of effort. Although this may seem strange at first, one can imagine that internal labour market contracts in time lead to better job matches, which are more efficient (and more productive) than job matches under one-period contracts (Abraham and Farber, 1987). In this way productivity increases modelled by $\mathrm{s}>1$ occur as well, regardless of worker effort. If workers on the external labour market have long-term contracts without promotion opportunities, higher wages on the internal labour market will only result if it is assumed that such employees develop no relevant skills, despite their long-term contract. This is, for instance, consistent with the assumption that it is the existence of promotion opportunities which provides incentives to acquire firm-specific human capital. This assumption is elaborated below.

A crucial question in this analysis is whether the above modelling of the extemal labour market is correct. Workers on the extemal labour market apparently never provide an effort above the minimum effort level e, which prevails on the intemal labour market. This leads to the discussion of the assumed market structure in the framework of the prewious section. Apparently, productivity for workers employed on the extemal labour market is fixed in advance by the production technology at the (low) level $\mathrm{e}$. Next, it is assumed that workers can be motivated to perform at a higher effort level under internal labour market contracts, if incentives are provided by internal promotion opportunities.

When we assume that the external labour market can alternatively be modelled by perfect competition over wages and effort, a wage level $W$ and effort level $\vec{e}$ will result (- this assumption is also made in two-sector models discussed below). The Malcomson model then is not appropriate anymore, because the effort level $\mathrm{a}$ is likely to differ from $\bar{e}$. Let internal labour market firms be characterized by a production technology which involves imperfect information on the productivity of employees. In these firms workers are inclined to shirk, which implies an effort level lower than the first best level $\bar{e}$ which can be attained at the external labour market. The firm is forced to pay a wage above the discounted wages on the external labour market, in order to reduce the (amount of) shirking, as in efficiency wage models (see Section 3.6). Hence, gross expected wages on the internal labour market exceed extemal wages. Note however that, since it is unclear whether the effort levell which arises on the internal labour market exceeds that on the extemal market, it is unknown whether net wages ( $w$ corrected for effort) are higher or lower on the internal labour market.

In sum, these considerations lead to the conclusion that wages for workers employed under internal labour market contracts are above those for workers on the external labour market. It must be emphasized however that further research on these topics is required (Chapter 8). 
Turning to our third point, we emphasize that the analysis so far is conducted in a partial equilibrium context. A proper examination however requires a modelling in a general equilibrium context. A set of equilibrium models which can be considered to represent a modelling of internal and external labour market are so-called 'two-sector models" (see for instance Harris and Todaro, 1970; MacDonald and Solow, 1985; Ballot and Piatecki, 1986; Bulow and Summers, 1986; Van de Klundert, 1988; Perrot and Zylerberg, 1989). In these models there is a primary segment, or an internal labour market, with high (efficiency) wages, and a secondary sector with market clearing wages. It is assumed that on the primary sector, which represents the internal labour market, workers leave the firm only for refirement, and that every period a number of jobs is open for entrance. Because wages are higher for jobs on the internal labour market, these are preferned generally by those outside the internal labour market. These models show that in equilibrium situations with a wage difference between the internal labour market and a competitive external labour market may exist in the short run. Whether this wage differential will persist in the long run depends on the structure of the goods market in which the internal labour market firm operates, and the competitive behaviour of workers. If in the long run internal labour market firms earn extra profits, a surplus is likely to attract new firms which leads to zero profits. If higher wages on the internal labour market are financed out of extra profits, the consequence would be that in long run equilibrium firms will eam zero profits and the wage differential disappears. Thus, the persistence of a wage differential between the internal labour market and the external labour market will depend on the existence of barriers of entry. The persistence of extra profits on the internal labour market in the long run requires therefore additional assumptions on the market structure. However, in this study this aspect is not discussed in detail, and thus our analysis may be considered as a short-run analysis. This shortcoming indicates a road for further research (see also Chapter 8).

The wage differential could also disappear by underbidding. The theories reviewed in Chapter 3 provide however two explanations for the persistence of such a wage difference. First, efficiency wage theory argues that it is not profitable for the firm to hire applicants which claim to be as efficient as those already employed, for a lower wage. Because of monitoring problems these workers are likely to shirk once they are hired. Thus if firms have production structures which involve imperfect information there is no reason to lower the wages (see Section 3.6). In insider outsider theory an additional argument is presented. Workers already employed within the firm can threaten to influence productivity by harassment or refusing co-operation, if the firm hires outsiders at lower wages. Such threats may also lead to the persistence of a wage gap between those employed on the internal labour market and those employed outside (see Section 3.7).

Overall, the conclusion from the arguments in this section is that average wages for (initially) identical workers on internal labour markets are above average wages for employees on the external labour market. First, these higher wages can be a result of the development of firmspecific human capital, which makes workers on the internal labour market differ in productivity from those outside. This implies that, after correction for these differences in firm-specific human capital, this wage difference may vanish. However, these higher wages may also be a result of efficiency gains, caused by increased effort of the employee. This implies that workers employed on the internal labour market earn higher wages than identical workers employed on the external market. These considerations lead to the following hypothesis: 
HYPOTHESIS 4.1: Average (expected) wages on the internal labour market are higher compared to those outside the internal labour market for identical workers on identical jobs.

Beside these arguments, which more or less follow from the model above, there are some additional ad hoc arguments to expect higher wages under two-period contracts. First, if productivity depends on the kind of job as well, these higher wages can also be the result of differences in job characteristics between the internal and the external labour market. It is argued in segmentation theories, which relate the internal labour market to the primary segment, that internal labour markets consist of better jobs (see Section 2.3). Second, higher wages can also be a result of superior human resource management policies and career planning progranmes which use the labour force more efficiently. This would result in higher wages for workers under multi-period contracts, even after correcting for differences in job and worker features, if workers with multi-period contracts are employed in situations with better human resource management. Third, one can argue that firms which offer multi-period contracts with delayed payments will have to pay a premium to convince workers that they will not be cheated upon (Hutchens, 1989). Thus firms which offer multi-period contracts can be expected to pay higher wages to their employees. Fourth, if there is worker heterogeneity, higher wages can result if internal labour markets attract higher productive workers (as in adverse selection models, for instance Akerlof, 1970, see Section 3.6), or if workers on internal labour markets are screened, and better (nore productive) job matches result in due time. Such considerations lead to the general hypothesis that average wages on the internal labour market are higher. This hypothesis reflects one of the features which are explicitly adhered to the internal labour market (Doeringer, 1986, p. 46; Mace, 1979).

HYPOTHESIS 4.2: Average (expected) wages on the internal labour market are higher than those on the external labour market.

Now attention is directed to the relationship between wages, productivity and seniority. This relationship may be different depending on which of the two sources of internal labour markets prevails. First, we discuss the case of firm-specific human capital. Above we mentioned that the development of firm-specific capital can result in the trelative efficiency of internal labour market contracts. However, in the model above this development was a result of costless productivity increases. It is more realistic to consider these costs explicitly. This leads to profiles as depicted in Figure 4. Ia (see Becker, 1975; or Hashimoto, 1981). In these models it is assumed that employer and employee decide on the amount of investment in firm-specific human capital. The wage profile which arises in these models is presented in Figure 4.1.

In Figure 4.1 a we assume that the productivity of workers in period 1 decreases from e to $\mathrm{e}^{\mathrm{L}}$ because of time spent on firm-specific training. Outside the firm the worker can earn wage was a reward for his productivity $\mathrm{e}$. In period 2 the productivity on the internal labour market increases to s.e. Under the optimal contract workers receive a wage $w_{\mathbb{1}}$ between $\mathrm{s}$ (which equals $w$ ) and $\mathrm{e}^{\mathrm{L}}$ in period 1 , and a wage $w_{2}$ between $\mathrm{e}$ and $\mathrm{s}$. in period 2 . In this way the firm invests $w_{1}-e^{L}$ in period 1 and receives s.e $-w_{2}$ in period 2 , while the worker invests $w-w_{1}$ in period 1 and receives $w_{2}-w$ in period 2. Investment and returns are shared between worker and employee. It can be shown that these contracts are efficient if there are transaction costs involved in obtaining precise information on the productivity and alternative value of the worker and agreeing on these values (Hashimoto, 1981). In order to minimize the occurence of inefficient separations, costs and returns of investment in specific training 
are shared between firm and worker; "workers neither bear the full cost nor reap the full return from specific training" (Hutchens, 1989, p. 51). The stylized model of Figure $4.1 \mathrm{~b}$ is presented in Barron and Loewenstein (1985). They discuss contracts with increased efficiency over time as a result of better job matches. In general, we conclude that with investments in firm-specific human capital the cost-reducing effects of tying the worker to the firm determine the relative efficiency of long-term contracts. These costs can be determined by turnover cost, recontracting costs and hiring and firing costs. On the other hand the employee must be induced to stay within the firm by offering future wages above the wage on the external market. Of course these multi-period contracts are more efficient the higher the costs of turnover and the lower the future wages needed to tie the worker. A point to be noted here is that the productivity-tenure profile, which results under these (seniority) contracts, is steeper than the wage-tenure profile. The seniority contract can however be adapted, which results in the feature of wages exceeding marginal product for senior workers. In fact, Carmichael (1983) presents such a model, based on Hashimoto (1981). In the model of Hashimoto (1981) inefficient separations occur since parties breaking the employment relation incur cost on each other. In Carmichael (1983) the number of inefficient separations is reduced by develloping a contract internalizing "the entire expected losses from a separation, regardless of who initiates it" (p. 252). In this model the most senior workers are promoted, during the second period, to higher level jobs which pay a wage above their marginal product.

Figure 4.1a Two period (Hutchens, 1989)

Figure 4.1b Stylized
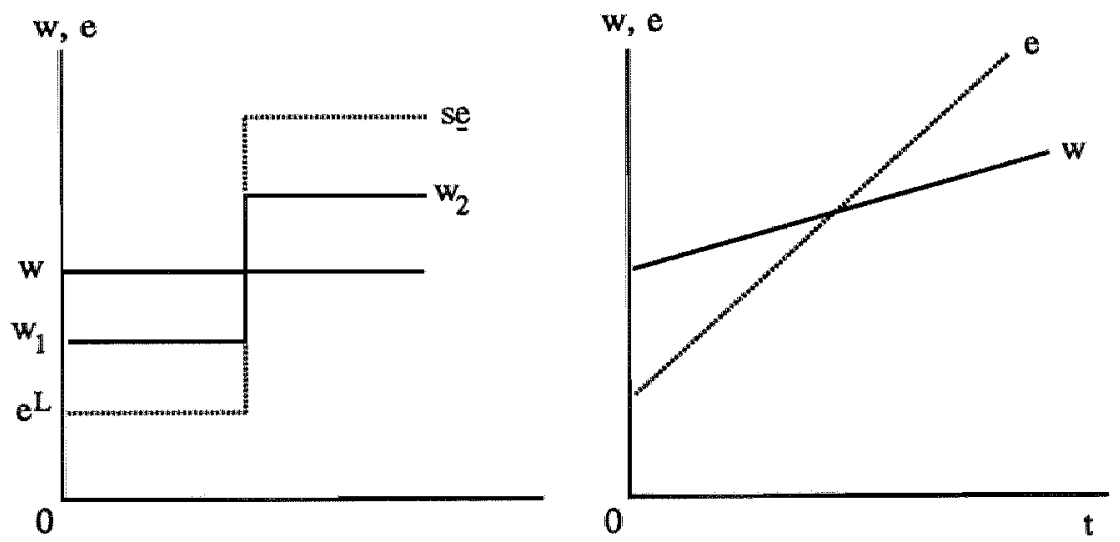

Some recent empirical findings (which will be mentioned in Section 5.5) on the relationship between wages and productivity (Medoff and Abraham, 1980, 1981) and the existence of mandatory retirement (Lazear, 1979) indicate that wages for older workers seem to exceed their marginal product. "Indeed, wages may grow with seniority even in situations where productivity falls with seniority" (Hutchens, 1989, p. 56). Carmichael demonstrates "that when a job inwolves specific training, it can be efficient for the firm to pay older workers a wage that exceeds the value of their marginal product." (see Hutchens, 1989, p. 57). The profile which better corresponds to these findings can also be the result of promotion contracts based on incentives, and is characterised in Figure 4.2a (see Lazear, 1979). In these models the 
increase in productivity in time is lower than the increase of the wage level.

The profile which can be derived from the two-period Malcomson model is presented in Figure $4.2 \mathrm{~b}$. It has the same feature of less steep productivity (or effort) lines, compared with the development of the wage level. ${ }^{28}$ As in the model of Section 4.5 , the productivity level is e in period 1 and decreases to in the second period. The wage workers receive in period 1 is $w_{1}$ in the first period and increases to a higher (expected) wage level in the second period. This higher expected wage provides incentives to remain employed and receive the higher future wage. Referring to the mode] in Section 4.5 this higher future wage is an expected future wage: $w_{2}=P w_{2}^{H}+(1 \sim P) w_{2}^{L}$. The rellative steepness of the wage-tenure and the productivity-tenure profiles may thus differ from that of the models based on firm-specific skills. While on average expected wages equal productivity, under seniority contracts productivity may exceed wages in later periods, while under promotion contracts wages exceed productivity. However, since we have no information on worker productivity, it is impossible for us to test a hypothesis on the relationship between the wage-tenure and the productivity-tenure profile.

Figure 4.2a Stylized (Lazear, 1979)

Figure 4.2b Two-period (Malcomson, 1984)
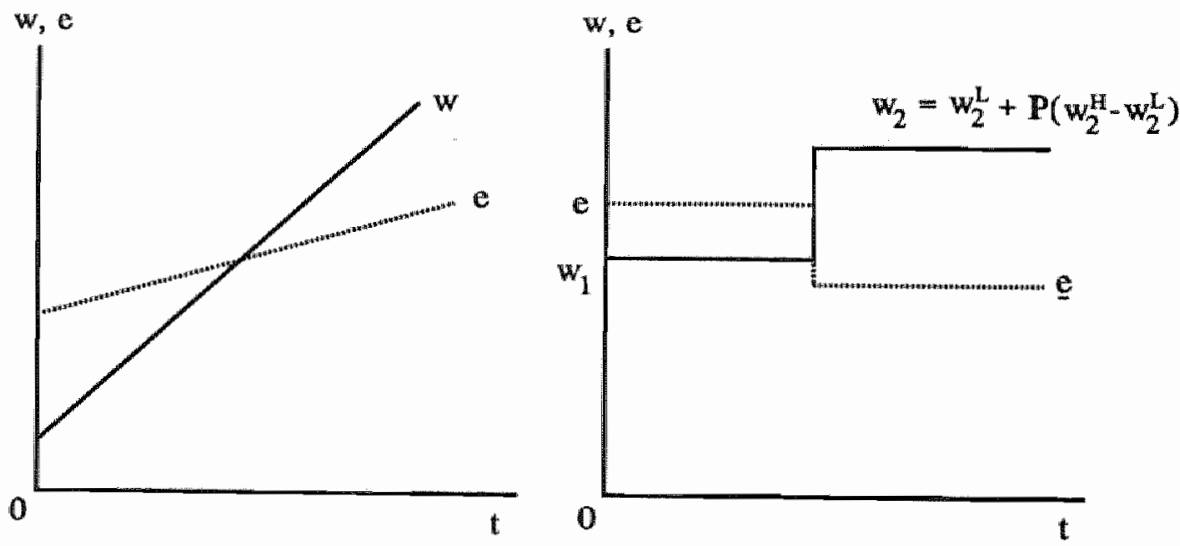

However, with respect to the relationship between wages and seniority both the seniority contract and the promotion contract imply that wages increase with seniority. This however, does not mean that wages rise because of seniority. "This is the case if internal labour market conuacts arise because of firm-specific skills (Hutchens, 1989). In models of the internal labour market based on incentives, positively sloped profiles increase efficiency in earlier periods. Nevertheless, in both profiles the slope of the wage-tenure profile exceeds that on the external labour market. First, because firm-specific skills play a less important role outside the internal labour (Althauser and Kalleberg, 1981, p. 136) market. Second, in the incentive model wages

28 The productivity decreases in Figure 4.2b. In the original model of Malcomson (1984) this decrease of effort from $\mathrm{e}$ to $\mathrm{e}$ is counterbalanced by the increase in general human capital, so productivity does not necessarily decrease in that model. 
increase with seniority because of the deferred payment character of the payment schedules. By paying workers higher wages in later periods, with internal promotion opportunities, productivity is increased. ${ }^{29}$ Barron and Loewenstein (1985) state that "Internal labor markets are typically characterized by a rising wage profile" (p. 437). Therefore the final hypotheses of this section is derived.

HYPOTHESIS 4.3: On the internal labour market the slope of the earnings profile is steeper than the slope on the external labour market.

\subsection{Consequences of internal labour market contracts}

The third research question (Table 1.1) addresses the consequences of internal labour markets, especially with respect to wage rigidity and labour mobility. Due to the partial nature of most models of internal labour markets, and their emphasis on short run considerations, only some general remarks can be made. In our model of Section 4.5 seniority contracts and promotion contracts are preferred by workers over one-period contracts. In this model with homogeneous workers turnover is reduced under these two-period contracts. The internal. labour market is defined by long-term employment relations with promotion opportunities. On the extemal labour market both long-term contracts without internal promotions and short term contracts appear. This implies that the average tenure of those employed on the intemal Jabour market can ultimately be expected to be higher. In most investigations actual tenure is measured. If the survey is representative (so younger workers are not overrepresented on the internal labour market), average actual tenure will be higher on internal labour markets. Thus for workers employed under internal labour market contracts interfirm mobility will be lower and average tenure is higher. If workers are not homogeneous, but differ in their preference for short and long-term employment agreements, workers with preference for long-term employment and internal promotions will apply for internal labour market contracts. Furthermore, employers will offer long-term contracts to employees which can be expected to remain employed for a considerable time (see Section 3.2). These considerations also lead to higher average tenure on internal labour markets. Caution must be taken with the interpretation of variables on tenure and turnover. Usually, turnover is measured at firm level, while tenure can be measured at both firm or individual level. A single firm can have high turnover on average and high average tenure as well. This may be the result of long tenure for part of the employees, as a result of long-term employment contracts, and (very) short tenure for employees under short term contracts. The relative importance of both groups influences the average tenure. Thus one might erroneously conclude that a firm is not an internal labour market, while a part of the workers is employed under long-term contracts.

Furthennore, as a result of the policy instrument of internal allocation and internal promotions, mobility within a firm will be higher on the unternal labour market compared to the external labour market. Under the internal labour market contract workers are concerned with

29 A further justification for hypothesis 4.3 seems to be provided by results from research by Lazear and Moore (1984), who show that the age-eamings profile of employees, who suffer from the incentive problem, is steeper than that of self-employed, who lack the need for incentives provided by deferred payments. It should however be noted that in this section we decided not to discuss the consequences of self-employed on the extemal labour market. 
firm internal jobs changes and the resulting wage changes. Firms offer workers contracts with opportunities for career advancement. It is assumed that the perception of the employee cannot be manipulated (permanently) and thus actual promotion opportunities must exist on the internal labour market. Therefore we expect that job changes occur by internal mobility, which can be horizontal as well as vertical. So the following hypothesis on mobility is formulated:

HYPOTHESIS 4.4: In firms with internal labour markets the inter-firm mobility is lower and the intra-firm mobility is higher compared to the externallabour market. Further, awerage tenure is higher on the internal labour market.

To be somewhat more specific on the variables to be tested empirically, with respect to intrafirm mobility it can be expected that the average number of job changes for those employed under internal labour market contracts is higher, as well as the percentage of workers which report to have experienced at least one job change. Furthermore, internal flexibility of workers is higher, since they can be employed more easily an different jobs. With respect to inter-firm mobility we expect that job satisfaction on the internal labour market is higher and that a lower percentage of workers employed on the internal labour market is currently looking for another job. On the other hand a lower percentage of workers expects to be unemployed within a year. Finally, with respect to average actual job tenure, it is expected that this is higher on average for workers on the internal labour market.

Question 3 of Chapter 1 also concerns the consequences of internal labour markets for the flexibility of wages. Since our model is a static model, hardly any conclusions can be derived from the model on this question. Therefore, at this point, only some general remarks are made. In our approach internal labour market contracts are featured by long-term employment and internal promotion opportunities, and internal promotions lead to wage increases. If it is assumed that wages are coupled to jobs one can argue that, on internall labour markets, efficiency is attained by allocating workers ower jobs, instead of continuously adjusting individual wages to worker productivity. In the theories discussed in Chapter 3 this argument, of wages being coupled to jobs instead of workers on internal labour markets, can be found (see Williamson, 1975; Thurow, 1975). This implies that wages per worker change if workers change jobs. However, in our framework it is not excluded that workers experience wage increases without job changes. Nevertheless, such wage changes are explicikly considered as intemal promotions (for reasons mentioned in Section 2.5). So the following arguments for wage rigidity on internal labour markets only hold in our framework if wages are strictly coupled to jobs. These arguments state that through the use of internal promotion as adjustment policy, instead of wage adjustments, employers have created an additional policy instrument, which reduces the use of wage adjustment as an instrument to achieve an efficient outcome. This implies that under changing economic conditions wage adjustments are less urgent. Instead of adjusting wage levels, employers can manipulate promotion opportunities, and hiring standards (Thurow, 1975), and thus influence expected wages. Under the seniority contract, for instance, the employer can respond to changing economic conditions by adjusting the time period between two salary changes. Under promotion contracts the rate of promotion can be adjusted. The use of these career patterns and internal allocations of workers on internal labour markets is also mentioned by the radical approach (see Section 3.2). From these arguments it can be expected that actual wage changes occur less frequently under seniority and 
promotion contracts. ${ }^{30}$ Nevertheless, since our definition of the internal labonit market does not necessarily imply that wages are strictly coupled to jobs, a hypothesis on wage rigidity is not formulated. An additional reason for this decision is that the data used in our empirical research do not allow a test of wage rigidity.

\subsection{Further characteristics of internal labour markets}

In correspondence with the first question of Table 1.1 in the present section which jobs and workers appear under internal labour market contracts are examined. Since the model above assumes that workers are homogenous, no direct variables cam be derived from this model. Therefore hypotheses are derived by using additional arguments and ad hoc explanations. In the previous discussion we already identified two main conditions which are fundamental to the occurence of internal labour market contracts. First, the existence of incentive problems related to difficulties of monitoring worker productivity. Second, the development of firmspecific human capital. Accordingly, internal labour market contracts are to be expected in situations of imperfect information or monitoring problems, and situations in which firmspecific human capital or job idiosyncracies are important. If worker effort is difficult to observe and workers develop firm-specific skills by remaining employed at the same firm, offering multi-period contracts with opportunities for further wage increases can be efficient. By offering these internal labour market contracts, instead of one-period contracts without employment guarantees in the same firm, workers can be motivated to perform on a higher level and to develop firm-specific skills. Such contracts, or "tenure systems appear to prevail in situations where human capital, creativity and an unstructured environment are particularly important in the production process, and where long lags between action and observation of outcomes make performance measurement and evaluation difficult" (Baker et al., 1988, p. 604). This leads to the general conclusion that internal labour market contracts appear if productivity is hard to observe and firm-specific skills and high turnover costs are involved. Below we try to identify more precise worker and job features which reflect such monitoring problems and firm-specific skills, in order to formulate testable hypotheses.

Employers are expected to offer internal labour market contracts to employees from which they expect stable employment behaviour. Theories of statisticall discrimination argue that, since the exact productivity of a worker cannot be observed directly, the expectation on the workers' productivity will be based on earlier experience of the employer. In this respect women, part-time workers and younger workers have shown more unstable employment behaviour in the past. In spite of all recent changes in labour market behaviour, women still sooner withdraw (temporarily) from the labour market to look after the children (Tijdens, 1989). Part time and younger workers also show less job attachment and consequently more inter-firm mobility, because of "job shopping", while older workers can sooner be expected to settle down and remain at their firm until retirement. From these considerations it can be hypothesized that firms do not offer internal labour market contracts to these groups, and thus male workers, full time employees and older workers appear more frequently on the internall

${ }^{30}$ Additionally, if "wage rigidity is defined relative to what would occur in a spot market" (Lazear. 1984, p. 339), it can be shown that contracts with delayed payment as in the promotion contract lead to wage rigidity in this sense "since no one worker's wage at any point in the life cycle moves as rapidly as product price" (Lazear, 1984, p. 342). 
labour market. Moreover, productivity is difficult to observe in jobs which require specialized skills and involve complex tasks. A variable which can reflect such task complexities is, for instance, the initiation period. So we hypothesize that task complexity leads to the use of internal labour market contracts, and thus the average length of initiation period for those employed on the internal labour market is longer. Longer initiation periods on intemal labour markets can also be a result of a higher amount of firm-specific human capital. With respect to the firm-specific human capital it can further be expected that development of specific capital increases with seniority and tenure, due to on-the-job training and learning by doing (Doeringer and Piore, 1971; Williamson, 1975).

With respect to the amount of general human capital, measured by the average years of schooling, it is unclear whether this is higher on internal labour markets. On the one hand one can argue that higher educated workers have received more specialized education or training and thus can be expected to be employed on complex jobs which require more better-skilled workers. On the other hand human capital theory emphasizes that it is the importance of firmspecific skills, instead of general skills, which binds the worker to the firm, and thus leads to the long-term employment feature of internal labour markets. Therefore it is unclear whether the educational level on internal labour markets is higher, compared to those employed on the extemal labour market. Since variables such as age and previous experience can be regarded to reflect general human capital, the same conclusion holds for these variables. Note however with respect to age that above arguments are provided for older workers to appear on internal labour markets.

Further variabes are derived from the argument that larger firms experience more problems in measuring individual worker productivity (Masters, 1969; Oi, 1983). With the same argument it can be hypothesized that firms or industries with capital-intensive production technologies can be found on the internal labour market. In these firms or industries it is more difficult to link output to worker effort. Katz (1986, p. 253) argues that "The cost of foul-up is likely to be large in industries with expensive equipment (possibly proxied by high capital//abor ratios) and for workers in positions where poor performance may affect many other workers' performances (e.g., workers in coordinating positions and workers involved in integrated production processes)." Therefore, it is hypothesized that internal labour market contracts with internal promotion opportunities are used in large firms with capital intensive production technologies. Also these (multi-period) promotion-based payment systems appear in liuge and growing firms with many lierarchies, which have more opportunities for internal promotion. On the highest level jobs promotion opportunities are smaller and more emphasis is on (one-period) bonus-based payment (Baker ef al., 1988, p. 601). Furthermore, large firms are less likely to "quit the business" and care more for reputation. Therefore, they offer longterm contracts with delayed payment without renegotiation of the contract (Hutchens, 1989 , p. 56). Finally, these contracts appear on high-level jobs, which ustally involve more complex tasks, with high degrees of responsibility and freedom to decide. Of course monitoring is accordingly mone difficult. Instead of formulating a separate hypothesis for every variable, they are lumped together in the following hypothesis on the features of jobs and workers on the internal labour markets. 
HYPOTHESIS 4.5: On the internal labour market the proportion of male and full-time workers is higher than on the external labour market. Further, the length of the initiation period, average job level, average firm size and capital intensity is higher on the internal labour market. Finally, average age, years of education and previous experience are not significantly different from the external labour market.

\subsection{Summary and conclusions}

At the end of the theoretical part of the thesis the findings concerning the internal labour market are summarized. The research has consisted of three steps, all treated in a separate chapter. The first step, in Chapter 2 , was to argue that the internal labour market may be defined by long-term employment relations with internal promotion opportunities.

In the second step, in Chapter 3, current labour market theories were examined on their power to provide answers to the research questions: 1) which jobs and which employees are situated on the internal labour market,2) what is the relationship between internal labour markets and wages, and 3) what is the influence of internal labour market contracts on the flexibility of wages and the mobility of labour? The following six theories were examined: human capital theory, radical theory, insider outsider theory, efficiency wage theory, transaction cost theory and implicit contract theory. None of these provided a consistent framework to treat the internal labour market completely, but some useful concepts were found. First of all, efficiency wages which stress the influence of wages on the labour productivity or efficiency in situations of imperfect information on worker productivity. Second, the development of firm-specific human capital which leads to productivity differences between those employed inside the firm and those outside the firm.

In this chapter the third step is taken. In an attempt to answer the three research questions a framework is presented based on the internal labour market as a contract. In this framework the internal labour market is considered as a multi-period employment contract with future wage increases due to internal promotion opportunities. Such contracts arise because of incentive effects or the development of firm-specific capital (or both). Within this framework hypotheses concerning the research questions could be made. On the first question into the jobs and employee characteristics of the intemal labour market it is hypothesized that internal labour markets appear if monitoring problems occur and skills are firm-specific (hypothesis 4.5). Under these circumstances internal labour market contracts can provide efficient solutions. The hypotheses in relation to the second research question on the relationship between internal labour markets and wages formulate that average wages per worker on the internal labour market are above those outside the internal labour market (hypothesis 4.2). Further it is hypothesized that even if workers on the internal labour market and those employed outside have identical characteristics, wages on the internal labour are higher (hypothesis 4.1). This is a result of higher efficiency, either due to higher effort (as under the promotion contract) or increased firm-specific human capital (as under the seniority contract). Furthermore, it is hypothesized that the tenure earnings profile on the internal labour market is steeper than on the external market (hypothesis 4.3 ). The static nature of our analysis forbids strong conclusions with respect to the third research question into the consequences of internal labour markets in terms of wage and labour flexibility. Nevertheless, it is hypothesized that intrafirm mobility on intermal labour markets is higher, and interfirm mobility is lower (hypothesis 4.4). Further, there are some indications that wages on internal labour 
markets are more rigid, but neither our contract theoretical framework, nor the data of our empirical inwestigations, permit the derivation and testing of such a hypothesis.

In the empirical part of the thesis, consisting of the next three chapters, the hypotheses derived above are empirically tested. But first, in Chapter 5 , the significance of previous research on internal labour markets is examined. In Chapter 6 , we turn to our own empirical investigations. In this chapter the internal labour market, defined by long-term employment relations and internal promotion opportunities, is operationalized and a first indication of the extent of the internal labour market in the Dutch economy is provided. Finally, in Chapter 7 , the hypotheses are tested one at a time. 


\section{CHAPTER}

\subsection{Introduction}

The second part of this study concentrates on empirical research. The purpose of this chapter is twofold. First of all, it reviews previous research on firm internal labour markets and some related topics in order to answer the research questions and test the hypotheses. In general, research into firm internal labour markets is limited (Creedy and Whitfield, 1988, p. 249, p. 262) and diverse, as well in the definitions used, the topics investigated and the methods applied. This thwarts an orderly rewiew of current research. Therefore attention is mainly restricted to the questions in Chapter 1. The different definitions and concepts of the internal labour market employed in previous research, the size of the internal labour market, its characteristics, the relationship between wages and internal labour markets, and some results concerning turnower and labour (im)mobility are discussed. Next, some shortcomings of prior research are mentioned. Thus, the second goal of this chapter is to point to improvements to be made with regard to prior research. These improvements concern both the operationalization of the internal labour market and the methods applied. The results of the empirical research are presented in the next wo chapters.

Since the empirical investigations concern the Dutch labour market we start with a review of previous research on the Dutch labour market in Section 5.2. It appears that there are hardly any investigations which explicitly concentrate on the internal labour market, so we decided to discuss some studies on labour market segmentation, in which the internal labour market is not explicitly a topic of research, as well.

In research for other countries discussed in subsequent sections, the same scarce and scattered pattem appears. As is already clear from Chapter 3 many topics can be related to the internal labour market. Examples of such topical investigations are studies into tumover, job mobility, career patterns, payment systems, hiring and selection criteria. A lengthy discussion of all topics related to the internal labour market is avoided by restricting attention to the research questions. Section 5.3 offers a discussion on the different concepts of the internal labour market and the methods to investigate the internal labour market.

In Section 5.4 the size and characteristics of the internal labour market are examined. For iwo reasons general conclusions on the size of the intemal labour market cannot be given. First, the size of the internal labour market is dependent on its definition, which differs wide- 
1y. Sccond, most research is based on case studies, which prohibits generalization of the results.

Section 5.5 addresses the rellationship between wages and internal labour markets. This section concentrates on the question whether wages on internal labour markets exceed those outside the internal labour market, and examines the relationship between seniority, wages and productivity.

An important feature of the internal labour market in our definition is long-tern employment relations. In this respect the appearance of long tenures on the labour market would (partly) justify the research into internal labour markets. Section 5.6 therefore is directed to a discussion of results on labour (im)mobility by discussing tenure distributions. Before we turn to our own investigations a summary is provided in Section 5.7.

\subsection{Research on the Dutch economy}

This section presents a short summary of the main enpirical investigations into the internal labour market for the Netherlands. Such research for the Netherlands is scarce (Van Ours and Zoethout, 1990, p. 8) and diverse. Some structure is brought into the discussion by distinguishing three groups of studies. The first is mainly concerned in investigating the existence of internal labour markets in the Netherlands (Bergeijk and De Grip, 1986; Van Ours and Zoethout, 1990). The second group focuses on the size of the internal labour market (or the primary sector) and its characteristics (Valkenburg and Vissers, 1979; Ten Have and Vissers, 1987; Soeters and Schwan, 1990). Finally, a group of studies which discusses the dynamics or development of internal labour markets are distinguished (Warmerdam and Van den Berg, 1986; Scholten, 1984; Tijdens, 1986).

Turning to studies explicitly addressed to the existence of intemal labour markets we start with Bergeijk and De Grip (1986). They present some results mainly based on annual sociall reports of 19 large Dutch corporations from 1974 to 1983 , covering about $10 \%$ of workers in private industries. Since this research concentrates on large firms, a bias towards internal labour market firms is created. Several features adhered to the internal labour market are studied. In this respect a distinction is made between intrinsic features of an internal labour market, such as internal promotion lines, inhouse training and mobility chains, and extrinsic features, such as turnover, tenure, entry level and recrutment. Since elaborate information on intrinsic features is unavailable, most attention is on extrinsic features. With respect to tenure it was found that in all firms, but one, tenure increased in the period observed. In 1983 the percentage of workers with a tenure of at least 10 years in all firms was (high) above $30 \%$. Additionally, turnover was studied since stable employment for one part of the workers can be accompanied by high turnover for another group. Using a turnover rate of $10 \% 16$ of the 19 corporations showed turnover below 10\% in 1981, 1982 and 1983, while over the whole period six companies have a turnover below $10 \%$. It appears that decreases in turnover are accompanied by increases in unemployment. Bergeijk and De Grip point to a process of closure of the internal labour market: (even in the absence of internal promotion opportunities) workers stay at the current firm because of decreased outside employment opportunities, thereby decreasing opportunities for outsiders to enter the firm. A third extrinsic feature is the entry level. Distinguishing jobs to their hierarchical function level a clear difference can be observed between the level of entrance and the average level for all workers.

With respect to the intrinsic features all firms claim to give priority to internal vacancy fil- 
ling and most of them have some formal procedures for internal mobility. A tendency to an increased use of systematic planning systems is found. From the nine firms which offered information on their inhouse education seven reported to have formalized educational provisions. From the finding that the remaining two firms had higher tumover rates, the authors conclude (rather premature) that training and internallabour markets (with low turnover) are closely related. Although no general conclusions on the size of the internal labour markets in the Netherlands can be drawn from this research because of its biased data set, the conclusions correspond well with our expectations. Tenure, turnover and installment of more or less formal personnel planning systems provide strong signs for the appearance of internal labour markets in large firms.

Van Ours and Zoethout (1990) investigate the existence of the internal labour market for civil servants. They examine the existence of an internal labour market for 5 of the 45 departments of the city Amsterdam, which includes 5734 employees of the 26000 employed in 1985. Three criteria are used to show the existence of an internal labour market. First, turnover appears to be low according to the criteria of Alexander (see Section 5.3) and the even narrower turnover criterium of Bergeijk and De Grip (1986). A second indication for internal labour markets is that the salary level at entry ports is below the average salary level for that department. Third, they examine career opportunities, which appear to be poor. These career opportunities are measured by the distribution of the workers over the salary groups and the opportunities for advancement to higher salary levels. Although these career opportunities in terms of wage increases for most employees are rather small, the authors suggest that the above-mentioned finding of low turnover might be explained by a relatively high wage compared to that of identical non-governmental jobs.

The second group discusses the size and characteristics of internal labour markets. In an explanatory analysis of the existence of a dual labour market in the Dutch economy, Valkenburg and Vissers (1979) perform a secondary analysis on data previously gathered by Zanders et al., (1977). The sample consists of 1748 workers, questioned in 1977 , who are employed in various industries, for at least 20 hours a week (so the sample is biased). Although one is repeatedly warned by the authors against hasty conclusions some results are worth mentioning. Instead of restricting attention to a single distinguishing criterium to split the labour market into a primary and a secondary part, Valkenburg and Vissers subdivide the sample according to several criteria, such as industries, firms or jobs, or combinations of these. This results in seven different ways to dichotomize the labour market, such as primary and secondary industries, primary and secondary firms, and primary and secondary jobs. For these segments they investigate characteristics such as income distribution, employment stability, internal promotions and union membership. In Chapter 2 we already pointed out why we are not interested in a detailed segmentation of the labour market. Moreover, according to our contract interpretation of the firm internal labour market a simultaneous appearance of internal labour market and external labour market positions within one firm or industry is allowed. Hence, of the results of Valkenburg and Vissers only some findings on the subdivision of the labour market according to jobs are discussed. Thus, in their study firm internal labour market jobs ${ }^{1}$ are defined as jobs with autonomous, responsible, varying work with stable employment conditions, high commitment to the firm and firm internal promotion opportunities (see Valkenburg and Vissers, 1979, Appendix VII). The remainder of the jobs are identified as

${ }^{1}$ Valkenburg and Vissers refer to these jobs as primary intemal jobs. 
extemal labour market jobs. This results in 614 internal labour market positions and 947 external positions, so $39 \%$ is on the internal labour market ${ }^{2}$ For these jobs the following conclusions with respect to the characteristics of firm internal labour markets are found.

First, income distribution on the internal labour market is skewed to high income groups. With respect to internal mobility workers on the intemall labour market had experienced firm internal job changes more often compared with those outside $(51 \%$ versus $30 \%)$ and of these internal. movers a higher percentage reached a higher job level (97\% versus $93 \%$ ). The percentage of workers reporting the need of an initiation period for their job was higher on the internal labour market ( $83 \%$ versus $68 \%$ ). Considering their definition of internal labour market jobs it is surprising that promotion opportunities hardly differ between the internal labour market and the external market (39\% versus $35 \%$ ). The tenure distribution is skewed towards longer tenure groups on the internal labour market: $71 \%$ of those employed on the internal labour market have a tenure exceeding 5 years, while this percentage outside the internal labour market is $46 \%$. Some further results show that on the internal labour market $17 \%$ is female, while this percentage is $22 \%$ on average. Further, in agriculture $32 \%$ is employed on the internal labour market, in the industry $38 \%$, in trade and services $38 \%$, and in the government sector $42 \%$. Of those employed in large firms, with 200 employees or more, $52 \%$ have intemal labour market jobs, those in small firns only $32 \%$. Finally, of those with low level jobs $25 \%$ is on the internal labour market, and for both intermediate and high level jobs this is $43 \%{ }^{3}$

Some evaluating remarks can be made. Although most of the results are in accordance with theoretical considerations, the finding that promotion opportunities hardly differ between the internal labour market and the external market is surprising, especially since the above-mentioned definition of the internal labour market itself is based on internal promotions. In previous chapters we have argued at length that an essential feature of the internal labour market is the existence of internal promotion opportunities. Furthermore, in this study attention is on primary versus secondary segments and not firm internal versus external segments or labour markets. These considerations as well as the use of many definitions for primary and secondary segments and the exploratory character of the analysis forbid clear conclusions. Nevertheless the authors observe some tendency for duality in the Dutch economy, which we consider as a signal for internall labour markets, although this duality is not a strict one.

In a study by Ten Have and Vissers (1987) into features of different labour market segments three types of labour relations are identified in the Dutch economy. A sample of 1465 employees from a survey of the Organisation for Strategic Labour Market Research is used. ${ }^{4}$ Referring to studies on employment relations from organization theory (Williamson, 1981; Mintzberg, 1979), employment relations are classified according to the autonomy of work and degree of job idiosyncracy. This results in a classification of employment relations including the spot market relation, the professional relation, and clan relations. This division resembles the division of Section 2.3 into firm internal labour markets (clan), accupational markets (professional relation) and the external market. Comparing the features of these types

${ }^{2}$ A difference exists between the size of this sample and the complete sample because not all questions are answered by all respondents.

${ }^{3}$ The job level, which initially ranges from 1 to 7 , is divided in low level jobs ( $\left.N=292\right)$ with simple tasks (level 1 and 2), medium level jobs $(N=685)$ with somewhat complicated tasks (level 3 and 4), and high level jobs $(\mathrm{N}=579)$ with complicated tasks (level 5, 6 and 7 ).

${ }^{4}$ This same survey will be used in Chapter 6 and 7 . 
leads to the following results. With respect to the size of the internal Jabour market, the exter* nall market covers $45 \%$ of the sample, the firm internal labour market $32 \%$ and the occupational market $23 \%$. Some further characteristics indicate that an initiation period exceeding 3 months appears in $77 \%$ of the firm internal market, for $70 \%$ of the accupational market and only $24 \%$ of the external market. Of those employed in large firms with at least 60 employees $40 \%$ is on an internal labour market, $19 \%$ on the occupational market and $41 \%$ on the external market. In small firms these percentages are $20 \%$ (intermal), $30 \%$ (occupational) and $50 \%$ (external). Of those employed on the internal market $30 \%$ has experienced vertical promotion, and only $3 \%$ of the occupational market and $4 \%$ of the external market. Although a relatively low percentage of workers on the internal market is satisfied with their wage (51\%), a large percentage is satisfied with their promotion opportunities $(60 \%)$. For the occupational market these percentages are $60 \%$ and $48 \%$. Workers on the external market are relatively satisfied with their wage $(59 \%)$ but not with the promotion opportunities $(31 \%)$. The results also show that workers on the internal labour market perceive that their current firm offers the best achievement opportunities (33\%) and $84 \%$ have not changed their job between 1980 and 1985. For those in the occupational market only $19 \%$ perceives the best achievement opportunities in the current firm and $68 \%$ has not changed a job between 1980 and 1985 . For the external market these percentages are $21 \%$ and $73 \%$.

Research into internal labour markets is also performed by those who try to relate internal labour market features and organizational configurations (Soeters and Schwan, 1990). In this respect the organization types designed by Williamson (1981) are related to the types distinguished by Mintzberg (1979). The four-fold classification based on the specificity of human capital and observability of labour services results in the spot market or simple structure (with nonspecific skills and easy observability), the obligational market or machine bureaucracy (specific and easy observable), the primitive team or professional bureaucracy (nonspecific and difficult to monitor), and the relational team or adhocracy (specificity and difficult to observe). The question is in which of these types internal labour market features appear. In this respect 11 internal labour market features are distinguished and measured. ${ }^{5}$ The data apply to six firms which were chosen as representative of the Mintzberg types of firm. For each firm a sample of the workers is questioned on these features. Next the dichotomized answers are added which results in a figure showing the "degree" of the internal labour market. It appeared that in the firm which represents a machine bureaucracy and in the adhocracy most internal labour market features are found, while in the professional bureaucracy this was lowest. Contrary to the expectation the simple structure showed a surprising high degree of internal labour market-ness, which is explained by the relative growth of this firm in the last years and the increased perception of promotion opportunities as a result of this.

Research like this is useful for gaining insight into the relationship between firm structures and internal labour markets. "This might be helpful for human resource management and personnel practices. However, because of the rather arbitrary choice of the firms under investigation, caution must be taken in generalizing the results. Further, the internal labour market is defined by a list of features. This leads to a "degree" of internal labour market-ness for the whole firm, which excludes the possibility that part of the firm is considered as an internal

5 These intemal labour market features are a high promotion rate, high number of vacancies, insiders in high positions, job rotation policy, high job liquidity, easy promotion, few candidates for promotion, growth job, long tenure, high number of previous promotions and low overall tumover (Soeters and Schwan, 1990, pp. 279-280). 
لabour market, while another part is not.

The last group distinguished in this section discusses the dynamics and development of internal labour markets. The most elaborate investigation into internal labour markets in the Netherlands is performed by Warmerdam and Van den Berg (1986) for the Ministry of Social Affairs and Ernployment. The influence of technological and organizational changes on the internal labour market is described, based on the data of 17 organizations and two labour pools. An intemal labour market is defined by the arrangement conceming the agreements on the absorption of the employment consequences for employees of technological and/or organizational developments (Warmerdam and Van den Berg, 1986, p. 5). The data cover the "recession" period 1980-1985 and consist of a secondary analysis of case study material gathered in 1981-1982, analysis of annual social reports of 1981-1985, previous research and interviews with central figures. The descriptive report with mainly qualitative results shows that during this period, within which all firms experienced organizational and technological changes, the consequences for the personnel policy are a decrease in external hiring, and increased attention to internal mobility. Firms avoid involuntary dismissal and concentrate on internall allocation. Functional as well as numeric flexibility is increased. ${ }^{6}$ Career perspectives decrease and spontaneous internal mobility is replaced by an active allocation policy, and in almost all firms more rules and procedures are introduced.

In this study three kinds of internal labour markets are distinguished: a liberalized market with only a few rules and weak structuring, an oriented market with restricted ruling, and a regulated market with strong structuring and rules. Some succesion of these types of internal labour markets in time is carefully signalled, but, as long as the internal labour market is not integrated in the personnel and human resource approach of the firm, developments in both directions are open. Although this study provides an elaborate description of the internal labour market of Dutch organizations, the theoretical depth is limited and quantitative results are lacking altogether. Furthermore, governmental organizations are absent and because of the restriction to the period 1980-1985 only an idea of an internal labour market in a declining economy is provided.

A case study research which explicitly focuses on internal labour markets is presented by Scholten (1984). Being interested in the way the social policy concerning internal mobility is organized as a reaction to a recession, the introduction of internal labour bureaus in five organizations is examined. While in a situation of a tight labour market the internal labour market is used to decrease tumover, in a period of recession organizations will be inclined to strengthen the internal labour market to increase internal mobility. The internal labour bureaus in all five organizations (a publisher, a financial organization, a bank, a government organization and a machinery firm) differ with respect to the level of the intemal labour bureau in the organization (concern or sector level), the competence of the internal bureau and its degree of formalization. Three types of internal labour bureaus are distinguished: the marginal type (type 1), the policy-influencing type (type 2) and the policy-integrated or bureaucratic type (type 3 ). The first has restricted formalization and power but is flexible, while the last is the opposite with inflexibility and "overstructuring". Although all five organizations claim that the installment of the internal labour bureau is a temporary measure to reallocate

Gunctional flexibility is adjustment by intemal pooling, job roulation and integrated functions, while numeric llexibility addresses varying working time, hiring workers from employment agencies, temporary workers, and free-lance workers. 
workers internally, Scholten points to economic reasons, as well as forces from labour relation institutions, for the internal labour bureau to endure. A tendency of a development from type 1 internal bureaus in the direction of type 2 or type 3 , is also observed, although this process is not irreversible. Firms seem to look for a balance between flexibility and structuring. Although this study is one of the few investigations into the institutions at work on an internal labour market, its character is exploring and generalizations are not possible.

The position of women on internal labour markets in large banks in the Dutch economy is investigated by Tijdens (1986a, 1986b). The data are gathered by interviewing 59 employees of one of these banks and written material conceming the other banks. In discussing the organization of the banking sector Tijdens points to a policy of cost control during the eighties. Since that time turnover decreased (mainly because of a decrease of voluntary leave of employees), external hiring decreased and the average age of the employees as well as the average tenure increased. As a result there was a stagnation of internal mobility. All banks show an increased interest in the internal labour market, which can be explained by the increased attention for cost control and for an efficient use of the labour force. An increase of rules and procedures, such as function evaluation systems, is found as well. The research of Tijdens is explicitly directed to the position of women on the internal labour market. This position has not improved in the eigthies: women appear in lower income groups and are overrepresented in part-time jobs. The overall conclusion is that women are working in the secondary part of the labour market with low chances of entering the primary part. The distinction between primary and secondary segments is derived from the above-mentioned criteria of Valkenburg and Vissers (1979). The primary segment consists of jobs with high responsibility, variety and autonomy, while jobs in the secondary segment do not possess these features. In fact Tijdens identifies the lower income groups with the secondary labour market. Unfortunately, the two other features adhered to the primary part by Valkenburg and Vissers, namely stability of the jobs and internal promotion opportunities, are not taken into account. The former because almost every workers has a stable job, the latter because no data were available. This again makes a comparison with our definition of the internal labour market difficult. Furthermore, Tijdens points to an increased use of these banks of the internal labour market or career planning in the secondary segment, which further obscures the definitions. It is unclear whether jobs in the secondary segment with good promotion opportunities are considered as part of the internal labour market, and whether jobs with good promo* tion opportunities are secondary jobs, characterized by employment instability.

Ignoring differences in definitions and methods used in these studies, some general preliminary conclusions can be drawn. The size of the internal labour market ranges from $32 \%$ (Ten Have and Vissers) to $39 \%$ (Valkenburg and Vissers), and intemal labour markets exist for civil servants (Van Ours and Zoethout), less for women (Tijdens), and in organizations described as machine bureaucracies and adhocracies (Soeters and Schwan). Further the results show that intemal labour markets have more prior internal promotion, longer tenure, employ more men, and more high-level jobs (Valkenburg and Vissers), and have longer initiation periods and greater firm size (Valkenburg and Vissers, Ten Have and Vissers).

These general conclusions must be considered as (very) preliminary for three reasons. First, a clear definition of the intemal labour market is not available, so comparison of prior results is difficult. Second, a broad investigation into the size, existence, features and wages of internal labour markets is still lacking. In this respect some research only sideways mention the internal labour market (Valkenburg and Vissers, Ten Hawe), while others are directed to one

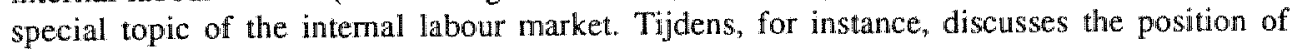


women on internal labour markets, Scholten discusses the organization of internal mobility, Warmerdam and Van den Bierg discuss the influence of technological and organizational change and Van Ours and Zoethout discuss the internal labour market for civil servants. Third, no general conclusions can be drawn since data are either based on case studies (Tijdens, Bergeijk and De Grip) and are often descriptive (Scholten, Warmerdam and Van den Berg). As we argue more extensively below, improvements can be made on these points: first, a proper definition of the internal labour market which allows empirical research must be chosen. Second, a more general research which examines the existence, size and features of internal labour markets in the Dutch economy, based on such a definition, is needed. It is on these points that we try to improve on previous research on the Dutch labour market in Chapter 6 and Chapter 7 . However, before turning to an attempt to quantify some aspect of the internal labour market in the Dutch economy we discuss results found in empirical studies for other countries concerning the hypotheses.

\subsection{Concepts of the internal labour market}

From the review of Dutch research it is clear that the methods of investigating internal labour markets and definitions used in empirical research differ widely. The same picture emerges for foreign research. Whereas in Section 2.4 theoretical approaches are summarized, in this section empirical measures will be reviewed, although not exhaustively. One might expect some agreement between various measures but this hope turns out to be illusory. Partly due to the different methodological approaches (such as case studies, interviews or the use of cross-sectional surveys), and partly to different research questions (into mobility or earnings), the list of features is long, although sometimes overlapping. In Table 5.1 concepts and methods of some of these investigations are summarized. A further discussion of the results of these investigations is found in later sections.

In one of the first empirical investigations into the internal labour markets (Alexander, 1974) labour mobility between firms and between industries is used as a criterium for an. internall labour market. Referring to the analysis of Kerr it is stated that the "central assumption behind our classification scheme is that structure is related to mobility" (Alexander, 1974, p. 66). More specific, the internal labour market is defined by a firm mobility below $10 \%$. In this respect firm mobility is defined as "the proportion of workers in an industry who left their firms between the first quarter of 1965 and the first quarter of 1966" (Alexander, 1974, p. 67). Thus the only feature used by Alexander to define the internal labour market is firm mobility, or turnover. As argued above, this ignores the importance of internal promotions or promotion opportunities inside the firm.

Different concepts are used by Mace (1979), Pfeffer and Cohen (1984) and Bergeijk and De Grip (1986). Instead of a single statistic they define the internal labour market by a list of features. In this respect Mace states that "I.L.M.s have three important characteristics that distinguish them from "open" "or competitiwe markets. First, the openness to the external labour market will be reduced; in other words, the ports of entry to, and exits from the firms,

\footnotetext{
${ }^{7}$ The small sample of 8900 individuals used was drawn from a larger sample of 16000 individuals. Only full time white males aged 20 to 60 are in the (small) sample, excluding "workers in agriculture, cily, state and local govemment, and ... industries with less than fourty observations" (Alexander, 1974, p. 67).
} 
will change. Secondly, the mobility patterns between firms and within firms will be transformed. Thirdly the rules that determine internal mobility and manpower adjustment will change.. "These changes will all work to the benefit of the incumbant workforce" (Mace, 1979, p. 51). As mentioned in Section 2.4 Mace argues that a single statististic cannot establish the existence of an internal labour market. Therefore in his empirical research based on interviews in British firms no less than seven features of the intemal labour market are distinguished. These are low turnover, entry ports (measured by present job level and age and age and job level at entry), promotion ladiders (internal promotion policy and changes in responsibility level), job clusters (explicit use of horizontal and vertical mobility), the use of in-house training, salaries (the use of job evaluation schemes and the permanence of salary differences "between firms employing similar types of labor", Mace, 1979, p. 54), and adjustment mechanisms to changing economic conditions (the use of constrained versus less constrained mechanisms 8 ).

Pfeffer and Cohen (1984) also examine more than one feature. In their study the internal labour market is not a dichotomous variable, but ranges from zero to seven. An establishment scored a 1 on the following items if it:" (1) followed an established promotion-from-within policy, (2) had promoted most employees with at least five years of service at least once, (3) filled all or almost all jobs from within, (4) offered entry-level jobs with at least some promotion potential and requiring no prior work experience and no more than high school graduation, (5) offered entry-level jobs with some promotion potential and requiring no prior work experience except such educational qualifications as graduation from junior college or a college degree, (6) frequently promoted unskilled laborers to semi-killed jobs (in manufacturing establishments only), and (7) frequently promoted semiskilled laborers to skilled jobs (for manufacturing firms only)." (Pfeffer and Cohen, 1984, p. 559). For convenience we summarized in Table 5.1 these seven aspects of the internal labour market by three measures: entry ports, internal promotions, and explicit internal vacancy filling as a policy (by a vacancy bureau). Their method is rather eclectic, since they borrow arguments from several theories to formulate their hypotheses (such as human capital theory, transaction cost econonics, the radical approach and organization theory). The idea of a scaled internal labour market variable is attractive and is used in other research as well (see for instance, Soeters and Schwan, 1990).

While Alexander defined the internal labour market by a single feature and others (Mace, Pfeffer and Cohen) used a list of features, there are also studies which restrict the number of features to two. Two of such studies will be mentioned since the method used in these studies resembles the method of Chapter 6 and 7 . The two studies, which are performed in Germany, concern investigations in the tradition of segmentation theories. Blossfeld and Mayer (1988) are interested in the mobility of workers between different segments of the labour market. Between 1981 and 19832171 German workers of three birth cohorts ${ }^{9}$ are asked to reconstruct their entire employment history, especially with respect to job changes. This results in a sample of 5309 job changes which allows longitudinal research into job changes between seg-

${ }^{8}$ This distinction between constrained and less constrained mechanisms, which is also found in Doeringer and Piore (1971), refers to instruments as "suggested in competilive theory, such as altering the wage structure, job structure, or allocative procedures" (Mace, 1979, p. 54), whille examples of less constrained instruments are "subcontracting, allowing vacancy lewels to rise (particularly at lower levels), increasing overtime, widening recruitment and screening procedures (..), curtailing production, and retraining"' (Mace, 1979, p. 54).

9 Those bom in $1929-1931,1939-1941$, or 1949-1951 were questioned. 
ments. The segmentation of the labour market is produced with two dichotomized criteria: firm size, which distinguishes internal markets (above 50 employees) from external markets (below 50 employees), and the quatification required on the job which distinguishes primary jobs (high qualifications) from secondary jobs (low qualification). ${ }^{10}$ Of the four resulting segments, "Jedermannsarbeitsmarkt" in small and in large firms, an occupational market, and a firm internal labour market, the last is closest to our firm internal dabour market definition. 11

Using a different data set, that of the Socio-Economic Panel which includes about 12000 individuals for each year between 1984 and 1988, Szydlik (1990) performs an analysis based on Blossfeld and Mayer (1988). This data set differs from that of Blossfeld and Mayer in that it is not restricted to three birth cohorts, that foreigners are included, civil servants and the self-employed are excluded, and the reconstruction period is at most a year. Again the labour market is divided in four segments, but the definition of the segments differs somewhat. First, the firm size criterium is 200 instead of 50 . Second, Szydlik does not consider job qualifica. vion but the skill lewel reported by the employee as criterium for primary or secondary jobs. It is argued that the qualification level, as measured by the required skills indicated by the worker, leads to a better dichotomization than the method of assigning occupations either to the primary or secondary sector (see footnote 10), as Blossfeld and Mayer (1988) do. How this different definition of Szydlik, as well as changes in the firm size criterium, influences the size of the internal labour market is discussed in the next section. But before we discuss the results of all investigations mentioned above some concluding remarks concerning the concepts and methods used can be made. In Table 5.1 a summary of internal labour market concepts is provided.

First, as already has been mentioned in Chapter 2 , a definition of the internal labour market partly depends on the question of research. Hence, definitions will differ with the topics investigated. However, it seems that even in investigations into similar questions, such as the size or existence of the internal labour market, empirical concepts differ significantly. Some use a single characteristic (for instance Alexander, 1974), while others investigate a list of features (for instance Mace, 1979). A second remark is closely related to the first and concerns the method used. Three methods are common: 1) case studies based on descriptive material and interviews, 2) cross-sectional dafa based on a survey among firms or individuals, and 3) panel data covering several years. Since only recently panel data are available on a somewhat larger scale most research is either based on case studies or on cross-sectional data. This restricts the number and kind of topics of investigation, since these are also limited by the type of data sets available.

However, the method applied also depends on the definition of the internal labour market. In this respect some simply believe that the internal labour market cannot be defined by a single variable and therefore cannot be measured by a single statistic. Creedy and Whitfield state that the internal labour market "is a complex phenomenon which cannot be reduced to a small number of measures" (Creedy and Whitfield, 1988, p. 262). It is also useful to quote Mace (see also Section 2.3) who believes "that a large sample, analysed by a battery of

10 The jobs are classitied into high or low qualification jobs according to the percentage of unschooled workers in a job in 1970 (Szydlik, 1990, p. 56).

11 Again conceptual differences between these definitions of primary and secondary segments occur (sse Section 2.3). Note, for instance. the confusing defunition of low qualification jobs in small firms as secondary internal jobs. 
sophisticated statistical tests would almost certainly have concealed rather than revealed the way in which labour markets actually operate. In any case, the researcher in labour economics usually cannot choose whether to use purposively or randomly collected data. In order to collect a random sample he would have to persuade large numbers of firms to open their personnel records and, without government sponsorship, this virtually impossible. For these two reasons then (the state of the theory and the practical problems invoived), a limited case study approach was adopted." (Mace, 1979, p. 51) In the same spirit he remarks that "the investigat tion of this concept may require the small sample, social survey techniques of sociologists rather than the large sample, statistical techniques currently favoured by most economists, if only because the necessary data cannot be raised in any other way." (Mace. 1979, p. 51).

Table 5.1

Summary of internal labour market concepts

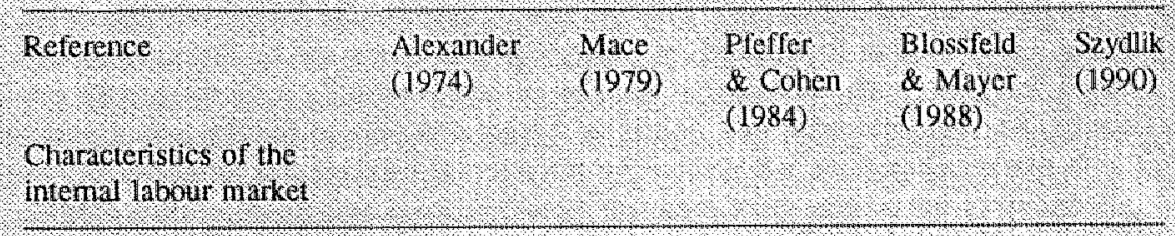

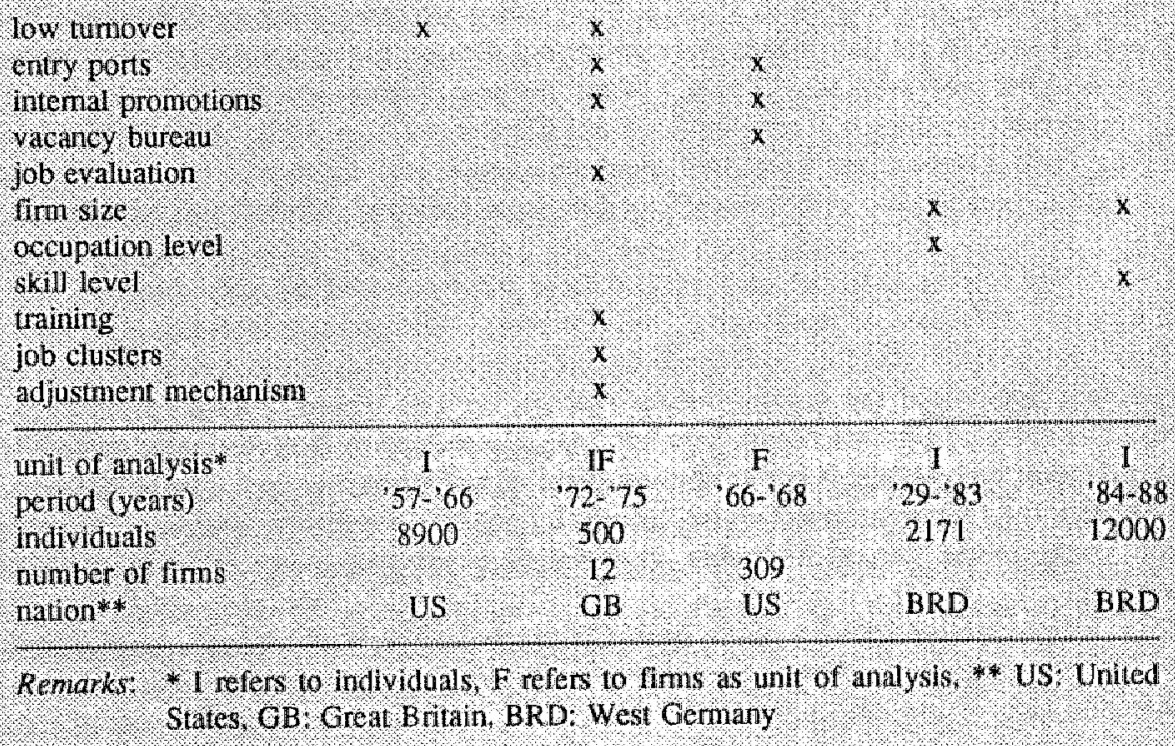

Although these arguments plead for the use of case studies, the drawbacks of the case study method for research into internal labour markets are summarized by George and Shorey (1985, pp. 427-428). Firstly, good quality data are difficult to find; secondly, interest of firms in gathering these data is limited; thirdly, since interviews form a great part of the data, perceptions of the person interviewed, as well as those of the researcher, interfere; fourthly, the number of hypotheses tested and firms to be approached is limited by the technique, and 
fifthly, generalization is dangerous (Brüderl 1990, p. 20). This calls for empinical research in which generalizations are allowed. Hence, cross-section (or longitudinal) data are needed.

With respect to cross-section data most authors argue that for research into firm intemal labour markets, data must be avallable on firm internal matters. This involves data on job hierarchies, intemal mobility, the personnel strategy of the firm, the criteria for hiring, selecting, screening and firing personnel, the eamings of the workers, their career chances, and their performance. Some of these variables are simply not available since many firms, especially small firms, do not keep extensive personnel records. Additionaly, as far as firms do have a personnel system, a management development system, or some other personnel planning and perfomance evaluation device, they are reserved in opening these files for scientific empirical research. Therefore the topics investigated are restricted by the avallability of material. Also for this reason, many studies involve case studies, with the advantage of providing details which are not available in cross-sectional data, but with the disadvantage that general conclusions cannot be drawn.

So far we have concluded that panel data are scarce, case studies do not allow general conclusions, and cross-section data based on surveys among firms are hardly available for research. Two ways are open. The first is to take an active attitude in gathering appropriate data. Creedy and Whitfield state that "(I)t is no longer appropriate for the labour economist to deal with market operations while ignoring the internal workings of employing organizations. ... Economists have been more reluctant to undertake data collection than other social scientists" (Creedy and Whitfield, 1988, p. 249). Some are quite clear on this point: "Economists would have to get their hands dirty collecting data on the actual operation of organisations. Unless the profession is willing to reward this type of time-consuming research activity, many important questions will remain unsolved" (Thaler, 1989, p. 190). Medoff and Abraham argue that "major steps .. can be taken through interaction with those who formulate company compensation policies and with those affected by these policies" (Medoff and Abraham, 1981, p. 215).

The second road is to use cross-section data of surveys based on individuals or workers. With a proper definition of the internal labour market such representative household surweys can improve the understanding of internal labour markets. Frequently workers are questioned on essential features of the internal labour market, such as tenure, internal promotion, and wages. Therefore in Chapter 6 and 7 the internal labour market is investigated, using crosssection data on individuals. It is our opinion that internal labour markets can be defined, and investigated, by a few features (two in our case). For now, we discuss previous research, although comparisons are difficult due to the conceptual and methodological differences mentioned.

This section is closed with a quote from George and Shorey which represents a common view: "In fact empirical evidence is still relatively rare for two reasons. First, research into the demand side of the labour market is notoriously difficult, requiring the sort of detailed information from individual fims which is not readily available, and which is complicated and expensive to collect. Second, there is no dominant, unified theory of the structured internal labour market. This means that there is a large number of different propositions to test, some of which are either too general to generate definitive tests or untestable with available techniques" (George and Shorey, 1985, p. 427). Commenting on both points it is our opinion that, provided a proper definition or framework is constructed, internal labour markets can well be examined with cross-section data based on household surveys, which include both demand-side and supply-side elements. 


\subsection{Characteristics of the internal labour market}

As can be expected from empirical research into a relatively new concept, such as the internal labour market, most effort is directed to establishing its existence and size. This is partly done by examining features which are usually adhered to internal labour markets (Mace, 1979; Bergeijk and De Grip, 1986). In other research the internal labour matket is defined in advance and the features of internal labour markets are compared to those outside (Blossfeld and Mayer, 1988; Szydlik, 1990). Though we prefer the second road, since it requires a theoretically sound a priori definition, results of studies from both methods will be reviewed below. A separate examination of all the results from previous research on each internal labour market feature would be ideal. However, given the many differences in definitions, concepts, samples and methods, in this section the papers are discussed one at a time, and some general conclusions are presented at the end.

An example of the first approach can be found in Mace (1979). Investigating the existence of internal labour markets among engineers in Britain, case studies based on interviews with personnel managers are used. The data are from a labour market project covering the period between 1972 and 1975 and the resulting sample consists of 500 engineers of 12 British firms. Mace argues that no single statistic is capable of determining the internal labour market, so the analysis involves seven criteria which characterize the internal labour market (see Section 5.3). Several remarks concerning the method are made. First, since only large firms are involved the sample is biased ${ }^{12}$; second, in order to make proper comparisons the investigation is restricted to a homogeneous group of workers (i.e. engineers) in different firms; and third, whereas Doeringer and Piore investigated blue-collar workers, engineers are professional workers. In this sense the investigation by Mace elaborates on previous research. The overall conclusion is that the evidence for the presence of internal labour market structures is "overwhelming" (Mace, 1979, p. 61). On allmost all seven criteria strong indications for the existence of internal labour markets are found. Generalizing the results of the sample of engineers Mace states that "there are good a priori reasons to believe that such structures will exist among other workers too" (Mace, 1979, p. 59), since the origins of the internal labour market (specific training and customary practice) are not restricted to professional engineers and not even to engineers. However, the case study approach prohibits quantitative statements on the size of the internal labour market in Britain.

A more detailed summary of the results shows that turnover was below the $10 \%$ turnover criterium of Alexander (see Section 5.5), and "for nine firms 50 per cent or more of their engineers thad been with the firm all their working lives" (Mace, 1979, p. 55), while there uppears to be no bias toward young workers since the average age was nearly 40 years. The existence of entry ports is indicated by the results that the age at entrance, as well as the job level, is considerably below the present age, and that the same applies to the job levels. The existence of promotion patterns is measured by the correlation between the level of responsibility and the years of experience, and by the stated policy of priority to internal. promotion. Both measures show internal labour market structures in all twelve firms. Horizontall and vertical mobility appeared in response to worker and employer preferences, and career development policies are apparent, which indicates that job clusters exist. The finding that all firms had induction programmes of 18 to 24 months, and that "training and experience together ac-

12 The same problem appears in many other investigations, for instance Bergeijk and De Grip (1986) and Pfeffer and Cohen (1984). 
counted for over 50 percent of the knowledge used", established the presence of internal labour markets on this point concerning training. Explicit fitting of the salary hierarchy to the job grading, without possibilities to pay more than some range, is one signal for internal labour markets concerning salaries. The second criterium conceming salaries is the finding of different salaries between firms, for the rather homogeneous group of university graduates. Finally, with respect to the adjustment mechamisms, the firms state that they apply less restricted instruments to react on labour market changes, before more direct instruments are used (see footnote 8 ).

An explicit investigation into the variables which determine whether a firm has an internal labour market is performed by Pfeffer and Cohen (1984). The data are from interviews with officials of 309 firms $^{13}$ with at least 100 employees in the San Francisco Bay Area during 1966-1968. Pfeffer and Cohen develop a firm internal labour market measure to assess the degree of internal labour market-ness of a firm. This measure is based on seven zerome variables indicating the use of internal promotion and the appearance of ports of entry (see Section 5.3). In a rather eclectic approach they derive arguments from a broad scope of theories from human capital theory to the radical approach to formulate ten hypotheses on variables influencing the internal labour marketmess. On the one hand, these consist of so-called economic factors, which are assumed to stress efficiency, such as skill specificity, technological change and being in the core (not periphery) sector. On the other hand, they distinguish organizational factors based on institutionalization of employment practices rather than efficiency. These factors consist of being a governmental organization, having a personnel department, the degree of unionization, the appearance of labour scarcity, firm size, being a branch (instead of a unit site or headquarters), and being a growing or declining firm. Next they perform OLS regressions with internal labour market-ness as dependent variable.

The results show that for the whole sample economic factors appeared to have a significant influence: on-the-job training, technological change and being in a core sector. Of the other variables, being a branch firm and having a personnel department had a positive significant influence, while the unionization has a negative influence. ${ }^{14}$ "The other variables were not significant, except for firm size of which the significance disappears with the introduction of the personnel department variable. Although this suggests "that large organizations are more likely to follow intemal labour market arrangements because they are more likely to provide training and to have a personnel department rather than because of the effects of size" (Pfeffer and Cohen, 1984, p. 565), caution must be taken because the sample is restricted to large firms. The negative relationship between unionization and internal labour market gives rise to the argument that creating an internal labour market can keep the union out of the firm. The main conclusion of Pfeffer and Cohen is that "the fact that other variables such as size, type of establishment, and unionization were significant indicates that the organization of the employment relationship cannot be understood solely as a response to the technical requirements of work and the need to organize employment to minimize transtaction costs" (Pfeffer and Cohen, 1984, p. 569). This suggesis a clear difference between economic and organizational factors. This must be relaxed, since organizational factors, such as a personnel department, can wery well be installed for efficiency reasons.

The existence of the internal labour market in professional or occupational markets is

13 Most calculations refer to 282 firms for which complete data were available.

14 Some further remarks on the relation between intemal labour markets and unions are found in Chapter 8. 
examined by Wholey (1985). He examines the deteminants of internal promotions versus lateral promotions (hiring of external candidates) in large law firms. For 80 large law firms (employing 10 or more employees) data are available for the period between 1980 and 1982 on (among others) the number of promotion and lateral entries, permanent associates, firm size and major clients. ${ }^{15}$ Generalized least square estimations are conducted with the number of internal promotion and lateral entries as dependent variable. The results show that firm growth, the number of major clients and the addition of major clients significantly increase internal promotion, while promotion in prior periods leads to a decrease of internal promotion. With respect to lateral entries it is found that addition of major clients and promotion in prior periods increases lateral entry. Contrary to a suggestion of Doeringer and Piore (1971) that in professional (or occupational) markets promotion is rare and lateral entry is comnon, Wholey concludes that firm internal labour markets also appear in professional occupations, such as lawyers in these law firms (Wholey, 1990, p. 322).

In an investigation into the extent to which structured internal labour markets display the characteristics of the internal labour market, George and Shorey (1985) use data on internal promotion, wages and training, supplemented by interviewing management, and gathered from case studies on 18 engineering establishments in South Wales. The period covers 1975 to 1980 , with about 16000 manual workers employed in these firms in 1980. In their analysis structured internal labour markets are distinguished from unstructered (or competitive) internal labour markets (George and Shorey, 1985, p. 423). The former corresponds to the primary sector, while the latter corresponds to the secondary sector. From a description of the job structure, the recruitment and internal promotion, training, turnover and absenteeism, pay structures, internal mobility and discrimination in these firms, they conclude that "certain characteristics of theoretical structured internal labour markets were present in our sample of firms: specific skills, internal promotion, continuous on-the-job training, low labour turnover and rigid pay structures" (George and Shorey, 1985, p. 437). Additionally, they learn from the interviews that management is well aware of the rigidities caused by using internal labour market mechanisms, such as stable wage structures, preference for internal allocation and the influence of unions in decision making. Newertheless, management argues that this may well be efficient both from cost-reducing and from effort-increasing arguments (George and Shorey, 1985 , p. 438). This corresponds remarkably well with arguments from efficiency wage theories. Furthermore it "certainly appeared to be the case that earnings were higher in our firms than elsewhere and there was clear evidence of a queue to enter (George and Shorey, 1985, p. 437). They conclude that structured internal labour markets are different from competitive internal labour markets "but, given the important human, social and technological constraints that in practice play such a big part in economic processes, they are reasonably efficient in allocating resources" (George and Shorey, 1985, p. 438). With respect to the quality of jobs they qualify that the emphasis on internal promotion opportunities and career advancement in internal labour market theories cannot be found in the firms under investigation. Opportunities for promotion, both within as well as between grades, were often restricted, merely due to a high number of applicants for higher level jobs and to a low tumover of those in higher level jobs.

Based on a large sample of about 80000 employees of the UK Labour Force Survey Dale (1987) concentrates on the position of women and part-time workers with respect to move-

15 Since only law firms which actively recruit at prestigious law schools are included in the sample, it will be biased toward large fims (Wholey, 1985, p. 325). 
ments within and betwen fims, and within and between occupations. The data refer to the periods 1978-1979 and 1980-1981, with 161 different occupations listed. Only full-time males, full-time women and part-time women are selected, without those self-employed. Workers selected are employed at both points in time (with a year in-between). The classification of the segments is based on the segmentation by Althauser and Kalleberg (1981, see also Chapter 2), which is confined to the occupational market, internal market and secondary market. Contrary to other research, with segmentation based on industries or firms (Blossfeld and Mayer, 1988; Szydlik, 1990), the classification is based on job mobility. On the firm internal labour market one observes a job or occupation change without a change of employer, on the occupational market one changes from employer without changing its occupation, and a change of occupation and employer implies a secondary market. During the periods 1978 1979 and $1979-1980,11 \%$ and $7.6 \%$ of the men, $12 \%$ and $8 \%$ of the full-time women and only $8 \%$ and $6 \%$ of part-time women respectively, experienced a change of job or employer. This is somewhat surprising since it suggests that the attachment of part-time workers is higher than thase with full-time enmployment. An analysis of the distribution of these (job or employer) changes for $1978-1979^{16}$ shows that for all groups about $40 \%$ of the changes occur on the occupational market. The major difference arises with respect to the firm internal market: $15 \%$ of the changes for full-timer workers (men and women) take place on the internal labour market, and only $9 \%$ for part-time women. The secondary market accounts for $45 \%$ of the full-time workers who move, while for part-time women this is $52 \%$. The major finding that women working part time hardly experience firm internal changes is interpreted as an indication of a low participation of women on internal labour markets.

An example of the second approach, as mentioned at the start of this section, is Szydlik (1990). Using a definition based on Blossfeld and Mayer (1988), workers of the sample are classified in four segments according to the size of the firm and the level of occupation. Contrary to Blossfeld and Mayer the firm size criterium is reached at 200 employees, and attention is on the required skill level mentioned by the employee (see previous section). Of course the size of the internal labour market differs according to the definition used. Szydlik reports that the internal labour market covers $24.5 \%$ of the labour market if the definition of Blossfeld and Mayer is used ${ }^{17}$ (high job level and firm size above 200 employees) and $32.8 \%$ if the skill level criterium is used. Furthermore, Szydlik points to the sensibility of the results for changes in the criteria: if the firm size criterium is lowered from 200 employees to 20 employees, the internal labour market covers $55.6 \%$ of the labour market. Further results are based on the internal labour market of $32.8 \%$.

Szydlik investigates the quality of jobs in the four labour market segments. One of the quality indicators is the wage level. These are reported in Section 5.5. The other findings are summarized as follows:

"Die günstigen Arbeitsbedingungen herrschen insgesamt im betriebintemen Segment. Körperlich schwere Arbeit, belastende Umwelleinflïsse, monotone Tatigkeiten und befristete Arbeitsver-

\footnotetext{
16 Although the percentages for the period 1979-1980 are somewhat different they show the same tendency.

17 Since the sample of Blossfeld and Mayer concems job changes instead of individuals, the size of the intemal labour market cannot be measured for their sample. Therefore Szydlik applies the definition to the Socio Economic Panel.
} 
träge treten hier am seltensten auf. Nirgend wo bestehen grobbere Möglichkeiten für eind selbstàndige Gestaltung des Arbeitsablaufs, für Mitentscheidungen bei der Entlohnung oder Befordenung anderer Mitarbeiter und für die Inanspruchnahme einer betrieblichen Alterswersorgung. Andererseits müssen aber auch die Beschaffigten im betriebsinternen Markt für ihren besonders hohen Verdienst bestimmte Nachteile in Kauf nehmen. Die psychische Belastung ist im koinem Segment so grob wie im betnebsintemen Teilarbeitsmarkt. Ärger und Konflikte mit Vorgesetzten treten im betriebsintemen Segment, wo es naturgemäb melur Führungskräfte gibu, am häufigsten auf." (Szydlik, 1990, pp. 95-96).

Some of these results are not surprising considering the choice of the definition of the firm internal labour market, since some of these features are related to low skill level jobs. It is, for instance, not possible to inwestigate whether the internall labour market employs higher educated employees. Tuming to some other differences between the segments it is found that of the older workers a larger number is employed on the internall labour market. The distribution of tenure on the intemal labour market is more skewed towards high tenure compared with the other segments: over $50 \%$ of those employed on the internal labour market has a tenure of at least 9 years (Szydlik, 1990, p. 104). The difference between full-time jobs and other jobs is also clear: $89 \%$ of those employed on the internal labour market has a fulltime job, while outside the internal labour markets this percentage is at most $81 \%$. With respect to gender the results indicate that on the internal labour market $77 \%$ is male, white in the other segments this is at most $60 \%$. Finally, $40 \%$ of the men is employed on the internal labour market, while for women this percentage is only $20 \%$.

Ignoring the differences in concepts and methods between these studies the results concerning the existence, features and size of the internal labour market can be summarized as follows. Although the original results of Doeringer and Piore concemed blue-collar workers, further research shows that internal labour markets, measured by various features, are also important for engineers (Mace, 1979), engineering firms (George and Shorey, 1985), and professional environments, such as law firms (Wholey, 1985). Furthermore, appearance of internal labour markets is positively related to on-the-job training, technological change, being a core sector, branch units, personnel departments, firm size, and negatively to unionization (Pfeffer and Cohen, 1984). On the internal labour market men are more frequently employed (Szydlik, 1990), as well as full-time workers (Szydlik, 1990; Dale, 1987), older workers and those with long tenure (Szydlik, 1990). The size of the internal labour market is seldom estimated. A major reason is that most investigations are based on case studies (Mace, 1979; George and Shorey, 1985). A second reason is that most samples are biased toward large firms (Mace, 1979; Pfeffer and Cohen, 1984; Wholey, 1985). The size of the internal labour market is, however, estimated for Germany. Depending on different definitions the size ranges from $24.5 \%$ to $55.6 \%$ (Szydlik, 1990 ), while $32.8 \%$ is considered as a reasonable estimate. With this conclusion attention is turned to the relationship between internal labour markets and wages.

\section{5}

\section{Internal labour markets and wages}

Above only casual remarks are made on the relationship between internal labour markets and wages. In George and Shorey (1985) and Mace (1979) it was found that wage structures on internal labour markets are rather rigid, while Mace (1979) also found considerable 
differences in the age-earnings profiles of a rather homogenous group of universily graduates in engineering, employed in different firms. In this section we concentrate on some aspects of the relationship between wages and internal labour markets.

First, we turn to the wage level on the internal labour market. This concerns the question whether wages on firm internal labour markets are higher (for instance Alexander, 1974; Szydlik, 1990; Dickens and Lang, 1985). Next, some results are mentioned on wage structure and compensation systems, which support to some extent the feature of wage rigidity and deferred payment systems on intemal labour markets (for instance Mace, 1979; George and Shorey, 1985; Baker et al., 1988; Thaler 1989). Finally, some investigations are discussed, which concentrate on topics which might be relevant for the relationship between internal labour markets and wages. These studies examine the relationship between firm size or industry and wages, and the relationship between seniority, productivity and wages (for instance Medoff and Abraham 1980, 1981; Abraham and Farber, 1987).

Alexander (1974) investigates the "relationship between the structure of internal labor markets and the mobility, experience, and income of workers" (Alexander, 1974, p. 63). The sample is derived from a larger file of about one million individuals based on members of the US Social Security System and consists of 8900 white males in 79 four-digit SIC industries with the variables age, income, mobility, and (firm and industry) experience in the period 1957 $1966{ }^{18}$ Induscries are classified according to the (three-way) distinction of Kerr, into manorial (or firm internal), craft (or occupational) and unstructured markets by average firm and industry mobility. ${ }^{19}$ Thus, the internal labour market is defined by the industries with firm mobility below $10 \%$, craft industries have firm mobility minus industry mobility above $10 \%$, while unstructured have firm mobility above $20 \%$ and at the same time was no guild industry. Accordingly industries are classified as manorial, craft and unstructured.

A firm mobility equation is estimated for all individuals with age, income, experience, firm size and change of income (between 1964 and 1965) as explanatory variables. Next, by substituting the characteristics of individuals in one segment in the equation, the average firm mobility is estimated for every segment. The results of comparing this average estimated firm mobillity to average actual firm mobility show that working in the manorial industries decreases firm mobility from the estimated percentage of $13 \%$ to the actual percentage of $6 \%$, in the guild industries the firm mobility increases from the estimated percentage of $27 \%$ to the actual percentage of $34 \%$, and it leaves the firm mobility in the unstructured industries almost unchanged at $23 \%$. For an examination of the influence of experience on eamings, firm experience (or firm-specific training), indlustry experience (or industry-specific training), and age (or general experience) are distinguished. Unfortunately, information on occupational,

${ }^{18}$ In the study experience has a maximum of nine years because of the period 1957-1966 of the data. Only the data on 1965 and 1966 are intensively used in the rest of the research. The sample is restricted to male workers aged twenty to sixty, with an income above some minimum (in order to exclude part-ime workers, excluding those employed in "agriculture, city, state and local govemment, and four-digit S.l.C. industries with less than forty observations" (Alexander, 1974, pp. 66-67). Also "only the most manorial, the most guild-like, and the least structured industries were chosen" (Alexander, 1974, p. 67).

19 "Average firm mobility for an industry is defined as the proportion of workers in an industry who left their firms between the first quarter of 1965 and the first quarter of 1966 . Industry mobility is the proportion of an industry that left that industry." (Alexander, 1974, p. 67). 
ability and educational influences on earnings is not available. To correct for their joint influence separate wage equations are estimated for low, middle and high-income classes for all three segments ${ }^{20}$, which results in nine wage equations. A comparison of these equations shows that differences between income classes are significant, those within income classes are small. This suggests that stucture is not important. However, Alexander argues that "(D)espite the similarity in income-experience patterns across structures for individuals in the same income class, structure does manifest itself in other ways-chiefly through differences in labor force composition and in income distribution" (Alexander, 1974, p. 80). Alexander compares the influence of firm experience and age on firm mobility and earnings. This shows that for low income groups firm experience reduces firm mobility more and increases earnings more than age, compared to high income groups. Apparantly those in lower income classes must start at the bottom of a career ladder in a new firm and an additional year of firm experience has a large influence on earnings. On the other hand those in high income classes (which stands for higher education, occupation level or ability) "realize the benefit of their general experience even in the first year with a new employer" (Alexander, 1974, p. 79). This explains why firm experience is less important compared with age for higher income level groups. Structure has its influence since in the manorial industry high incomes are heavily weighted, while in the unstructured and guild industry the low incomes are prevalent. Furthermore, even after correcting for various employee characteristics, wages in the manorial industry appear higher. ${ }^{21}$

Alexander mentions that this tendency of internal labour markets to pay higher wages is corroborated in other research: Weiss argues that earnings in concentrated industries are higher (Weiss, 1966) and Masters argues that it is plant size which has that effect (Masters, 1969). Since large firms and concentrated industries are classified as manorial this corresponds to the Alexander findings. One final remark on this study is that workers are assumed be on the internal labour market if they are employed in an industry which is identified as manorial. This means that the internal labour market covers the whole industry while we opt for a different approach. Neverthless, the overall conclusion is that wages are higher in the manorial segment.

The wage level on the internal labour market is also discussed in Szydlik (1990). As discussed in Section 5.3 the labour market is divided into four segments, one of which is the internal labour market. A computation of average wages for every segment showed that gross average wages for workers on the internal labour market are higher (DM 3283, $\Rightarrow$ ) compared with those outside (at most DM 2221, $=$ ). Even after correction for differences in the percentage of full-time workers and for the level of education, wages on internal labour markets are higher. The result appears for net wages, too. Considering the differences among all four segments Szydlik concludes: "Besonders ausgeprägt sind die Verdienstdifferenzen zwischen dem betriebsinternen Segment und den anderen Teilarbeitsmärkten" (Szydlik, 1990, p. 77). This might justify our choice to segment the labour market in two parts: the firm internal labour

20 These income classes were determined by 1966 data (by deviations from the average estinated income), wile the estmations were performed will 1965 data. For a discussion of the advantage of this method the reader is referred to p. 76 of the article. Using OLS, and 2SLS shows no qualitative differences in the results.

21 The same method is applied: worker characteristics are introduced in a wage equation and the average estimated wage for every segment is compared with the actual average wage. That of the manorial segment is higher, that of the guild and unstructured segment is lower. 
market and the external labour market.

A study which elaborates on previous studies such as Osterman (1975) is performed by Dickens and Lang (1985). They present "a test of two of the most important claims of dual market theory - that there is a distinct low-wage (secondary) labor market in which there are no returns to schooling and workers do not receive on-the-job training, and that there are noneconomic barriers that prevent at least some secondary workers from obtaining better (primary) jobs" (Dickens and Lang, 1985, p. 792). Arguing that previous investigations have not been able to confirm or refute dual labour market theory ${ }^{22}$, they claim to provide strong tests for both the duality and the rationing of jobs in the primary segment. In fact they argue that the second claim, more than the first, constitutes the test of dual market theory, and this claim is hardly investigated. In their approach workers are not assigned a priori to the primary or secondary sector. It is tested whether one wage equation or two separate wage equations better fits the data. The sample of 2812 men is drawn from the 1980 wave of the Panel Study of Income Dynamics and excludes those who worked less than 1000 hours in the previous year and those employed in government. The findings show that "Two wage equations fit the data considerably better than one" (Dickens and Lang, 1985, p. 797). While the wage equation for the primary sector resembles the one equation for the complete sample, the hypothesils that the wage equation for the secondary sector is flat cannot be rejected. "Further, the secondary sector wage equation is almost everywhere below the primary sector" (Dickens and Lang, 1985, p. 797). In a further test they also find support for the queue hypothesis for the primary sector. Overall, their research points to the existence of a primary sector with high wages, which might correspond to the internal labour market, and a secondary sector with low wages, related to the external labour market.

A second group of results which might be of interest for the internal labour market addresses pay structures and compensation systems. Pay structures on internall labour markets are also inwestigated by the studies of George and Shorey (1985) and Mace (1979), discussed previously. All firms appeared to use rigid structures and management gave as a reason for low turnover that they "paid the best rates in the area" (George and Shorey, 1985, p. 432). Although most firms felt that wage differentials between skills might be too low, management did not dare to adjust these differentials being worried "that this would disturb the whole wage structure" (Ceorge and Shorey, 1985, p. 434). With respect to the payment of workers Mace (1979) finds that on internal Jabour markets job-evaluation schemes and job-grading schemes are used. Every job grade has a salary band. The hierarchy of salaries is coupled to the hierarchy of jobs in order to minimize the need for new evaluations and avoid influences on enployee morale caused by salary changes. Mace also finds salary differentials between firms employing rather homogeneous workers (university graduates in engineering). With respect to internal promotions every firm stated a preference for internal appointments over external ones.

Some interesting results for the internal labour market are found in a review article on the

22 They point to two main shortionings of previous investigations into dual llabour markets which we have mentioned before. First. "dividing the sample on the basis of occupation or industry has major drawbacks" (Dickens and Lang, 1985, p. 793) since there is a danger of selection bias. Second, "the assumption that all members of an occupation or industry are in the secondary sector may significantly reduce the power of the test" (Dickens and Lang. 1985, p. 793). In later chapters we hope to improve on both shortcomings. 
use of compensation structures (Baker et al., 1988). First the restricted use of direct pay-forperformance systems is mentioned (p. 595), as well as a preference of firms for promotion based incentive systems instead of bonus-based system (pp. 600-601). Further "up-or-out systems are almost never observed in large multilevel hieranchical organizations. These firms, large hierarchies accounting for a substantial portion of Corporate America, are characterized by strong promotion-based reward systems and little use of bonuses" (p. 605).

An interesting exploratory investigation into the existence of deferred payment systems as in the incentive model (see Section 4.4) is found in Hutchens (1986), who argues that in jobs with deferred payments older workers tend to be employed but not hired. These jobs are featured by longer temure, existence of pensions and mandatory retirement, and high wages. His results show that these features are positively related to industry-occupation pairs with a low percentage of newly hired older workers, whites, highly educated workers, and low initial age. This points to the existence of internal labour market positions for some groups of workers.

Further results which might be relevant to our question concern the relationship between wages on the one hand and industries and firm size on the other. Generally it is found that there is a separate firm size and industry effect on wages. Larger plants and firms seem to pay higher wages to otherwise identical workers (see for instance Mellow, 1982; Schmidt and Zimmermann, 1989; Gerlach and Schmidt, 1990). The same relationship is found for employment in some industries. Industry wage differentials appear to be stable over time, between countries and even for occupations (see for instance Schlichter, 1950; Pugel, 1980; Krueger and Summers, 1988; Thaler, 1989). Further results show that in general wages are positively related to size, profits and concentration, capital internsity and union density (Thaler ${ }^{\text {19899). }}$ The wage differentials cannot be explained by compensating differentials nor unobserved quality (Krueger and Summers, 1988), so other explanations are required. The finding that such wage differentials persist over occupations is especially puzzling. The only two explanations which might explain such wage differentials are the union threat model, which uses market power considerations, and sociological explanations, which focus on equity considerations (Thaler, 1989, p. 264). Katz further reports some results which point to lower turnover costs (due to absenteeism) and reduced shirking (as in our incentive model).

The findings that firm size as well as industry have a positive influence on wages do not conflict with our hypotheses if internal labour markets are apparent in large firms and in the industries which show positive wage influences. ${ }^{23}$ If one could correct for the influence of demand-side variables, such as firm size or industry, and a wage difference would still remain for identical workers employed on the internal labour market compared with those on the external labour market, this might point to the difference in contracts being offered. Some are employed on long term employment contracts with promotion opportunities (and higher wages), while others are not. Since no research whicl explicitly investigates this relltionship is known to us we perform such analysis in the next two chapters. There we investigate whether internal labour markets appear in large firms and in some industries. Further we ask whether a wage difference still exists between workers employed on the internal labour mar"ket and those outside, after correction for firm size and industry differences. One could hypothesize that wage differences for otherwise identical workers in identical firms points to the shortcoming of definitions as mentioned by Blossfeld and Mayer (1988) and Szydlik (1990).

${ }^{23}$ This of course cannot be investigated if internall labour markets are defined by firm size or industry, as others have done. 
The third group of studies examines the relationship between wages, seniority and productivity. Following human capital theory it is usually assumed that wages rising with seniority indicate that productivity also rises with seniority. Using data from personnel records of some large US companies ${ }^{4}$ in the manufacturing sector Medoff and Abraham $(1980,1981)$ investigate this relationship. Their research concerns a relativelly homogeneous group of white males in full-time managerial and professional jobs. They investigated whether higher relative sallary ranking corresponds to higher relative performance ranking given by their immediate supervisors ${ }^{25}$, by estimating wage equations. Introducing performance rating dummies in equations which already include human capital variables (education and experience) and grade-level dummies "reveals that, although higher rated performance is associated with significantly and substantially higher earnings, introduction of the rating dummies has virtually no effect on the relevant education and experience dummies." (Medoff and Abraham, 1980, p. 714). The finding that the education and experience influences do not move to zero indicates that there is no positive relationship between human capital and performance rating, although there is a positive relationship between performance rating and wage level. In the companies under investigation workers within grade levels with more experience receive higher wages, but their performance ranking does not correspondingly move upward. Similar results are found in Dalton and Thompson (1971) whose "findings imply that although engineers older than thirty five received relatively low performance ratings, they received relatively high earnings" (Medoff and Abraham, 1980, p. 730).

Medoff and Abraham (1980) offer some arguments for their findings. Decreasing productivity might be explained by motivational arguments which suggest that older workers tend to be less motivated and less interested in promotion. In an attempt to explain why wages still increase with seniority, arguments are offered which correspond to the incentive effects of our promotion contracts of Chapter 4 . The importance of this study is that it seems to suggest that payment schedules, such as the promotion contract (see Figure 4.2), do occur. Since their findings are based on only a few corporations, no general conclusion concerning the appearance of these payment schedules on the internal labour market can be given.

The findings of Abraham and Farber (1987) are also highly relevant for our hypotheses, although their research is not directed to the internal labour market. In prior research a significant positive relationship is found between seniority and wages, even after accounting for total experience. Usually, such a relationship is explained by development in firm-specific human capital or incentives. However, Abraham and Farber argue that the supposed influence of seniority on earnings is overstated because the models are not correctly specified. In their opinion the observed relationship between senionity and wages points to a positive relationship between the quality of the job match and wages. The argument is that better job matches will last longer. Assuming that better job matches lead to higher wages, a positive relationship will occur between seniority (since better matches last longer) and wages. This implies that the introduction of job-match quality into a wage equation, which already includes seniority, will reduce the importance of the seniority term. Such a test is performed by Abraham and Farber. "They measure job-match quality by completed job duration, which is estimated for every individual. This completed job tenure variable is introduced into the wage equation. Two

${ }^{24}$ In their 1980 article Medoff and Abratham discuss the filles of two companies with 4788 and 2841 employees. Their 1981 article addresess a third company with 8238 employees.

25 The assumption that higher perfomance ratings by supervisors correctly indicates higher productivity is justified by further examination (Medoff and Abraham, 1980, p. 725). 
findings occur: 1) the influence of seniority is reduced, and 2) "that workers in long jobs earn substantially more throughout their jobs than do workers in short jobs" (Abraham and Farber, 1980, p. 295).

Basically, these results support our argument that wages on the internal labour market are above those outside, since it is considered as a contract with long-term employment relations (see Chapter 4). The finding that the influence of seniority is diminished does not contradict hypothesis 4.3 that the seniority term on the internall labour market exceeds that outside it. On the other hand the finding that wages for longer lasting jobs are higher, even after correction for seniority terms, confirms hypotheses 4.1 and 4.2. In fact in Chapter 7 we perform a slightly different test directly applied to the internal labour market. There we distinguish between internal labour market positions (which have long completed duration) and those outside the intemal labour market and investigate whether wages are higher, even after correcting for seniority (and other variables).

Similar results, on the relative minor importance of seniority on wages, are reported elsewhere. In reviewing recent findings on seniority and wages Hutchens (1989, p. 60) mentions two other articles which find "that when controls are introduced for the unoberwed heterogeneity, the estimates of $B_{2}$ (tenure, $G W$ ) are not only close to zero but often statistically insignificant (see Abraham and Farber, 1987; Altonji and Shakotko, 1987; Marshall and Zarkin, 1987)". Although these results seem at odds with hypothesis 4.3 some remarks can be made. First, in these studies all workers are lumped together and no difference is made between internal and external labour markets. Note that hypothesis 4.3 states that wages rise more with tenure (or seniority) on the internal labour market compared with the external labour market. Hutchens points to the same aspect when he emphasizes that delayed payment schedules "only explain wage growth in specific types of jobs" (Hutchens, 1989, p. 60). So the results on the overall sample in these studies do not reject our hypothesis. Furthermore, Hutchens mentions some other studies which reach opposite conclusions (for instance Topel, 1987), and thus confirm the positive influence of tenure on wages ${ }^{26}$ (see also Brüderl, 1990, p. 115).

The results of this section on internal labour markets and wages are summarized as follows. In accordance with our hypothesis 4.2 , in general it is found that internall labour markets pay higher wages (Alexander, 1974; Szydlik, 1990). Whether this also applies to otherwise identical workers, as in hypothesis 4.1 , is not investigated in depth. Howewer, from the findings of Abraham and Farber (1987) we find that jobs that will lasi longer are better paid. Considering our definition of the internal labour market, which is partly based on long-term employment relations, this might justify hypothesis 4.1 . Although the influence of seniority on earnings is toned down in these studies, whether seniority is better rewarded on the internal labour market, as we hypothesize in hypothesis 4.3 , is not investigated. Another interesting finding is that large firms (for instance Masters, 1969; Mellow, 1982; Gerlach and Schmidt, 1990) pay higher wages for identical workers, as well as some industries (Krueger

26. Hutchens' review of the relation between seniority, wages and productiwity concludes with three questions which remain unanswered: 1) What types of jobs have the characteristics of delayed payment contracts? 2) What theory (or theories) provides the best explanation for the existence of and variation in delayed compensation?, and 3) How important are theories of delayed payment contracts for purposes of explaining the wage-seniority relationship and other economic phenomena? (Hutchens, 1989. pp. 61-62). We feel that our treatment of internal labour markets might be of some help in answering these questions. 
and Summers ${ }_{n}$ 1988; Dickens and Katz, 1987). However, no investigation is found in which wage differences between internal labour markets and other segments is investigated, taking firm size and industry into account. Such a research will be performed in Chapter 7. Finally, preliminary research into the relationship between tenure and productivity seems to indicate that older workers are paid higher wages although they are not more productive. This might correspond to our promotion contracts (see Figure 4.2). Unfortunately, we are unable to test this hypothesis with our own data. The other hypotheses will be examined in Chapter 7.

\subsection{Internal labour markets and job tenure}

Roughly following the sequence of the three research questions of Chapter 1 (Table 1.1) we discussed previous research on the characteristics of internal labour markets in Section 5.4. In Section 5.5 attention was turned to the relationship between internal labour markets and wages. Our third question, concerning the consequence of internall labour markets for labour mobility, is examined below by a review of previous research on the importance of long tenure in the labour market. As argued in Chapter 4 the firm internal labour market is considered as a contract with long-term employment and internal promotion opportunities. The finding of long tenure would (partly) justify our research into internal labour markets. First research directed at finding the extent of long tenure is addressed. It is, however, not the extent of actual tenure which indicates long-term employment, but the importance of so-called eventual tenure (De Grip, 1985, p. 333). In this respect actual tenure refers to the time the worker is already employed within the firm, while eventual tenure indicates how long employment relations within the same firm will last eventually. Since only actual tenure is known for jobs in progress, the eventual tenure, or the time a job will ultimately last, must be estimated. This can lead to results which deviate from actual tenure figures. Therefore we turn to investigation directed at finding the importance of long eventual tenure. Finally we turn to research into the mobility between firms or segments. It is hypothesized that internal labour markets increase intrafirm mobility which leads to long (eventual) tenure, and reduce interfirm mobility.

One of the first investigations concerned with actual long tenure is performed by the Organization for Economic Cooperation and Development (OECD, 1984). To obtain an impression of the importance of tenure, tenure distributions for several countries are summarized in Table 5.2. Japan is chosen because it is much discussed for its unique labour market, characterized by extremely high tenure rates and life-time employment. The United States, often depicted as an economy with a relatively high number of short-term jobs, is presented as a contrast. Some European countries are presented to compare the Japanese and the American labour market figures with those of Europe, and compare the Dutch figures with those of its neighbouring countries.

Although there are differences in the definitions and the methods of gathering the data ${ }^{27}$

${ }^{27}$ In Table 5.2 average tenure is calculated by taking the midpoint of each closed interval (and 27.5 for the open interval). The dats on Japan and the US had slightly different intervalls (0 to 4.5 years, 4.5 to 9.5 years, 9.5 to 19.5 years, and more than 19.5 years). Furthermore, data on the US refer to all employed persons and are collected by household surveys. Although the data of Japan are collected by household surveys as well they exclude agricultural employment. The European data are collected by the Statistical Office of the European Communities (Eurostat) from a sample of firms with at least 
which might influence the results, some remarks can be made. The distributions over different tenure categories for these five economies confirm the general ideas which describe the Japanese and the U.S. labour market. Japan and the U.S. are relatively opposite cases. Japan has the highest average tenure (11.7 years) and U.S. the lowest ( 7.2 years). Further, almost $50 \%$ of the Japanese tenure rates exceed 10 years, whille that number for the U.S. is onlly $27 \%$. In the U.S. $54 \%$ of the tenure rates are below 5 years, while Japan has $33 \%$ of the workers in jobs which currently last less than 5 years. The European countries are intermediate cases between the U.S. and the Japanese economy. The differences in tenure rates between these European countries are less pronounced. The French economy has relatively high tenure rates, and the Dutch and the West German economy are much alike.

Table 5.2 Tenure distribution and average tenure (in \%)

\begin{tabular}{|c|c|c|c|c|c|}
\hline $\begin{array}{l}\text { Tenure } \\
\text { (years) }\end{array}$ & $\begin{array}{l}\text { US } \\
1983\end{array}$ & $\begin{array}{l}\text { Japan } \\
1982\end{array}$ & $\begin{array}{l}\text { France } \\
1978\end{array}$ & $\begin{array}{l}\text { Germany } \\
1972\end{array}$ & $\begin{array}{l}\text { Netherlands } \\
1972\end{array}$ \\
\hline 0.5 & 54.2 & 332 & 37.5 & 49.0 & 497 \\
\hline 5.10 & 18,6 & 18.8 & 279 & 175 & 18.2 \\
\hline 1020 & 173 & 26.1 & 219 & 219 & 191 \\
\hline$>20$ & 999 & 219 & 132 & 11.6 & 130 \\
\hline Average & 12 & 11.7 & 8.8 & 8.5 & 82 \\
\hline
\end{tabular}

(Source. OECD, 1984 )

Our definition of the internal labour market is based on long-term employment with good promotion opportunities. The results above seem to indicate that for some countries long-term employment is unimportant. However, one should note that the tenure datid refer to actual tenure. What matters for the internal labour market definition is the importance of eventual tenure, or the time workers will ultimately be employed. It can very well be the case that average actual tenure on the labour market is low while a considerable part of the workers is employed in jobs which will last a long time. These jobs with long eventual tenure can be internal labour market positions if they have good promotion opportunities. So to have an idea of the content of the internal labour market we must look at eventual tenure distributions, instead of actual tenure distributions.

A method to estimate eventual tenure distribution is presented in Hall (1982) and used by a series of others afterwards (see for instance Akerlof and Main, 1981; Main, 1981, 1982a; Hashimoto and Raisian, 1985; Addison and Castro, 1987; Carter, 1988; Bellmann and

10 employees. They refer to all manual and non-manual workers in mining and quarrying, manufacturing, building, and civil engineering. The service sector is included for France, not for West Germany and the Netherlands. Finally, the data for European countries refer to employees, while those of Japan and the US include the self-employed (see OECD, 1984, Appendix C). 
Schasse, 1990). The method is based on the retention rate, which is the probability that workers of a given age and tenure will remain employed within the same firm for at least a given number of years (see Wolfs, 1990, 1991, or the references above). This retention rate can be found by relating workers of a given age-tenure group to the corresponding higher (or older) age-tenure group. If retention rates for all age-tenure groups are available the overall distribution of eventual tenure can be computed. This giwes an estimate of how long workers currently employed can be expected to remain employed at the same firm. In Table 5.3 actual and eventual distribution for the U.S. economy can be found in columns 1 and 2, and those for the Dutch economy in columns 3 and 4 (see Wolfs, 1990, 1991). If an eventual tenure of 15 years and more is -arbitrarily-defined as life-time employment the percentage workers in the U.S. economy which will eventually have a life-time job is $33 \%$. The percentage of those already in a life-time job is not even half as high, namely $15 \%$. Although Hall draws the conclusion from these figures that the U.S. economy does not differ much from the Japanese economy, Hashimoto and Raisian oppose this view (Hashimoto and Raisian, 1985). Although they admit that long-term employment also appears for a considerable number of workers in the U.S. economy, they show that Japanese labour relations are still longer than those of Anerica.

Table 5.3 Actual and eventual tenure distribution (in \%)

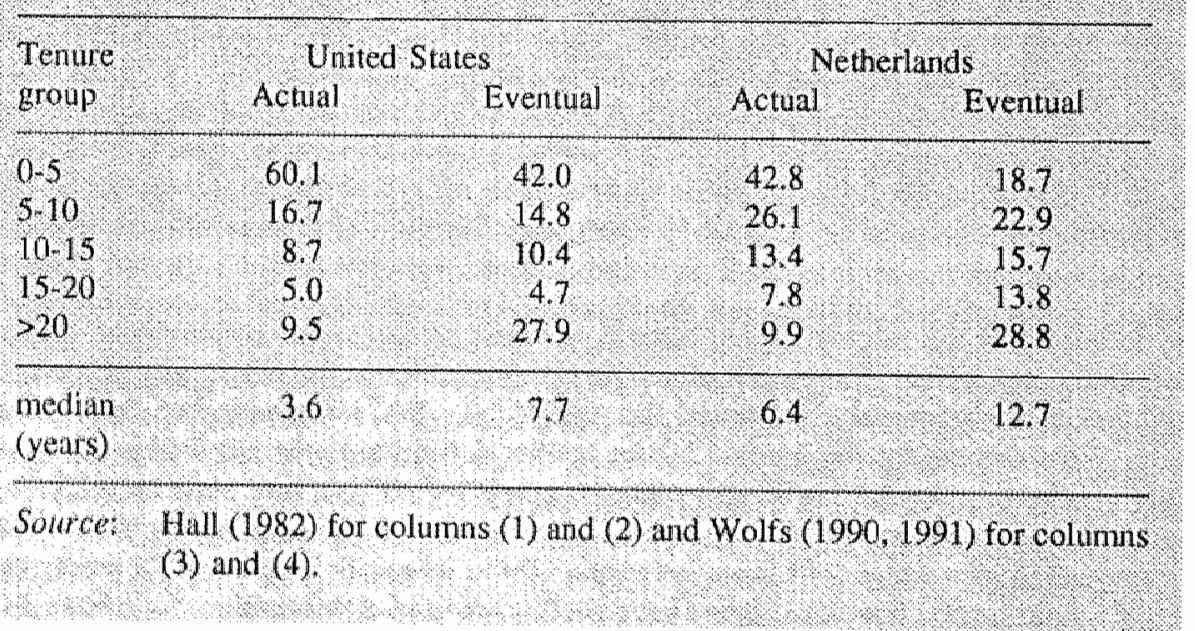

In columns 3 and 4 comparable results can be found for the Netherlands. The share of lifetime employment, again defined as a tenure of (at least) 15 years, is more than twice as high $(17.7 \%$ to $42.7 \%)$. While the actual percentage of life-time jobs was only slightly higher in the Dutch economy, compared to that of the U.S. (18\% versus $15 \%$ ), the percentage of life-time jobs to be expected is considerably higher in the Netherlands (43\% versus $33 \%$ ). In fact, the percentages for all jobs expected to last at least 5 years are higher for the Dutch economy. In the U.S. $42 \%$ of all jobs will reach an eventual tenure of less than 5 years, while that percentage is only half as high in the Netherlands. Another finding is that the median eventual tenure is twice the actual tenure, both for the U.S. and for the Dutch economy. Nevertheless 
the median value for the Dutch economy is almost twice that of the U.S.

Nevertheless, Hall's method has some severe drawbacks. First, there are extreme stationarity assumptions (see note 29). Second, as mentioned above the method gives a conservative estimate of eventual tenure. ${ }^{28}$ Third, the way of computing eventual tenure probably only gives a crude approximation of the Dutch eventual temure distribution, since only age and actual tenure make the workers differ from each other, while it seems reasonable to assume that other variables such as educarion, gender, job satisfaction, full-time or parttime work, and relative wage level also play an important role in determining whether a worker will remain on his job or leave the firm. Fourth, this method does not prowide a reliable estimation of individual eventual tenure. Nevertheless, in the next chapter we will determine whether a worker is on an internal labour market position or not, so individual eventual tenure estimates are needed. Recently an alternative method has become popular: the hazard function method, with which individual tenure rates cam be computed. In the next chapter results based on this method will be used.

Hence, the results on eventual tenure distribution are likely to underestimate the appearance of long-term jobs and the percentage of long-term jobs will be even higher, which strengthens our conclusion. Overall we can conclude that by taking account of eventual tenure, instead of actual tenure, the tenure distribution shows that a large part of the jobs currently in progress will last a long time. This justifies our research into the internal labour market with regard to long-term employment.

Some other results on tenure and long-term employment can be mentioned. One should note that the results mentioned above apply to workers already employed, not to the average job. In this respect, "it is quite possible for the average job to be short but for most people to hold jobs which will last a substantial length of time - a picture consistent with the "queue for jobs' view of the labour market. And a picture which is also consistent with the internal labour market arguments recently reintroduced to the literature by Doeringer and Piore (1971). If most employment falls in long jobs then there is ample scope for the development of internal career ladders and social customs which would be difficult to sustain if all jobs lasted only a short time" (Main, 1981, p. 156). Computing the results for Great Britain it is found that the average job spell in the period 1970-1976 was 3.5 years for men and 2.2 years for women, while those already employed in 1976 could be expected to remain employed ultimately 20 years for men and 12 years for women. "Such findings seem to provide some basis for the possibility of internal labour market systems" (Main, 1981, p. 163; see also Akerlof and Main, 1981, p. 1009). In an inwestigation on eventual tenure in Great Britain using data on 1968 Main finds for males in full-time employment in all industries and services the average eventual tenure is 20 years, and that $44 \%$ of the jobs will last 20 years or more. Again he states that "(T)he fact that 69 per cent, or over three-fifth, of employment in 1968 falls in jobs that were to last over ten years indicates the scope for development of internal labour markets" (Main, $1982 \mathrm{a}$, p. 330). ${ }^{29}$

28 In short, this is a restilt of the open eventual calegory of 20 years and more, and of the stationarity assumptions of the Hall method, "i.e. inflow, outflow and composition of the slock of labour relations remaining unchanged in time" (Kerckhoffs and Wolfs, 1991). For more details see Kerckhoffs and Wolfs $(1991,1992)$ and Wolfs $(1990,1991)$.

${ }^{29}$ Ouner studies into the length of employment relations focused on eventual tenure for union and nonunion workers (Addison and Castro, 1987), for the US labour market and Japan (Hashimoto and Raisian. 1985), for West Germany (Bellmann and Schasse, 1988), for men and women in West 
Research into the mobility between labour market segments is closely related to research into internal labour markets and mobility. Blossfeld and Mayer (1988) investigate the mobility between four segments defined by firm size and job qualifications (see Section 5.3). Workers on the internal labour market are employed in firms with at least 50 emplyees and are on high level jobs. Although their definition is disputable, some results will be summarized. First, they find that most workers $(83 \%)$ never leave the internal labour market segment once they entered. Of these $44.8 \%$ remains employed at the same job, $14.7 \%$ changes job but not employer, and only $23.7 \%$ changes employer within the internal labour market segment. Since usually higher figures for intrafirm mobility are presenetd, Blossfeld and Mayer conclude from these results that in most research intrafirm mobility apparently is overstated. Further, they investigate variables which influence changes from one segment into another. With respect to the internal labour market the probability of entering the intemal labour market increases with education level. This is hardly surprising since the internal labour market is defined by high-level jobs in their study. The probability of leaving the firm is lower for the higher educated. Finally, in discussing firm internal job changes on the internal labour market they find that education is not significant anymore. Other variables, such as the number of job changes (positively) and the number of employer changes (negatively), and being male, must account for this.

Mobility between labour market segments is also investigated by Szydlik (1990). It is expected that mobility between the internal labour market segment (for definitions see Section 5.3) and the other segments are relative scarce. Investigating the mobility between segments in the period 1984 to 1988 it appears that of those employed in the internall labour market segment in 1984, about $73 \%$ remains employed in that segment during the next four years. For the other segments this percentage is at most $62 \%$. Mobility between the four segments is rather restricted and is even lower than the percentage of workers which leave employment altogether. If attention is directed to the cases ${ }^{30}$ in which a worker changes employer in the period 1984-1988, it turns out that only $20 \%$ of all these (firm) changes are workers who were previously employed on the internal labour market. Almost $50 \%$ of these workers, which were initially employed on the internal labour market and experience a change of employer, find a new job on the internal labour market (Szydlik, 1990, p. 138). This indicates that interfirm mobility on the internal labour market is low. Analysing job changes within the firm, it turns out that $66 \%$ of this intra-firm mobility takes place on the internal labour market segment (Szydlik, 1990, 141).

To conclude, this section on the relationship between internal labour markets and the mobility of labour in prewious research has shown that there is considerable room for internal labour markets. Investigation into long-term employment has provided results which indicate that a large number of the workers, currently employed, will ultimately develop long term employment relations. As we argued, long-term employment is a main feature of the internal labour market. Hence these findings might support the importance of internal labour markets. Nevertheless, these investigations do not examine the existence of internal promotion, so clear conclusions on the internal labour market cannot be derived. Other results on the mobility of labour indicate that on segments, which are identified as firm internal labour markets, mobility between firms is lower and mobility within the firm is higher compared with other segments. This corresponds with hypothesis 4.4 .

Germany (Bellmann and Schasse, 1990) and for the early year 1892 (Carter, 1988).

${ }^{30}$ Every change is considered to be a separate case. 


\subsection{Conclusions}

In this chapter empirical investigations are reviewed on three questions. First, on the empirical definition of the internal labour market and accordingly on the size and characteristics of the internal labour market. Second, on the relationship between internal labour markets and wages. And third, on the relationship between internal labour markets and mobility. The major conclusion is that the hypotheses have not been tested directly. There is no study which investigates all three topics together (although that of Szydlik, 1990, comes near). Of course a major reason for this finding is that we apply a definition of the internal labour market which most previous studies do not share. In general, investigations explicitly directed to the internal labour market are scarce (Creedy and Whitfield, 1988, p. 249, p. 262; Van Ours and Zoethout, 1990, p. 3). Most investigations concentrate on closely related topics, such as labour market segmentation or focus on partial aspects, such as turnover, tenure or job level. The reason why the hypotheses cannot be tested with these partial approaches is that the results of different earlier investigations cannot be compared with each other. This is caused by differences in the definitions used and the methodology followed.

As already mentioned in Chapter 2 there are two reasons why elaborate research into internal labour markets is lacking. First, there is an assumed lack of appropriate data. This argument is brought to the fore by many researchers. However, in our opinion a second reason, which is closely related to the first, is more important. This concerns the lack of a proper definition of the internal labour market. By a proper definition we mean a definition which is theoretically sound and which can be empirically operationalized. Without such a definition the internal labour market is nothing more than a list of features. This impedes empirical research, especially if the features concern firm internal variables. The lack of data is often blamed for the lack of empirical research, and existing empirical research is usually restricted to case studies, interviews or descriptives methods which allow a multitude of features.

What is lacking altogether is an empirical inwestigation into the size of the internal labour market, based on a representative sample (which allows generall conclusions). Of interest is which workers appear on the internal labour market, which firm or job characterize the internal labour market, and the consequences for wages. As discussed in the previous chapter, the internal labour market can be interpreted as a multi-period contract between employer and employee. In this view the internal labour market is featured by long-term employment relations, supplemented by internal promotion opportunities. It is argued previously that internal labour market contracts arise in situations of monitoring problems and development of firmspecific skills. Finally, it is hypothesized that wages for workers employed under internall labour market contracts are higher, either because of improved morale and effort, or because of increased productivity due to firm-specific investment. It is this view that will be empirically tested for the Dutch economy in the following chapters. 


\section{CHAPTER}

6

\subsection{Introduction}

Since it is our goal to draw some general conclusions concerning the internal labour market in the Dutch economy, in this chapter we start with the operationalization of our internal. labour market contract. There are a few investigations which define the internal labour market by a restricted number of features. In the previous section we mentioned Alexander (1974), who defines the internal labour market by the turnower rate, Blossfeld and Mayer (1988), who use firm size and occupation level, and Szydlik (1990), who uses firm size and skill level. The drawback of these definitions is that all workers within a firm or an industry are assumed to be employed on the internal labour market. This does not correctly characterize the internal labour market since it may well be possible that within a firm or industry some workers are employed on an internal labour market, while others are employed outside the internal labour market. According to our discussion in Chapter 4, the former have contracts which guarantee long-term employment with good promotion opportunities, while the latter have other kind of contracts. Thus we opt for a definition of the internal labour market which makes it possible to discower for every worker whether he has an internal labour market contract or not.

Hence, the goal of the present chapter is to find for every individual whether lie has a long-term or short-term employment relation and whether he has good or bad promotion opportunities. Dichotomizing on both variables allows us to establish on an individual level whether a worker is employed on an intemal labour market. In this chapter both features of the internal labour market are operationalized, and subsequentlly used to assess the size of the internal labour market in the Dutch economy. In the next chapter our hypotheses are tested. The set up of the present chapter is as follows.

In Section 6.2 the relationship between our definition of the internal labour market ${ }$ the method of investigation, and the use of cross-section data based on individuals (or workers) is discussed. It is argued that the use of such data for our purposes is justified.

The data used in this study concern the Dutch labour market and are gathered and supplied by the Organization for Strategic Labour Market Research (OSA). A general description of these data is presented in Section 6.3. 
The ultimate goal of this chapter is to find for every individual whether he has a long-tern or short-term employment relation and whether he has good or bad promotion opportunities. So we dichotomize both features of the firm internal labour market. This allows us to distinguish between those employed on the internal labour market, having both long-term employment relations and good promotion opportunities, and those outside. Newertheless, variables on long term employment relations and promotion opportunities are not directly available in the survey. Thus tenure and promotion opportunities must be estimated in some way or proxied by other wariables. This will be done in Section 6.4 and Section 6.5 . With respect to the length of the employment relation it is argued that, instead of the actual tenure of a worker, his eventuall tenure is needed. Therefore in Section 6.4 we concentrate on the measurement of the length of the employment relation by estimating eventual tenure for every worker and distinguish between workers with long and short employment relations.

Next, in Section 65, we turn to the second feature of the internal labour market: the internal promotion opportunity. This variable is also not directly available from the survey. However, using answers to a set of questions concerning the advancement opportunities within the firm allows us to construct such a variable. Now workers can be divided into two groups, distinguishing those with good promotion opportunities from those with bad promotion opportunities.

By using both the division of workers into long and short eventual tenure, and into good and bad promotion opportunities, for every worker it can be determined whether he is on an internal labour market position. Following our definition, workers with long eventual tenure as well as good promotion opportunities are assumed to be on the firm intermal labour market. Accordingly, in Section 6.6, the size of the internal labour market in the Dutch economy is measured. In order to obtain an idea of the size of the internal labour market for some groups, this will be investigated for men and women, and for full-time and part-time workers.

Before we turn to the testing of the hypotheses 4.1 to 4.5 in Chapter 7 , Section 6.7 provides a conclusion.

\subsection{Operationalization of the internal labour market}

The differences in investigations concerning the internal labour market, as discussed in Section 5.3 , concern both the definition of the internall labour market and the methods of research. Both are strongly related since the definition of the internal labour market influences the method of research. In this respect many investigations use a list of features to define the internal labour market, which restricts the method of investigation to case studies (see Mace, 1979). General research into the internal labour market is scarce and most investigations concentrate on a specific aspect of it, examining for instance turnover or job tenure. The research questions as mentioned in Chapter 1 ask for general conclusions which require research based on a representative sample of the labour market. Cross"section data, which can be based on firms or on individuals (or workers), provide such samples." Some investigators argue that firm-based surveys are needed to investigate the internal labour market since they provide information on firm intemal variables (see Section 5.3). However, cross-section data based on workers can also do the job, depending of course on the question of research and provided a proper definition of the internal labour market is used.

\footnotetext{
${ }^{1}$ Van Ours (1990) distinguishes between Labour Force Surveys and Establishment Surveys.
} 
The difference between cross-section data based on individuals (or households) and firms is that they usually focus on different variables and are gathered on a different level. With respect to the latter difference, household data are usually on an individual level, while most fim data are at firm or department level. It is clear that it depends on the question of research which data set is to be preferred. If detailed information into career patterns or firm internal mobility between job clusters is needed, firm data covering subsequent years are preferred. These kind of data are systematically gathered by personnel departments using personnel information systems. As mentioned in Section 5.3 only a small number of firms possess such information systems, and an even smaller number is prepared to provide such data for empirical investigation to outsiders. This hinders broad empirical research into internal labour markets, and explains why most investigations are based on case studies or interviews with a restricted number of employees.

For the (general) research questions into the different features of those on the internal labour market and those outside, and the differences in wage level and wage profile, such detailed information is not necessary although interesting. Therefore, we argue, household data can be used as well, provided they allow us to determine on an individual level whether a worker is on an internal labour market or not. This is what will be done in the present chapter. Contrary to case studies, which necessarily focus on small parts of the labour market, this approach allows us to draw more general conclusions on the internal labour market.

Basically our investigation, based on survey data, is according to the following method. From a representative sample of the potential working population of the Dutch economy those employed are selected. This sample of workers is divided in two groups: those employed on the internal labour market and those who are not employed on the internal labour market. This means that we must establish for every worker whether he is, or will be, employed for a long time, and whether he has good promotion opportunities. Of course such variables are not directly available, and must be proxied. This will be done for the length of the employment relation in Section 6.4. For every worker we estimate whether he will remain employed at the same firm for a long time. If he will, he is considered to have a long-term employment relation. The same is done for promotion opportunities in Section 6.5. Using a set of questions on firm internal advancement opportunities, it is estimated for every worker whether he has good (or above average) or bad (below average) promotion opportunities. Combining boti dichotomized measures it can be determined which worker is on the intemal labour market and which is not. With this information the size of the internal labour market is easily found in Section 6.6.

In Chapter 7 we turn to the hypotheses of Chapter 4 . In order to test hypothesis 4.6 we investigate the differences between the features of the workers and jobs which are part of the internal labour market, and those which are not. For a test of hypotheses 4.1 and 4.2 we investigate whether wages on the internal labour market are above those outside the internal labour market. As argued in Chapter 4 a wage difference can be a result of the differences between workers and jobs. Therefore corrections are made for these differences by estimating two different wage equations, and it is investigated whether a wage difference remains between those employed on the internal labour market and those outside. Some variables which might point to wage rigidity are discussed (for hypothesis 4.3), and further the slope of earnings profile is examined (hypothesis 4.4). Finally, whether employees on the internal labour market experience more labour immobility than those outside is examined for hypothesis 4.5 . 


\subsection{Description of the data}

Our empirical research is based on survey data on the Netherlands gathered by the OSA. This organization has conducted household surveys in 1985, 1986, 1988 and 1990. In our research mainly data of the first wave of 1985 (gathered in April 1985) are used. The reason for this restriction is that at the time the study was started only the 1985 data were available. ${ }^{2}$ Only for the estimation of eventual tenure some additional information of the second wave of 1986 (gathered in October) was necessary (see Section 6.4). In these surveys individuals older than 16 years, who are not in full-time education nor in military service are questioned. The respondents were selected from delivery points of the Post and Telegraph Service. The long list of questions not only concerned their present labour market position, but also asked for a reconstruction of the period from January 1980 to 1985 . The data are a representative sample of the Dutch potential working population (for further details see OSA, 1987, Appendix). The 1985 survey consists of 4020 individuals, among which we found 2325 employees. In 1986 again about 4100 individuals were questioned, $70 \%$ of which were also questioned in 1985.

The sample used in our investigation is restricted for the following reasons. Since firm internal labour markets concen employees, the self-employed are left out of our investigation. Later on we wish to investigate the relationship between the industry of employment and internal labour markets. Since the number of employees in agriculture and fishing, mining industries and public utilities are very low "they are also left out. Thus we are left with those employed in the industry, services and government. ${ }^{3}$ of course respondents who provided inconsistent answers were left out, as well as cases with at least three variables missing. This finally reduced the sample to 1846 employees. Most of our calculations ${ }^{4}$ are based on this sample of 1846 employees, of which we had a number of personal and job characteristics. To give an impression of the sample, the most important characteristics of the data set are presented below in Table $6.1 .^{5}$

From Table 6.1 we see that the average age in the sample is 36 years. Most workers are men, $66 \%$, and $77 \%$ of the workers has a full-time job, which means they are employed at least 35 hours a week (as in OSA, 1987, or Krueger and Summers, 1988). For men and

${ }^{2}$ Our empirical research was already ongoing. when the information on 1988 became available. Since the period between 1985 and 1988 covered only three years, we decided not to extend the investigations to this enlarged period. Moreover, the 1985 data provided retrospective information on the period between 1980 and 1985, so a 5 year labour market history of employees was already available. Nevertheless, for further research into the dynamics of internall labour markets these panel data will be very useful.

${ }^{3}$ Using the Dutch Standard Industry Code ('Standaard Bedrijfsindeling", SBI) which ranges from 0109 , "industry" includes manufacturing (SBI 2 and 3) and building (SBI 5), "services" includes trade and catering (SBI 6). transport (SBI 7) and banking (SBI 8), and the govemmental sector is SBI 9.

${ }^{4}$ As we will see, for the calculation of our hazard function estinnates in Section 6.5, additional information was needed from the follow up of the survey in October 1986, showing whether those working in April 1985 had left their firm between April 1985 and October 1986. Because the followup did not cover the onginal sample completely, this leaves a dataset of 1328 people. The "drop-out" is assumed to be random. Of these 1328 workers, 215 left the firn between April 1985 and October 1986.

${ }^{5}$ AS in most samples we do not have information on all wariables for all individuals. However, as mentioned above, those with more than three variables missing were deleted. 
women these percentages differ considerably. Only $7 \%$ of the men has a part-time job, and $55 \%$ of the women. Or stated otherwise: $80 \%$ of the full-time workers is male and $80 \%$ of the part-time workers is female. In discussing our results therefore we discuss the influence of differences in gender and full-time or part-time workers. From the other variables we see that the sum of previous experience, 7.2 years, and actual tenure 8.5 years, gives an average total experience of about 15 years. With respect to education workers indicated their highest accomplished educational level, which according to the standard educational level (of the Dutch Central Bureau for Statistics) ranged from level 1 (basic education) to level 5 (university). Accordingly a number of years are adhered to these levells, corresponding to the standard length of education. From level 1 to level 5 this was $6,9,12,15$ and 17 years. The average length of education is 11.2 years. The measure of occupation level ranges from 1 to 7 , following the usual categories from untrained work (level 1 and 2) to trained work (level 3 and 4 ) to the higher levels of specialized and very specialized work (level 5, 6 and 7). For a further description see Huijgen (1989). The average occupation level on this scale is 3.7. Average firm size, measured by the number of workers in the plant, is about 400.

Table 6.1 Some characteristics of the sample $(N=1846)$

\begin{tabular}{|c|c|c|c|}
\hline Vaniable & Mean & Standard Deviation & Cases \\
\hline Age (years) & 36.2 & 10.6 & 1846 \\
\hline Male $(\%)$ & $66 \%$ & 0.47 & 1846 \\
\hline Fuli lime $(\%)$ & $71 \%$ & 0.42 & 1846 \\
\hline Tenure (years) & 8.5 & 7.9 & 1846 \\
\hline Previous exp. (years) & 72 & 79 & 1846 \\
\hline Education (Years) & 112 & 3.1 & 1846 \\
\hline Occupation level (seale) & 3.7 & 16 & 1657 \\
\hline Firn size (woukers) & 402 & 814 & 1791 \\
\hline Iniration period (scale) & 4.8 & 16 & 1808 \\
\hline Supervisory work $(\%)$ & $30 \%$ & 0,46 & 1844 \\
\hline Industry $(\%)$. & $26 \%$ & 0.44 & 1846 \\
\hline Service $(\%)$ & $35 \%$ & 0.48 & 1846 \\
\hline Governinent $(\%)$ & $39 \%$ & 0.49 & 1846 \\
\hline
\end{tabular}

Furthermore, the initiation period differs among workers. The range is from levell 0 to level 6 , indicating no initiation period (level 0), less than one day (level 1), one or two days (level 2), and so on to over three months (level 6). The average level is 4.8 . About $30 \%$ of the emp loyees performs supervisory tasks. Finally, with respect to the sector of employment $39 \%$ has a job in the government sector, whille $35 \%$ is employed in the service sector, and $26 \%$ in manufacturing. In a more detailed subdivision we find that $18 \%$ works in manufacturing, $8 \%$ in the building industry, $17 \%$ in trade and catering, $7 \%$ in transport, and $11 \%$ in banking."

${ }^{6}$ The distribution over industries is representative for the Dutch labour market as found from other sources (Central Bureau voor de Statistiek, several years). A slight overrepresentation of government employees and a corresponding underrepresentation of industry employees is found. The first figure 
In order to test the hypotheses of Chapter 4 with this sample of 1846 employees, workers employed on the internal labour market must be distinguished from those outside it. Thus it must be assessed whether a worker is employed on the internal labour market or not. This means that we must investigate whether an individual worker has a long-term employment relation as well as goad promotion opportunities. Since this information is not directly available from our sample, as in most other samples, proxy variables for both tenure and promotion opportunities must be constructed. This will be done for tenure in Section 6.4 and for promotion opportunities in Section 6.5 .

\section{4}

\section{Measuring eventual tenure}

As already mentioned in Section 5.6 low tumover or high tenure is repeatedly investigated. Usually one concentrates on how long workers are employed at the same firm (Bergeijk and De Grip, 1986; Mace, 1979). This research analyses the actual tenure of workers. In our research we need information on the time workers remain employed at the same firm (De Grip, 1985, p. 333). The reason is that a worker who has just entered the internal labour market has only developed a short (actual) tenure, while he may ultimately develop a long (eventual) tenure. ${ }^{7}$ This eventual tenure, which includes actual tenure, must be estimated from the data. Prior investigation which estimated eventual tenure distribution, applying a method by Hall (1982), showed that a considerable part of those already employed can be expected to remain at the same firm for some years (see Section 5.6). However, aside from the fact that the method by Hall (1982) is based on severe stationarity assumptions (see Kerckhoffs and Wolfs, 1992), its main drawback for our research is that it does not provide an estimate of eventual tenure on an individual level.

Therefore the hazard function method is used to estimate individual eventual tenure. Basically the hazard method gives the probability (or the hazard) that an individual will leave the firm. Using some assumptions this hazard can be used to estimate individual eventual tenure, and thus provide a suitable proxy for the length of the employment relation. In our analyses the eventual tenure resulting from this hazard method is used. Since our interest is not primarily in the results of the hazard function method, but in the implications of the results of this method for intemal labour markets, we only shortly describe the hazard function method. For details on this hazard method we refer to Kerckhoffs and Wolfs (1992).

The hazard rate is a conditional probability concept. It refers to the probability density that a worker will leave his firm at a tenure of length $t$, given that he is still with his firm after tenure t. A justification of our decision to use this hazard rate as criterium for the internal labour market is found in Alexander (1974) who states that "(T)he central assumption behind our classification scheme is that structure is related to mobility. In particular, a relatively low probability of an employee leaving a firm characterizes manorial structure; a relatively high

in brackets refers to CBS data, the second to our sample of 1846 workers: manufacturing $(22 \%, 18 \%)$, building $(8 \%, 8 \%)$, trade and catering $(17 \%, 17 \%)$, transport $(7 \%, 7 \%)$, banking $(12 \%, 11 \%)$, and govemment $(34 \%, 39 \%)$.

${ }^{7}$ We prefer the tem eventual tenure (Hall, 1982) over completed tenure (see Abraham and Farber, 1987) io indicate the length of time a (currently employed) worker will ultimately (or eventually) remain enployed at the same firm. 
probability of leaving the firm and industry is a measure of unstructured markets; and a large positive difference between the probability of leaving the firm and the probability of leaving the industry is associated with guild structures" (Alexander, 1974, p. 66).

The hazard depends on elapsed tenure $t$, as well as on individual characteristics $X$ (which will be discussed below). The unconditional probability of leaving the firm at a tenure of length $t$ is simply the usual probability density function of the random wariable job tenure, say $f(X, t)$. With $F(X, t)$ as the corresponding cumulative distribution function the hazard rate ${ }^{8}$ is

$$
\theta(X, t)=\mathbb{f}(X, t) /[1-F(X, t))
$$

We have to find a proper specification for the hazard function. In this respect we follow the existing empirical work, which usually employs a Proportional Hazard form

$$
\theta(X, t)=\mu_{1}(X) * \mu_{2}(t)
$$

In this specification, the effects of regressors $X$ and elapsed (or actual) tenure $t$ factorize. Hence, the time profile of the hazard function is the same for all individuals. To ensure nonnegativity, the first factor in equation $(6.2)$ is usually specified as an exponential function of $\mathrm{X}$. The second factor expresses the duration dependence (the time profile) of the hazard function and is often called the baseline hazard. Although traditionally this factor is modelled using rather restrictive parametric forms such as Weibull or Gompertz, we use a much more flexible semi-parametric baseline hazard specification (see e.g., Meyer, 1988; Han and Hausman, 1990) in which the baseline hazard $\mu_{2}(t)$ is essentially modelled as a step function, $\alpha(t)$, of duration $t^{9}$ One might then interpret the tenure effect as a series of dummies, each representing a distinct tenure interval within which the hazard is assumed to be constant:

$$
\theta(X, t)=\exp \left(X^{\prime} \beta\right\}_{*} \exp \{\alpha(t)\}, \quad \text { where } \alpha \text { is a step function. }
$$

The estimation of the hazard function parameters is performed by Maxinum Likelihood. As mentioned in Section 6.3 the dataset for estimation of the hazard rates is constructed from two interview moments. In 1985 workers were selected and their elapsed tenure $t$ is observed. It is examined at the second interview from the survey of $1986 \mathrm{it}$ is examined which workers are still at the same firm (the "ins"), and which have left their firm in the meantime (the "outs"). 10 For these "outs" we observe an additional tenure s since their first interview,

${ }^{8}$ A hazard exhibits negatiwe duration dependence if it declines as tenure proceeds $(\delta \theta / \delta \mathrm{l}<0)$. "The denominator $\{1-F(X, t)\}$ is called the survival function $S(X, t)$. It expresses what proportion of the persons with characteristics $X$ is still at their original firm after a tenure of length $t$.

9 The tenure intervals for the step function $\alpha(t)$ were data-inspired, gradually increasing the interval width as tenure proceeds and the number of leavers observed ('outs' in the likelihood function below') declines (see Kerckhoffs and Wolfs, 1992).

${ }^{10}$ Because the follow-up did not cover the original sample completely, this leaves a dataset of 1328 people. 215 of whom had left their firm by October 1986. OSA (1987, appendix III) shows that the "drop-out" of respondents (nore than $40 \%$ ) is fairly random with respect to observed personal and job characteristics. In addition, if selection is based on the endogenous variable (elapsed duration) or on unobserved characteristics, this will bias the estimates (selection or attrition bias). Lindeboom and Theeuwes (1990, p. 15) perform some informal tests, suggesting the absence of such bias. They rigorously delete cases with missing values. This leaves them with only 1276 workers, 167 of whom 
hence their eventual tenure is $1+\mathrm{s}$. For the "ins" we only observe a lower bound: we know that their eventual tenure must be at least $t+h$, where $h$ represents the 18 -month period between April 1985 and October 1986 . Indexing individuals with $i$, our likelihood function is:

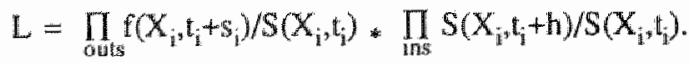

This likelihood function represents the probability of the events that happened between the two interview moments, conditional on the composition of the dataset at the first interview moment. Finally, after working out equation (6.4) in terms of the hazard function (6.3), it is maximized in order to estimate the parameters of this hazard function. These estimates will be consistent, provided the hazard function is correctly specified. ${ }^{11}$

At this point we must choose the variables that should be included in $X$. Of course many variables can be found from the analyses in Chapter 3 and 4. As argued in Chapter 4, two important explanations for the existence of internal labour markets are the development of firm-specific human capital and the problems of monitoring workers, due to imperfectness of information on the ability, effort and performance of workers (Grip, 1985; Creedy and Whitfield, 1988; Wolfs, 1988). Both, complementary, explanations will be used below to select variables in our dataset which explain long-term employment. Furthermore it can be expected that respondents indicating relatiwely good career advancement opportunities inside the firm will develop long-term employment.

Two intuitively important variables influencing (firm-specific) human capital are age and elapsed tenure. These human capital variables are intimately related: as time elapses without job separation, both age and tenure increase at the same rate. With respect to age, which is assumed to reflect some kind of general human capital, one can expect that younger as well as older workers have a greater probability of leaving the firm. The younger ones are still in their period of "job shopping" (Hall, 1982, p. 720), trying to find a job which suits their talents and preferences in order to reach an optimal job match. The older workers can be expected to leave the firm because of (early) retirement. A related argument applies to the variable elapsed tenure. The longer workers stay within a firm, the better their job will match their preferences and the more firm-specific skills will be acquired. But as time proceeds leaving may increase, if only because of approaching the retirement age. For some variables the appropriate sign is unclear a priori, mainly because of their inability to distinguish

had left the fim by October 1986 . We, on the other hand, replaced any missing value with the average value for that variable (except. of course, for elapsed tenure). Hence we have 52 additional cases. consisting almost entirely of people who left their firm. Our treatment seems more appropriate to avoid upward bias in the estimated eventual tenure. However, because the additional 52 cases all show missing values for at least one variable, it is impossible to rework Lindeboom and Theeuwes' attrition checks appropriately.

11 An important source of misspecification is unobserved heterogeneity: if not all relevant variables are incorporated in the vector $X$, this will (a.o.) create a bias towards negative duration dependence. In our application, corrections for unobserved heterogeneity using the traditional gamma correction (see Luncaster, 1979), or a discrete distribution correction along the lines of Heckman and Singer's (1984) NonParametric Maximum Likelihood Estimator (see Kerckhoffs, de Neubourg and Palm, 1990) proved insignificant. Hence, the second step of our eventual tenure calculation will be discussed for the case in which there is only observed heterogeneity, captured in $X$. 
between general and firm-specific human capital. Education leads to higher human capital, hence higher productivity, and management has an interest in tying these workers to the fim. However, as far as human capital is general and thus can be used in other firms as well, not much can be said about the influence of education on job mobility. The same applies to workers who have higher previous experience (years of labour market experience preceding the current labour relationship). On the one hand, these workers thave gathered more information about the labour market and thus have more often reached a good match, but on the other hand, one can argue that this previous experience increases their general human capital. Turning to a variable which reflects firm specific skills, workers which thave long initiation periods are assumed to have developed more firm-specific human capital and will thus have lower exit rates.

Three variables are assumed to be related to problems of monitoring workers: firm size, occupation level and supervisory work. With respect to firm size, larger firms are better equipped to implement active human resource management policies and other personnel develop. ment programmes. More attention will be on internal mobility, which makes the probability of leaving the firm smaller. To work in a supervisory position generally implies more responsibility, better job matches, better promotion opportunities and better working conditions and might hence be expected to lower the job separation rate. On the other hand workers in superwisory positions might have better jobs available outside the firm as well, which increases their exit rates. The skill level of the job may also be influential. Since jobs which require no skill inwolve less specific human capital and usually have less problems concerning information on productivity, job-separation rates will be higher. Nevertheless, workers in high skill jobs will probably possess skills that can be used in other firms as well, tending to increase their job mobility. Once again, the presence of general human capital makes the direction of the effect unclear.

Some variables which point to relative good career adwancement opportunities inside the firm are mentioned. Those stating to be looking for another job apparently do not have a good job match and will thus leave the firm sooner. When job satisfaction is greater, the worker will not leave the firm. Of course higher wages can be expected to decrease the hazard rate. With respect to the kind of contract it can be expected that workers with permanent appointments will leave the firm less quickly than those with temporary contracts. Likewise a worker with good firm internal promotion opportunities will not leave the firm because he will pursue career advancememt internally. However if a worker's last promotion occurred a long time ago, i.e., if the has not been recently promoted, he could become disappointed and leave the firm sooner.

Finally, gender should be of influence. Women are expected to develop on average lower tenure than men, because of the typical features of female labour market behaviour ( $e . g$., staying at home to look after children) and the subsequent reaction of employers (as emphasized by theories of statistical discrimination, see Section 3.5). So higher job separation rates for women can be the result of their own preferences, or of the attitude of employers, which offer women mainly temporary contracts or assign them to jobs with fewer promotion opportunities. Workers on a full-time job can be expected to remain longer at the same firm than those with part-time jobs. Since many women have part-time jobs, and almost no men, the effect of gender can be partly intermingled with the variable for full-time work. 
Of course, one can easily think of other interesting regressors ${ }^{12}$, which are not present in our dataset. On the other hand, our dataset originally included some variables which have been discarcled a priori or were excluded during the estimations, if they appeared to be extremely insignificant. The precise treatment of some of the above-mentioned variables (e.g.* the choice of categories for several categorical variables) was influenced by the empirical results (e.g., lumping together insignificantly differing categories). For a further description of the data, see Kerckhoffs and Wolfs (1991, appendix).

In Table 6.2, hazard functions estimated with three different subsets of explanatory variables are presented, all based on the semi-parametric hazard function (6.3) with time-varying age. Since the alternative Hall method (see Section 5.6) for computing eventual tenure distribution only requires information on tenure and age, we first present results using only these as explanatory variables: the simplified model. Further, a complete model is presented, using all the variables summarized above. Finally, we present an intermediate model, containing those variables that are sure not to change as tenure proceeds. Concretely, this concerns the variables gender, previous experience and education.

Before discussing the results concerning the hazard parameters in some detail, three remarks are in order. First, one can easily test whether the introduction of additional variables from left to right in Table 6.2 enhances the explanatory power of our model. Using the familiar Likelihood Ratio test, the intermediate model does not significantly improve upon the simplified model, whereas the complete model clearly beats the other two.

Secondly, we tried to apply a heterogeneity correction to all our models, using either a gamma or a discrete heterogeneity distribution. When applied to the complete model, the parameters associated with the heterogeneity distribution proved extremely insignificant, which suggests that our regressor set is fairly exhaustive. However, when applied to the restricted models, comparable results emerged. This is rather worrysome, since we know, from the previous remark, that unobserved heterogeneity must necessarily be present in the restricted models. We did not investigate this problem formally, ${ }^{13}$ because the heterogeneity correction seems of minor importance for constructing an eventual tenure distribution (see Lancaster and Nickell, 1980; Meyer, 1988, footnote 2l).

\footnotetext{
${ }^{12}$ E.g., more appropriate variables conceming promotion opportunities, performance indicators and variables concerning previous labour market behaviour of the employee (such as the number of jobs previously occupied, or the time unemployed before finding the current job).

${ }^{13}$ See, however, Kerckhoffs and Wolls (1991, footmote 9) for some suggestions as to the origin of this phenomenon.
} 
Table 6.2 Estimation results for hazard functions

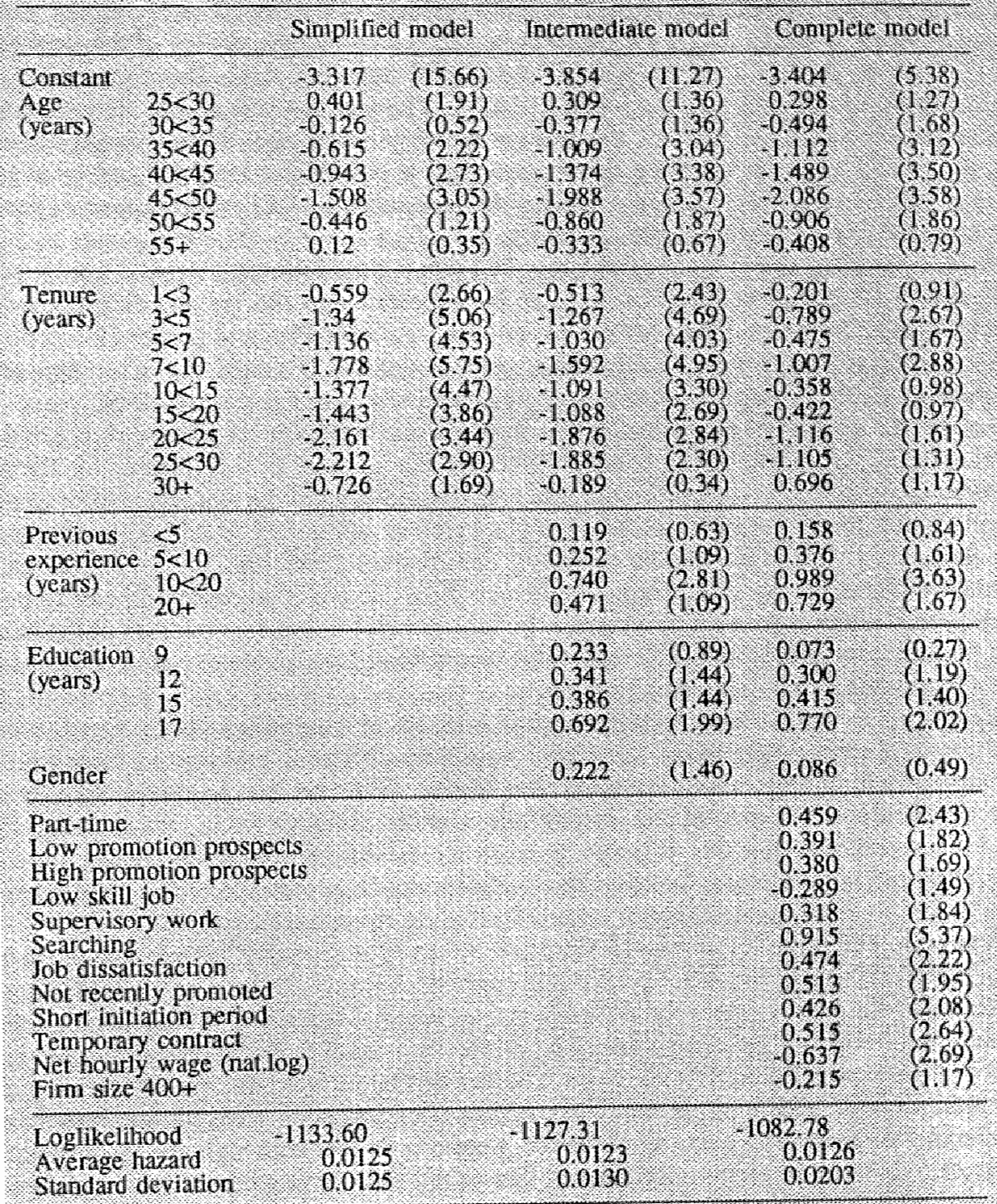

Remarks t-ratios between brackets. Hazard time unit is monthi. Re rerelice categories: age below 25 years, tenure below 1 year, provious experience none or less than 1 year, education 6 years (primary education), male, full time, average promolion prospects. nomal or high skill level, no supervisory worl, nol searding, satusfied with job, recently promoled, long tinitiation petiod, permanent ob, firm size stmaller than 400 employees: 
Thirdly, we computed the average monhly hazard in Aprill 1985 implied by our three models, simply by calculating each person"s hazard and then averaging. As one can see the more variables included, the more dispersed the individual hazard rates become. Assuming that the average hazard of about $1.25 \%$ remains unchanged for 18 months, $20.1 \%$ of the workers in our dataset should have left their job at the second interview date. This figure compares reasonably well with the actual exit rate of $16.2 \%$. The fact that it is a little higher does not contradict our model; in practice, the average monthly hazand will decline during these 18 months, both because of a sorting out process (people with high hazard leaving on average sooner, causing the average hazard among the remainder to fall), and because of mainly negative duration dependence and age effects.

With respect to the explanatory variables in Table 6.2 the following remarks apply. Many variables in the complete specification have the expected sign and are significant at a $10 \%$ level. Further, the signs of the previous experience, age, education and gender effects do not differ among the complete and intermediate specifications. A U-shaped age effect appears in all three models: the hazard rate decreases monotonically with age until 45 to 50 years. The tenure effect, though roughly showing a U-shape, is much messier: in all models it has three local minima. However, we deliberately decided not to smooth this picture by lumping together different tenure categories, because non-monotonicity of the real tenure effect cannot be ruled out a priori, and any aggregation might therefore obscure the underlying mechanisms. All three models imply a rapidly declining hazard during the first five years of tenure. Further, the inclusion of more regressors (hence the reduction of unobserved heterogeneity) leads to less negative duration dependence. Finally, remember that the time path of the hazard rate for any specific individual depends on the interaction of age and tenure effects, since both of these variables change as tenure proceeds.

For the other variables we find that workers who are looking for another job, part-timers, workers on a temporary contract, those who report short initiation periods and those who are dissatisfied with their job, will leave the firm sooner. Firm size has the correct sign, but its effect is smaller than expected and insignificant. Gender, although having the expected sign, is also insignificant, but this is partly because the relationship between gender and fulltime/part-time is very close. Deleting this variable makes gender larger and significant, at least in the complete model. Higher wages, finally, decrease the hazard rate.

It appears that the variables which explicitly refer to firm-specific human capital, such as long initiation period and tenure, give the expected negative signs. The positive sign of education and previous experience indicates that these variables reflect general human capital. Further, the positive sign of supervisory work and the negative sign of low-skill jobs might indicate that these variables reflect general human capital as well. The most surprising sign concerns workers with high promotion prospects who appear to have higher hazard rates compared with those with average promotion prospects. In fact both high and low promotion prospects increase job mobility relative to that of the average worker, whereas we a priori expected only workers with lower promotion prospects to leave sooner. However, the result can be explained (ad hoc) by arguing that promotion-prone workers might experience high promotion prospects both inside and outside the firm, and thus leave sooner. Finally, it is found that workers having had no promotion for the last five years (or no promotion at all) leave sooner.

The purpose of all this is to find the hazard with which the eventual tenure can be estimated. At this point, using for every individual his job and worker features, three different hazard rates for every individual in our sample $(N=1846)$ are available according to the three specifi- 
cations in Table 6.2. As mentioned above, this hazard rate gives the probability that a worker leaves the firm within a month. Since our goal is to find for every worker whether he has long or short employment relations we must estimate the time he will remain employed in the current firm. For simplicity we assume that the individual hazard rate does not change. ${ }^{14}$ In this way we can compute an expected additional tenure (in months) by taking the inverse of the hazard. ${ }^{15} \mathrm{By}$ adding the actual and the additional tenure for every individual we have the eventual tenure for every individual.

In fact, since we have three different hazard rates from our three specifications, three measures for eventual tenure are available. An investigation of the hazards from these three specifications shows that the correlation between hazards of the intermediate model and the simplified model is rather high (0.95). The other correlations are somewhat lower (see Table 6.3).

Table 6.3 Correlations between hazards of three specifications $(\mathrm{N}=1846)$

\begin{tabular}{|c|c|c|}
\hline & Simplified & Internuediare \\
\hline Internediate nodel & 0.9532 & \\
\hline Complete nodel. & 0.6104 & 0.6321 \\
\hline
\end{tabular}

With these three hazards accordingly three eventual tenures are calculated for every individual. The averages of these eventual tenures are 19.1 years for the simplified model, 19.4 years for the intermediate model, and 21 years for the complete specification. In Table 6.4 we find the correlations between these resulting eventual tenures. Again very high correlations are found.

Table 6.4 Comelations between eventual tenures of three specifications ( $N=1846$ )

\begin{tabular}{|c|c|c|}
\hline & Siruplified & Intermediate \\
\hline Internediate riodel & 0.9829 & $\%$ \\
\hline Gomplete morel & 0.9092 & 092501 \\
\hline
\end{tabular}

The only finding which is of importance for our dichotomous approach is whether a worker has long-term employment or not. More detailed information is not needed. So we need a division of workers into those with high and low tenure. Thus a criterium must be chosen. There is no a priori argument for a criterium available. Sometimes 10 years is used as crite-

14 As we argue below, this ignorance of negative duration dependence has only a small influence.

15 Simply estimating the additional tenure for every worker in this way gives very long additional tenures, however. Therefore, if the length of the additional plus actual tenure exceeds the retirement age of 65 years we assume that the additional tenure lasts until retirement. 
ritum for long-term employment (Hall, 1982; Bergeijk and De Grip, 1986), sometimes 15 years (Hashimoto and Raisian, 1985; Bellmann and Schasse, 1990) and others use 20 years (Hall, 1982; Carter, 1988). At this point we take a rather arbitrary number of 10 years as dividing criterium. Workers with an eventual tenure of at least 10 years are assumed to have long employment relations, whille those with a lower number of years are assumed to have short evertual tenure. ${ }^{16}$

At this point we proceed only with the results of the intermediate specification in the remainder of our investigations. The results of Table 6.3 and 6.4 suggest that the differences between the specifications are rather small, especially for the simplified and intermediate model. Although the correlation between the intermediate and the complete model is somewhit lower, the resulting percentage of workers with long eventual tenures hardly differs. ${ }^{7}$ Furhermore, in Chapter 7 separate wage equations are estimated for workers employed under internal labour market contracts and those employed outside the internal labour market. In the complete model the wage is included as an explamatory variable. To avoid selectivity bias only the results of the intermediate specification are used further. This means that having long-term employment relations is determined by age, actual tenure, previous experience, education and gender.

Using the distinction between those with eventual tenure above and below 10 years, we find (with the intermediate specification) that for the Dutch economy about $72 \%$ of the workers have long-term employment relations. ${ }^{18}$ A larger number of men and full-time workers also has a long eventual temure. For men this percentage is $77 \%$ and for full-time workers $75 \%$. For women this is only $62 \%$ and for part-time workers only $63 \%$. These figures give no clue to the size of the intemall labour market since it is defined by long-term employment relations and good promotion opportunities. So those with long employment relations might be employed on the internal labour market, provided they experience good promotion opportunities. This means that for the second feature, promotion opportunities, a similar distinction must be made. This will be done in the next section.

\subsection{Measuring promotion opportunities}

In this section whether a worker has good or bad promotion opportunities is assessed. Since this variable is not directly available from the data it must be operationalized. Fortunately, the sturvey includes a set of questions into the opportunities for further advancement inside the

${ }^{16}$ In order to examine the sensibility of our results with respect to this eventual tenure criterium, the criterium was changed with one-year steps from 5 years to 15 years. The results showed no abrupt changes in the proportion of workers cmployed on the internal labour market and those employed outside.

${ }^{17}$ Using the promotion opportunity results of Section 6.5 we found that the correlations between the dichotomous variable of being employed on the internal labour market are very high: simpliffed with intermediate: 0.9633 , simplified with complete: 0.9158 , and internediate with complete: 0.9322 .

18 In the simplified specification this percentage is $70.9 \%$, in the intermediate $71.8 \%$, and in the complete specification $73.3 \%$. So the differences in the results between the specifications are rather small. Furthermore, the influence of ignoring the negative duration dependence on the dichotomous variable which distinguishes workers with long tern employment from those with short employment is only snall. This difference is investigated by comparing the results of this study to the results in Kerckhofs and Wolls (1992) in which the duration dependence is not ignored. 
firm. This provides information on perceptions of employees on career opportunities in their job. We assume there is a positive relationship between actual promotion opportunities and the perception of the promotion opportunities within the firm. With this assumption we ignore the possibility of strategic misleading of the firm by overstating the promotion opportunities. Nevertheless, we think this assumption is reasonable since in the long run workers discover deviations of actual promotion opportunities from promised ones. This can have serious effects on the reputation of the firm. The questions used are presented in Table 6.5. Notice that the questions concern the work or the job of the employee, not specifically the employee himself. ${ }^{19}$

Table 6.5

Questions concerning promotion opportunities (translated from OSA, 1985)

1. My work offers ample scope for advancentent;

2. My work offers opportinities if one performs well;

3. My work offers nore opportinities every years

4. My work is a job without prospects:

5. My work gives good chances for advancement;

6. My work gives unequal chances for advancement;

7. My chances fot advancement are obstructed by others.

8. My work gives good prospects if one works hard;

9. My work offers a bad starting situation if one wants to achieve something

The questions could be answered with "yes", "no", or "don't know". An answer which means that there are promotion opportunities is valued 1 , an answer which denies promotion opportunities has the value 0 , while "don't know" is valued $1 / 2 .{ }^{20}$ Next by adding the nine values for all answers a scale from 0 to 9 can be constructed for the variable referring to promotion opportunities. The average value on the scale from 0 to 9 turned out to be 5.1 . Some differences can be found for different groups. For men the average was higher than for women ( 5.4 versus 4.5), indicating that men on average perceive higher promotion opportunities than women. Full-time workers also experience better promotion opportunites (5.3 versus 4.3 ).

Although the internal labour market is a continuous concept more than a discrete one (Pfeffer and Cohen, 1984; Ryan, 1981), for our empirical investigation into the difference between the internal labour market and the external labour market, workers are assigned to the internal labour market or outside the internal labour market. Therefore, in order to distinguish between low and high promotion opportunities, a criterium must be chosen concerning promo-

19 Workers will higher actual tenure have higher promotion opportunities. This may indicate that the answers given to the questions of Table 6.5 indeed refer to the promotion opportunities of the work, instead of the worker. The assumption behind this reasoning is that workers with longer actual tenure might experience lower career advancement opportunities.

20 This means that the answer "yes" to questions $1,2,3,5,8$ and 9 , and the answer "no" to question 4,6 and 7 , leads to the value 1 . 
tion scale. Anallysing the promotion variable distribution a bimodal distribution emerges with the first top at the value 3 or 4 , and the second top at the highest value (Figure 6.1). The distribution for men is below that for women for the lower promotion values, and higher for the high promotion values. However, an examination of those with low and high promotion opportunities showed no other significant or remarkable difference in features, so the promotion variable does not appear to represent another influence (see De Gijsel, Muysken and Wolfs, 1990 , appendix 3).

Figure 6.

Distribution of promotion opportunities

(For all workers, men and women)

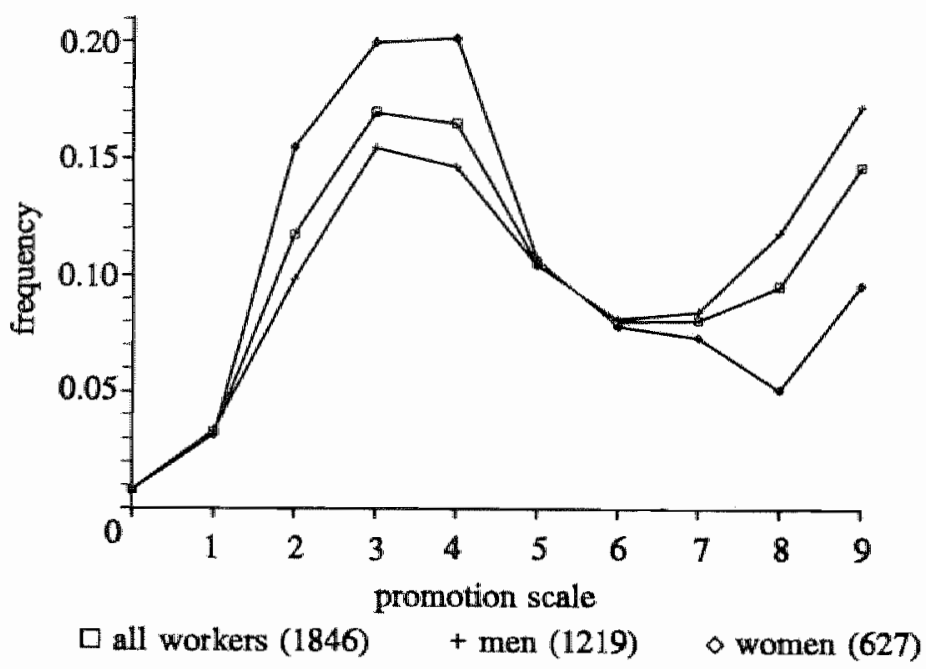

From Figure 6.1 we conclude that there appears to be a clear distinction between workers with low and high promotion chances. Accordingly we distinguish two groups with the average promotion chance $(i . c, 5.1)$ on the scale from 0 to 9 , as distinguishing criterium: workers whose individual promotion opportunity variable value exceeds 5.1 are assumed to have high promotion opportunities, whille those below that value have low or bad promotion opportunities. "This leads to the following results: of all workers $40 \%$ has high promotion opportun:ties. For men this is $46 \%$, while for women this $30 \%$. Of the full-time workers $45 \%$ has good promotion opportunities, and of the part-time workers only $25 \%$.

\subsection{Size of the internal labour market}

It is the combined appearance of long tenure and good promotion opportunities which determines whether a worker is employed under an internal labour market contract. Since we have empirical estimates of both features on an individual level under disposal, based on the same data set, the size of the internal labour market in the Dutch labour market can be assessed. As discussed in Section 6.5 promotion opportunities are dichotomized in high 
promotion opportunities, when the variable was abowe the average of 5.1 , and low promotion opportunities, when the variable was below the average. Thus we found that $40 \%$ percent of all workers had good promotion opportunities. Furthemore men and full-time workers have more often good promotion opportunities than women and part-time employees. With respect to the dichotomization of the tenure variable in Section 6.4 a distinction is made between employees with an eventual terure of 10 years or more, and the employees which do not develop such a long tenure. As we have seen this eventual tenure is based on both the actual tenure and an estimate of the additional tenure, based on the hazard. In this way $72 \%$ of the employees ultimately develops a tenure of at least 10 years. A larger part of full-time workers and of the men will develop long tenure relations.

Combining both results on an individual level the size of the internal labour market in the Dutch economy can be found. Below we present four-fold tables based on promotion opportunities and tenure. First, in Table 6.6 the size of the internal labour market for all workers, according to the criteria discussed in previous sections, is presented. These results are further investigated for men and women in Table 6.7, and full-time and part-time employees in Table 6.8. Finally, Table 6.9 shows the four-fold table based on the distinction between good and bad promotion opportunities on the one hand, and actual (instead of eventual) tenure on the other.

Table 6.6 Labour market segmentation based on eventual tenure $(\mathrm{N}=1846)$

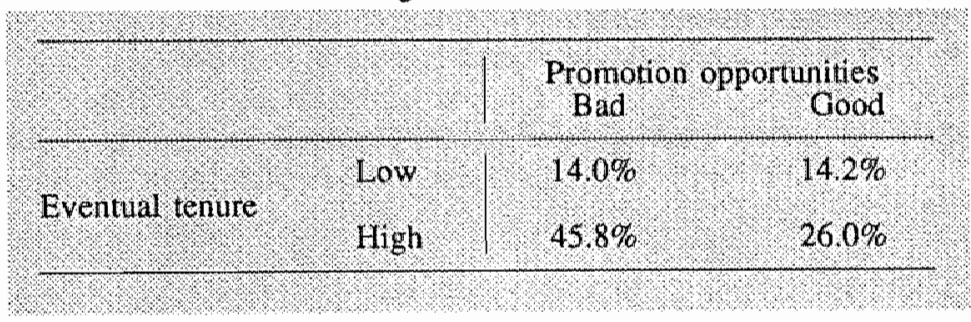

In Table 6.6 the results are presented using the distinction in long and short employment relation based on the findings on eventual tenure of Section 6.4 and on promotion opportunities of Section 6.5 . The results show that according to our definition $26 \%$ of all workers $(\mathrm{N}=1846)$ is employed on the internal labour market. ${ }^{21}$

21 Chaning the criteria of our definition, of course, leads to changes in the size of the internal labour market. As mentioned in note 19, one-year step changes in the eventual tenure variable does not lead to abrupt changes. Changing the more crude wariable on promotion opportunities from $4 / 2$ to $51 / 2$ to $61 / 2$ leads to the following results on the size of the intemal labour market, with eventual tenure at 8 years, 10 years, 12 years and 15 years:

\begin{tabular}{r|rrrr}
\hline & 8 & 10 & 12 & 15 \\
\hline $41 / 2$ & 35.7 & 34.2 & 30.8 & 27.4 \\
$51 / 2$ & 27.2 & 26.0 & 23.3 & 20.6 \\
$6 \%$ & 21.6 & 20.6 & 18.3 & 15.8 \\
\hline
\end{tabular}


Since men and women are assumed to have different labour market positions the results for men and women are presented below in Table 6.7. The figures on the left refer to men $(N=1219)$, while the figures on the right refer to women $(N=627)$. The difference between men and wome is striking. Of the men $32.8 \%$ has an internal labour market position, while for the women this percentage is only $13.7 \%$. Further it appears that the main difference appears for the most extreme cases: the part of the jobs with long employment relations and good promotion opportunities, and the part with low promotion opportunities and short tenure. This could indicate some duallity on the labour market.

Table 6.7 Labour market segmentation based on eventual tenure for men (left, $\mathrm{N}=1219$ ) and women (right, $\mathrm{N}=627$ )

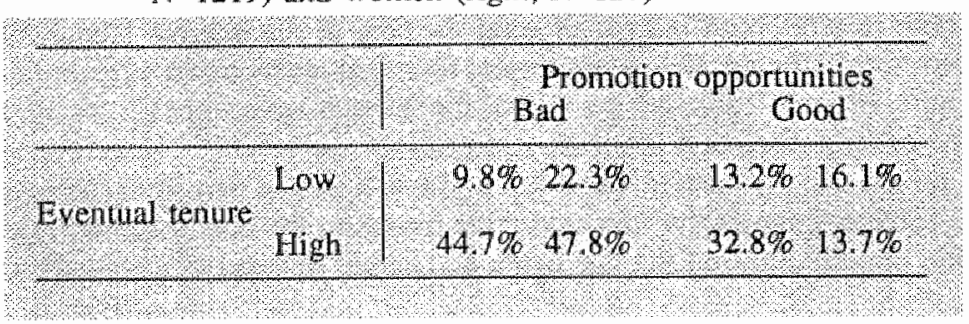

The results for full-time workers and part-time workers are presented in Table 6.8. Of the full-time workers almost $31 \%$ is emplloyed on the internal labour market. The percentage of part-time workers is much lower: $11 \%$

Table 6.8

Labour market segmentation based on eventual tenure for full-time (left, $N=1417$ ) and part-time workers (right, $N=429$ )

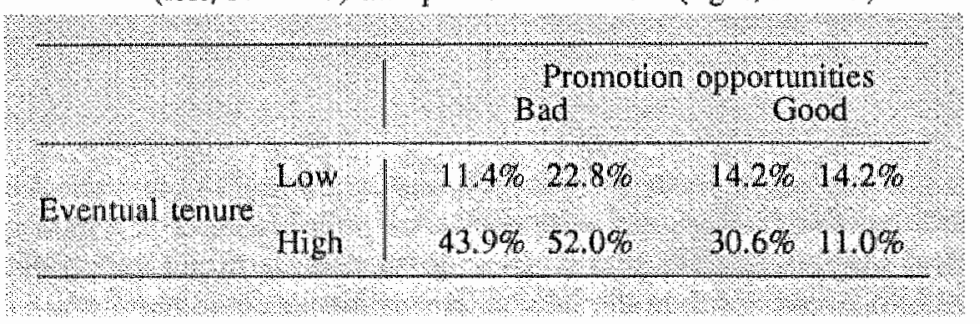

Finally, the division with actual tenure as criterium is presented. Workers with an actual tenure of at least 5 years are supposed to have long-term employment, while those below 5 years have short tenure. The number of 5 years is chosen since it can be shown that under some steady state assumptions the eventual tenure is twice the actual tenure (Kaitz, 1970; Salant, 1977; Akerlof and Main, 1981, 1983; Main, 1981, 1982a, 1982b; Layard, 1981; Cartson and Horrigan, 1983). Thus, our eventual tenure criterium, which is based on an eventual tenure of 10 years, corresponds in the steady state to an actual tenure of 5 years. The results of a dichotomization of the length of the employment relation at 5 years, show that $22 \%$ of the employees are employed at the internal labour market. The drawback of this measure is that young workers hardly appear on the internal labour market, since they have not (yet) been able to develop tenures longer than 5 years. The eventual tenure on which the results of Table 6.6 to Table 6.8 are based does not suffer from this shortcoming. 


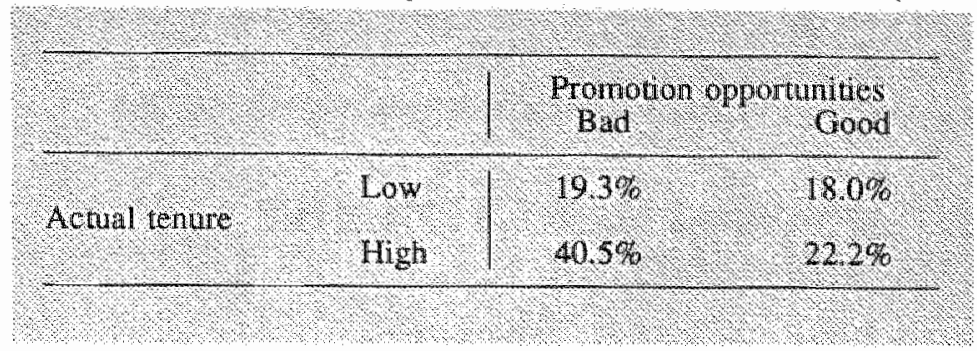

Summarizing the findings concerning the size of the intemal labour market in the Dutch labour market we find that about $26 \%$ of the workers works on an intemal labour market. For men the percentage is higher compared with women, $i . e .33 \%$ of the men is on an internal labour market, while for women this percentage is $14 \%$. Men work more than twice as often on an internal labour market. Similar results are found for full-time and part-time workers. Of the workers with a full-time job $31 \%$ is employed under an internal labour market contract, while only $11 \%$ of the part-time workers has such a contract.

\subsection{Conclusions}

In the previous chapters we concluded that most research on internal labour markets suffered from a lack of a clear definition of intemal labour markets. It was more often described than defined. This results in most empirical research being either case-study oriented, which hampers drawing general conclusions, or in scattered and fragmentary investigation, concentrating on separated items such as turnover or wage level.

We follow a different road. A representative sample of the Dutch working population is used. This allows us to draw general conclusions on the Dutch labour market. In this chapter the labour market is dichotomized into those employed on the internal labour market and other workers. This is done by determining for every worker whether he is employed on the internal labour market. This amounts to the question whether a worker will remain employed with the same firm for more than 10 years and whether his firm or job offers promotion opportunities which are above the average.

The measure for eventual tenure is found by estimating the probability that a worker will leave the firm within some time and extrapolating that probability into the future. The promotion opportunity is found by evaluating the perception of workers on their career opportunities within the firm. Combining both dichotomous measures we find a dichotomous variable indicating whether or not a worker is employed on an internal labour market.

Operationalizing the internal labour market in this way we found that about $72 \%$ of all workers ultimately develop a tenure of at least 10 years, that $40 \%$ of the workers has good promotion opportunities, and, combining both measures, that $26 \%$ is employed on the internal labour market. With this analysis the hypotheses of Chapter 4 concerning the differences between both groups of workers are investigated. 


\section{CHAPTER}

7

\section{THE INTERNAL LABOUR MARKET IN THE NETHERLANDS}

\subsection{Introduction}

In Chapter 1 our research questions were formulated. A review of several recent labour market theories (Chapter 3) and the interpretation of the internal labour market as a contract (Chapter 4) resulted in various hypotheses conceming these questions. The argument was based on the efficiency of intemal labour market contracts under conditions of monitoring difficulties and dewelopment of firm-specific human capital. While in Chapter 5 the relevance of previous empirical research for our questions was studied, in the following chapters attention was directed to our own empirical research.

Thus, in Chapter 6 the internal labour market is operationalized. In accordance with previous arguments, it is assumed that workers who will remain employed at the same firm for a long time and have good promotion opportunities, are employed under an internal labour market contract. For every worker it is determined whether he is employed under an internal labour market contract. This leads to the result that the intemal labour market covers about $26 \%$ of the workers in the Dutch economy. In this chapter we explicitly concentrate on the questions raised in Chapter 1 and the hypotheses formulated in Chapter 4, which are both summarized in Table 7.1.

The questions (and the related hypotheses) are discussed in the same order as they appear in Table 7.1. So in Section 7.2 hypothesis 4.5 is tested by examining whether there are significant differences in supply-side and demand-side features. The characteristics of workers and jobs on the internal labour market are compared to the characteristics of those on the external labour market. Further the influence of such variables on the probability of being employed under an internal labour market contract is estimated by probit analysis. Section 7.3 turns to the hypotheses on the relationship between internal labour markets and wages. In order to examine whether (identical) workers on the internal labour market receive higher wages, average wages of workers on the intemal labour market are compared with the wages of workers outside the internal labour market. Whether the seniority aspect of wages on the internal labour market is higher than on the external labour market is also investigated. The third question of Table 7.1 is discussed in Section 7.4. A complete inwestigation of this question 
is prohibited by the data (and by the framework of Chapter 4). In this section variables on labour immobility and some additional variables are examined, which seem to provide some support for hypothesis 4.4 . Section 7.5 summarizes the results.

Table 7.1 Research questions and related hypotheses

\section{Question 1: \\ What are the characteristic features of workers and jobs on the internal labour narket?}

Mypothesis 45 . On the internal labour market the proportion of male and full time workers is higher compared to the external labour market Further, the length of the initiation period, average job level, average fim size and capital intensity is higher on the internal labour market. Finally, average age, years of schooling and previous experience are not significantly different from the external labour market.

\section{Question II:}

What is the relationship between firm internal labour markets and uages?

Hypothesis 41. Average (expected) wages on the internal labour market are higher compared to those outside the internal labour narket for identical workers on identical jobs.

Hypothesis 4.2 . Average (expected) wages on the internall labour niarket ate higher than those outside the interna labour narket.

Hypothesis 43 . On the internal labour market the slope of the earnings profile is steeper than the slope on the external labour noarket.

\section{Question III: \\ What is the consequence of internal labour markets for the mobility of labour?}

Hypothesis 4.4. On the internal labour market the inter-finm mobility is lower and the intra-firm mobility is bigher compared to the extenal labour market Further, average tenure is biglier on the internal labour market.

\subsection{Characterizing the internall labour market}

This section is concerned with the different features of employees and jobs under internal labour market contracts and those on the external labour market. Following hypothesis 4.5 the age of emplloyees is investigated, as well as the proportion of male workers, the percentage 
of full-time workers, average tenure, the length of the initiation period, the years of education, the average job level, firm size, and capital intensity. The hypothesis is analyzed in two ways. First, jobs and workers under intemal labour market contracts are compared with those of the extemal labour market. It is investigated whether the average values of seweral variables (for instance average age or furm size) for jobs and workers on the internal labour market differs significantly from those employed outside the internal labour market. Additionally, it is examined whether some groups of workers (for instance men) or some kind of jobs (for instance high-level jobs) appear more frequently on the internal labour market. Some further attention is paid to the relationship between internal labour markets and industry in order to find in which industries intemal labour markets are located. Second, in order to investigate the simultaneous influence of these variables on the probability of employment under an internal labour market contract, some results from probit estimations are presented.

To repeat the arguments which lead to hypothesis 4.5 it was argued that internal labour market contracts are offered to employees who can be expected to stay employed at the same firm for a long time, such as men and full-time employees. Further, internal labour market contracts are long-term contracts which are accordingly featured by long tenures. From the argurnents in Chapters 2 to 4 it followed that internal labour market contracts are efficient if monitoring worker productivity is difficult and the development of firm-specific human capital is important. Therefore it is argued in Chapter 5 that internal labour market jobs are featured as high-level, supervisory jobs with long initiation periods. Since large firms are assumed to have more monitoring problems, average firm size is expected to be larger on the internal labour market. Finally, with respect to variables representing general human capital, such as age, previous experience and years of education, no decisive conclusions could be drawn.

In Tables 7.2 and 7.3 the differences of the average value of these variables for those employed on the internal labour market and those outside are presented. In Table 7.2 the average value or proportion of several characteristics are found. Further it is investigated whether these means or proportions differ significantly. A slightly different approach is followed in Table 7.3. For some categories of workers and jobs the proportion identified as internal labour market is presented. For these proportions too, the significance of the differences are investigated. The test thus examines whether the hypothesis of equal average (or proportion) can be rejected (see note 1).

In Table 7.2 the results are presented for all workers in the first two columns, and for fulltime workers, employed for at least 35 hours a week, in the last two columns. "The average value of most variables differs significantly for each group of workers. Of the workers on the internal labour market $90 \%$ has a full-time job, while outside the internal labour market only $72 \%$ has one. However, restricting the sample to full-time workers only does not change the results. Thus we merely discuss the results for all workers, while those for the restricted sample can be found in Table 7.2. Of those employed on the internal labour market $82 \%$ is male, while outside the internal labour market this percentage is lower, i.e., $60 \%$. This is not surprising since most women are part-time workers (see Section 6.3) and part-time workers

1 With two (large) sample sizes $n_{1}$ and $n_{2}$, average values $x_{1}$ and $x_{2}$, and standard deviation $s_{1}$ and $s_{2}$, the relevant test statistic for the null hypothesis of equal means is $Z=\left(x_{1}-x_{2}\right) /\left(s_{1}{ }^{2} / n_{1}+s_{2}{ }^{2} / n_{2}\right)$. To test the null hypothesis of equal proportions the statistic is accordingly adjusted. With proportions $\mathrm{p}_{1}$ and $p_{2}$ and $p=\left(n_{1} p_{1}+n_{2} p_{2}\right) /\left(n_{1}+n_{2}\right)$ the test statistic is $\left.Z=\left(p_{1}-p_{2}\right) / V \mid p(1-p)^{*}\left(\left(n_{1}+n_{2}\right) / n_{1} n_{2}\right)\right\}$. If $|Z|>$ 1.96 the null hypothesis of equal means (or proportion) is rejected at 5 or significance level (see Newbold, 1984, p. 364 ff]. 
are over-presented outside the intemal labour market. Indeed, restricting the sample to fulltime workers leads to a reduction in the difference between male participation on the internal labour market $(88 \%)$ and outside $(76 \%)$. Surprisingly with respect to the variables years of education and prewious experience, which are considered to represent general human capital, hardly any difference can be found between those on the internall labour market and those outside.

Table 7.2 Characteristics of jobs and workers

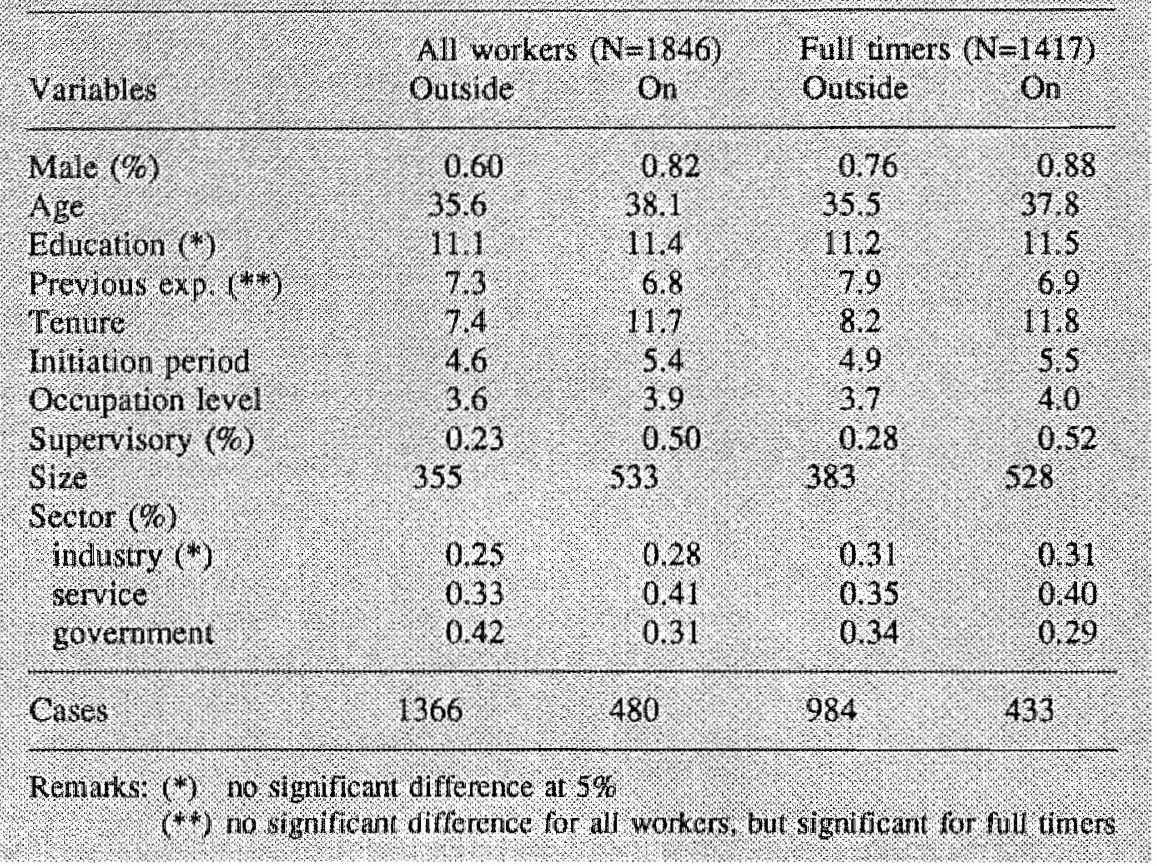

The difference in average years of education, and the years of previous experience between employees on internal labour market contracts and those employed on the external labour market is insignificant. Turning to variables which represent the existence of firm-specific human capital, such as initiation period and tenure ${ }^{2}$, the difference is as expected: on an internal labour market more firm-specific human capital is apparent. The average tenure on the internal labour market is 11.7 years and only 7.4 years outside the internal labour market. Furthermore, the initiation period variable, ranging from 0 to 6 , is 5.4 on the internal labour market, compared with 4.6 outside the internal labour market. This corresponds to our argument that it is firm-specific human capital, more than general human capital, which is a cause of the efficiency of internal labour market contracts. It further indicates that internall labour

\footnotetext{
${ }^{2}$ Tenure, however, might also point to problems of monitoring workers if workers with more firmspecific human capital are more difficult to monitor.
} 
market contracts are not offered to highly educated employees only. The initiating research of Doeringer and Piore (1971) into internal labour markets concentrated on blue-collar workers. As reported in Chapter 5, later investigations found internal labour market features for engineers (Mace, 1979), engineering firms (George and Shorey, 1985) and law firms (Wholey, 1985). So the result that educational level is not significantly different for those employed on the internal labour market and those outside is not completely surprising. It indicates however, that one should be cautious in using a classification of labour market segments based on the level of education. Table 7.2 further shows that there is a difference between the average age of those employed under intemal labour market contracts and other workers.

With respect to variables, which are related to problems of monitoring workers, such as occupation level, the percentage of workers in supervisory positions and firm size, significant differences are found. The occupation level, which ranges from 1 (low) to 7 (high), is significantly higher on the internal labour market. The percentage of employees in supervisory positions is even twice as high on the internal labour market; $50 \%$ versus $23 \%$. Average firm size, measured by the number of workers, is 532 on the internal labour market and only 355 outside. Finally, most workers employed on the internal labour market are working in the services industry, while outside the internal labour market most workers are employment in the government sector. Note however, that the difference in the proportion employed in the industry on the internal labour market $(28 \%)$ does not differ significantly from that proportion outside the internal labour market $(25 \%)$.

Overall, we conclude from Table 7.2 that differences between jobs and workers under internal labour market contracts and those on the external labour market show in both demandside and supply-side variables. Variables which reflect firm-specific human capital and variables which are related to monitoring problems differ significantly for workers and jobs on the internal labour market and those outside. Almost all variables show significant difference, except for years of education and previous experience. Although the differences are reduced somewhat if the sample is restricted to full-time workers, the conclusions remain the same.

The results of a slightly different approach to investigate hypothesis 4.5 are presented in Table 7.3. For several "mutually exclusive, subgroups it is investigated whether the proportion of internal labour market positions differs significantly. For instance, the percentage of men employed under an internal labour contract is compared with the percentage of women employed under one. The results are comparable to those found above. Significant differences between intemal labour market positions and those outside the internall labour market are found for almost all variables. Again variables reflecting general human capital in this case education and age, are an exception to this finding. Apparently, higher educated employees are not more frequently employed under internal labour market contracts, and neither are older workers. This result is important since it supports research into internal labour markets for both blue-collar and white-collar workers. It also shows that our definition of the internal labour market does not result in a bias towards higher educated or older workers. Finally, it suggests that definitions of the intemal labour market based on training or educational level might be inappropriate. In this respect we refer to research by Blossfeld and Mayer (1988) and Szydlik (1990), discussed in Chapter 5. In these studies the firm internal labour market is defined by occupational level or skill level (and firm size). Since there is usually a close correspondence between occupational level or skill level and the level of education, such definitions exclude research into the average educational level on the internal labour market. 
Table 7.3 Distribution over the internal (ILM) and external labour marke:

\begin{tabular}{|c|c|c|c|c|c|}
\hline \multirow[b]{2}{*}{ Triables } & & \multicolumn{2}{|c|}{ AII workers $(N-1846)$} & \multicolumn{2}{|c|}{ full iners $\mathrm{N}=1417$ ) } \\
\hline & On & the $1 . \mathrm{M}$ & Caress & On the $1 \mathrm{LM}$ & Castos \\
\hline geniler & nelin & $32 \%$ & 1219 & $34 \%$ & 1133 \\
\hline & Wonnen & $14 \%$ & 627 & $18 \%$ & 284 \\
\hline entuchtion $($ h) & 1igh & $27 \%$ & 411 & $32 \%$ & 315 \\
\hline & 10u & $26 \%$ & 1435 & $30 \%$ & 1102 \\
\hline tenurre & high & $39 \%$ & 550 & $42 \%$ & 476 \\
\hline & Short & $20 \%$ & 1296 & $25 \%$ & 941 \\
\hline $\operatorname{lgc}(4)$ & old & $28 \%$ & 602 & $33 \%$ & 455 \\
\hline & young & $25 \%$ & 1244 & $29 \%$ & 962 \\
\hline initition period & 10018 & $34 \%$ & 958 & $37 \%$ & 818 \\
\hline & short & $17 \%$ & 850 & $21 \%$ & 570 \\
\hline superv150ry & 186 . & $4, \%$ & 948 & $45 \%$ & 501 \\
\hline & no & $18 \%$ & 1296 & $220 \%$ & 914 \\
\hline occipation level & high & $33 \%$ & 1168 & $36 \%$ & 404 \\
\hline & $160 x^{2}$ & $25 \%$ & 489 & $30 \%$ & 808 \\
\hline frin size & Marge & $31 \%$ & 763 & $35 \%$ & 612 \\
\hline & small & $23 \%$ & 968 & $27 \%$ & 731 \\
\hline
\end{tabular}

Remart: $(6)$ no signifieant difference.

More precisely, the results show that men are more frequently employed on the internal labour market (32\%) than women (14\%). Of those with high tenure, which is defined as an actual tenure of at least 10 years, $39 \%$ is employed on the internal labour market, while only $20 \%$ of those with short tenure has an internal labour market contract. Of the employees with long initiation periods (of at least 3 months) $34 \%$ has an internal labour market position, compared with $17 \%$ for those with short initiation periods. Of the supervisors $44 \%$ is employed on an internal labour market; of those without supervisory tasks only $18 \%$. Workers on a high occupational level, which means they perform (very) specialized work, $33 \%$ is on the internal labour market, and only $25 \%$ of workers with low occupational levels. Finally, of those employed in large fims (with at least 100 employees) $31 \%$ has an internal labour market position, compared with $23 \%$ of those in small firms. With respect to age older workers, aged 40 years or more, are compared with younger workers. The difference in age under an internal labour market contract is insignificant. The same result is found for workers with a high educational level, defined as at least 12 years of education, and lower trained employees. In this approach the results for a sample of all workers (columns 1 and 2) and a sample restricted to full-time workers (columns 3 and 4) also shows no essentiall changes. However, the percentage employed under an intemal labour market contract increases for all groups once attention is focused on full-time workers. In sum, we find that hypothesis 4.5 is corroborated. Significant differences for the proportion employed on the internal labour market are found for men and women, workers with long and short tenure, workers with long and short initiation periods, workers on high and low occupational level jobs, supervisors and workers with no supervisory tasks, and workers in small and large firms. No significant difference is found be- 
tween older and younger workers, and between workers with high and low educational levels.

Being interested in the occurence as well as the features of internal labour market contracts, at this point the occurence of internal labour markets in different industries is further explored. Two arguments can be provided for this elaboration. First, internal labour market contracts are often regarded as being related to industry or firm size. As discussed in Section 5.3 some economists even go so far as to define the internal labour market by firm size (Blossfeld and Mayer, 1988; Szydlik, 1990) or industry (Alexander, 1974). The second argument concems the effect of firm size and industry on the wage level. "This, it is argued in Section 5.6 , might be related to internal labour markets. Generally, it is found that wages are consistently higher in some industries and that wages are higher in large firms. Trying to explain these findings economists sometimes refer to internal labour markets or closely related theories such as efficiency wage theories (for instance Krueger and Summers, 1988). For these reasons it is worth while examining in which industries the internal labour market is prevalent.

Table 7.4 Internal labour market per industry $(\mathrm{N}=1846)$

\begin{tabular}{|c|c|c|c|}
\hline Mindistry & $\%$ on II M & \%o long tenure & $\begin{array}{l}\text { \% good promotion } \\
\text { opportunities. }\end{array}$ \\
\hline Manutactuning & $29 \%$ & $73 \%$ & $43 \%$ \\
\hline Buriding & $29 \%$ & 779 & $39 \%$ \\
\hline Trade & $26 \%$ & $69 \%$ & $41 \%$ \\
\hline Transport & $26 \%$ & $78 \%$ & $40 \%$ \\
\hline Binking & $39 \%$ & $69 \%$ & $58 \%$ \\
\hline Goveninent & $21 \%$ & $71 \%$ & $34 \%$ \\
\hline Tota & $26 \%$ & $72 \%$ & $40 \%$ \\
\hline
\end{tabular}

In Table 7.4 the industry effect is analysed in some detail. The percentage of internal labour market positions ranges from $21 \%$ to $39 \%$. Remember that overall $26 \%$ of the employees is employed on the internal labour market. Most industries have about the same proportion of internal labour market contracts (26\% and $29 \%$ ). Only two industries have results which differ clearly from the average of $26 \%$ : banking and the government. Especially the low percentage of internal labour market contracts in the government sector is surprising. Only $21 \%$ of the workers in the government sector are identified as internal labour market workers, while for banking this percentage is about twice as high (39\%). Further, since banking and manufacturing are relatively capital-intensive, and government and trade are relatively labour-intensive, a positive relationship between capital intensity and the percentage of internal labour market positions can be signalled.

In order to discover how the small percentage of the governmental employees, who are identified as being employed under internal labour market contracts, can be explained, both the percentage of those with long-term employment relations as well as the percentage of workers with good promotion opportunities is presented separately in Table 7.4. The reason the intemal labour market percentage in the government sector is relatively low appears not 
to be the short duration of employment relations, but merely the low percentage of workers perceiving good promotion opportunites. As much as $71 \%$ will develop an employment relation of at least 10 years. But only $34 \%$ reports more than average promotion opportunities. So, although workers can be expected to remain employed for a long time with the same organization in the governmental sector, their chances of firm internal career advancement are rather low in comparison with other industries. ${ }^{3}$ In banking the high percentage of internal labour market positions is due mainly to the large number of employees who perceive good promotion opportunities ( $58 \%$ ); a relatively low percentage of workers will develop long-term employment relations (69\%). These results also emphasize the importance of considering both features of internal labour market contracts: eventual tenure as well as internal promotion. Ranking industries according to one of these two features, length of employment or internal promotion, would considerably change the results on the accurence of internal labour markets over industries.

So far, the simultaneous influence of these variables is ignored. In a second step, probit estimations are presented. The dependent variable in these estimations is the (dummy) variable of being employed under an internal labour market contract. This variable has value 1 for those employed under an internal labour market contract, and is valued zero in the other case. In Table 7.5 the results of the estimation are presented. Tenure, previous experience, age, years of education, initiation period, firm size, full-time work and supervisory work, are introduced as explanatory variables. In the first equation the influence of these variables on the probability of being employed on the internal labour market is examined for all workers. Corresponding to the abovementioned analyses, a significant influence is found for variables which represent firm-specific human capital, such as tenure and initiation period. Furthermore, demand-side variables such as firm size, full-time jobs and supervisary jobs are significant. Again however, variables representing general human capital, such as age, previous experience and years of education, show no significant influence. Thus, it seems to be the amount of firm-specific capital, represented by variables such as initiation period and tenure, which positively influences employment under internal labour market contracts, instead of general human capital, represented by age, previous experience and years of education.

Restricting the sample to men or full-time workers provides similar results. The second equation corresponds to the sample which includes all men, and the third equation is for fulltime employees. The limitation of the sample only leads to a change in the significance of the age variable. The result that previous experience, as well as years of education, have no significant influence, remains unchanged.

The overall conclusion of this section is that hypothesis 4.5 is corroborated. The comparison of internal labour market positions indicates that workers and jobs significantly differ on some aspects such as the percentage of men, tenure, initiation period, occupational level, firm size and industry of employment. No significant differences are found for educational level, previous experience and age. Further investigation shows that internal labour market positions are over-represented in the banking industry and under-represented in the government sector.

${ }^{3}$ Athough the results are hardly comparable, in Chapter 5 a similar result was reported in Van Ours and Zoethout (1990) with respect to the intemal labour market for the City of Amsterdam. Poor career advancenent perspectives together with low turnover were found. 
Table 7.5

Probit results on probability of employment on the intemal labour market

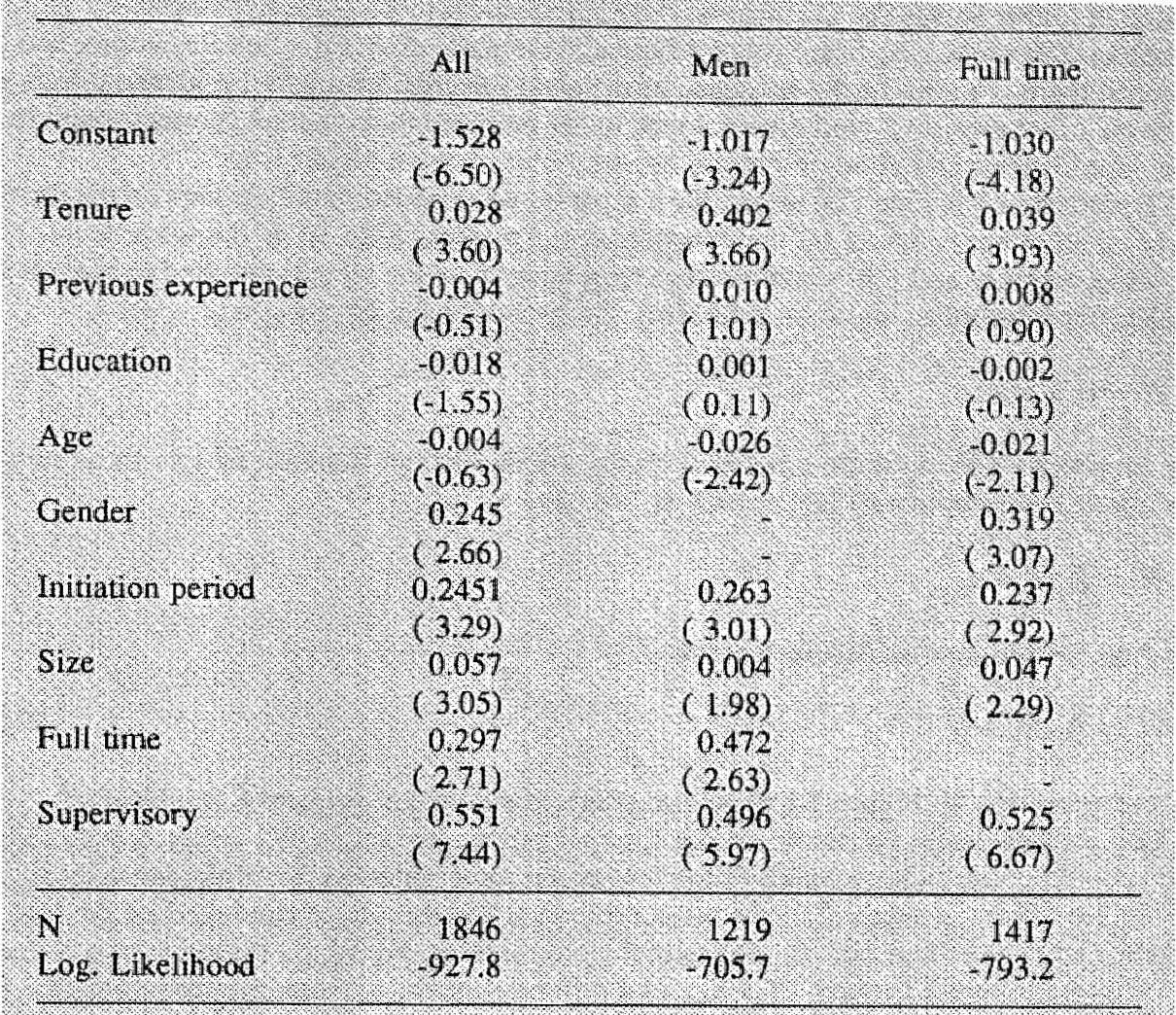

\subsection{Internal labour markets and wages}

This section concentrates on the relationship between internal labour markets and wages by testing hypotheses 4.1,4.2 and 4.3. As a first step the method of testing these hypotheses is described.

Hypothesis 4.2, which states that average wages on an internal labour market exceed those outside, is simply tested by comparing average wages for workers on the intermal and the external labour market, and examining the significance of the difference. However, higher wages on the internal labour market can be a result of job and worker differences. Thus, hypothesis 4.1 is more precise in stating that identical workers on identical jobs are paid higher wages on the internal labour market. ${ }^{4}$ Our contract interpretation of the internal labour market implies that workers on the internal labour market are employed under different con-

\footnotetext{
${ }^{4}$ For a discussion on the term identical, see Section 4.6 .
} 
tracts compared to those outside the internal labour market. It is argued that instead of the differences in job and worker features, a different contract offered to both groups of workers. results in higher wages for identical workers on identical jobs. Thus, hypothesis 4.1 is interpreted as follows: if significant wage differentials remain after correction for worker and job features, there is room for the existence of different rewards for otherwise identical jobs and workers. More precisely, workers employed under internal labour market contracts, with longterm employment and good promotion opportunities, receive higher wages.

Hypothesis 4.1 is tested by estimating a separate wage equation for workers on the internal labour market and workers on the external labour market. With $W$ as the wage level, $\mathbb{X}$ as the set of (worker and job) characteristics, parameter $B$ as the weight attached to the job and worker characteristics, and $\varepsilon$ as error term, the general wage equation is:

$$
W=\beta X+c
$$

Let subscript i refer to those employed on the internal labour market and e to those outside the internal (thus external) labour market, we have

$$
W_{i}=\beta_{i} X_{i}+\varepsilon_{i}
$$

for those on the internal labour market, and

$$
W_{\mathrm{e}}=\beta_{\mathrm{c}} \mathrm{X}_{\mathrm{e}}+\varepsilon_{\mathrm{e}}
$$

for those outside. In Figure 7.1 these two wage equations are presented graphically. ${ }^{5}$

The average wage for those on the internal labour market is $W_{i}$, while that for those outside is $W_{e^{*}}$ The characteristics of the former are represented by $X_{\mathrm{i}}$, of the latter by $X_{e}$. As can be seen from equation (7.2) the wage difference between those employed on the internal labour market and those outside the internal labour market, $W_{i}-W_{e}$, is the result of a different set of worker and job features $\left(X_{i}-X_{e}\right)$, of a different weight of these characteristics $\left(\beta_{i}-\beta_{e}\right)$, and the error term $\left(\varepsilon_{\mathrm{i}}-\mathbf{e}_{\mathrm{e}}\right)$ :

$$
W_{i}-W_{e}=\beta_{i}\left(X_{i}-X_{e}\right)+X_{e}\left(\beta_{i}-\beta_{e}\right)+\left(\varepsilon_{i}-\varepsilon_{e}\right)
$$

Now, with a proper set of variables $X$, and with estimated wage equations (7.1a and $7.1 \mathrm{~b}$ ) for workers on the internal labour market and those outside, it can be examined whether the wage gap is the result of the difference between the worker and job features on the internal and external labour market, or whether it is a result of a different reward on the internal labour market. Formally, this comes to interpreting hypothesis 4.1 as testing if $\beta_{\mathrm{i}}$ differs from $\beta_{\mathrm{e}}$. In this way it can be investigated whether wages on the internal labour market are higher because workers and jobs are different (which is reflected in $\mathrm{X}$ ) or because labour market positions are rewarded differently (which is reflected in $\beta$ ). ${ }^{6}$

\footnotetext{
5 This kind of analysis has been previously used to investigate the amount of discrimination (see Elliot, 1991. pp. 401-404). See also Blinder (1973) and Oaxaca (1973).

"Of course one can also choose for substituting $X_{i}$ into the wage equation for employees outside the internal labour market, which gives an estimated wage of what insiders would eam if employed outside the intemal labour market, and test for the significance of the wage difference of this estimated
} 
Figure 7.1

Wage equation for workers on (i) and outside (e) the internal labour market

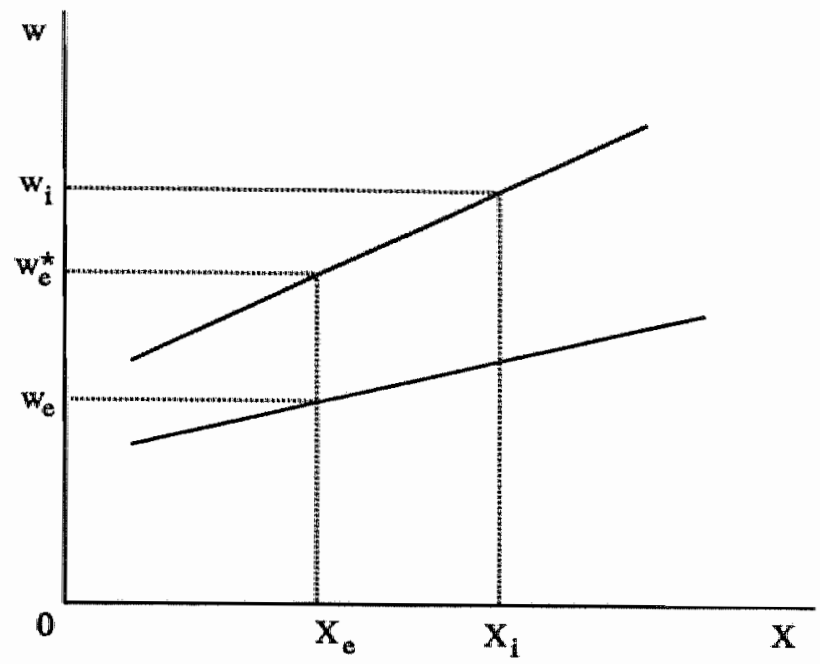

In fact internal labour markets can be considered as having a different rewards structure, paying higher wages to some features. Substitution of $X_{e}$ for $X_{i}$ in equation 7.1 a results in an estimated wage $W_{e}^{*}$, with $W_{e}^{*}=\beta_{i} X_{e}+\varepsilon_{i}$. This estimated wage $W_{e}^{*}$ represents the wage which workers, who are currently employed outside the internal labour market, would earn if they were employed on a similar jobs on the internal labour market. Of the total wage difference $W_{i}-W_{e}$ the part $W_{i}-W_{e}^{*}$ is due to differences in features, while the remaining part $W_{e}^{*}-W_{e}$ is due to differences in the $\beta^{\prime} s$. Stated otherwise, if $W_{e}^{*}$ differs significantly from $W_{e}$, this suggests that otherwise identical employees are treated differently on the internal labour market and outside the internal labour market. If such a difference is found, it is interpreted as a signal for a difference in rewarding on the internal and external labour market. This points to a different method of rewarding features $X$, or to the existence of discrimination (see Section 3.4 on -statistical- discrimination in Thurow, 1975). ${ }^{7}$ Following the framework of Chapter 4 the wage difference is a result of increased efficiency due to a higher effort of employees or a higher amount of firm-specific human capital, which is not already measured by the variables in the equation which reflect firm-specific human capital (such as initiation period and tenure).

The last hypothesis on the relationship between wages and internal labour market, hypothesis 4.3 , states that on the internal labour market wages increase more with seniority than on the external labour market. This hypothesis is investigated by comparing the influence of an additional year of seniority on the wage level. It is examined whether the corresponding

\footnotetext{
wage $W_{i}^{*}$ with $W_{i}$.

Tof course, this can also refer to the existence of other wage determining variables which not measured in the equations.
} 
parameter in the wage equation is significantly higher for internal labour market positions.

Table 7.6

Average wages for several categories (in guilders, f)

\begin{tabular}{|c|c|c|c|c|c|c|}
\hline & All & $\begin{array}{l}\text { II work } \\
\text { On nN }\end{array}$ & Outside & All & 19tiners & Outside \\
\hline All workers & 1578 & 18.71 & 1475 & 16.01 & 18.57 & 1489 \\
\hline Men & 1701 & 19,28 & 1.92 & 1690 & 1911 & 15,8 \\
\hline Women & 13.39 & 16.08 & 1296 & 12,48 & 14.57 & 12.02 \\
\hline Manufacturing & 1561 & 18.62 & 14.39 & 1578 & 18.67 & 14.46 \\
\hline Building $(*)$. & 15.49 & 15.30 & 15.57 & 15,31 & 15.03 & 15.43 \\
\hline Trade & 1307 & 18.44 & 12.43 & 14,79 & 18.59 & 1315 \\
\hline Transport & 16.14 & 18.09 & 15.44 & 1593 & 17.81 & $15 / 4$ \\
\hline Bankn 8 & 17,42 & 22,19 & 14,37 & 17,32 & 21,34 & 14.41 \\
\hline Government & 16.18 & 18.11 & 15,69 & 16.58 & 18.25 & 15.97 \\
\hline Cases & 1846 & 480 & 1366 & 1417 & 433 & 984 \\
\hline
\end{tabular}

Remark $(0)$ no significant diference at $5 \%$.

Hypothesis 4.2 is tested by comparing average net hourly wages of workers on the internal labour market to average wages of workers employed on the external labour market. ${ }^{8}$ In Table 7.6 these average net hourly wages (in guilders, $f$ ) are presented for different groups of workers.

Table 7.6 provides strong evidence for the hypothesis that, in general, hourly wages on the internal labour market are higher than those outside. Again, these differences are significant. ${ }^{9}$ The building industry is the only exception to this. The difference is not significant. Average net wages on the internal labour market are $f$ 18.71 while outside the internal labour market this is only $f$ 14.75. It appears that on the internal labour market men earn higher wages than women: $f 19.28$ versus $f 16.08$. In Section 7.2 it is found that a large number of the women has a part-time job. This can influence the hourly wages as a result of the (progressive) Dutch tax system. In the results of Table 7.6 for the sample of full-time employees, the eventual influence on the net hourly wages of the number of hours worked in a week (under the Dutch tax and premum system), is (largely) excluded. It appears that the same conclusion holds: workers on the internal labour market earn higher wages ( $f$ 18.57) compared with those outside ( $f$ 14.89).

Investigating wage differences between industries the highest wages are paid in banking,

\footnotetext{
Note that there is a difference between gross and net wages in this chapter and in Chapter 4 . In Chapter 4 this related to the correction for effort terms, while in this chapter the difference is a result of taxes and premiums.

${ }^{9}$ See footnote 1 for a description of the test statistic.
} 
while trade pays the lowest average wages. This is consistent with the observation that internal labour markets pay higher wages since Table 7.4 showed that the highest pencentage of internal labour market positions was found in banking. On the other hand, the result that the government sector has relatively few number of internal labour market positions does not imply a rellatively low average wage. Nevertheless, the lowest paying sector is among the industries with the lower number of internal labour market positions.

If the wages on the internal labour market and outside the intemal labour market are presented separately, a considerable difference in the ranking of undustrial wage levels on the internal labour market and outside occurs. This might indicate that these two labour market segments differ considerably and that within an industry an internal part and an external part can be distinguished. Industries which pay the highest wages on the internal labour market (such as banking with $f 22.19$ ) are among the lower paying industries outside the internal labour market (only $f$ 14.37). And industries which are among the lower paying on the intermall labour market (such as building with $f 15.30$ and the government with $f$ 18.11) are among the higher paying industries outside the internal labour market $(f 15.69$ and $f 15.57$ ). Moreover, the highest paying industry on the internal labour market pays $45 \%$ higher wages than the lowest paying industry, while outside the internal labour market this difference is only $26 \%$. A possible explanation for this smaller difference between the highest and the lowest average outside the internal labour market is that circumstances outside the internal labour market are more competitive than on the internal labour market. At this point we conclude that hypothesis 4.2 , which states that average wages on the internal labour market are above those outside the internal labour market, is corroborated.

Above we mentioned that testing hypothesis 4.1 requires a wage equation. Thus, explanatory variables for the level of individual wages must be chosen. Usually, wage differences are analysed using the human capital model (see Chapter 2). This framework discusses questions such as the return to education and wage discrimination and emphasizes the importance of supply-side or human capital variables. The main drawback of the model, as reckoned by some of its earliest followers (e.g., Blaug, 1976, 1987), is that it directly links productivity to the worker. In the human capital model a higher amount of (investment in) human capital leads to a higher productivity and to higher wage levels. This stress on supply-side variables is challenged by various theories, such as screening theories (Spence, 1974), matching theories (Jovanovic, 1979, 1984), segmentation theories (see Section 2.3), and seniority schedules (Lazear, 1979, 1981), as well as by empirical findings that older workers earn higher wages although they are not always more productive (see Section 5.5). Although these alternatives differ widely, their common point is the argument that there is a separate influence of demand-side, or structural, variables. Apart from worker differences, wage differences can be a result of differences between firms, industries or jobs (Osterman, 1975; Briderl, 1990, p. 4). Below the explanatory power of adding demand-side variables, to a wage equation based on human capital variables, is examined. As a third step we examine the additional explanatory power of the industry of employment. The purpose is to find a proper wage equation in order to test hypothesis 4.1 . 
Table 7.7 Wage equations for all workers

\begin{tabular}{|c|c|c|c|c|c|c|}
\hline & $1 \mathrm{NM}$ & Outside & IIM & Outside & $1 \mathrm{LM}$ & Outside \\
\hline Constant & 1.40 & 1.58 & 1.57 & 169 & 1.67 & 1.81 \\
\hline Tenure & 0.03 & 0.02 & 0.03 & 0.02 & 0.03 & 0.02 \\
\hline Experience & 0.03 & 0.02 & 0.03 & 0.02 & 0.03 & 0.02 \\
\hline Squared $\left(10^{-4}\right)$ & 813 & .5 .65 & 6.77 & -4.97 & -6.59 & -5.02 \\
\hline Age & 0.02 & 0.01 & 0.01 & 0.01 & 0.01 & 0.01 \\
\hline Cender & 0.20 & 017 & 0.17 & 0.15 & 0.17 & 0.16 \\
\hline Educatton & 0.04 & 0.04 & 0.03 & 0.02 & 0.03 & 0.02 \\
\hline full times & $000 \%$ & 0.05 & $0.09 \%$ & 0.09 & $0.07 \%$ & 0.10 \\
\hline Initiation & & & 0,11 & 0.09 & 0.10 & 008 \\
\hline Supervisory & & & $0.08 \%$ & 0.07 & 0.10 & 0.07 \\
\hline Occupation level & & & 0.15 & 0.15 & 0.16 & 0.14 \\
\hline Size & & & 0.02 & 0.02 & 0.02 & 0.02 \\
\hline Manufacturing & & & & & -0.18 & -0.09 \\
\hline Building & & & & & -0.25 & $-0.05^{*}$ \\
\hline Trade & & & & & 0.13 & 0.14 \\
\hline Transport & & & & & $-0.03 \%$ & $0.03 \%$ \\
\hline Government: & & & & & -0.22 & 0.04 \\
\hline $\mathrm{R}^{2}$ adjusted & 0.32 & 035 & 0.41 & 0.41 & 0.45 & 0.42 \\
\hline Cases & 480 & 1366 & 416 & 1097 & 416 & 1097 \\
\hline RSS & 47.73 & 132.76 & $33,3 !$ & 83.81 & 30.20 & 82.03 \\
\hline
\end{tabular}

Remark, (W nol siginficanl at $5 \%$

In Table 7.7 the results of three wage equations are presented, both for workers employed on the internal labour market and those outside. First, a human capital model is estimated with education, previous experience, tenure, age and gender. Next, a more elaborate model is presented by adding demand-side variables. The choice of additional variables is based on the arguments provided in previous chapters: imperfect information on worker productivity and firm-specific human capital. So, next to the human capital variables, the initiation period, firm size, occupation level and management level are introduced. As mentioned above, in a last step the influence of industry is discussed. The wage equation is estimated by OLS ${ }^{10}$ with

${ }^{10}$ In order to test for heteroscedasticity first a plot of the squared residuals was made against the predicted values of the dependent variable. This showed no obvious relationship or indication of heteroscedasticity. Nevertheless, a Park test was conducted for every variable of the equation. The results suggested heteroscedasticity for tenure, because of a significant t-value (Gujarati, 1988, p. 329). However, a subsequent Goldfeld-Quandt test on this variable produced "labda' values below the critical $F$ value at $1 \%$, so the null-hypothesis of homoscedasticity could not be rejected. This was found for 
the net hourly wage (which includes extra payments, except those due to overtime) as dependent variable. ${ }^{11}$ Following the literature in this field of research, a semi-log specification for this hourly wage is taken (see Schippers, 1987, p. 50, and Heckman and Polachek, 1974). This implies that the paraneters indicate relative changes of the hourly wage as a result of absolute changes in the explanatory variables.

In accordance with previous arguments, the human capital variables are the years of education, the years of experience with other employers, and tenure at the current firm. In order to capture the decreasing effect of extra experience on the wage level (Osterman, 1975), the square of total experience (which is tenure plus previous experience) is also included (see also Blaug, 1976, p. 837). The age variable is introduced in order to capture some kind of general human capital which older workers are assumed to possess. Finally, dummy variables representing gender and full-time work are taken, which are valued $\mathbb{1}$ if the respondent is a man or a full-time employee. The variables included in the equations explain a reasonable part of the observed variance. Normally the adjusted correlation coefficients are between 0.20 and 0.35 (Osterman, 1975), ours are somewhat higher. In all specifications the human capital variables show a significant influence on the wage level and the sign of the variables confirms our expectations. All variables have a positive influence on the wage level, which means that more human capital leads to higher wages, although the negative sign of the squared total experience shows that this influence decreases. These results are hardly surprising and are found in many prior investigations. Furthermore, the influence of the variables in the wage specification for the employees on the internal labour market seems somewhat higher. This suggests that the returns to human capital are higher and human capital is better rewarded on the internal labour market.

The separate influence of structural, or demand-side, variables indicates that workers with identical human capital on different jobs or in different firms experience a different wage level. The choice of demand-side variables is determined by the arguments of Chapter 4 . In that chapter it is argued that internal labour market contracts are efficient if there are firmspecific skills and monitoring problems. Thus, if hypothesis 4.1 has to be tested, variables representing firm-specific skills and monitoring difficulty must be included. As stated in Chapter 6, it is assumed that firm-specific skills and accordingly productivity is higher if the respondent has a high initiation period (more than 3 months), and if he is on a high-level occupation (level 5 or higher). Further it is argued that employees on lower hierarchical levels are easier to supervise and those in supervisory positions are more difficalt to monitor. In accordance with Chapter 4 we argue that wages are higher in jobs with such monitoring problems. Further, in large firms it is more difficult to assess the productivity of the workers (Masters, 1969). The smaller a firm, the easier it is to relate output to effort or pertormance. Moreover, large firms have more possibilities of establishing personnel development program-

all workers together, as well as for those on the internal labour market separately. From these findingsi we concluded that there are no signs of heteroscedasticity, and that our Tables produce rellable information on the parameters and the t-values.

"In order to investigate whether there are signs of self-selectivity (see Maddala, 1983), the Mills ratio is estimated from the probit equation of Table 7.3. This Mills ratio is introduced as an extra explanatory variable in the equations of Table 7.5. From the result that the parameters of this additional variable were insignificant, with t-values well below the $5 \%$ significance level. we conclude that the data in the sample provide no indication for self-selectivity, and the equations are presented without this Mill ratio. 
mes to motivate workers to increased efforts. Since the log of firm size is the explanatory variable in the regressions, the parameter represents the elasticity of size with respect to wages. Table 7.7 shows that these demand-side variables have the expected sign, are of significant influence on the wage level, and increase the adjusted $\mathrm{R}^{2}$ significantly. ${ }^{12}$ Further it appears that the initiation period and supervisory level have a larger influence on the internal labour market than outside, which indicates that these demand-side wariables are of greater influence on the internal labour market.

In a third step industry effects are discussed. The importance of analysing industrial wage differences follows from results of previous research, which pointed to stable industrial wage differences, both over time and over industries (see Section 5.5). Therefore, it is tested whether the wage difference between the internal labour market and the external market still holds after correcting for industry influences, by introducing a dummy variable for every industry. The banking sector is used as industry of reference since it seems to pay the highest wage on the internal labour market. From the results we see that introducing sector dummies increases the adjusted $\mathrm{R}^{2}$ significantly. ${ }^{13}$ Introducing industry dummies shows that there is a separate industry influence on the internal labour market, even with the previous supply and demand-side variables already included. A surprising result is that on the internal labour market nearly all sector dummies are significant, indicating significant differences between the sector wages, but outside the internal labour market this effect is absent. This again confims the above-mentioned suggestion that on the internal labour market competitive pressures are reduced and there is room for different wages for otherwise identical employees. It also indicates that a sector can consist of an internall labour market besides an external labour market, since there is a different effect on the internal labour market of an industry and outside the internal labour market. Comparing the ranking of industry wages on the internal labour market with the results of Table 7.6 shows that after correcting for the other variables the ranking is slightly changed, although banking still pays the highest wage on the internal labour market, and building the lowest.

With these wage equations hypothesis 4.1 can be tested. From equation (7.2) it was clear that the wage difference between the internal labour market and the external labour market could be due either to different characteristics of internal labour market positions, or of a different treatment, or payment of these characteristics, on the internal and external market. Aiso we already concluded that job and worker characteristics differ between the internal and the external market (Section 7.2). So the question now is whether the wage differential is totally due to differences between the labour market positions, or whether the payment also differs between the internal and the external market, in casu $\beta_{\mathrm{i}}$ differs from $\beta_{\mathrm{e}}$. Therefore we test if the wage system on the internal labour market differs from that outside the internal labour market. In order to test this hypothesis on payments on the internal labour market, three tests are performed. In the first test a dummy variable for employment on the internal labour

${ }^{12}$ With sample size $\mathrm{N}$ and the number of parameters $\mathrm{k}_{1}$ for the old regression and $k_{2}$ for the new, the relevant statistic is $F=\left\{\left(R_{\text {new }}^{2}-R_{\text {bld }}^{2}\right) /\left(k_{2}-k_{1}\right)\right\} /\left\{\left(1-R^{2}{ }_{\text {new }}\right) /\left(N-k_{2}\right)\right\}$. The resulting values are 15.46 for those on the intemal labour market and 29.84 for those outside, for the second regression compared with the first. Both are significant at a 1 o level (Gujarati, 1988, p. $223 \mathrm{ff}$ ).

${ }^{13}$ The relevant statistic is presented in note 5 . The $F$ values are 8.27 for those on the intemal labour market and 4.62 for those outside, for the second regression compared with the first. Both are significant at a $1 \%$ level. 
market was introduced as additional variable. This dummy was positive and significant for a regression on all employees, and one for full-time workers only. In a second test estimate what workers currently employed outside the internal labour market would earn if they were employed on the internal labour market. Third, we investigate whether the influence of the wage determining variables differs significantly between the internal labour market and the externall labour market. This is done by the Chow test, which examines whether two equations are different or whether they come from the same underlying model.

The results of the second test are presented in Table 7.8. First, the results for all workers are presented. However, previous investigations with this data set pointed to the influence of the number of hours worked in a week (De Gijsel, Muysken and Wolfs, 1990, 1991). Therefore, the results for a sample restricted to full-time workers is presented in Table 7.8 as well. Since the same tendency appears for the restricted sample, only the results which refer to all workers are discussed. The average wage of workers on the internal labour market is $f 18.71$. Outside the internal labour market the average wage is $f$ 14.75. Substituting worker and job features of those employed outside the internal labour market in the wage equation for the internal labour market a wage of $f 15.68$ occurs $\left(W_{e}^{*}\right)$ for the human capital specification. Using the other two specifications wages of $f 15.51$ and $f 15.12$ occur. So workers currently employed outside the internal labour market would earn higher wages on the internal labour market. As is shown by the statistics between brackets (see footmote 1) the difference between their present wage $\left(W_{e}\right)$ of $f 14.75$ and the estimated wages $\left(W_{e}^{*}\right)$ is significant in all three cases. These findings suggest that identical workers are paid higher wages if they are employed on the internal labour market. Apparently rewarding job and worker features on the internal labour market differs from that on the externall labour market.

Table 7.8

Hourly wages before and after substitution

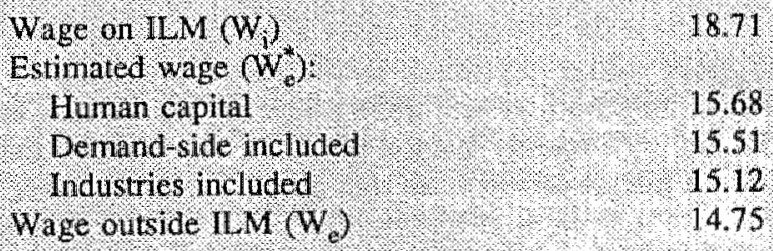

Remark. Estinited 2 value in brackets (see footnote 1 ):

These results further show that a large part of the gap between the wages for workers under internal labour market contracts and workers on the external labour market, is due to differences in the characteristics between workers on the internal labour market and those outside. This suggests that the internal labour market also serves as a selection mechanism. This corresponds to arguments mentioned in Chapter 3 by, for instance, the radicals (Section 3.2) and the job competition model of Thurow (Section 3.4). These theories argue that internal labour market contracts are offered to certain groups of workers (for instance, workers which are assumed to have stable working habits) and are used on jobs with certain features (high 
level jobs). Nevertheless, Table 7.8 shows that part of the wage gap is not explained by differences in worker and job features. Results reported in De Gijsel, Muysken and Wolfs (1990, 1991 ) on the wes for men and women point in the same direction. Separate estimations for men and for women indicate that workers with identicall (worker and job) characteristics earn higher wages if they are employed on the internal labour market.

For a further justification of the conclusion that the rewarding of job and worker features on the internal labour market differs from that on the extemal labour market, a third test, the Chow test, is performed. The purpose in our case is to investigate whether the coefficients of the wage equations for employees on the internal labour market differ from the equation for those employed outside the internal labour market. If the estimated $F$ value of the Chow test is above the critical value this means that each equation is different. ${ }^{14}$ In the first column the results of these tests on the wage equations of Table 7.7 are presented in Table 7.9. These refer to all workers. The results of the same test applied to the wage equations of full-time workers are presented in the second column.

Table 7.9

Chow test for different equations

\begin{tabular}{|c|c|c|c|}
\hline & Al & Full cimers. & Critical values. \\
\hline Human capital & 6.92 & 8.06 & $\left(\mathrm{~F}_{\left.8,1000^{-2}, 53\right)}\right.$ \\
\hline Demand side ncluded & 2.53 & 3.55 & $\left(\mathrm{~F}_{12,1000}-2,20\right)$ \\
\hline Industries included & 293 & 3.33 & $\left(\mathrm{~F}_{16,1000-2.01)}\right.$ \\
\hline
\end{tabular}

Since the estimated. $F$ values are well above the critical values for all wage equations we conclude that workers on an internal labour market experience a different reward structure than those outside, and thus we argue that the reward system differs between the internal labour market and the external market. So from the finding that the $\beta$ 's differ we conclude that the payment system on the internal labour market differs from that on the external market.

Finally we turn to hypothesis 4.3 which states that seniority is better rewarded on the internal labour market. From the equations presented in Table 7.7 it is already observed that the parameter for tenure on the internal labour market is higher compared to that of workers outside the internal labour market. Hypothesis 4.3 is further tested by estimating wage equations as presented in Table 7.7 , for a sample of all workers and a sample of full-time workers only, adding a multiplicative variable to these equations. This multiplicative variable is constructed

${ }^{14}$ The difference between two regressions is tested by estimating two seperate regressions as well as a pooled regression. With $\mathrm{k}$ parameters, sample size $\mathrm{N}, \mathrm{RSS}_{\text {pool }}$ for the residual sum of squares of the pooled regression and $\mathrm{RSS}_{\text {sum }}$ for the sum of the RSS of both separate regressions, the $\mathrm{F}$ value to be estimated is $F=\left\{\left(R_{S S}\right.\right.$ pool $\left.\left.-R S_{\text {sum }}\right) / k\right\} /\left\{\operatorname{RSS}_{\text {sunn }} / \mathrm{N}-\mathrm{k}\right\}$. The use of this test is allowed if there is no heteroscedasticiy (see Gujarati, 1988, p. $443 \mathrm{ff}$ ). From footnote 4 we know this is not the case. 
from a dummy for being employed on the internal labour market (ILM) and the variable representing senionity in years or tenure (TEN). This multiplicative variable (ILM*TEN) appears positive and significant in all wage equations. ${ }^{15}$ The $\mathrm{F}$ statistic (see footnote 6 ) showed that the addition of the term (ILM*TEN) significantly improved the explanatory power. These results suggest that hypothesis 4.3 is confirmed and that the parameter for seniority or tenure is significantly higher on the internal labour market.

To summarize, in this section on the influence of internal labour markets on wages, strong indications are found that the internal labour market, defined by long eventual tenure and intemal promotion opportunities, has its influence on the payment of employees. Confirmation of hypothesis 4.2 shows that average wages are higher. This, however, could be due to a different sample of workers employed on the intemal labour market than outside the internal labour market. Investigating hypothesis 4.5 in the previous section already showed that workers and jobs differ. Further investigating this by hypothesis 4.1 shows that these different characteristics indeed have a significant influence on the wage level. Neverthelless, part of the wage difference can be due to a different treatment. Testing hypothesis 4.1 , therefore leads to the conclusion that workers are paid by a different rewand structure which leads to the finding that identical workers are paid different wages on the internal and the external labour market. So we state that internal labour market positions arise in situations of difficult productivity measurement and development of firm-specific capital. In these situations workers are paid higher wages. Overall, workers in larger firms, and those employed in some specific industries are paid higher wages. So beside the traditional human capital variables the internal labour market indicates that denand-side variables play a separate role. The influence of these variables is explained by effort motivating and specific capital investment arguments. It can be concluded that on the internal labour market wages are higher and that the payment system differs from that outside the internal labour market.

\subsection{Consequences of the internal labour market}

Hypotheses 4.4 states that being employed on the internal labour market has its influence on the mobility of labour. The consequences of the internal labour market discussed here refer to the discussion in Chapter 1 . Hypothesis 4.4 states that mobility between firms on the internal labour market is decreased, while mobility inside the firm is increased. Due to better promotion opportunities within the firm, workers are focused more on internal than outside opportunities. Accordingly, internal mobility is higher since internal labour markets are partly defined by internal promotion opportunities. Both consequences are examined, as far as possible given the limitations of the data. In Table 7.10 the average values of these consequences are summarized. Below we only mention the results for all workers, but in Table 7.10 the results for full-time workers are presented as well. All differences described below, and presented in Table 7.10, are significant (see footnote 1). With respect to firm internal mobility it can be expected a larger percentage of workers on the internal labour market have experienced internal mobility inside the firm. Consequently the average number of horizontal or vertical job changes will be higher on the internal labour market. The results show that

${ }^{15}$ More precisely, the parameters (and t-values) for this multiplicative variable (ILM*TEN) in the three specifications are $0.008(6.13), 0.006(4.89)$ and $0.006(4.37)$ respectively. 
$41 \%$ of those employed on the internal labour market have previously experienced a firm internal job change, while outside the internal labour market this is only $19 \%$. A result which corresponds to this intrafirm mobility is that average job change within the firm of those employed on the internal labour market is 0.31 , while outside the internall labour market this in only 0.13. A third measure of firm internal mobility is the labour flexibility of the employees. Since attention is focused on firm internal job allocations inside flexibility will be higher and workers can be employed sooner on a larger number of jobs. Indeed, job flexibility, reflected in the "usability" of the employee in other jobs, on the internal labour market is higher; $82 \%$ reports to be employable in more jobs, while outside the internal labour market this is only $75 \%$.

Table 7.10

Variables on mobility and payments (average values)

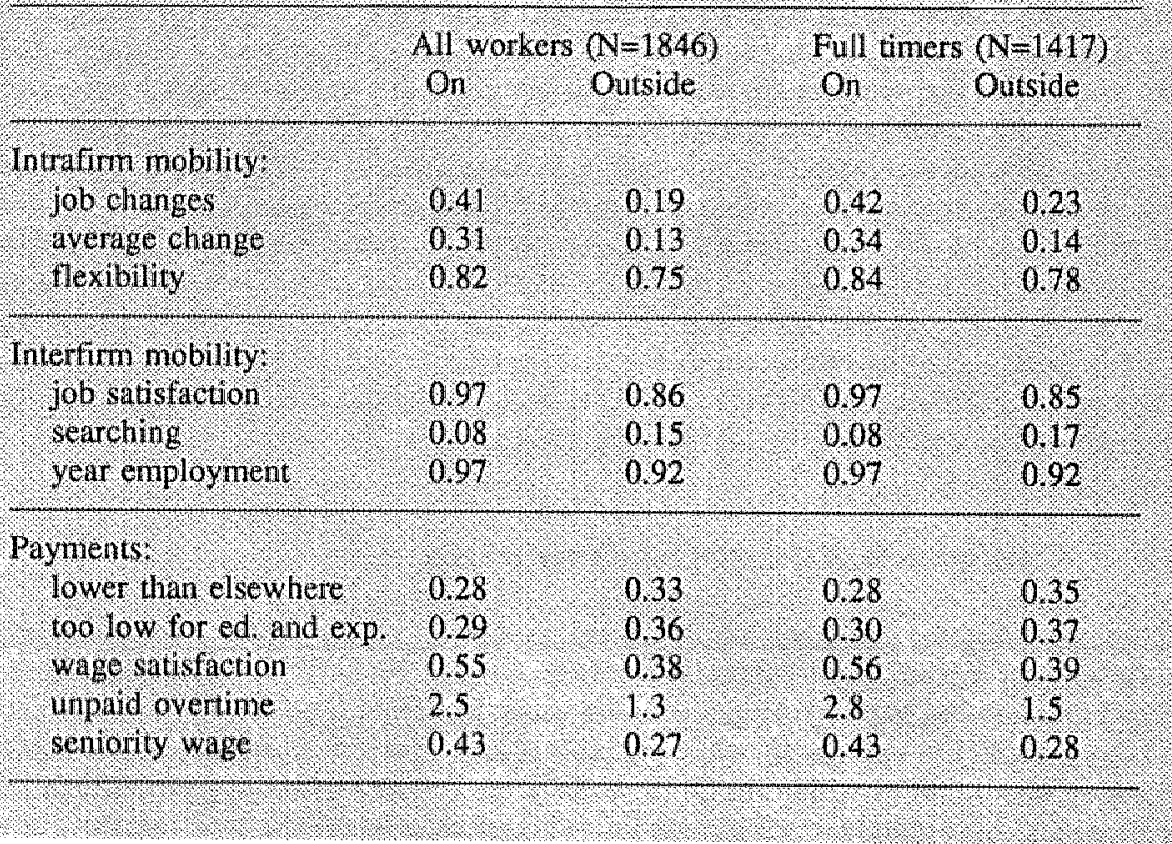

Tuming to interfirm mobility, workers on internal labour market positions with longer expected tenure and promotion opportunities will be more satisfied with their job than those outside the internal labour market. It thus is likely that they are less focused on external job opportunities. Of those employed on the internal labour market $97 \%$ is satisfied with their job, outside the internal labour market this is $86 \%$. Since we have no information on turnover a different proxy, which states whether the worker is currently looking for another job, is presented in Table 7.10 (see variable "searching"). It appears that only $8 \%$ of those employed on the internal labour market is looking for another job outside the firm, while for those employed outside the internall labour market this percentage is $15 \%$. When asked for their expectation of becoming unemployed during the next 12 months it can be expected that a 
lower percentage of workers will answer that they will leave the firm within a year, either voluntarily or through dismissal. Indeed the results show that $97 \%$ expects to remain employed, while outside the internal labour market this is $92 \%$. Finally, in Section 7.2 it is already shown that on the internal labour market average tenure is higher.

It is argued above that with our contract theoretical framework of Chapter 4 , and the crosssection data used in Chapter 6 and 7 , the consequence of internal labour markets with respect to wage rigidity cannot be examined in detail. Instead, in previous theories it was argued that on internal labour markets wages are coupled to jobs, and accordingly wages become more rigid (see, for instance, Thurow, 1975). However, no hypothesis is formulated with regard to internal labour markets and wage rigidity. Our data set, however, provides some additional information on the relationship between internal labour markets and wages, which will shortly be mentioned.

First, in previous sections it is already argued that wages are higher on an internal labour market. Thus it can be expected that, if workers are asked into their perception of their wage level compared with that of their colleagues in other firms, a lower percentage states that their wage is lower than that of their colleagues. Moreover, looking into the fairness of the wage related to the experience and education of the worker, a lower percentage will answer that the wage is too low. Indeed, when asked to compare their wage level to other standards $28 \%$ on the internal labour market reports that the wage is lower than that of collegues in other firms, and $29 \%$ reports it is too low in relation to their education and experience (abbreviated in Table 7.10 as "too low for ed. and exp."). Outside the internal labour narket these percentages are higher, $33 \%$ and $36 \%$ respectively. Overall, it is expected that wage satisfaction on an internal labour market will be higher. The results show that of the workers on the internal labour market $55 \%$ is satisfied with their wage, and those outside the internal labour market $38 \%$ is satisfied. Two additional results concerning the payment of labour are that the average number of hours unpaid overtime is about twice as high on the internal labour market; 2.5 hours versus 1.3 hours. This might indicate that workers receive a salary which is coupled to their job, more than to their productivity. Further, on intemal labour markets more employees report that their job regularly pays a wage increase. Of course, this suggests the existence of some seniority payment. It is found that on the internal labour market about $43 \%$ states that there job regularly gives a wage increase, while outside the internal labour market only $27 \%$ reports this seniority component.

Concluding it is admitted that hypothesis 4.4 cannot be tested in depth with our data. However, the findings of this section seem to provide some support for hypothesis 4.4. On the internal labour market intra-firm mobility is higher compared with workers employed outside the internall labour market. Furthermore inter-firm mobility is lower. Finally, there are indications that workers experience that wages on the internal labour market are higher than elsewhere and that there are regular wage increases.

\subsection{Conclusions}

This chapter presents the results of the investigation into the characteristics of the internal labour market, the relationship between internal labour markets and wages, and some consequences of internall labour markets. Contrary to most previous research in this examination an a priori definition of the internal labour market is used, which enables us to distinguish workers employed under internal labour market contracts from those on the external labour 
market. Employees on the intemal labour market positions were those with long-term employment relations as well as good promotion opportunities. In this way $26 \%$ of the employees were identified as being employed on the internal labour market.

Overall, the main conclusion of the empirical research in this chapter is that most hypotheses derived in Chapter 4 to answer the questions of Chapter 1, are confirmed. Our results on job and worker characteristics correspond closely with findings previously reported. Without being complete, and ignoring the conceptual and methodological differences between those studies and our investigation, the following results can be mentioned. On the internal labour market a higher percentage of male workers is found (Szydlik, 1990) and a lower percentage of women (Valkenburg and Vissers, 1979; Dale, 1987). The proportion of full-time workers on the intemal labour market is higher (Dale, 1987; Szydlik, 1990). The tenure distribution is skewed to high tenure groups (Valkenburg and Vissers, 1979; Szydlik 1990). Further, a higher occupational level is found on the internal labour market (Valkenburg and Vissers, 1979), as well as larger average firm size (Valkenburg and Vissers, 1979; Pfeffer and Cohen, 1984). Next to these results more need for initiation periods is found on the internal labour market (Valkenburg and Vissers, 1979). Furthermore, it is reported that there is no significant difference between the educational level, previous experience and age of workers on the internal labour market and those outside (for a discussion of this result, see Section 7.2). Investigating the industry of employment shows that internal labour market positions are overrepresented in the banking industry and underrepresented in the government sector.

Having established these differences the payment of employees reveals that awerage wages on an internal labour market are higher compared with those outside the internal labour market. This corresponds with results reported by Alexander (1974), Valkenburg and Vissers (1979), and Szydlik (1990). Above we elaborate on these findings by further examining this wage difference. It is shown that, beside the human capital variables, structural variables. influence the wage level, as well as the industry of employment. Although differences in worker and job features explain part of the wage difference between those employed on the internal labour market and those outside, a significant wage gap remains. This suggests that identical workers on identical jobs who are employed on the internal labour market receive higher wages. This means the kind of contract has a separate influence on the wage level.

The last question on the consequences of the internal labour market is briefly examined. The findings show that on the firm internal labour market intrafirm mobility is higher (Valkenburg and Vissers, 1979; Szydlik, 1990) and interfirm mobility lower (Szydlik, 1990). Finally, our results indicate that workers on the internal labour market more often experience wages to be higher on the internal labour market. 


\section{CHAPTER}

8

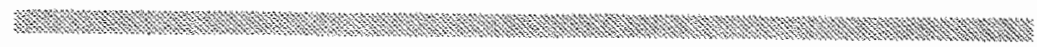

SUMMARY AND CONCLUSIONS

\subsection{Summary and conclusions}

The starting point in Chapter $l$ of our examination of internal labour markets was the problem of unemployment. In that chapter a trend was marked which indicated that an increasing number of economists seem to admit that the labour market model in its traditional shape is unsuitable to explain widely observed labour market phenomena such as wage rigidity, labour immobility and unemployment. This is not to say that the traditional labour market model is worthless. Instead the common opinion seems to be that this model needs to be refined, ameliorated or adjusted. In this respect other analysing concepts, such as segmented labour markets and internal labour markets, appear useful.

Nevertheless, these recent approaches are not full-grown yet, and cannot replace the traditional model. In this study attention is focused on one of these relatively new concepts: the internal labour market. This is commonly described as (that part of) an organization in which the payment of employees, as well as the way in which they are distributed over the job hierarchy, is subject to rules and procedures of personnel policies and management. The distinguishing characteristic of the internal labour market concept from other labour market concepts is that it mitigates the influence of market forces, usually referred to as the price system. ${ }^{1}$ The cliche which is used to refer to this development in labour economics is that the black box, i.e., the firm, is opened.

Topics previously discussed in diverging research areas such as personnell management, organization sociology, management development, microeconomics, organization theory and labour psychology, can all be related to this new concept. It is clear that it is impossible to study all aspects related to the internal labour market. Therefore, the number of research questions is limited to three, which refer to the characteristics of internal labour markets and the relationship between internal labour markets, wages and mobility (see Table 8.1).

1 In later approaches conceming the intemal labour market, as well as in ours, this distinction is less sharp. 


\section{Table 8.1 Research questions of this study}

1. What are the chardeteristic features of workers and jobs on the triternal labour mitiket?

11. What is the relitionship between frm internal labour markets and 1. 80.59

III. What are the consequences of internal labour narkes for the flexibility of wages and he nobility of labour?

The first question concerns an investigation into the aspects which make internal labour market positions differ from those outside. In fact it tries to examine how workers employed on the internal labour market differ from those outside, and how jobs on the internal labour market differ from those on the external labour market. The second question enquires into the relationship between internal labour markets and wages. Since internal labour market theory might, in the future, be a serious candidate for explaining unemployment, it must be clear how the pricing process on the labour market works if internal labour markets exist. The third question asks for general conclusions on the relationship between internal labour markets and labour mobility. In Chapters 2 to 7 we have tried to find answers to these questions.

In Chapter 2 we started with a discussion on the origin of the internal labour market concept. This is done by shortly referring to the discussion on the segmentation of labour market following the historical line from Mill and Cairnes, to Ken and Dunlop, until Doeringer and Piore. In fact it is their definition of the intemal labour market which is the starting point of most analyses. Neveriheless, a review of prior definitions of the internal labour market shows that there is no agreement on its essentials. Instead, this review results in a long list of features adhered to the internal labour market. Since it is our purpose to empirically investigate the internal labour market with survey data, this forces us to define the internal labour market in our own terms by a restricted number of essential features. In line with the arguments of Doeringer and Piore we consider both long-term employment relations and internal promotion opportunities as essential to the internal Jabour market.

Having defined the internal labour market in this way, in Chapter 3 an attempt is made to answer the questions of research by inwestigating prior labour market theories. Six labour market theories are examined in order to explain long-term employment relations and internal promotion opportunities. These are the radical approach, transaction cost theory, human capital theory, implicit contract theory, efficiency wage theory, and insider outsider theory. The conclusion is that, although the concept internal \#abour market appears in some theories, none of these approaches offers clear-cut answers to why jobs exist with long-term employment relations and good promotion opportunities. Nevertheless, what can be found from this review is that two explanatory concepts appear fruitful for the research questions. These are the development of firm-specific human capital and the existence of imperfect information on the productivity of employees. Our further examinations are based on these two fenomena.

In Chapter 4 we offer a contract interpretation of the internal labour market. Contracts are classified according to two criteria: whether employment is ex ante guaranteed for a long time or not, and whether wages are ex ante fixed or variable. Several contracting modes are distinguished according to these two criteria. Of the resulting contracts some capture the essence 
of the internal labour market. Starting from our definition of the internal labour market we argue that it can be interpreted as a labour contract between employer and employee which covers more payment periods and includes internal promotion opportunities. Internal labour market contracts are altematively referred to as delayed payment contracts. Subsequently contracts are examined in a two-period model based on Mallcomson (1984). According to the findings in Chapter 3 two sources of the internal labour market are distinguished: firm-specific human capital and incentives. If there is firm-specific human capital it can be efficient for the employer to bind the worker to the firm by offering him long-term employment contracts with good promotion opportunities. If worker productivity is hard (and thus costly) to observe, it can be efficient for the employer to offer contracts with guaranteed employment and opportunities for future wage increases. By these promotion opportunities workers are motivated to excert higher effort levels. Thus promotion contracts and seniority contracts can result from the development of firm-specific human capital or monitoring problems. Of course these two contracts, seniority and promotion contracts, are highly complementary, for instance, because workers who have developed a serious amount of firm-specific skills are increasingly difficult to monitor.

With this distinction of two types of internal labour market contracts an attempt is made to answer the research questions. Accordingly some hypotheses are derived from the Malcomson model and some related models. These hypotheses are summarized in Table 8.2 and related to the original research questions (note that the order of hypotheses differs from that of the research questions). With respect to the question into the features of workers and jobs on the internall labour market in comparison with those on the external labour market it is argued that intemal labour market contracts are used if the development of firm-specific skills is important and problems of monitoring workers exist. Accordingly in hypothesis 4.5 features of workers and jobs are listed. Question 2 concerns the relationship between internal labour markets and wages. In general it is argued that internal labour markets consist of better (higher paying) jobs and better qualified (or more productive) workers. This leads to hypothesis 4.2: average wages on the internal labour market exceed those on the external labour market. With the Malcomson model it is argued that even for (initially) identical workers wages are higher on internal labour markets. Workers on the internal labour market are rewarded for their higher productivity which is a result of more firm-specific skills and higher effort. So higher wages exits even after differences in characteristics of jobs and workers are taken into account (hypothesis 4.1). Furthermore, the deferred payment schedule which characterizes internal labour market contracts results in a higher increase in wages with seniority than outside the internal labour market (hypothesis 4.3 ). Finally, with respect to question 3 it is hypothesized in hypothesis 4.4 that on internal labour markets intrafirm mobility is higher and interfirm mobility is lower. At most some indications that internal labour markets lead to more rigid wages are found in this study.

The formulation of the hypotheses closes the theoretical part of this study. Next attention is tumed to the empirical part, which includes our own empirical investigations into these hypotheses. First, in Chapter 5, prior empirical research into internal labour markets and some related topics are reviewed. It appears that prior research into internal labour markets is scarce. However, many features which are usually adhered to the internal labour market, have previously been a matter of discussion. Moreover, most research is based on case studies or interviews, which prohibits general conclusions. One of the reasons for this restriction to case studies in previous research is the argument that the internal labour market cannot be described by a single statistic, and thus many empirical methods fail. A further argument is that data on firm side variables are scarce. In response to these considerations we argue that inter- 
nal labour markets can be described by a single (in fact two) statistics: long-term employment and internal promotion opportunities. Furthermore, supply-side data, as in household surveys, can be used as well to investigate some questions concerning the internal labour market. Thus in the proceeding chapters results are presented based on such a definition and such a data set.

Table 8.2 Research questions and related hypotheses

\section{Queston $\mathrm{l}$.}

Hypothesis 4.5 . On the internal labour market the proportion of male and full time workers 15 higher than on the external labour market. Further the length of the initiation period, average 1016 level, average fim size and capital intensivy is highter on the internal labour narket Finally, average age, years of education and previous experience are not significantly different from the external labour narket.

\section{Question II:}

Hypothesis 41 . A verage (expected) wages on the intemal labour market are higher compared to those outside the internal labour market for identical workers on identical jobs:

Hypohesis 42 . Average (expected) wages on the internal labour market are higher than those on the external labour market.

Hypothesis 4.3. On the internal labour narket the slope of the earnings profile is steeper than the slope on the external labour nuarket.

\section{Question $\mathrm{II}$ :}

Hypothesis 4.4 . On the internal labour market the inter-fim mobility is lower and the intra firm mobility is higher compared to the external labour market Further, average cenure is higher on the internal labour market.

In Chapter 6 empirical research is presented which is based on a cross-section of the Dutch potential labour population of 1985, gathered by the Organization of Strategic Labour Market Research. The main purpose of this chapter is to operationalize our definition of the internal labour market. Therefore the labour market is divided in an internal labour market, defined by good promotion opportunities and long employment relations, and the remainder of the labour market, the external labour market. The internal promotion criterium is constructed by using nine questions which reflect the perception of the employee of the internal promotion opportunities of his work. With respect to the second criterium it is argued that it is not actual tenure which is of interest for the importance of long term employment relations on the internal labour market, but the eventual tenure of an employee. Since there is no such variable directly available from the survey it must be calculated first. So for every individual worker 
in the survey an eventual tenure is estimated with the hazard. This hazard is an estimate of the individual's probability of leaving the firm within some time. In the next step of the analysis workers with an expected tenure of ten years or more are assumed to be on an internal labour market, provided they have good (or above average) promotion opportunities. With these proxies for good promotion opportunities and long tenure, the size of the internal labour market can be found. It appears that on the Dutch labour market about $26 \%$ of the workers is employed on the internal labour market. With $32 \%$ this percentage is more than twice as high as that for women $(14 \%)$. This could be due to the finding that most part-time workers are women. However, restricting the sample to full-time workers these percentages are $31 \%$ for all workers, while for men (with $34 \%$ ) this is still almost twice as high as for women $(18 \%)$.

Chapter 7 tests hypotheses 4.1 to 4.6. Using the method of Chapter 6 workers are divided into those employed on the internal labour market and those on the external labour market. Now both groups are compared with respect to their worker and job characteristics. With respect to question 1 (or hypothesis 4.6) the following results are found: the percentage of men was significantly higher on the internal labour market. Furthermore, average age, average tenure, the initiation period, job level, and firm size were higher. However levell of education was hardly different, which suggests that low level workers can be employed at the internal labour market as well. Finally it appeared that the percentage of workers on the internal labour market was rather high in banking and rather low in governmental jobs.

In order to investigate question 2 (or hypothesis 4.2) average wages are compared. Indeed average wages for all workers, as well as for men and women separately and for full-time workers and part-time workers are higher on the internal labour market. Of course this could be caused by the differences found under hypothesis 4.6 . Thus wage equations are estimated with OLS controlling for worker and job differences as mentioned under hypothesis 4.6. Substituting features of workers outside the internal labour market into the wage equation of those on the internal labour market gives an indication of the wage difference between the groups, controlling for a set of other influences. It appeared that employment on the internal labour market leads to higher wages. Furthermore, the wage equations differed significantly. Finally seniority wages are investigated.

With respect to question 3 the hypothesis into labour mobility resulted in the findings that intra firm mobility is relatively high and interfirm mobility is lower.

\subsection{Evaluation and further research}

Two matters remain to be discussed. First, we argue in what way this study improves on other studies. Second, its shortcomings are summarized and some directions for further research are listed. Starting with the improvements of this study, it improves on previous research on several points. First, a thourough discussion on the essential features of the internal labour market is provided in order to avoid descriptive, rather vague, definitions of the internal labour market which hamper empirical investigations. Second, the internal labour market concept is related to recent developments in labour economics which focus on information imperfections and firm internal processes. This is achieved by interpreting the internal labour market as a contract. This location of the internal labour market in this contract theoretical tradition opens the way to more analytical approaches of the internal labour market. Third, empirically this study has shown that the theoretical concept can be used in empirical research as well. It is possible to assess on an individual level whether a worker is employed on the inter- 
nal labour market. In fact his is one of the first studies which allows general conclusions on the size and characteristics of the intemal labour market, especially for the Netherlands. Fourth, and more precisely, this research has shown that the wage differential which exists between those employed on the internal labour market and those outside is not a result of differences in jobs and workers only. So it provides an argument for efficiency wage theories which argue that some parts of the labour market employ human resources more efficiently. Fifth, and last, this investigation has empirically specified down some features of workers and jobs on the internal labour market, instead of assuming a priori that workers differ in these characteristics.

Nevertheless, this study certainly has its drawbacks. In general, every study which focuses on both theoretical and empirical matters incorporates the risk of being criticized by specialists of both "sides". Therefore, we close this study by listing those points on which ask for improvement in future research. As a general point, attention is restricted to a limited number of questions. Undoubtedly, one can point to many questions which are not treated in this study, but are of importance in this research area. Some remarks on this point are in order. First, the method of investigation, with cross-sectional survey data, restricts the topics discussed. Some for instance argue that, in order to study the essentials of internal labour markets, longitudinal data are needed concerning firm internal processes, or case studies ame required to capture all aspects of internal labour markets. Our research is based on crosssectional data for a single year and a single country. One reason for this is that no longitudinal data were available at the start of our investigations. Nowadays such data are available and subsequent research based on longitudinal data will most certainly lead to interesting complementary findings. Nevertheless, we regard our cross-sectional data as appropriate for our research questions (see Section 2.5 and 5.3). Second, having mentioned this restriction, the important question to ask is whether the questions treated are worthwhile. In this respect we think that, referring to the problem of unemployment, which originates this research in a way (see Chapter 1), the question of internal labour markets and wages, which is the core of our examinations, is essential. Further, to clarify some of the discussion on the features of internal labour markets a discussion on its jobs and workers is of value. Since our discussion evolves around these two topics, we think that our choice of research questions is justified. Notwithstanding, other questions remain which provide a research agenda for future research.

First, we stress that the development of internal labour markets needs to be discussed in more detail. Dynamic aspects of internal labour markets are hardly discussed in this thesis. Some studies mentioned in Chapter 5 addressed this topic (see for instance Scholten, 1984; Warmerdam and Van den Berg, 1986; Blossfeld and Mayer, 1988). For a better understanding of the mechanisms of the labour market it is worthwhile to know whether the internal labour market moves in the same direction as the business cycle. Do internal labour markets increase during a boom because employers try to bind their employees who perceive better opportunities elsewhere (Verburg, 1985). Or, on the contrary, does the internal labour market increase during a downswing because of reorganizations, and protection of inside workers (Albeda, 1985; Scholten, 1984) ${ }^{2}$ In fact our approach to the internal labour market is static, while several authors have emphasized its dynamic character. Thus we give no explanation for cyclical movements in wages, employment, profits and productivity, although this is an important elaboration for policy questions.

\footnotetext{
${ }^{2}$ Some other references on this discussion are Akerlof and Yellen $(1986$, p. 11), Katz (1986, p.241242), De Grip (1985), Bills (1987, p. 218), Osterman (1984, p.20) and Sengenberger (1981).
} 
Second, the model discussed in Chapter 4 provides no comprehensive discussion on the relative efficiency of contracts. Several contracts were ruled out a priori since they were of minor importance for the research questions. Examples of these are piece rates and "up-orout" contracts. Also the relative efficiency of internal labour market contracts, especially seniority contracts and promotion contracts, is not discussed. A model including firm specific skills as well as effort or incentive effects is required for such an analysis. Thus the comparison of contracts should be extended in future research. In this respect it is useful to point to the importance of long run considerations. Some theoretical studies have argued that in the long run different contracts might lead to similar outcomes in effort and wage tems (Weitzman, 1983; Malcomson, 1986). A complete investigation in the efficiency of (internal) labour markets contracts should take these considerations into account. It implies that, despite some remarks made in Chapter 4 , our investigations merely concentrate on the short run.

Last, but not least, if the internal labour is to become the alternative (or improved) framework of the traditional labour market model it has to be modelled in a general equilibrium context. Most approaches discussed in this study are partial, concentrating on the labour market, and mainly concerned with short run aspects. For a proper modelling of the labour market the equilibrium two-sector models in the tradition of Harris and Todaro (see Section 4.8) are heipful. Evidence, as presented in this study, for the existence of internal labour markets increases the need for economists to discuss and model these firm internal processes in a proper way. Interesting in this respect is the question mentioned above, whether the contract offered to employees matters in the long run. The equivalence theorem of Malcomson (1986) shows that under some conditions for every piece rate contract a toumament contract can be developed which reaches the same efficient outcome. Weitzman (1983) also has pointed to the long run indifference of payment systems.

Third, to keep our discussion of internal labour market rather simple, several phenomena are a priori ruled out. Wage increases between periods are considered as internal promotions. This implies that vertical and horizontal job changes are similarly treated. Wage changes without internal promotion, or internal promotions without wage changes are also not discussed in this study. In the same way a drawback is that firm internal demotions are not discussed. Nevertheless, it is our opinion that the contract approach, on which our analysis is based, is able to incorporate these elements. Internal promotions can be modelled considering both changes in monetary and status aspects, so intemal mobility with an increase in status without an increase in income can be analysed.

The previous point is part of a more general shortcoming. In general, little attention is paid to varying topes of internal labour markets (Bills, 1987) and detailed firm intermal processes such as careers, job clusters, and vacancy chains. There are two reasons for our relative ignorance on this point. First, it is our opinion that the general questions into the definition, existence, size and features have to be addressed before a detailed analysis of firm internall processes can be performed. It is possible to use our definition of the internal labour market in a subsequent research into different kind of internal labour markets, firm internal career patterns, and job clusters which make up an internal labour market. A second reason why we did not concentrate on such questions was that our dataset did not allow such an approach. Although the data set of the Organization of Strategic Labour Market Research (OSA) is rich, it does not contain very detailed information on the required data for such research questions. It is likely that the new cross-sectional surveys of the OSA, based on firms instead of households, will provide improved information on these aspects.

Moreover, at this point we refer to two types of research for these kinds of questions. First of all there is the organizational perspective on internal labour markets (for review articles 
see Schreuder, 1985; Hendrikse and Schrewder, 1987). From an organizational point of view there are many interesting questions concerning the structure of organizations, personnel management, diversity of payment systems and the different kind of promotion ladders, job clusters and career trajectories. What precise administrative rules and procedures are used on an internal labour market? what do the promotion ladders look like?, how do workers move along the ladders?, what is the advantage of having many short ladders compared to one long ladder?, what is the function of job clusters?, and how important is horizontal mobility compared with vertical mobility? A part from extensive treatment of all kinds of questions concerning personnel management techniques, human resource management and organizational behaviour with respect to internal labour market is not presented. Research like that of Bills (1987), Soeters and Schwan (1990), Schwan and Soeters (1991a, 1991b, 1991c), Di Prete (1987), Baron, Davis-Blake and Bielby (1986), Lawler III (1987), Jensen and Meckling (1976), Brilderl (1990) and Rosenbaum (1979a, 1979b) focuses on these firm internal processes.

A second type of research which focuses on these questions from a microeconomic perspective is concerned with the development of career lines and reward structures. References in this respect are Cooter and Restrepo (1979), Morrison and Schmittlein (1981), Oswald (1981), and Beckmann (1978, 1983). A topic which is regularly discussed in these models is the relative efficiency of ability and seniority as promotion criteria (Abraham and Medoff, 1985; Mills, 1985). Perhaps our discussion in Chapter 4 of turnover and incentive models might provide arguments for this analysis.

Fifth, there is little attention for considerations of equity, fairness, custom and status. Nevertheless, these might play an important role on internal labour markets. In fact, the moral hazard problem, which is solwed by the promotion contract, can be solved by considerations of faimess. In the partial gift exchange model of Akerlof (1982) workers exchange effort for employment guarantee. Since these approaches are not directed to promotion opportunities, they are beyond the scope of our internal labour market analysis. Additionally, we do not state that these aspects are empirically irrelevant, but merely stress that our data, as most data, provide no information on equity and fairness.

Sixth, although internal labour markets are concerned with institutions, rules and procedures concerning firm internal processes, there is no explicit treatment of such institutions, such as rade unions. Although unions are casually mentioned in this study, a complete description of the relationship between unions and internal labour markets is not given. Nevertheless, this relationship is interesting, since the question is raised whether unionization and the development of internal labour markets are complementary (internal labour markets being highly organized), or substitutes (by installing an internal labour market a union can be kept out of the firm). On the one hand unions in highlly unionized firms or industries can persuade or force the employer to offer acceptable working conditions, even including long-term employment and good promotion opportunities. Investigating internal labour markets in US and British iron and steel industries Elbaum (1983, p. 264) suggests that internal labour markets are (partly) originated by unions or "pressure collectively exerted by workers for employment security and advancement, with consequences which may include rigid internal promotion rules". On the other hand one can argue that in firms or industries with an internal labour market workers have no incentives to join a union and union membership will be low. In this respect we quote Bills, who investigated the internal labour market in a City Hospital: "The hospital's wage and salary administration indicated that the high wage rates are a part of City Hospital's effort to remain union-free" (1987, p. 209). Theories which discuss these relationships are found in Freeman and Medoff (1984), Katz (1986, p. 236), Doeringer and 
Piore (1971), Creedy and Whitfield (1988, p. 248), and Addison and Castro (1987). In the previous point the relative efficiency of seniority and ability as criterium for promotion is discussed. In this respect it can be asked whether unionized firms sooner use seniority as a promotion criterium compared with non-unionized firms. Such questions are investigated in Abraham and Medoff (1985) who find that, although seniority seems more important in union settings, the difference with non-union settings is rather small. In contrast Mills (1985) finds no separate influence of unionization on the use of seniority as an internal promotion criterium.

So, although from Section 8.1 we concluded that some questions concerning internal labour markets are answered, at the end of this closing section we are with our feet back on the ground. Section 8.2 has shown that at least as many questions remain unanswered, and ask for further research. It is our hope that this study has provided a useful discussion and definition of the concept of the internal labour market, and that it has shown that cross-sectional data can be useful in answering (some) questions concerning intemal labour markets and the processes which are going on inside the black box. 

Het verschijnsel werkloosheid stelt economen in het algemeen voor grote problemen. Voor de verklaring ervan grijpt men vaak terug op achterliggende problemen als starheid van lonen en immobiliteit van arbeid. Arbeildsrelaties zouden nief flexibel genoeg zijn, en lonen te star, om te zorgen dat iedereen die een baan will er ook een $\mathrm{kan}$ krijgen. On een beter inzicht te krijgen in de omstandigheden waarin loonstarheid en immobiele arbeid voorkomen is het zinvol de aandacht te richten op de plaats waar beslissingen over loonhoogte en duur van de arbeidsrelatie tot stand komen: de organisatie. Het onderzoeksgebied dat schuil gaat achter de term interne arbeidsmarkt omvat het onderzoek naar loonvorming en allocatie van arbeid binmen de bedrijfsinterne arbeidmarkt. Ondat bij een onderzoek op dit terrein legio begrippen, aspecten en factoren van invloed zijn, en diverse disciplines zich met aan de interne arbeidsmarkt gelieerde verschijnselen hebben beziggehouden, is een van de eerste stappen in deze studie het afbakenen van het onderzoeksterrein. Daarom is besloten het onderzoek te beperken tot drie vragen. De eerste gaat na door welke kenmerken de interne arbeidsmarkt wordt beschreven. Welke werknemers komen op de interne arbeidsmarkt voor, welke banen zijn er te vinden en wat voor soort bedrijven hebben zulke interne arbeidsmarkten. De tweede vraag richt zich direct op de beloning van arbeid en onderzoekt de relatie tussen de interne arbeidsmarkt en beloning. De derde en laatste vraag grijpt enigszins terug op het achterliggende probleem van werkloosheid, en gaat in op de gevolgen van het bestaan van interne arbeidsmarkten voor de mobiliteit van arbeid en de starheid van beloning. Deze afbakening van het onderzoek aan de hand van drie onderzoekswragen windt plaats in hoofdstuk 1 . Het doel wan de dissertatie is deze vragen zowel theoretisch als empirisch te onderzoeken.

In hoofdstuk 2 wordt dieper ingegaan op de term interne arbeidsmarkt. Een bestudering van eerdere definities van het begrip interne arbeidsmarkt latat zien dat er geen consensus bestaat over de definitie van de interne arbeidsmarkt. Hoogstens bestaat er overeenstemming over de definitie van Doeringer en Piore, maar deze is nogall vaag en biedit geen direct aanknopingspunt voor empirisch onderzoek. De definitie stelt dat de interne arbeidsmarkt bestaat uit een verzameling regels en procedures die zorgen voor de beloning en allocatie van arbeid. Als centraal kenmerk van de interne arbeidsmarkt nemen we eigenschap dat werknemers op de interne arbeidsmarkt afgeschermd zijn van de buitenwereld. Sommige banen op de interne arbeidsmarkt zijn alleen toegankelijk voor hen die reeds op de interne arbeidsmarkt werkzaam zijn. Op zo'n interne arbeidsmarkt ontwikkelen zich daarom langdurige arbeidsrelaties. Maar omdat een langdurige arbeidsrelatie zonder mogelijkheden om vooruit te komen geen juiste beschrijving is van de interne arbeidsmarkt, is het bestaan van interne promotiemogelijkheden als tweede kenmerk meegenomen. Zo komen we tot onze definitie van de interne arbeidsmarkt: de interne arbeidsmarkt bestaat uit die werknemers en die banen welke gekenmerkt worden door langdurige arbeidsrelaties met interne promotiemogelijkheden.

In hoofdstuk 3 proberen we door het bestuderen van een zestal recente arbeidsmarktheorieën antwoorden te vinden op onze onderzoeksvragen en op het verklaren van langdurige arbeidsrelaties en interne promotiemogelijkheden. $\mathrm{Na}$ bestudering wan de zes theorieën, te weten de radicale benadering, de theorie van de transactiekosten, de theorie van het menselijk kapitaal, de impliciete contracten theorie, de efficiênte loon theorie en de insider-outsider theorie, is de conclusie dat geen enkele een afdoende verklaring geeft voor de drie onderzoeksvragen. Wel zijn twee concepten gevonden welke centraal lijken te staan bij vrijwel elke 
verklaring van langdurige arbeidsrelaties, namelijk het bestaan van meetproblemen met betrekking tot het vaststellen van de productiviteit van de werknemer en de ontwikkeling van bedrijfsspecifieke vaardigheden. De rest van ons betoog is dan ook in hoge mate gebaseerd op deze twee begrippen.

Voor een meer analytische benadering van de interne arbeidsmarkt wordt in hoofdstuk 4 aansluiting gezocht bij de contracttheoretische benadering van de arbeidsmarkt. In navolging van de transactiekostenbenadering vatten we de interne arbeidsmarkt op als een contract. Contracten worden gerangschikt volgens twee criteria. Ten eerste of een werknemer en een werkgever op voorhand besluiten tot een kortdurend contract dan wel een langdurig contract. Ten tweede, of de beloning op voorhand vastligt, of dat deze afhankelijk is van de prestaties van de werknemer. Op deze manier onderscheiden we diverse soorten contracten, waarvan de belangrijkste op dit moment zijn: het prestatieloon, een vast salaris, het senioriteitsloon en de promotiebeloning. Het interne arbeidsmarktcontract, dat vanwege onze definitie gekenmerkt wordt door langdurige arbeidsrelaties met promotiemogelijkheden, wordt beschreven door het senioriteitsloon, alsmede door het promotieloon. Onze stelling is dat het senioriteitsloon, waarbij een werknemer voor een lange tijd wordt aangenomen en waarbij vantevoren gegarandeerde loonstijgingen zijn afgesproken, voorkomt als er sprake is van bedrijfsspecifiek kapitaal. Het promotiecontract, waarbij een werknemer woor lange tijd wordt aangenomen, maar waarbij eventuele loonswerhogingen in de toekomst (als gevolg van promoties) afhankelijk zijn wan zijn prestaties, komt voor als er sprake is van meetproblemen met betrekking tot de exacte productiviteit van de werknemer. Senioriteitscontracten zijn efficiënt wanneer specifieke vaardigheden van grote betekenis zijn en de werknemer dus aan het bedrijf gebonden moet worden door hem loonsverhogingen in het vooruitzicht te stellen. Promotiecontracten zijn efficiênt wanneer ze werknemers aanzetten tot een hogere productiviteit door het leveren van een hogere inspanning. Met deze interpretatie van de interne arbeidsmarkt als een contract wordt onderzocht in hoeverre een antwoord geven kan worden op de drie onderzoeksvragen. Vervolgens worden een zestal hypothesen afgeleid, welke in het empirische deel van de studie getoetst worden.

In het tweede deel van de studie bespreken we allereerst empirisch onderzoek dat in Nederland en het buitenland verricht is naar de interne arbeidsmarkt. Het blijkt dat ook in het empirisch onderzoek geen overeenstemming bestaat over de variabelen welke een maatstaf zijn voor de interne arbeidsmarkt. Veelal worden in een studie diverse variabelen of kenmerken onderzocht en wordt uit hun gemeenschappelijk voorkomen geconcludeerd dat interne arbeidsmarkten bestaan. Veel onderzoek bestaat dan ook uit case studies. De resultaten van zullk onderzoek zijn in de regel niet generaliseerbaar. Wij proberen daarentegen in de volgende hoofdstukken de inteme arbeidsmarkt te onderzoeken met behulp van een representatieve steekproef van de werkende Nederlandse beroepsbevolking. In de bespreking van de resultaten wan eerder onderzoek, in hoofdstuk 5 , worden, zij het gefragmenteerd, in diverse studies aanwijzingen gevonden die wijzen op een ondersteuning voor de meeste hypothesen. Dat duidt erop dat interne arbeidsmarkten voor het merendeel bevolkt worden door mannen en full timers. Verder lijken inteme arbeidsmarkten vaker voor te komen in grote bedrijven. Werknemers op interne arbeidsmarkten ontvangen gemiddeld hogere lonen, maar het is onduidelijk in hoeverre dat een gewolg is van de hierboven genoemde verschillen in kenmerken tussen werknemers op en buiten de interne arbeidsmarkt. Gegeven het fragmentarische karakter van de bevindingen is voorzichtigheid geboden met het generaliseren van de resultaten. Om onze drie onderzoekswragen consistenter te beantwoorden is onderzoek nodig waarin deze gezamenlijk beantwoord worden. Dat wordt in hoofdstuk 6 en hoofdstuk 7 uitgevoerd. 
In hoofdstuk 6 wordt de data set beschreven waarmee het empirisch onderzoek wordt uit. gewoerd. Het betreft hier de resultaten van een in 1985 in opracht van de Organisatie voor Strategisch Arbeidsmarkt Onderzoek (OSA) gehouden enquête onder de potentiële Nederlandse beroepsbevolking. De gebruikte steekproef, welke representatief is wor de het werkende deel van de beroepsbevolking, bestaat uit 1846 personen. Om onze onderzoeksvragen te beantwoorden is het eerst nodig dat we voor elke werknemer vaststellen of hij werkzaam is op de interne arbeidsmarkt. Gezien onze definitie impliceert dit dat we moeten vaststellen of hij nog lange tijd bij dezelfde werkgever werkzaam zal zijn, en of hij goede promotiemogelijkheden binnen het bedrijf heeft. Met behulp van de zogenaamde 'hazard rate methode' wordt voor elke werknemer een te verwachten baanduur berekend, op basis van zijn persoons- en baankenmerken. Met behulp van de resultaten onderscheiden we werknemers die uiteindelijk minstens 10 jaar bij dezelfde werkgever zullen blijven, en zij die deze baanlengte niet zullen halen. Vervolgens bekijken we de promotiemogelijkheden voor elke werknemer. Met behulp van een negental vragen over de mogelijkheden die het werk biedt om vooruit te komen wordt een maatstaf ontwikkeld woor promotiemogelijkheden. Iemand die meer dan gerniddeld scoort op die maatstaf wordt verondersteld goede promotiemogelijkheden te hebben. Door de gegevens over de verwachte baanduur en promotiemogelijkheden te combineren is het mogelijk vast te stellen of iemand op de interne arbeidsmarkt werkzaam is. Dit leidt to de bevinding dat in Nederland 26\% van de werknemers op de interne arbeidsmarkt werkzaam is.

Met behulp van deze gegevens wordt de steekproef opgesplitst in twee groepen, namelijk de werknemers op en werknemers buiten de interne arbeidsmarkt. In hoofdstuk 7 worden de drie onderzoekswragen beantwoord door beide groepen met elkaar te vergelijken. Bij een vergelijking van de kenmerken van beide groepen blijken ze op bepaalde punten duidelijk te verschillen. Mannen zijn vaker werkzaam op de interne arbeidsmarkt, evenals full timers. Verder is de gemiddelde lengte van het dienstverband langer. De verschillen in de leefijd, het aantal jaren scholing en de jaren ervaring opgedaan in andere bedrijven, zijn minder pregnant. Werknemers op de interne arbeidsmarkt hebben echter een duidelijk langere inwerktijd, bezetten banen van een hoger niveau en verrichten waker leidinggevend werk. De omvang van de bedrijven, gemeten aan het aantal werknemers, is groter voor de werknemers op de interne arbeidsmarkt en de interne arbeidsmarkt is vooral aanwezig in de banksector en minder vaak bij de overheid. Bij de bestudering van de lonen blijkt dat het gemiddelde loon op de interne arbeidsmarkt hoger ligt. Ook als we rekening houden met het feit dat werknemers en banen op de interne arbeidsmarkt verschillen van die erbuiten blijken de lonen op de interne arbeidsmarkt hoger te zijn. Dat duidt er op dat werknemers op de interne arbeidsmarkt cen extra hoog loon krijgen. Tenslotte zijn de gevolgen voor loonrigiditeit en mobiliteit bestudeerd. Alhoewel hierover niet veel informatie te vinden is, zijn er toch aanwijzingen dat werknemers ervaren dat ze hogere lonen krijgen voor dezelfde werkzaamheden en dat ze vaker tevreden zijn met hun loon. Verder duiden de bevindingen, dat ze vaker onbetaald overwerk verrichten en dat ze regelmatig loonsverhogingen krijgen, erop dat er een bepaalde mate van starheid in de beloning zit. Als we de mobiliteit van arbeid in beschouwing nemen blijken werknemers op de interne arbeidsmarkt vaker mobiel te zijn binnen het bedrijf. Verder is een lager aandeel van de werkenden op de interne arbeidsmarkt op zoek naar andere banen en verwacht een lager percentage binnen een jaar werkloos te worden. Dit duidt op een lagere mobiliteit tussen bedrijuen. Al met al lijken de hypothesen bevestigd te worden in dit onderzoek.

In het afsluitende hoofdstuk 8 worden tenslotte de verbeteringen van deze studie ten opzichte van eerder onderzoek beschreven, maar worden ook de voornaamste tekortkomingen genoemd, welke wellicht een agenda bieden woor toekomstig onderzoek. 


\section{REFERENCES}

Abraham, Katharine G. and James L. Medoffi (1985), "Length of Service and Promotions in Union and Nomunion Work Groups", Industrial and Labor Relations Rewiew, vol. 38, no. 3. pp. 408-420.

Abraham, Katherine G. and Henry S. Farber (1987), "Job Duration, Seniority, and Eamings", American Economic Review, vol. 77, no. 3, pp. 278-297.

Addison, John T, and Alberto C. Castro (1987), "The Importance of Lifetime Jobs: Differences between Union and Nonunion Workers", Industrial and Labor Relations Revew, vol. 40, no. 3, pp. 393-405.

Akerlof, George A. (1970), "The Market for "Lemons": Quality Uncertainty and the Market Mechanism", Quarterly Journal of Economics, vol. 84, pp. 488-500.

Akerlof, George A. and Brian G.M. Main (1981), "An Experience-Weighted Measure of Employment and Unemployment Durations", American Economic Review, wol. 71. no. 5, pp. 1003-1011.

Akerlof, George A. and Brian G. Main (1983), "Measures of Unemployment Duration as Guides to Research and Policy: Reply", American Economic Review, vol. 73, no. 5, pp. 1151-1152.

Akerlof, George A. (1982), "Labor Contracts as Partial Gift Exchange", Quarterly Journal of Economics, vol. 97, no. 4, pp. 543-569.

Akerlof, George A. (1984), "Gift Exchange and Efficiency-Wage Theory: Four Views", American Economic Review, vol. 74, no. 2, pp. 79-83.

Akerlof, George A. and Janet L. Yellen (1986), Efficiency Wage Models of the Labor Market, Cambridge University Press, Cambridge.

Albeda, W. (1985), "Arbeidsmarkt en Arbeidsorganisaties", in: Muysken, J. and H. Schreuder (eds.): Economische Wetenschappen: Eenheid in Verscheidenheid? Van Gorcum. Asser/Maastricht, pp. $138-150$.

Alchian, Armen A. and Harold Demsetz (1972), "Production, Information Costs, and Economic Organization", American Economic Review, vol. 62, pp. 777-795.

Alexander, Arthur J. (1974), "Income, Experience, and the Structure of Internal Labor Markets", Quarterly Journal of Economics, vol. 88, no 1, pp. 63-85.

Althauser, Robert P. and Arne L. Kalleberg (1981), "Firms, Occupations, and the Structure of Labor Markets: A Conceptual Analysis", in: Berg. Ivar (ed.), Sociological Perspectives on Labor Markets, Acadenic Press, New York, pp. 119- \49.

Altonji, Joseph G. and Robert A. Shakoko (1987), "Do Wages Rise With Job Seniority?", Review of Economic Srudies, vol. 54, pp. 437-459.

Arrow, Kenneth J. (1974), The Limits of Organization, Nonton and Company, New York.

Arrow, Kenneth, J. (1985), "The Economics of Agency", in: Pratt, J.W. and R. Zeckhauser (eds.), Agency: the Structure of Business, Harvard Business School Press, Cambridge, Mass., pp. 27-41.

Azariadis, Costas (1975), "Implicit Contracts and Unemployment Equilibria", Journal of Political Economy, vol. 83, no. 6, pp. $1183-1202$.

Azariadis, Costas (1979), "Implicit Contracts and Related Topics: A Survey", in: Hornstein et al. (eds.): The Economics of the Labour Market, pp. 221-248.

Azariadis, Costas and Joseph E. Stiglitz (1983), "Implicit Contracts and Fixed Price Equilibria", Quarterly Journal of Economics, vol. 98, Supplement, pp. 1-22.

Baily, Martin Neil (1974), "Wages and Employment under Uncertain Demand", Review of Economic Studies, vol. 41, pp. 37-50.

Baker, George P., Michael C. Jensen, and Kevin J. Murphy (1988), "Compensation and Incentives: Practice ws. Theory", The Journal of Finance, vol. 43, no. 3, pp. 593-616.

Ballot, Gerard and Cyrille Piatecki (1986), "Tumover, Productivité, et Hiérarchie dans le Marché Inteme du Travail", Revue Economique, no. 2, pp. 285-306. 
Baron, James N., Aligon Davis-Blake and Willam T. Bielby (1986)."The Structure of Opportunity: how Promotion Ladders vary Within and Among Organizations", Administrative Science Quarierly, 31, pp. 248-273.

Barron, John M. and Mark A. Loewenstein (1985), "On Employer-Specific Information and Internal Labor Markets", Southern Economic Journal, vol. 52, no. 2, pp. 431-445.

Becker, Gary S. (1975), Human Capital: A Theoretical and Empirical Analysis, with Special Reference to Education, Midway Reprint, University of Chicago Press, second edition (first edition: 1964)

Beckmarn, Martin J. (1978), Rank in organizations, Springer-Verlag, Berlin.

Beckmann, Martin J. (1983), Tinbergen Lectures on Organzation Theory, Springer-Verlag, Berlin.

Bellmann, Lutz (1986), Senioritätsentohnung, betriebliche Hierarchie und Arbeirsteistung, Campus, Frankfurt.

Bellmann, Lutz (1988), "Senionity Wages and Rank-Order Toumaments as Complements", Research Memorandum, Hannover.

Bellmann, Lutz and Ulrich Schasse (1988), "Employment Tenure in the United States and the Federal Republic of Germany" Discussion Paper, Hannover.

Bellmann, Lutz and Ulrich Schasse (1990), "Dic erwartete Dauer der Betriebszugehórigkeit von Frauen und Männem in der Bundesrapublik Deutschland", Zeisschrift fur Wirtschafts- und Sozialwissenschafien, pp. 413-431.

Bergeijk, C. van and A. de Grip (1986), "Bestaan en Ontwikkeling van Inteme Arbeidsmarkten in Nederiand", Sociaal Maandblad Arbeid, pp. 437-451.

Bester, Helmut (1989), "Incentive-Compatible Long-Term Contracts and Job Rationing", Journal of Labor Economics, vol. 7, no. 2, pp. 238-255.

Bills, David B. (1987), "Costs, Commitment, and Rewards: Factors Influencing the Design and Implementation of ILM", Administrative Science Quarterly, 32, pp. 202-221.

Blaug. Mark (1976), "The Empirical Status of Human Capital Theory: A Slightly Jaundiced Survey", Journal of Economic Literature, pp. 827-855.

Blaug, Mark (1987), "Where Are We Now in the Economics of Education?". pp. 17-28.

Blinder, E.S. (1973), "Wage discrimination, reduced form and structural estimates" , Joumal of Human Resources, vol. 8, pp. 436-465.

Blossfeld, Hans-Peter and Karl Ulrich Mayer (1988), "Arbeitsmarktsegmentation in der Bundesrepublik Deutschland", Kölner Zeirschrift fur Soziologie und Sozialpsychologie, 40, pp. 262-283.

Bowles, Samuel (1985), "The Production Process in a Competitive Econony: Walrasian, Neo-Hobbesian, and Marxian Models", American Economic Review, voll. 75, no. 1, pp. 16-36.

Briderl, Josef (1990), Berriebliche Mobilitatsprozesse. Dynamische Modelle zur Untersuchung von Mobilitarsprozessen in betrieblichen Personalsystemen, Thesis "München University.

Bulow, Jeremy I. and Lawrence H. Summers (1986), "A Theory of Dual Labor Markets with Application to Industrial Policy", Discrimination and Keymesian Unemployment, Journal of Labor Economics, vol. 4, no. 3, pp. 376 414.

Cain, Glenn G. (1975), "The Challenge of Dual and Radical Theories of the Labor Market to Orthodox Theory", American Economic Reviem, vol. 65, no. 2, pp. 16-22.

Cain, Glen G. (1976), "The Challenge of Segmented Labor Market Theories to Orthodox Theory: A Survey", Journal of Economic Literature, vol. 14, pp. 1215-1257.

Caimes, J.E. (1874), Some Leading Principles of Political Economy, MacMillan and co., London.

Calvo, Guillermo and Stanislaw Wellisz (1979), "Hierarchy, Ability, and Income Distribution", Joumal of Political Economy, vol. 87, pp. 991-1010.

Cantor, Richard (1988), "Work Effort and Contract Length", Economica, 55, pp. 343-353.

Cantor, Richard (1990), "Firm-Specilic Training and Contract Length", Economica, 57, pp. 1-14.

Carlson, John A and Michael W. Horrigan (1983), "Measures of Unemployment Duration as Guides to Research and Policy: Comment", American Economic Review, vol. 73, no. 5, pp. 1143-1150.

Camichael, H. Lome (1983), "Fim-Specific Human Capital and Promotion Ladders", The Bell Joumal of Economics 14 , pp. 251-258. 
Camichael, H. Lome (1989), "Self-Enforcing Contracts. Shirking, and Life Cycle Incentives", Journal of Economic Perspectives, wol. 3, no. 4, pp. 65-83.

Carter, Susan B. (1988), "The Changing Importance of Lifetime Jobs, 1892-1978", Industrial Relations, vol. 27 , no. 3, pp. 287-300.

Centraal Bureau voor de Statistiek $(1983,1984,1986,1988,1990)$, Statistiek Werkame Personen. Den Haag.

Coase, Ronald (1937), "The Nature of the Firm", Economica, 4, pp. 386-405.

Collier, P. and J.B. Knight (1985), "Seniority Payments, Quit Rates and Internal Labour Markets in Britain and Japan", Oxford Bulletin of Economics and Statistics, vol. 47, no. 1, pp. 19-32.

Cooter, Robert and Rodrigo Restrepo (1979), "A Closed Model of Careers in a simple Hierarchy", The Bell Journal, 10 , pp. 526-548.

Creedy, John and Keith Whitfield (1988), "The Economic Analysis of Intemal Labour Markets", Bulletin of Economic Research, vol. 40, no. 4, pp. 247-269.

Dale, Angela (1987), "Labor Market Structure in the United Kingdom: Evidence from Occupational Mobility", Work and Occupations, vol. 14, no. 4., pp. 558-590

Dalton, Gene W. and Paul H. Thompson (1971), "Accelerating Obsolescence of Older Engineers", Harvard Business Review, sept-oct., pp. 57-67.

Dickens, William T, and Kevin Lang (1985). "A Test of Dual Labor Market Theory". American Economic Review, vol. 75, no. 4, pp. 792-805.

Dickens, William T. and Lawrence F. Katz (1987), "Inter-Industry Wage Differences and Industry Characteristics", in: Lang and Leonard (eds.), Unemployment and the Structure of Labor Markets, New York, Oxford, pp. 48-89.

DiPrete, Thomas A. (1987), "Horizontal and Vertical Mobility in Organizations", Administrative Science Quarterly, 32, pp. 422-444.

Doeringer, Peter B. and Michael J. Piore (1971), Internal Labour Markets and Manpower Analysis, Lexington Books, Mass.

Doeringer, Peter B. (1986), "Intemal Labor Markets and Noncompeting Groups", American Economic Review, voll. 76, no. 2, pp. 48-52.

Douma, S.W. (1983), "De Agency-Relatie en Moral Hazard, enkele Theoretische Resultaten", Bedriffskunde, 1, pp. 5-9.

Dunlop, John T. (1957), "The Task of Contemporary Wage Theory", in: Taylor, George W. and F.C. Pierson (eds.), New Concepts in Wage Determination, McGraw-Hill, New York, pp. 3-27.

Dunlop, John T. (1966), "Job Vacancy Measures and Economic Analysis", in: The Meastrement and Interpretation of Job Vacancies: A Conference Report of the National Bureau of Economic Research, New York, pp. 27-47.

Drago, Robert and Richard Perlman (1989), "Supervision and High Wages as Competing Incentives: a Basis for Labour Segmentation Theory", in: Drago and Perlman, Microeconomic lssues in Labour Economics: New Approaches, Harvester Wheatsleaf, New York, pp. 41-61.

Eaton, C. and W.D. White (1982), "Agent Compensation and the Limits of Bonding", Econowic Inquiry, 20, pp. $330-334$.

Edwards, R.C. (1975), "The Social Relations of Production in the Firm and Labor Market Structure". in: Edwards, R.C., M. Reich and D.M. Gordon, Labor Market Segmentation, D.C. Heallh and Company, Lexington, pp. 3-26.

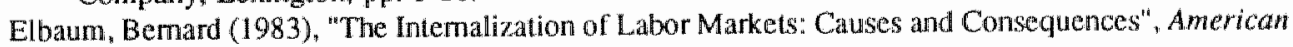
Economic Review, vol. 73, no. 2, pp. 260-265.

Elliot, Robert F. (1991), Labor Economics: A Comparative Text, McGraw-Hill Book Company, London.

Fama, Eugene F. (1980), "Agency Problems and the Theory of the Firm", Journal of Political Economy, vol. 88, no. 2, pp. 288-307.

Fama, Eugene F. and Michael C. Jensen (1983a). "Separation of Ownership and Control", Journal of Law and Economics, vol. 26, pp. 301-324. 
Fanta, Eugene F, and Michael C. Jensen (1983b), "Agency Problems and Residual Claims", Journal of Law and Economics, voll. 26, pp. 327-349.

Foster, James $\mathbb{E}$. and Henry $Y$. Wan (1984), "Involuntary Unemployment as a Principal-Agent Problem ", American Economic Review, vol. 74, no. 2, pp. 476-484.

Foulkes, F. (1980), Personnel Pollicies in Large Nonunion Companies, Englewood Cliffs, N.J., Prentice Hall.

Frank, Robert H. (1984), "Interdependent Preferences and the Competitive Wage Structure", Rand Joumal of Economics, vol. 15, no. 4, pp. 510-520.

Frank, Roben H. (1984), "Are workers Paid their Marginal Products?". American Economic Review, wol. 74, no, 4, pp. 549-571.

Frank, Robert H. (1989). "Frames of Reference and the Quality of Life", American Economic Review, wol. 79, no, 2, pp. $80-85$.

Freeman, R.B. and J.L. Medoff (1984), What do Unions do?, Basic Books, New York.

Gerlach, Knut and Elke Maria Schmidt (1989), "Untemehmensgrosse und Entlohnung", Mitteilungen aus der Arbeitsmarkt- und Berufsforschung. pp. 355-373.

George, K.D. and J. Shorey (1985), "Manual Workers, Good Jobs and Stuctured Internal Labour Markets", British Journal of Industrial Relations, wol. 23, no. 3, pp. 424-447.

Giebel, J. (1982), Japan, Creatieve Economie tussen Oost en West. Aula paperback 72.

Gijsell, P. de (1983), Verantwortung und Entohnung, Campus, Frankfurt.

Gijsel, P. de and G.L.M. Wolfs (1989a), Kombinierte Fix-Flexlohnsysteme aus empirischer und informationsokonomischer Sicht, in: Emmerich et al. (eds.). Einzel- und gesamitwirtschaftlichr Aspekte des Lohnes, Beilräge zur Artheitsmarkt- und Berufsforschung, pp. 83-100.

Gijsel, P. de and G.L.M. Wolls (1989b), "Zum zusammenhang zwischen betrieblichen Leistungsanreixsystemen und Beschaffigung aus informationstheoretischer Sicht", Research Memorandum RM 89-032, University of Limburg.

Gijsel, P. de, J. Muysken and G.L.M. Wolfs (1990), "Interne Arbeidsmarkten en Beloning bij Mannen en Vrouwen in Nederlland", Research Memorandum RM 90-010, University of Limburg.

Gijsel, P. de, J. Muysken and G.L.M. Wolfs (1991), "Inteme Arbeidsmarkten en Beloning bij Mannen en Vrowwen in Nederland", Mens en Maatschappij, vol. 66, no. 3, pp. 257-276.

Gordon, Donald $F_{.}$(1974), "A Neoclassical Theory of Keynesian Unemployment", Economic Inquiry, vol. 12 , pp. $431-459$.

Green, Jerry R. and Nancy L. Stokey (1983), "A Comparison of Toumaments and Contracts", Journal of Political Economy, woll. 91, no. 3, pp. 349-364.

Grip, Andries de (1985). "Inteme Arbeidsmarktheoricen" een Overzicht" "Maandschriff Econamie, 49 , pp. 333-345.

Grossman, S.J, and Oliver Hart (1981). Implicit Contracts, Moral Hazard, and Unemployment, American Economic Review, vol. 71, no, 2, pp. 301-307.

Gujarati, Damodar N. (1988), Basic Econometrics, MacGraw-Hill Intemational Editions, second. edition.

Hall, Rober E. (1982), "The Importance of Lifetime Jobs in the U.S. Economy", American Economic Review, vol. 72, no. 4, pp. 716-724.

Haliwanger, John C. (1983), "On the Relationship between Risk Aversion and the Development of Long Term Worker-Firm Attachments", Sowthern Economic Journal, oct., pp. 572-577.

Ham, J.C. van, J. Pauwe and A.R.T. Williams (1988), "Human Resource Management en Transactickostenbenadering", Economische Statistische Berichten, pp. 1109-1112.

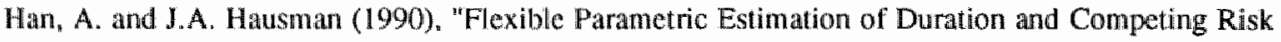
Models", Journal of Applited Econometrics, vol. 5, pp. 1-28.

Harris, John R. and Michael P. Todaro (1970), "Migration, Unemployment and Development: a Two-Sector Analysis". American Economic Review, 110, pp. 126-142.

Hari, Oliver and Bengt Holmström (11987), "The Theory of Contracts", in: Bewley, Truman F. (ed.), Advances in Economic Theory Fifth World Congres. Cambridge University Press, pp. 71-157. 
Hartog, Joop (1981), "Wages and Alocation under Imperfect Information", De Economist, 129, no. 3. pp. $311-323$.

Hartog, Joop (1984), "On The Efficiency of Labor Markets", De Economist, 132, no. 3, pp. 279-299.

Hartog, Joop and J.J.M. Theeuwes (1990), "Arbeidseconomie", in: Geest, L. van der (ed.), Economische Theorie: de Stand van Zaken, Academic Service, pp. 211-231.

Hashimoto, Masanori (1981), "Firm-Specific Human Capital as a Shared Investment", American Economic Review, vol. 71, no. 3, pp. 475-482.

Hashimoto, Masanori and John Raisian (1985). "Employment Tenure and. Eamings Profiles in Japan and the United States". American Economic Review, voll. 75, no. 4, pp. 721-735.

Have, K. ten and A. Vissers (1987), "Arbeid tussen Markt en Organisatie: cen Verhandeling over Kwalliteit van Arbeid in relatie tot Arbeidsmarktgedrag", OSA-werkdocument, nr. W 41.

Heckman, J.J, and B. Singer (1984), "Econometric Duration Analysis", Journal of Econometrics, 24. pp. 63-132.

Hecknan, James and Solomon Polacheck (1974), "Empirical Evidence on the Functional Form of the Eamings-Schooling Relationship", Journal of the American Statistical Association, vol. 69, no. 346. pp. $350-354$.

Hendrikse, G.W.J. and H. Schreuder (1987), "Economische Organisatictheorieèn", Economische Statistische Berichten, pp. 810-815.

Hicks, J.R. (1963), The Theory of Wages, MacMillan \& co., London.

Hutchens, Robert (1986), "Delayed Payment Contracts and a Firmt's Propensity to Hire Older Workers", Joumal of Labor Economics, vol. 4, no. 4, pp. 439-457.

Hutchens, Robert M. (1989), "Seniority wages and Productivity: A Turbulent Decade", Jownal of Economic Perpectives, vol 3, no. 4, pp. 49-64.

Huijgen, F. (1989). "De Kwalitatieve Structuur van de Werkgelegenheid in Nederland deel III: Bevolking in Loondienst en Functiestructuur in 1977 en 1985', OSA-voorstudie nr. V 33.

Jensen, Michael C, and Kevin J. Murphy (1988), "Perfornance Pay and Top Management Incentives", Working paper MERC.

Jensen, Michael C. and William H. Meckling (1976), "Theory of the Firm: Managerial Behavior, Agency Casts and Ownership Structure", Journal of Financial Economics, 3, pp. 305-360.

Jovanovic, B. (1979), "Job Matching and the Theory of Tumover", Journal of Political Economy, voll. 87. no. 5, pp. $972-990$.

Jovanovic, B. (1984), "Matching, Tumover, and Unemployment", Journal of Political Economy, vol. 92 , no. 1, pp. 108-122.

Kahn, Charles and Gur Huberman (1988), "Two-Sided Uncertainty and 'Up-or-Out' Contracts", Journal of Labor Economics, vol. 6, no. 4, pp. 423-444

Kaitz. Hyman B. (1970), "Analyzing the Length of Spells of Unemployment", Monthyy Labor Review. 15. pp. $11-20$.

Katz, Lawrence F. (1986), "Efficiency Wage Theories: A Partial Evaluation", NBER Macroeconomic Annual, pp. 235-289.

Kerckhoffs, C.C.J.M.C., C. de Neubourg and F. Palm (1990), "The Determinants of Individuatl Unemployment Duration in the Netherlands". Research Memorandum RM 90-052, University of Limburg.

Kerckhoffs, C.C.J.M.C. and G.L.M. Wolfs (1991), "Duration of Job Tenure in the Dutch Economy" " Research Memorandum RM 91.006 , University of Limburg.

Kerckhoffs, C.C.J.M.C. and G.L.M. Wolfs (1992, forthcoming), "Duration of Job Tenure in the Dutch Economy". De Economist.

Kert, Clark (1954), "The Balkanization of Labour Markets", in: Wight Bakke ef al, (eds.), Labor Mobiliry and Economic Oppornurity, MIT, Cambridge Mass, pp. 92-110.

King, J.E. (1990), Labour Economics, MacMillan, second edition (first edition 1972).

Klundert, Theo van de (1988), "Wage Differentials and Employment in a Two-Sector Model with a Dual Labour Market", Research Memorandum, no. 314, University of Tilburgs. 
Koutsoyiannis, A. (1979), Modern Microeconomics, MacMillan, second edition (first edition 1975).

Krueger, Alan B. and Lawrence H. Summers (1988), "Efficiency Wages and the Inter-Industry Wage Struclure", Econometrica, woll. 56, no. 2, pp. 259-293.

Lancaster, Tony (1979) "Econometric Methods for the Duration of Unemployment", Econometrica. wol. 47, no. 4, pp. $939-956$.

Lancaster, T. and S. Nickell (1980), "The Aralysis of Re-employment Probabilities for the Unemployed", Joumal of the Royal Statistical Society Series A, 143, pp. 141-165.

Lawler III, Edward E. (1987), "The Design of Effective Reward Systems", Lorsch (ed.): Handbook of Organizational Behavior, pp. 255-270.

Layard, Richard (1981), "Measuring the Duration of Unemployment: A Note", Scottish Journal of Political Economy, vol. 28, no. 3, pp. 273-277.

Lazear, Edward P. (1979), "Why is there Mandatory Retirement?", Joumal of Political Economy, vol. 87, no. 6, pp. $1261-1284$.

Lazear, Edward P. (1981), "Agency, Eamings Profiles, Productivity, and Hours Restrictions", Americar Economic Review. vol. 71, no. 4, pp. 606-620.

Lazear, Edward P. (1984), "lncentives and Wage Rigidity", American Economic Review, vol. 74, no. 2. pp. 339-344.

Lazear, Edward P. and Sherwin Rosen (1981), "Rank-Order Toumaments as Optimum Labor Contracts", Journal of Political Economy, wol. 89, no. 5, pp. 841-864.

Lazear, Edward P. and Robert L. Moore (1984), "Incentives, Productivity, and Labor Contracts", Quarterly Journal of Economics, vol. 99, pp. 275-295.

Lazear, Edward P. (1986), "Salaries and Piece Rates", Journal of Business, vol. 59, no. 3, pp. 405-431. Leibenstein, Harvey (1957), "The Theory of Underemployment in Densely Populated Backward Areas", in: Akerlof and Yellen (1986), Efficiency Wage Models of the Labor Market, John Wiley \& Sons, pp. 22-40.

Leonard, Jonathan S. (1987), "Carrots and Sticks: Pay, Supervision, and Turnover", Journal of Labor Econamics, vol. 5, no. 4, pp. 136 152.

Levinthal, Daniel (1988), "A Survey of Agency Models of Organizations", Journal of Economic Behavior and Organizations, 9, pp. 153-185.

Lindbeck, Assar and Dennis J. Snower (1988). The Insider Outsider Theory of Employment and Unemployment, MIT Press, Cambridge, Mass.

Lindeboom, Maarten and J. Theeuwes (1990) "Job Duration in the Netherlands: the Simultaneous Occurence of High and Low Tumover" Research Memorandum 90.03, Leiden University.

Loveridge. Ray (1983). "Sources of Diversity in Internal Labour Markets", Sociology, vol. 17, no. 1. pp. $44-62$.

Lupton, Tom and Angela Bowey (1983), Wages and salaries, Alderslot: Gower, second edition (first edition 1974).

Mace, J. (1979), "Intemal Labour Markets for Engineers in British Industry", British Journal of Industrial Relations, vol. 17, pp. 50-63.

Machlup, Fritz (1967), "Theories of the Firm: Marginalist, Behavioral, Managerial", American Economic Review, vol. 57, no. 1, pp. 1-33.

Maddala, G.S. (1983), Limited-dependent and qualitative variables in econometrics, Cambridge University Press, Cambridge.

Main, Brian G.M. (1981), "The Length of Employment and Unemployment in Great Britain", Scottish Journal of Political Economics, vol. 28, no. 2, pp. 146-164.

Main. Btian G.M. (1982a) "The Length of a Job in Great Britain", Economica, 49, pp. 325-333.

Main. Brian G.M. (1982b), "Three Summary Measures of the Duration of Unemployment", Scortish Journal of Political Economy, vol. 29, no. 1. pp. 99.101.

Malcomson, James M. (1981), "Unemployment and the Efficiency Wage Hypothesis", The Economic Journal. 91 , pp. 848-866.

Malcomson. James M. (1984), "Work Incentives, Hierarchy, and Intemal Labour Markets", Journal 
of Political Economy, vol. 92 , pp. 486-507.

Malcomson, James M. (1985), Incomplete Contracts and Involuntary Unemployment, Oxford Economic Papers, 37, pp. 196-209.

Malcomson, James M. (1986), "Rank-Order Contracts for a Principal with Many Agents", Rewew of Economic Studies, 53, pp. $807-817$.

Manning, Allan (1990), "Implicit Contract Theory", in: Sapsford, David and Zafiris Tzannatos, Current Issues in Labour Economics, MacMillan, Houndsmills and London, pp. 63-85.

Manwaring, Tony (1984), "The Extended Intemal Labour Market", Cambridge Journal of Economics, 8. pp. 161-187.

Marglin, Stephen (1974), "What Do Bosses Do? The Origins and Functions of Hierarchy in Capitalist Production". The Review of Radical Political Economy, reprint in: Putterman (1986). The Economic Nature of the Firm: A Reader, Cambridge Uniwersity Press, Cambridge, pp. 269-278.

Marshall, A. (1920). Principles of Economics, MacMillan, eighth edition (first edition 1890).

Marshall, Robert C. and Gary A. Zarkin (1987), "The Effect of Job Tenure on Wage Offers", Journat of Labor Economics, 5, pp. 301-324.

Masters, Stanley H. (1969), "An Interindustry Analysis of Wages and Plant Size", Review of Economics and Statistics, voll. 51, pp. 341-345.

McDonald, Ian M and Robert M. Solow (1985), "Wages and Employment in a Segmented Labor Market", The Quarterly Journal of Economics, nov., pp. 1115.1141.

Medoff, James L. and Katherine G. Abraham (1980), "Experience, Performance, and Earnings", Quarterly Journal of Economics, dec., pp. 703-736.

Medoff, James L. and Katharine G. Abraham (1981). "Are Those Paid More Really More Productive: the Case of Experience", Journal of Human Resources, vol. 16, no. 2, pp. 186-216.

Mellow, W. (1982), "Employer Size and Wages", Review of Economics and Statisrics, 64, pp. 495501 .

Meyer, B.D. (1988), "Unemployment Insurance and Unemployment Spells", National Bureau Economic Research, Working paper no. 2546.

Milkowich. G. and J. Newman (1984), Compensation, Business Publications Inc, Plano, Tx.

Mill, J.S. (1848), Principles of Political Ecomomy, Longmans Green and co., London (new edition 1923).

Mills, D. Quinn (1985), "Senionity versus Ability in Promotion Decisions", Industrial and Labor Reliations Review, vol. 38 , no. 3, pp. $421-420$.

Mintzberg. Henry (1979). The Structuring of Organizations, Englewood Cliffs. New York, Prentice Hall.

Mok. A.L. and J. Bracke (1976), "De Arbeidsmarkt: Een Poging tot Integratie van Economische en Sociologische Gezichtspunten", Economisch en Sociaal Tijaschrift, no. 4, pp. 551.577.

Morrison, Donald and David C. Schmittlein (1981), "A Model of Careers in a Simple Hierarchy: Generalizing the Junior Professional"s Decision Rule " "The Bell Journal of Economics, pp. $310-320$.

Muysken, J. (1990), "Classification of Unemployment: Analytical and Policy Relevance", De Economist, 137, nr. 4, pp. 397-424.

Muysken, J. and H. Schreuder (eds.) (1985), Economische Wetenschappen: Eenheid in Verscheidenheid?, Van Gorcum, Assen/Maastricht.

Nalebuff, Barry J. and Joseph E. Stiglitz (1984), "Prizes and Incentives: Towards a General Theory of Compensation and Competition", The Bell Journal of Economics, 2, pp. 21-43.

Newbold, Paul (1984), Statistics for Business and Economics, Prentice Hall.

Oaxaca, R. (1973), "Male-female wage differentials in Urban Labor Markets", International Economics Review, vol. 14, pp. 693-709.

OECD (1984), OECD Employment Outlook, Paris.

Oi, Walter Y. (1962), "Labor as a Quasi-Fixed Factor", Journal of Political Economy, 70, pp. $538-555$.

Oi, Walter Y. (1983), "Heterogeneous Firms and the Organisation of Production", Economic Inquiry, 
wol. $21, \mathrm{pp}, 147-171$.

O'Keeffe, Mary, W. Kip Viscusi and Richard J. Zeckhauser (1984), "Economic Contests: Comparative Reward Schemes", Journal of Labor Economics, woll. 2, no. 1, pp. $27-56$.

OSA (1987), Trendrapport 1987, OSA-Voorstudie nr. 18.

Osterman, Paul (1975), "An Empirical Study of Labor Market Segmentation", Industrial and Labor Relotions Review, vol. 28, no. 4, pp. 508-523.

Osterman, Paul (ed.) (1984), Internal Labor Markets, MIT Press, Cambridge Mass.

Oswald, Andrew J. (1981), "The Theory of Intemal Wage and Employment Structure", The Bell Journal of Economics, pp. 263-271.

Ours, J. van (1990), "An Intemational Comparative Study on Job Mobility", Labour, 4, no. 3, pp. 3355.

Ours, J.C. van and T. Zoethout (1990), "De Interne Arbeidsmarkt van de Gemeente Amsterdam", Research Memorandum $1990-33$, University of Amsterdam.

Perrot, Anne and Andre Zylerberg (1989), "Salaire d "efficience et duale du Marche du Travail", Rerue Economique, no. 1, pp. 5-20.

Pfeffer, Jeffrey and Yinon Cohen (1984), "Determinants of Internal Labor Markets in Organisations", Administrative Sclence Quarterly, vol. 29 , pp. $550-572$.

Phelps. E.S. (ed.) (1970). Microeconomic Foundations of Employment and Inflation Theory. New York.

Pot, Frank (1988), Zeggenschap over"Beloningssystemen 1850-1987, Leidlen.

Pratt, Joln W. and Richard J. Zeckhauser (1985), "Principals and Agents: An Overview", in: Pratt, J.W. and R. Zeckhauser (eds.), Agency: the Structure of Business, Harvard Business School Press, Cambridge, Mass., pp. 1- 35 .

Piore, Michael J. (1972) " Fragnents of A 'Sociological Theory of Wages", IRRA 25th Anniversary" Proceedings, pp. 286-295.

Piore, Michael J. (1983), "Labor Market Segmentation: To What Paradigm does it belong?", Americam Economic Reviem, wol. 73, no. 2, pp. 249-253.

Pugel, Thomas A. (1980), "Profitability, Concentration and the Interindustry Variation in Wages", Review of Economics and Statistics, 62, pp. 248-253.

Rees, Ray (1985a), "The Theory of Principal and Agent - Part I", Bulletin of Economic Research, 37. no. 1 , pp. 3-26.

Rees, Ray (1985b), "The Theory of Principal and Agent - Part II", Bulletin of Economic Research, 37, no. 2, pp. 75-95.

Reich, Michael, David M. Gordon and Richard C. Edwards (1973), "A Theory of Labor Market Segmentation", American Economic Review, vol. 63, no. 2, pp. 359-365.

Rosen, Sherwirn (1981), "The Economics of Superstars", American Econamic Review, vol. 71, no. 5 , pp. $845=858$.

Rosen, Sherwin (1982), "Authority, Control, and the Distribution of Earnings", The Bell Journal of Economics, pp. $311-323$.

Rosen, Sherwin (1985), "'Implicit Contracts: A Survey"', Journal of Economic Literature, vol. 23, pp. $1144-1175$.

Rosen, Sherwin (1986), "Prizes and Incentives in Elimination Touramerts", American Economic Review, vol. 76, no. 4, pp. 701-715.

Rosenbaum, James E. (1979a), "Toumament Mobility: Career Pattems in a Corporation", Administrative Science Quarterly, vol. 24, pp. $220-241$.

Rosenbaum, James E. (1979b), "Organizational Career Mobility: Promotion Chances in a Corporation During Periods of Growth and Contraction", American Journal of Sociology, wol. 85, no. 1, pp. $21-48$.

Ryan, Paul (1981). "Segmentation, Duality and the Intemal Labour Market", in: Willkinson (ed.), The Dynamics of Labour Market Segmentation, Academic Press, pp. 3m20.

Salh, Raaj Kumar and Jospeh E. Stiglitz (1986), "The Architecture of Economic Systems: Hierarchies 
and Polyarchies", American Economic Review, vol. 76, no. 4. pp. 716-727.

Salant, Stephen W. (1977), "Search Theory and Duration Data: a Theory of Sorts". Quarterly Journal of Ecomomics, vol. 91, no. 1, pp. 39-57.

Salop, Steven (1979), "A Model of the Natural Rate of Unemploynent". American Economic Review, vol. 69, no. 1, pp. 117-125.

Schippers, JJ. (1987), Beloningswerschillen tussen Mamnen en Vrowwen, Wolters-Noondhoff, Groningen.

Schlichter, S. (1950), "Notes on the Structure of Wages", Revew of Economics and Statistics, 32, pp. $80-91$.

Schmidt, Christoph M. and Klaus F. Zimmernann (1989), "Work Characteristics, Fim Size and wages", Research Memorandum, University of Munich.

Scholten, Gerard (1984). "De Organisatie van de Inteme Arbeidsmarki", Mens en Orgamisatie, no. 2, pp. 116-131.

Schreuder, H. (1985), "Econonic Theories of Organizations; An Overview and Assessment of some Recent Developments", Research Menorandum RM 85.007. University of Limburg.

Schreuder, H. (1990), "Coase, Hayek and Hierarchy", Research Memorandum RM 90.032, University of Limburg.

Schwan. Rolf and J. Soeters (1991a), "The Strategy of Vacancy Filling from Intemal and Externall Labor Market Sources", Research Memorandum RM 91.011, University of Limburg.

Schwan, Rolf and J. Soeters (1991b), "New Insights in the Division of Organizational Labor Markets", Research Memorandum RM 91.021, University of Limburg.

Schwan, Rolf and J. Soeters $(1991 \mathrm{c})$ ). "Beschäftigungsdawer und Beschäftigungsstrukturen Innerhalb Betrieblicher Organizationskonfigurationen" . Research Memorandum RM 91.022, University of Limburg.

Sengenberger, Wemer (1981), "Labour Market Segmentation and the Business Cycle", in: Wilkinson (ed.), The Dynamics of Labour Market Segmentation, Academic Press, pp. 243-257.

Shapiro, Carl and Joseph E. Stiglitz (1984), "Equilibrium unemployment as a worker discipline device", American Economic Review, vol. 74, no. 2, pp. 433-444.

Shavell, Steven (1979), "Risk Sharing and Incentives in the Principal and Agent Relationship", The Bell Journal of Economics, vol. 10, no. 1. pp. 55-73.

Sicherman, Nachum (1990), "Education and Occupational Mobility", Economics of Educarion Review, vol. 9, no. 2, pp. 153-179.

Sicheman, Nachum and Oded Galor (1990), "A. Theory of Career Mobility", Journal of Political Economy, vol. 98, no. 1. pp. 169-192.

Siebert, W. Stanley (1985), "Devellopments in the Economics of Human Capital" in: Carline et al. (cds.), Labour Economics, Longman, London, pp. 5-77.

Smith, A. (1776), The Wealth of nations, Penguin Books English Library (reprint 1982).

Soeters Joseph L. and G.L.M. Woll's (1991), "Economische Organisatietheoricen en Beloningssystemen" "Research Memorandum RM 91-005, University of Limburg.

Soeters, Joseph L. and Rolf Schwan (1990), "Towards an Empirical Assessment of Intemal Labor Market Configurations". The International Journal of Human Resource Management, vol. 1, no . 3, pp. $271-287$.

Solow, Robert M, (1979), "Another Possible Source of Wage Stickiness", in: Akerlof and Yellen (eds:) (1986), Efficiency Wage Models of the Labor Market, Cambridge University Press, Cambridge. pp. $41-44$.

Solow, Robert M. (1980), "On Theories of Unemployment", American Econamic Review, vol. 70, pp. $1-11$.

Solow. Robent M. (1985), "Insiders and Oulsiders in Wage Determination", Scandinavian Journal of Economics, 87 (2), pp. $411-428$.

Spence, A. Michael (1974), Market Sighaling: Informational Transfer in Hiring and Related Screening Processes, Harvard University Press "Massachusetts. 
Stark, David (1986), "Rethinking Internal Labour Markets: New Insights from a Competitive Parspective", American Sociological Review, vol. 51, pp. 492-503.

Stigler. George J. (1951), "The Division of the Market is Limited by the Extent of the Market", Jownat of Political Economy, vol. 59, no. 3, pp. 185-193.

Stiglit, Joseph E. (1975). "Incentives, Risk and Information: Notes towards a Theory of Hieranchy"

The Bell Journal of Economics, 6, pp. 552-579.

Stiglitz, Joseph E. (1986), "Theories of Wage Rigidity", in: Butkiewicz (et al.), Keynes" Economic Legacy: Contemporary Economic Theories, Praeger, New York, pp. 153-206.

Suglitz, Joseph E. (1987). "The Causes and Consequences of the Dependence of Quality on Price". Journal of Economic Literature, vol. 25. pp. 1-48.

Sxydllik, Marc (1990), "Die Segmentienung des Arbeitsmarktes in der Bundesrepublik Deutschland", Beitrdge zur Sozialökonomik der Arbeit, no. 24, Edition Sigma, Berlin.

Taubman, Paul and Michael L. Wachter (1986), "Segmented Labor Markets", in: Ashenfelter and Layard, Handbook of Labor Economics wolll. pp. 1183-1217.

Taylor, Mark P. (1987a), "The Simple Analytics of Implicit Labour Contracts", Bullerin of Economic Research, reprint in: Hey and Lambert (cds.). Surveys in the Economics of Uncertainty, Basil Blackwell, pp. 124-150.

Taylor, Mark P. (1987b). "Further Developments in the Theory of Implicit Labour Contracts", Bullerin of Economic Research, reprint in: Hey and Lambert (eds.). Surveys in the Economics of Uncertainty, Basil Blackwell, pp. 151-172.

Thaler, Richard H. (1989), "Interindustry Wage Differentials", Journal of Economic Perspectives, vol. 3. no. 2 , pp. $181-193$.

Thurow, Lester C. (1975), Generating Inequality. Mechanisms of Distribution in the U.S. Economy, Basic Books, New York.

Tijdens, Kea (1986a), "Bankautomatisering en Vrouwenarbeid", Tijischrift voor Politieke Ekonomie. no. 4. pp. $29-46$.

Tijdens, Kea (1986b), "Automatisering, Interne Arbeidsmarkt en Segmentering: een Studie naar de Positie van Vrouwelijke Medewerkers bij de Vier Grote Banken", Universiteit van Amsterdam.

Tijdens, Kea (1989), Automarisering en Vrouwenarbeid. Een Studie over Beroepensegregatie op de Arbeidsmarkt, in de Administratieve Beroepen in het Bankwezen. Uitgeverij Van Arkel, Amsterdam.

Topel, Robert (1987), "Wages Rising with Seniority", Unpublished Manuscript, University of Chicago. Valkenburg, F.C. and A.M.C. Vissers (1979). Theorie van de dubbele arbeidsmarkt, Staatsuitgeverij, Den Haag.

Varian, Hal R. (1984), Microeconomic Amalysis, Norton \& Company, second edition (first edition 1978).

Verburg, P. (1985), "Arbeidsmarkt en Arbeidsorganisaties", in: Muysken, J. and H. Schreuder, Economische Wetenschappen: Eenheid in Verscheidenheid?, Van Gorcum, Assen/Maastricht, pp. $138-1.50$.

Verhoeven, Kees J. (1981), "Corporate Manpower Planning", European Journal of Operational Reseanch, 7, pp. 341.349 .

Viscusi, W. Kip (1986), "Moral Hazard and Merit Rating over Time: An Analysis of Optimal Intertemporal Wage Structures", Southern Economic Jownal, pp. 1068-1079.

Wachter, Michael L. (1974), "Primary and Secondary Labor Markets: A Critique of the Dual Approach", Brookings Papers on Economic Activity. 3, pp. 637-693.

Wachter, Michael L. and Randall D. Wright (1990). "The Economics of Internal Labor Markets", Industrial Relations, vol. 29, no. 2, pp. 240-262.

Warmerdam, John and Jacques van den Berg (1986), Nieuwe Technologieën en het Functioneren vam Interne Arbeismarkten, ITS Nijmegen.

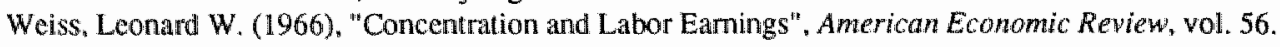
Weiss, Andrew (1.991), Efficiency Wages: Models of Unemployment, Layoffs, and Wage Dispersion, 
Clarendon Press, Oxford.

Weitzman, Martin L. (1983), "Some Macroeconomic Implications of Alternative Compensation Systems", Economic Journal, 93, pp. 763-783.

Wholey, Douglas R. (1985), "Determinants of Firm Internal Labor Markets in Large Law Firms", Administrative Science Quarterly, 30, pp. 318-335.

Williamson, O.E., M.L. Wachter and J.E. Harris (1975). "Understanding the Employment Relation: The Analysis of Idiosyncratic Exchange", The Bell Journal of Economics, 6, pp. 250-278.

Williamson, Oliver E. (1975), Markets and Hierarchies: Analysis and Ant-Trust Implications, Free Press, New York.

Williamson, Oliver E. (1981), "The Economics of Organization: The Transaction Cost Approach", American Journal of Sociology, 87, pp. 548-577.

Williamson, Oliver E. (1985), The Ecomomic Institutions of Capitalism: Firms, Markets, Relational Contracting, Free Press, New York.

Williamson, Oliver E. (1990), "The Firm as a Nexus of Treaties: an Introduction", in: Aoki. Gustafson and Williamson, The Firm as a Nexus of Treaties, Sage Publications, London.

Windolf, Paul (1986), "Recruitment, Selection, and Intemal Labour Markets in Britain and Germany", Organization Studies, 7/3, pp. 235-254.

Wise, David A. (1975), "Academic Achievement and Job Perfomance", American Economic Review, vol. 65 , no. 3, pp. 350-366.

Wise, David A. (1975), "Personal Attributes, Job Performance, and Probability of Promotion", Econometrica, vol. 43, no. 5-6, pp. 913-931.

Wolfs, G.L.M. (1988), "Pricing and Allocation on Internal Labour Markets", Research Memorandum $R M$ 88-028, University of Limburg.

Wolfs, G.L.M. (1990), "Tenure in the Dutch Economy", Research Memorandum RM 90-042, Uniwersity of Limburg.

Wolfs, G.L.M. (1991), "Tenure in the Dutch Economy", Kwantitatieve Methaden, vol. 12, no. 38, pp. $81-92$.

Worrall, Tim (1989), "Labour Contract Theory", in: Hahn, Frank (ed.), The Economics of Missing Markets, Information, and Games, Oxford University Press.

Yellen, Yanet L. (1984), Efficiency Wage Models of Unemployment, American Economic Review, vol. 74 , no. 1 , pp. $200-205$.

Zanders, H.L.G., A.L.J. van Buechem and J.J.C. van Berkel (1977), Kwaliteit wan Arbeid 1977, Ministerie van Sociale Zaken, Den Haag. 



\section{Curriculum Vitae}

Guido Wolfs (6-4-1961) sloot zijn middelbare school opleiding af in 1979 ann het Jeanne d'Arc College te Maastricht. Danma studeerde hij economie ann de Katholieke Universitent Brabant, waar hij in 1985 het doctoral examen Algemene Economie behanlde. Vanaf oktober 1985 was hij werkzaam bij de Vakgroep Algemene Economie wan de Faculteit der Economische Wetenschappen wan de Rijksunioersiteit Limburg te Manstricht. Sinds april 1987 verricht hij binnert het project "Arbeidsmarkt en Arbeidsorganisaties" onderzoek naar de Interne Arbeidsmarkt. De resultaten wan dit onderzoek zijn in dit proefschrift weergegeven. Per 15 november 1991 is hij werkzann bij de Provincie Limburg als Senior Beleidsmedewerker Arbeidsmorkt. 